\title{
LACANIAN PSYCHOANALYSIS
}

EDITED BY: Gertrudis Van De Vijver, Jos Antonius Maria De Kroon and Rémy Potier

PUBLISHED IN: Frontiers in Psychology

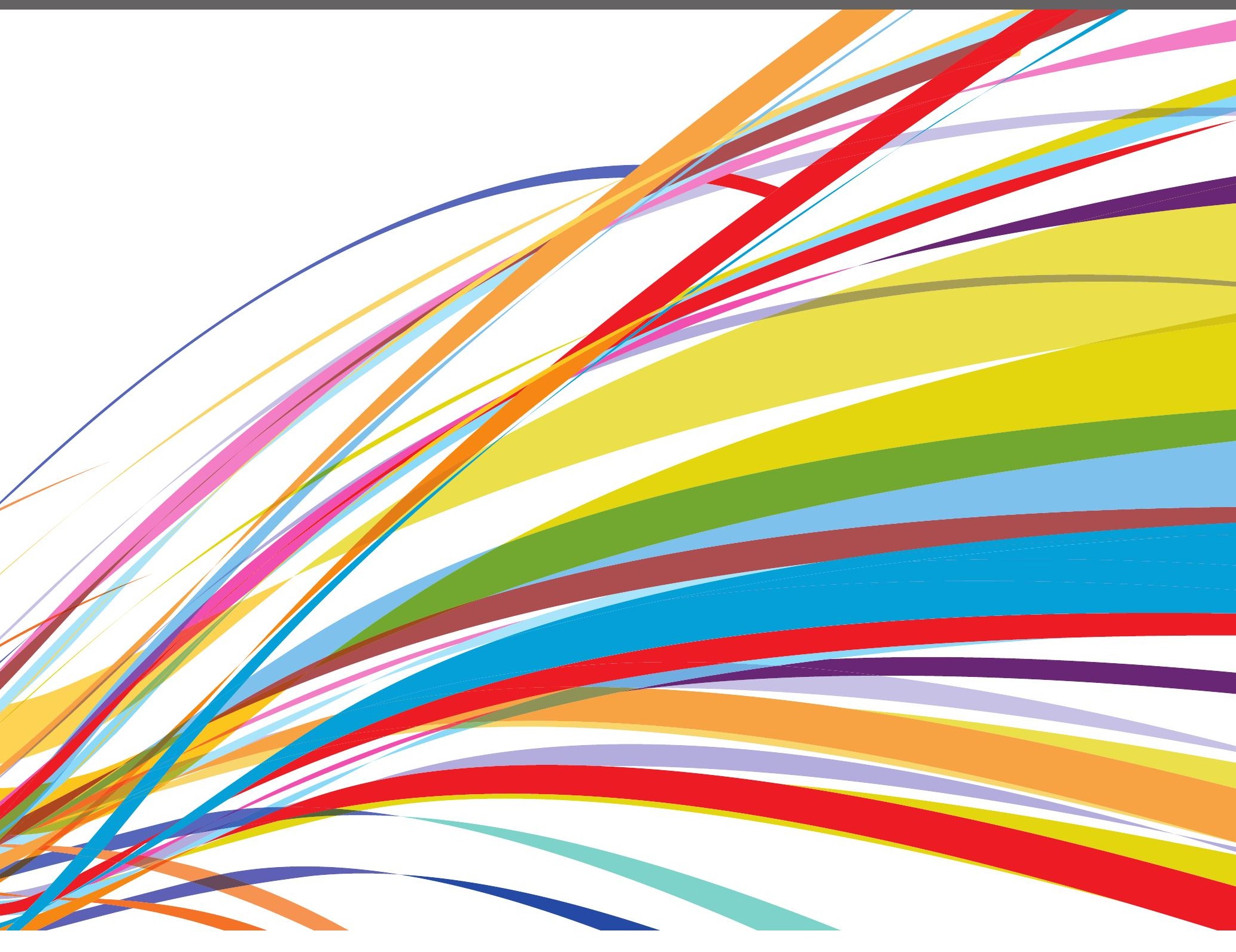

frontiers Research Topics 


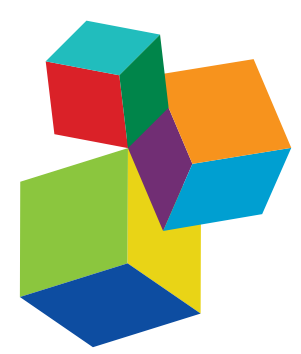

Frontiers eBook Copyright Statement

The copyright in the text of individual articles in this eBook is the property of their respective authors or their respective institutions or funders. The copyright in graphics and images within each article may be subject to copyright of other parties. In both cases this is subject to a license granted to Frontiers.

The compilation of articles constituting this eBook is the property of Frontiers.

Each article within this eBook, and the eBook itself, are published under the most recent version of the Creative Commons CC-BY licence. The version current at the date of publication of this eBook is CC-BY 4.0. If the CC-BY licence is updated, the licence granted by Frontiers is automatically updated to the new version.

When exercising any right under the CC-BY licence, Frontiers must be attributed as the original publisher of the article or eBook, as applicable.

Authors have the responsibility of ensuring that any graphics or other materials which are the property of others may be included in the

CC-BY licence, but this should be checked before relying on the

CC-BY licence to reproduce those materials. Any copyright notices relating to those materials must be complied with.

Copyright and source acknowledgement notices may not be removed and must be displayed in any copy, derivative work or partial copy which includes the elements in question.

All copyright, and all rights therein, are protected by national and international copyright laws. The above represents a summary only.

For further information please read Frontiers' Conditions for Website

Use and Copyright Statement, and the applicable CC-BY licence.

ISSN 1664-8714

ISBN 978-2-88963-604-4

DOI 10.3389/978-2-88963-604-4

\section{About Frontiers}

Frontiers is more than just an open-access publisher of scholarly articles: it is a pioneering approach to the world of academia, radically improving the way scholarly research is managed. The grand vision of Frontiers is a world where all people have an equal opportunity to seek, share and generate knowledge. Frontiers provides immediate and permanent online open access to all its publications, but this alone is not enough to realize our grand goals.

\section{Frontiers Journal Series}

The Frontiers Journal Series is a multi-tier and interdisciplinary set of open-access, online journals, promising a paradigm shift from the current review, selection and dissemination processes in academic publishing. All Frontiers journals are driven by researchers for researchers; therefore, they constitute a service to the scholarly community. At the same time, the Frontiers Journal Series operates on a revolutionary invention, the tiered publishing system, initially addressing specific communities of scholars, and gradually climbing up to broader public understanding, thus serving the interests of the lay society, too.

\section{Dedication to Quality}

Each Frontiers article is a landmark of the highest quality, thanks to genuinely collaborative interactions between authors and review editors, who include some of the world's best academicians. Research must be certified by peers before entering a stream of knowledge that may eventually reach the public - and shape society; therefore, Frontiers only applies the most rigorous and unbiased reviews.

Frontiers revolutionizes research publishing by freely delivering the most outstanding research, evaluated with no bias from both the academic and social point of view. By applying the most advanced information technologies, Frontiers is catapulting scholarly publishing into a new generation.

\section{What are Frontiers Research Topics?}

Frontiers Research Topics are very popular trademarks of the Frontiers Journals Series: they are collections of at least ten articles, all centered on a particular subject. With their unique mix of varied contributions from Original Research to Review Articles, Frontiers Research Topics unify the most influential researchers, the latest key findings and historical advances in a hot research area! Find out more on how to host your own Frontiers Research Topic or contribute to one as an author by contacting the Frontiers Editorial Office: researchtopics@frontiersin.org 


\section{LACANIAN PSYCHOANALYSIS}

Topic Editors:

Gertrudis Van De Vijver, Ghent University, Belgium

Jos Antonius Maria De Kroon, Independent Researcher

Rémy Potier, Université Paris Diderot, France

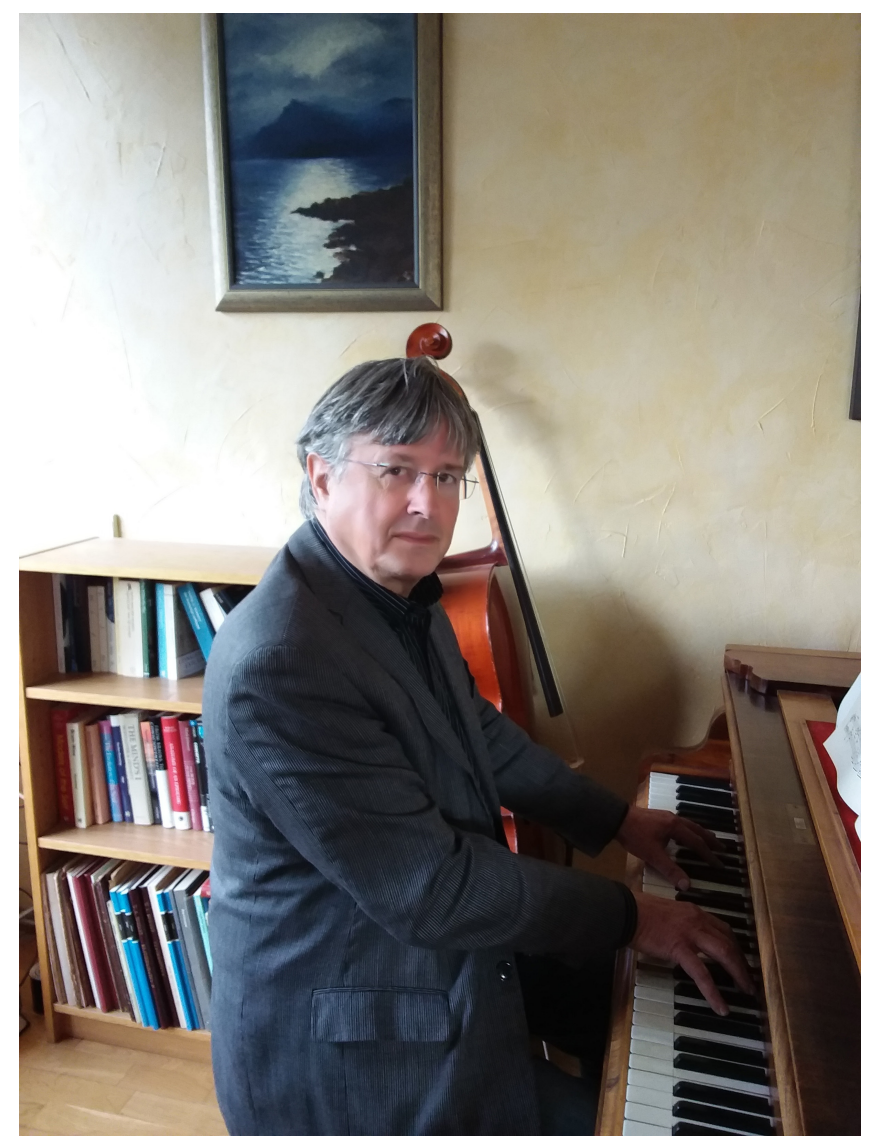

Citation: Van De Vijver, G., De Kroon, J. A. M., Potier, R., eds. (2020). Lacanian Psychoanalysis. Lausanne: Frontiers Media SA. doi: 10.3389/978-2-88963-604-4 


\section{Table of Contents}

04 Editorial: Lacanian Psychoanalysis

Gertrudis Van de Vijver, Jos de Kroon and Rémy Potier

06 Lacanian Concept of Desire in Analytic Clinic of Psychosis

Julieta De Battista

09 The Logic of Appearance: Dennett, Phenomenology and Psychoanalysis Jasper Feyaerts and Stijn Vanheule

24 The Lacanian Concept of Paranoia: An Historical Perspective

Thomas Lepoutre, Manoel L. Madeira and Nicolas Guerin

29 The Psychoanalytic Concept of Jouissance and the Kindling Hypothesis Yorgos Dimitriadis

41 The Lacanian Concept of Cut in Light of Lacan's Interactions With Maud Mannoni

Laure Razon, Olivier Putois and Alain Vanier

51 Language and Vulnerability-A Lacanian Analysis of Respect

Laurie Laufer and Beatriz Santos

55 The Mark, the Thing, and the Object: On What Commands Repetition in Freud and Lacan

Gertrudis Van de Vijver, Ariane Bazan and Sandrine Detandt

65 Lacan and Adolescence: The Contemporary Clinic of the "Sexual Non-rapport" and Pornography

Olivier Ouvry

69 The Individual and the Collective: Sociological Influences on Lacan's Concept of the Relation Subject-Other

David Schrans

78 The 'Real Without Law' in Psychoanalysis and Neurosciences Adriano Aguiar

85 The Clinic of Identifications in the Different Processes of Metamorphosis Into Woman

Laure Westphal and Thierry Lamote

97 A Lacanian Approach to Medical Demand, With a Focus on Pediatric Genetics: A Plea for Subjectivization

Rémy Potier and Olivier Putois 


\title{
Editorial: Lacanian Psychoanalysis
}

\author{
Gertrudis Van de Vijver ${ }^{1 *}$, Jos de Kroon ${ }^{2}$ and Rémy Potier ${ }^{3}$ \\ ${ }^{1}$ Philosophy and Moral Science, Ghent University, Ghent, Belgium, ${ }^{2}$ Independent Researcher, Eindhoven, Netherlands, \\ ${ }^{3}$ Paris Diderot University, Paris, France
}

Keywords: psychoanalysis, Lacan, Freud, drive, truth, speaking

\section{Editorial on the Research Topic}

\section{Lacanian Psychoanalysis}

The tricky thing about knowing is that one not just wishes to know, it is that one wishes to know, so to speak, for real. No kidding, the real-real, not the fake-real, that is what science, and yes, also psychoanalysis, are after. Certainly, the modern sciences were driven by the Greek ideal of being proven right in name of the truth-and not just, like the sophist, by the simple fact of wanting to be right. And the sciences of today are just on the same track, no matter how much relativity they are willing to take on board.

All this is a matter of speaking, of course, and psychoanalysis, and certainly Lacan's return to Freud, time and again confront us exactly with that: from the moment we speak, we, human subjects, are into the issue of truth, that is, into the issue of truth-seeking, inevitably and often quite desperately so. But then, psychoanalysis can reveal, perhaps more than any other discourse today,

OPEN ACCESS

Edited by:

Andrea Clarici,

University of Trieste, Italy

Reviewed by:

Daniela Flores Mosri,

Universidad Intercontinental, Mexico

Giampaolo Sasso,

Società Italiana di Psicoterapia

Psicoanalitica, Italy

*Correspondence:

Gertrudis Van de Vijver gertrudis.vandevijver@ugent.be

Specialty section:

This article was submitted to

Psychoanalysis and Neuropsychoanalysis,

a section of the journal

Frontiers in Psychology

Received: 31 October 2019

Accepted: 27 January 2020

Published: 19 February 2020

Citation:

Van de Vijver G, de Kroon J and Potier R (2020) Editorial: Lacanian Psychoanalysis.

Front. Psychol. 11:192. doi: 10.3389/fpsyg.2020.00192 the decoys at play in this truth-seeking business, as well as the eagerness with which we are all inclined to forget about them, as if truth must be there, somewhere, somehow, even if only a little bit, just a little bit,...

In psychoanalysis, it is Lacan who most insistently stresses that the drive to know is what pulls us into subjectivity. And the fact that he is known to be most difficult of access, is perhaps related to that: the question for him is not to tell how things really are-how could he, after all? - it is to have us, all of us, one by one, circle around the structural impossibility that marks us as speaking beings, and to have us, all of us, one by one, address the question of what it means for us to have wanted and to continue to want to know. To attempt to overcome this structural impossibility is what makes us suffer, as it is what makes up our pleasure and enjoyment. In this structural impossibility lies our whole possibility.

This small introductory note is meant to invite the readers of this special issue on Lacanian Psychoanalysis to look upon the contributions from this methodological angle: the point is not to approach them against the background of a possible "real-real" truth, it is to consider them, each in their own way, clinically, theoretically, philosophically, as potential small eye openers... Clinically, for the occasions where the overall "wanting to cure" - a scandal, as Artonin Artaud reminds us-risks to overrule the very singular way speaking beings have of traveling in subjectivity, of inhabiting it by finding their very own and proper way of dying, as Freud so poignantly states in "Beyond the pleasure principle." Theoretically, for the occasions where the sciences-in this regard it are most of the time the neurosciences-are invoked to bring on the "objective" authority, the "real" truth, and where not much room is left, except in the defensive mode, for a diverging voice, or a voice at all. Philosophically, for the occasions where the truth risks to pass only under the cover of an objectivity that speaks for itself, leading to an objectivism that can only side with a subjectivism that is as homeless and voiceless as it is itself.

This special issue contains 12 contributions.

Within the "Hypothesis and Theory" section, we have 5 contributions:

The contribution of Feyaerts and Vanheule, "The Logic of Appearance: Dennett, Phenomenology and Psychoanalysis," deals with Daniel Dennett's take on the neurosciences, 
psychoanalysis, and contemporary phenomenology. It is the logic of appearance, stemming from Lacanian psychoanalysis, that serves here as a wager to confront and assess ideas about the first person perspective, consciousness, and issues of naturalization.

Potier and Putois start in "A Lacanian Approach to Medical Demand, With a Focus on Pediatric Genetics: A Plea for Subjectivization" from clinical experience in pediatric genetics. They take Lacan's remarks on the unconscious demand as a source of inspiration, and address the question in what sense medical demand, with healing and curing as its objects, can be viewed as a special instance of it-medical demand as an instance of transference, i.e., as an instance of seeking knowledge on the cause of one's desire. The notion of implicit demand is especially highlighted here, in line with the work of Raimbault, in turn inspired by Lacan, and this allows the authors to suggest that it might be interesting to supplement the medical perspective of curing and healing by what the "family myth" presents in relation to guilt and disease.

From a more historical angle, Razon et al. then give, in "The Lacanian Concept of Cut in Light of Lacan's Interactions with Maud Mannoni," a detailed explanation on how Maud Mannoni's clinical experiences fed Lacan's theorizing of the concept of the cut and the symbolic operation through which the object $a$ is produced.

In "The Mark, the Thing, and the Object: On what Commands Repetition in Freud and Lacan" Van de Vijver et al.'s "Beyond the pleasure principle," the compulsion to repeat and Lacan's commentary on it. For Lacan the compulsion to repeat articulated in terms of jouissance, is a genuine break with the pleasure principle. Over and again Lacan stresses that repetition is the basis of subjectivity, not intentionality. Man is driven to repeat what was structurally missed and not be guided by what brings satisfaction to his needs.

Westphal and Lamote discuss in "The Clinic of Identifications in the Different Processes of Metamorphosis Into Woman" the function of identification of the unconscious subject in relation to the body, the body image, and the other. Clinical examples and examples out of the literature bring the authors to sustain that transsexualism, and metamorphosis into woman, can be considered as a way to problematize the relation to the body and to the other-a new opportunity and a new challenge in light of the changed legal context.

In the "Conceptual Analysis" section we have 4 contributions:

The relation between psychoanalysis and neuroscience is the subject of Aguiar's "The 'Real Without Law' in Psychoanalysis and Neurosciences." Lacan's adage "The real of psychoanalysis is without law" apparently contrasts sharply with what the real is for science, i.e., according to Lacan, entirely governed by laws. Neither Lacan nor Freud defended an incompatibility between psychoanalysis and science, and the latest discoveries in neuroscience seem to bring them closer, in as far namely that contingency ("the real without law") plays an ever more important role in the sciences.

Dimitriadis explores in "The Psychoanalytic Concept of Jouissance and the Kindling Hypothesis" the relation between Lacan's effort to articulate the concept of jouissance, current researches in the neurosciences, and clinical phenomena that witness to the fact that jouissance becomes "kindled," i.e., escapes the control of the symbolic process. He suggests that the process of kindling can have a destructive effect, also in the brain, that he proposes to coin as a "psychosomatic disease of the brain."

In "The Individual and the Collective: Sociological Influences on Lacan's Concept of the Relation Subject-Other," Schrans gives a large exposition of the development of the family in Western and other societies elaborated by thinkers as Durkheim, Mauss, and Lévi-Strauss. It is shown how Lacan was influenced by these sociologists, how he changed his standpoint from a principle of an imaginary identification in the family to a concept in which the subject is structured in a symbolic system.

Vulnerability is the main concept under study in "Language and Vulnerability-A Lacanian Analysis of Respect" by Laufer and Santos. The article discusses the way in which Lacanian psychoanalysis allows to take into account the vulnerability of the subject, without reducing it thereby to a victim. Underlying here is the issue of the identity of the subject.

In the "Perspective article" section we have 2 contributions:

Lepoutre et al. give in "The Lacanian Concept of Paranoia: An Historical Perspective" an outline of Lacan's concept of paranoia that he considered as the "resistant nucleus" of psychosis in contrast with schizophrenia. Opposite to the neo-Kraepelinian approach in the DSM-enterprise where paranoia as a concept loses of its importance, Lacan puts it in the center of his theory on psychosis. The authors plea for a reinvestment of Lacan's concept of paranoia because of its subtleties and theoretical potentiality.

Ouvry informs us in "Lacan and Adolescence: The Contemporary Clinic of the 'Sexual Non-rapport' and Pornography" on the "Sexual Non-rapport" and pornography among adolescent boys. He explores two clinical phenomena and their risk of pathological fixation: pornography and conspiring thinking. Two aspects of the same principle are at stake: "seeing it" [ça voir] and "knowledge" [savoir] applied to sexuality (pornography) and to truth (conspiracy theories). In both cases there is a denial of the recognition of the "other jouissance."

In the "Opinion Article" section, we have 1 contribution:

De Battista deals in on "Lacanian Concept of Desire in Analytic Clinic of Psychosis" with Lacan's concept of desire in psychosis. She discusses the relative absence of references to the concept of psychotic desire in Lacan scholarship, and takes up the challenge of attempting to reconsider it in ways other than departing from the concept of the Name-of-the-Father.

\section{AUTHOR CONTRIBUTIONS}

GV is the main author of this editorial, followed by JK and RP.

Conflict of Interest: The authors declare that the research was conducted in the absence of any commercial or financial relationships that could be construed as a potential conflict of interest.

Copyright (c) 2020 Van de Vijver, de Kroon and Potier. This is an open-access article distributed under the terms of the Creative Commons Attribution License (CC BY). The use, distribution or reproduction in other forums is permitted, provided the original author(s) and the copyright owner(s) are credited and that the original publication in this journal is cited, in accordance with accepted academic practice. No use, distribution or reproduction is permitted which does not comply with these terms. 


\title{
Lacanian Concept of Desire in Analytic Clinic of Psychosis
}

\author{
Julieta De Battista ${ }^{1,2,3 *}$ \\ ${ }^{1}$ Laboratorio de Investigaciones en Psicoanálisis y Psicopatología, Facultad de Psicología, Universidad Nacional de La Plata, \\ Buenos Aires, Argentina, ${ }^{2}$ Consejo Nacional de Investigaciones Científicas y Técnicas, Buenos Aires, Argentina, ${ }^{3}$ Comisión \\ de Investigaciones Científicas de la Provincia de Buenos Aires, Buenos Aires, Argentina
}

Keywords: desire, psychosis, psychoanalysis, Lacan, knot, jouissance, body, Joyce

\section{INTRODUCTION}

The conceptof desire is central to Lacan's theory and practice, even if it is not among the four fundamental concepts of psychoanalysis-unconscious, Trieb, repetition, transference, it can be understood that it underlies all of them. The concept of desire is inherent to the ethics of psychoanalysis that Lacan formulated, therefore it is especially concerned with a practice whose operation is defined by the function of analyst's desire. However, this central thesis of Lacan has been called into question with regard to psychosis. Some Lacanian scholars have derived from the foreclosure of the Name-of-the-Father a lack of desire in psychosis.

This paper aims to discuss the relative absence of references to the concept of psychotic desire in Lacanian schools. The debate is relevant because Lacan did exclude neither desire nor psychosis from his conception of analytic treatment.

It is frequent that in the transmission of the approach of this type of cases into the Lacanian schools, the concept of desire is not used, but rather the consequences of its absence are emphasized (De Battista, 2012). For example, in two of the latest publications compiled by Miller, where there are more than 20 clinical cases of psychosis treated by Lacanian analysts, the concept of desire is not evoked to think about the changes caused by the cure. In the clinical cases where this concept is mentioned, the authors highlight that desire has not operated (cf. Borie, 2011; Dewambrechies-La Sagna, 2011; Di Ciaccia, 2011; Zerghem, 2011; Klotz, 2012; Magnin et al., 2012).

In the argumentation of these authors, this non-operational desire would go hand in hand with intrusive and invasive phenomena that would account for a delocalized jouissance, whose restraint would depend on its fixation through identifications, delusional metaphors or writing practices, introducing a limitation of jouissance (Maleval, 2000; Soria Dafunchio, 2008; Miller, 2011, 2012).

Other authors claim that desire would not be absent in psychosis (Lombardi, 1992; Soler, 2004), nonetheless it is restricted to paranoia, declaring its abolition in schizophrenia (Quinet, 2006). However, even in those cases where psychotic desire is considered, the affirmation of its existence does not go hand in hand with a clarification of its operation in the cure. The authors again resort to the idea of an invasion of jouissance, which should be limited (Soler, 1987; Quinet, 2006; Soria Dafunchio, 2008; Miller, 2011, 2012; Redmond, 2013). The notion of limitation of jouissance is that which is most frequently used to account for the analytical treatment of psychosis (Maleval, 2000).

In view of the current state of affairs with regard to the subject treated, the following questions deserve-in my view-an investigation.

Firstly, Is desire the exclusive patrimony of those clinical types derived from the perre-version (neurosis/perversion)? What would be the Lacanian arguments to sustain the absence of desire in psychosis? Secondly and according to my hypothesis of the importance of psychotic desire, which kind of desire would operate in psychosis?

Received: 27 January 2017 Accepted: 27 March 2017 Published: 11 April 2017

\section{LACANIAN CONCEPT OF DESIRE}

On his return to Freud, the Lacanian perspective reintroduces the question of desire as the basis of analytic experience. Desire and unconscious go hand in hand for Freud. The Freudian 
notion of desire is early linked to the effort toward motility and the difference between what is found and what is sought: negativity and lack that drive the indestructible pursuit of desire.Unconscious desire is then the core of our being. Desire irrigates us, innervates us and includes that vital and sexual dimension. It seems to be the way by which Trieb, thanks to the institution of a fault, works in the unconscious, thus becoming a kind of Trieb destiny, a treatment of the real of the body.

Lacan (1966a) pointed out that the question of desire remained veiled in the conceptualizations of analytic experience. He proposed to reintroduce it in terms of an ethic that is not that of Aristotle-which exiles the desire to be beyond the domain of reason-but it is rather in harmony with the purposes of Spinoza, who conceives desire as the essence of human kind. A journey through references, brief and metonymic as our object seems to demand, reminds us that for Lacan desire is also linked to the vital impulse and to libido (Lacan, 1986, 1971-1972). Desire cannot be said, it is manifested in the interval, in the interstices and defined for Lacan as the metonymy of being in the subject, or the metonymy of the lack in being (Lacan, 2013).This definition is maintained throughout the entirety of his teaching. Even in 1975, Lacan argues that the unconscious determines the subject as being, being that disappears in the metonymy in which the desire is supported, impossible to say as such (Lacan, 1974-1975).The desire can be articulated but it is not articulable, it is irreducible to the demand and the necessity, cannot be named, cannot be sifted, it is of the order of the unconscious fault (Lacan, 1976-1977). However, desire can be clinically verified (Lacan, 2005).

For Lacan, desire is established in the dialectic of the fault. The Other gives the subject an experience of his desire which is the basis of the position in the structure. This implies a certain dependence on the desire of the subject with respect to the desire of the Other, whereby the desire for desire is the essential dimension (Lacan, 1986). The subject is born into language and is already determined in his unconscious by the desire of the Other, it is born of a desire (Lacan, 1971-1972, 1974-1975). The point is to have been desired, that is what we found in the analytic experience, even for those to whom that experience was perturbed in their constitution.

\section{NEUROTIC POSITION AND PSYCHOTIC POSITION WITH RESPECT TO DESIRE}

The relation of the subject's desire to the Other's desire is not a structure reserved solely for neurosis. Lacan (2013) is explicit in this respect, when he says that "it is an essential structure, not only of neurosis, but of every analytically defined structure" (p. 502). He does not renounce to situate the position of desire in different structures; there would then be different forms of desire and different subjective structures. The relations of desire become the field where analytic experience is articulated and this implies an ethic of desire characteristic of psychoanalysis, an ethics that sets the question of the analyst's desire. Analysts are intermediaries, they preside over the advent of desire, they are a kind of midwives of desire (Lacan, 2013).

If we return to the different subjective structures and the different forms of desire, we find that for the neurotic, whose position in desire is the fantasy, the metaphorical reference to the
Name-of-the-Father knots the registers and establishes an oedipal psychic reality, therefore religious. The object $a$, cause of desire, is trapped in the center of the knot. The desire is mediated by the phallic reference that gives it a common measure and symbolizes the $\mathrm{X}$ of the mother's desire. The function of the father knots desire to a law, that of the interdiction of incest: here is the perreversion (Lacan, 1974-1975). The X of desire is fixed on the fantasy that brings an interpretation. The neurotic subject has a relation to desire by the way of fantasy, due to the fact that fantasy has the function of sustaining desire.

Notably, the situation is different for the psychotic subject, because his condition implies the rejection of the father's metaphorical reference, that is, the foreclosure of the Name-ofthe-Father, a circumstance of the subjective position for Lacan (1966b). But the absence of the father's metaphor does not condition the presence of desire, whose support is not metaphor but metonymy. Consequently, if the Name-of-the-Father has been rejected, the metaphorical effect in this point does not occur and the $\mathrm{X}$ of the maternal desire is not symbolized by the signifier of the phallus: which is why the desire of the Other is not symbolized (Lacan, 1998).

According to Lacan (1986), the desire of the mother is the founding desire of the whole structure, and in the psychotic subject it is outside of the symbolization introduced by the paternal metaphor, therefore the knotting of records does not occur in an Oedipal way. This argument is not enough to say that there is no desire in the psychotic, but rather that it is a not symbolized desire, without the reference that introduces the phallus as a signifier of the lack.

Evidently, Lacan's intention has not been to exile desire from the field of psychosis. What is in question is the reference that desire can find in the signifier of lack, the phallus, but not the existence of desire itself. Then, the question would not be that of the absence of desire in psychosis, but that of a desire which is not symbolized by the Name-of-the-Father. That is, a desire that is not knotted to the law of the father, dimension that characterizes the position of the psychotic as one of rejection of the paternal imposture. The desire of the psychotic would not be sealed by the consent of the father.

A close bond between desire and the law of the father has veiled that for Lacan desire is an absolute condition. That is to say, desire is not relative to another thing, it is detached from the dependence to something else. Desire makes the law and not the law which introduces the desire. Desire is autonomous with regard to the mediation of the law, the law itself originates from desire and not vice versa (Lacan, 1966c). A certain transmission effect has reversed this assertion, by concluding that the law of the Father is the one that introduces the desire, and then it follows that the psychotic's rejection of the Name-of-the Father implies an exclusion from desire. But Lacan did not make the Name-of-Father or the law the absolute condition, but desire.

In this way, the question of desire remains in Lacan beyond the father, it concerns the condition of the speaking being in language and does not necessarily entail the operation of a metaphorical reference. The desire offers a key to read what could knot real, symbolic, and imaginary without reference to the Name-of-theFather and without this being constituted in a deficient condition, but simply different. 
Desire is an absolute condition, not relative to something else, desire is the essence of the human being. This thesis is maintained throughout the teaching of Lacan: from the 50s to the late 80 s, the desire is at the heart of the analytic experience as a possible Triebschicksale (Lacan, 1980). In 1962, Lacan affirms that the specificity of psychosis with respect to desire is that, in its structuring, the psychotic does not know the phallus and the Other, therefore the body acquires all the importance. One example of this thesis could be found in Cotard's syndrome where Lacan (1978) recognized a desire of death. However, this one is not the only form of psychotic desire that Lacan places, in 1974-1975 he also speaks of frozen desire in paranoia (Lacan, 1974-1975).

\section{CONCLUSION}

However, the position on the desire differs in neuroses, psychosis, and perversion. In the case of psychotic desire, Lacan has affirmed a fundamental relationship with the body (Lacan, 1961-1962). The references worked allow us to propose that the problem is not a lack of desire in psychosis, but rather its support. We can determine delusional supports of desire, as in Schreber's case, or symptomatic supports of desire as

\section{REFERENCES}

Borie, J. (2011). "Una paranoia familiar," in Cuando el Otro es Malo, ed J. A. Miller (Buenos Aires: Paidós), 113-116.

De Battista, J. (2012). Le Désir Dans Les Psychoses. Problématique et Incidences de la Cure Dans L'enseignement de J. Lacan. Doctoral Thesis, Toulouse: Université de Toulouse.

Dewambrechies-La Sagna, C. (2011). "Edición de autor," in Cuando el Otro es Malo, ed J. A. Miller (Buenos Aires: Paidós), 33-42.

Di Ciaccia, A. (2011). "El muchacho de la cuerda," in Cuando el Otro es Malo, ed J. A. Miller (Buenos Aires: Paidós), 43-50.

Klotz, J.-P. (2012). "Estar al tanto," in Embrollos del Cuerpo, ed J. A. Miller (Buenos Aires: Paidós), 63-68.

Lacan, J. (1961-1962). Le Séminaire. Livre IX. L'Identification. Available online at: www.valas.fr

Lacan, J. (1966a). "La direction de la cure et les principes de son pouvoir," in Écrits (París: Seuil), 585-646. Original work of 1958.

Lacan, J. (1966b). "D'une question préliminaire à tout traitement possible de la psychose," in Écrits (Paris: Seuil), 531-584. Original work of 1958.

Lacan, J. (1966c). "Subversion du sujet et dialectique du désir dans l'inconscient freudien," in Écrits (Paris: Seuil), 793-828. Original work of 1960.

Lacan, J. (1971-1972). Le Savoir du Psychanalyste. Entretiens à Sainte-Anne. Available online at: www.valas.fr

Lacan, J. (1974-1975). Le Séminaire. Livre XXII. RSI. Available online at: www.valas.fr

Lacan, J. (1976-1977). Le Séminaire. Livre XXIV. Linsu Qui Sait de L’une-Bévue S'aile à Mourre. Ornicar? 12-13.

Lacan, J. (1978). Le Séminaire. Livre II. Le Moi Dans la Théorie de Freud et Dans la Technique de la Psychanalyse. Paris: Seuil (Coll. Le champ freudien). Original work of 1954-1955.

Lacan, J. (1980). Le Séminaire. Dissolution. Ornicar? 20-21.

Lacan, J. (1986). Le Séminaire. Livre VII. L'éthique de la Psychanalyse. Texte Etabli par Jacques-Alain Miller. Paris: Seuil (Coll. Le champ freudien). Original work of 1959-1960. in Joyce's solution "desire to be an artist who will keep the critics busy for three hundred years" (Lacan, 2005: 88). Both of them have a common term: the asymptotic character. One possible clinical application of these references is to question the position of the psychotic in desire. From this perspective, the analyst's position is relevant because of its specificity: become the cause of the analysand's desire, a sort of "tailored partenaire" for the psychotic, who finds it difficult to sustain his desire.

\section{AUTHOR CONTRIBUTIONS}

The author confirms being the sole contributor of this work. She has designed the conception of the article, made the analysis and interpretation of sources, drafted the paper and revised and approval final version to be published.

\section{FUNDING}

This work was supported by the Consejo Nacional de Investigaciones Científicas y Técnicas (CONICET), the Universidad Nacional de La Plata (UNLP) and the Comisión de Investigaciones Científicas (CIC).

Lacan, J. (1998). Le Séminaire. Livre V. Les Formations de Linconscient. Texte Etabli par Jacques-Alain Miller. Paris: Seuil (Coll. Le champ freudien). Original work of $1957-1958$.

Lacan, J. (2005). Le Séminaire. Livre XXIII. Le Sinthome. Paris: Seuil. Original work of 1975-1976.

Lacan, J. (2013). Le Séminaire. Livre VI. Le Désir et Son Interprétation. París: Éd. La Martinière. Original work of 1958-1959.

Lombardi, G. (1992). La Clínica Del Psicoanálisis.3. Las Psicosis. Buenos Aires: Atuel.

Magnin, E. et al. (2012). "No toque mi TOC”, in Embrollos Del Cuerpo, ed J. A. Miller (Buenos Aires: Paidós), 69-78.

Maleval, J. C. (2000). La Forclusion du Nom-du-Père. Paris: Seuil.

Miller, J. A. (2011). Cuando el Otro es Malo. Buenos Aires: Paidós.

Miller, J. A. (2012). Embrollos del Cuerpo. Buenos Aires: Paidós.

Quinet, A. (2006). Psicose e Laco Social. Esquizofrenia, Paranoia e Melancolía. Rio de Janeiro: Zahar.

Redmond, J. D. (2013). Contemporary perspectives on Lacanian theories of psychosis. Front. Psychol. 4:350. doi: 10.3389/fpsyg.213.00350

Soler, C. (1987). "Quelle Place Pour l'analyste?," in Actes de L'École de la Cause freudienne XIII (Paris), 29-31.

Soler, C. (2004). Le partenaire du psychotique. Cahiers du Collège Clinique de Paris. Abord Psychanalytique des Psychoses 5:15-25.

Soria Dafunchio, N. (2008). Confines de Las Psicosis. Buenos Aires: Del bucle.

Zerghem, M. (2011). "Las trampas del Otro," in Cuando el Otro es Malo, ed J. A. Miller (Buenos Aires: Paidós), 61-70.

Conflict of Interest Statement: The author declares that the research was conducted in the absence of any commercial or financial relationships that could be construed as a potential conflict of interest.

Copyright (c) 2017 De Battista. This is an open-access article distributed under the terms of the Creative Commons Attribution License (CC BY). The use, distribution or reproduction in other forums is permitted, provided the original author(s) or licensor are credited and that the original publication in this journal is cited, in accordance with accepted academic practice. No use, distribution or reproduction is permitted which does not comply with these terms. 


\section{OPEN ACCESS}

Edited by:

Rémy Potier,

Paris Diderot University, France

Reviewed by:

Lewis Kirshner,

Harvard Medical School,

United States

Stephanie Swales,

University of Dallas, United States

${ }^{*}$ Correspondence:

Jasper Feyaerts

jasper.feyaerts@ugent.be

Specialty section:

This article was submitted to Psychoanalysis

and Neuropsychoanalysis, a section of the journal

Frontiers in Psychology

Received: 30 March 2017 Accepted: 08 August 2017 Published: 22 August 2017

Citation:

Feyaerts J and Vanheule S (2017)

The Logic of Appearance: Dennett,

Phenomenology and Psychoanalysis.

Front. Psychol. 8:1437.

doi: 10.3389/fpsyg.2017.01437

\section{The Logic of Appearance: Dennett, Phenomenology and Psychoanalysis}

\author{
Jasper Feyaerts* and Stijn Vanheule \\ Department of Psychoanalysis and Clinical Consulting, Ghent University, Ghent, Belgium
}

In the present essay, we aim to develop and contrast three different positions toward Sellars' distinction between the manifest and scientific images of man: Dennett's philosophical reconstruction of neurocognitive science, contemporary phenomenology and psychoanalysis. We will suggest that these respective traditions and the substantial differences between them can be understood in terms of a 'logic of appearance.' Related to this are differing ideas about the rights and limits of the first-person perspective, the relation between conscious experience and belief, and the issue of naturalization. In the final part, we will try to specify, on the basis of a detailed reading of the disagreement between Dennett and phenomenology, in what way psychoanalytic theory could respond to these different issues.

Keywords: Dennett, phenomenology, psychoanalysis, subjectivity, experience, belief

\section{INTRODUCTION}

In his Philosophy and the Scientific Image of Man, Wilfrid Sellars offered a condensed diagnosis that seems to retain a certain validity with respect to our current philosophical, scientific and social predicament. Sellars (1991) famously talked about a discord fueled by the conflict between two apparently opposing "images" of man-in-the-world (1991, p.5): on the one hand, a manifest image which represents the tentative and provisional collection of ideas and assumptions we spontaneously adopt to characterize ourselves and the world we live in. Chief among these are ideas closely related to our immediate self-understanding as subjects endowed with self-consciousness, a certain extent of freedom of choice, gifted with reason but also desires, and so on. On the other hand, a relatively recent, but continually expanding scientific image of man as a "complex physical system" (1991, p. 25) - that is, an image conspicuously unlike its manifest double, but one which can be progressively distilled from various burgeoning scientific disciplines, such as neurology, physics, evolutionary biology and cognitive science.

In a more recent past, Sellars' distinction has found a renowned application in the work of the well-known philosopher of cognitive neuroscience, Daniel Dennett. For the past few decades, Dennett has been vehemently advocating against "the fantasy of first-person science" (Dennett, 2001), arguing, amongst other things, that there is no such thing as a 'Cartesian theater' where private things happen that are spontaneously revealed before a 'mental I/eye', one that, moreover, would form an unsurpassable source for self-knowledge from a first-person perspective. Why indeed, Dennett asks, should we give up our scientific abstinence when, compared to some other notorious fictive entities such as the phlogiston or élan vital, it comes to seemingly less exotic matters such as the 'I', 'experience' and 'consciousness'? According to Dennett's well-known proposal, we should treat these manifest testimonies in the same way we treat testimonies in court, that is, as provisional fictions (Dennett, 1991, p. 79), where after we can safely let cognitive neuroscience do its job in deciding if, and to what extent, there might be "truth in fiction." 
Given the central importance of the first-person perspective in one way or another, and to be specified throughout our article in both contemporary phenomenology and psychoanalytic theory, the questions we want to pose in this article are therefore the following ones: where do these disciplines, respectively, stand with regard to such proposals? And in what way would these two disciplines respond to Dennett's proposal to consider subjective beliefs about ourselves as provisional fictions and, to be sure, in all likelihood, future illusions?

In the first part, we will give a detailed reading of what is understood by such terms as 'first-person experience' and 'subjective appearance' in both phenomenology and Dennett's account and, on the basis of that reading, press some arguments that can be advanced against Dennett's fictionalization of subjectivity in favor of phenomenology. In the second part, we will offer a similar exercise in the case of psychoanalysis. We will argue that Sellars' distinction, exemplified by the discussion between Dennett and phenomenology, touches upon a classic ambiguity in psychoanalytic theory. Finally, a possible way out of this ambiguity will be sought through a close examination of the psychoanalytic concept of 'belief'.

\section{DENNETT AND PHENOMENOLOGY: THE SEEMING OF SEEMING}

Let us take as a point of entry in the already quite extensive debate between phenomenology and Dennett ${ }^{1}$ one of the latter's most cherished examples which he uses in his Consciousness Explained in order to fortify his Multiple Drafts Model of consciousness, a model which, Dennett warns us, "is initially deeply counterintuitive" (1991, p. 45). Dennett refers to a certain perceptual effect, better known in the literature as the phi phenomenon or phi movement, first so called by the Gestalt psychologist Max Wertheimer, which was the object of repeated study in a series of experiments conducted by Kolers and von Grünau (1976). In the simplest case of the experiment, subjects were shown a single flash of a red spot, followed quickly by a displaced green spot, followed by another flash of the original red (each flash lasting about $150 \mathrm{~ms}$, with a gap of about $50 \mathrm{~ms}$ in between). Perhaps not that surprising given our everyday smooth television-experience, the subjects reported seeing not two discrete spots, but one spot rapidly moving over and back again. However, one might ask, what about the change of color from red to green? Interestingly, the subjects reported the spot changing color about halfway through its trajectory from the initial flash to the second. As Dennett (1991) recounts the result: "the first spot seemed to begin moving and then change color abruptly in the middle of its illusory passage toward the second location" (p. 114). Given this surprising result, one of the collaborators to the experiments, the philosopher Nelson Goodman, asked the following question: "how are we able to fill in the spot at the intervening place-times along a path running from the first to the second flash before that second flash occurs"

${ }^{1}$ For a representative sample of the different discussions running through this debate, see the collection of essays in Dreyfus and Kelly (2007).
(Goodman, 1978, p. 73)? A pressing question indeed in so far as we want to avoid positing strange ontological scenarios wherein effects precede their causes and time starts running backward.

So how then are we to proceed in answering Goodman's question? We will first begin by teasing out some basic principles in the way phenomenology would handle this issue, in order to articulate more clearly the dividing line which separates Dennett's account from the former.

\section{The Principle of Appearance Qua Appearance}

From a phenomenological perspective, when confronted with such an ambiguous situation, it would be wise to make use of Husserl's notorious maxim of phenomenological inquiry and "to go back to the things themselves" (Husserl, 2001, p. 168). Indeed, one of the guiding motifs and enabling assumptions of phenomenology is that in principle, and through availing ourselves of phenomenology's methodological procedures of 'epoché' and 'reduction', we would be able to put these explanatory questions aside for a moment and to focus instead on the experienced object (in this case the moving spot) precisely in the way it is experienced from the subjective or first person point of view. Rather than the hasty conjuring up of various theoretical explanations (e.g., Goodman's "how are we able to fill in the gaps?"), phenomenology's traditional first move is to get a clear descriptive picture of what is to be explained in the first place - the quod erat explicatum for a science of consciousness -, precisely by letting, to use Heidegger's inimitable phrasing, "that which shows itself be seen from itself in the very way in which it shows itself from itself" (Heidegger, 1962, p. 34). Despite the different ways in which contemporary phenomenology aims to fulfill its role in the debate around the nature of consciousness, there is indeed at least one unifying principle amongst the various phenomenological commentators. Let us call this the phenomenological principle of appearance qua appearance. In order to get a clear view of the sort of claims at stake in such a principle, let us begin by considering a few remarks by Husserl. In the Crisis of European Sciences and Transcendental Phenomenology, Husserl (1970) writes:

The first thing we must do, and first of all in immediate reflective self-experience, is to take conscious life, completely without prejudice, just as what it quite immediately gives itself, as itself, to be (p. 233).

Here we have the first point: if anything, phenomenology, as a transcendental investigation of the first-person perspective, takes its point of departure "in immediate self-experience", that is, it tries to offer a descriptive analysis of the way the world in general (Wertheimian spotlights included), but also other subjects and we ourselves, appear to us in ordinary experience. Crucially, in offering such a description of our everyday intentional involvement with the world, this appearance should be accepted "just as what it quite immediately gives itself, as itself, to be" (Husserl, 1970, p. 233). In short: on a phenomenological account, appearance should be taken as appearance as such, rather than as 
something else. Let us take one of Husserl's examples to clarify and develop the ramifications of such an idea a little bit further.

Suppose we walk through a garden and become struck by a blossoming tree. How do we go about analyzing our immediate experience of the appearing of this blossoming tree? It is here that Husserl's methodological tool of 'epoché' comes into play; a notion, however, particularly fraught with all kinds of misunderstandings we need to clear up before furthering our analysis (see Overgaard, 2015). According to a common misunderstanding, for example, the method of epoché or 'bracketing' would lead us to a consideration of the immanent contents of perception as they show up 'in' consciousness, severed and disconnected from any possible relation to the transcendent, real world which, conversely, is considered to be 'outside' consciousness (e.g., Burge, 2010). Accordingly, phenomenological bracketing would be first of all the bracketing of the realist presumption inherent in the natural attitude of our everyday experience. That is, the elimination of our prephilosophical belief in the real world in favor of the appearance of Husserl's blossoming tree as some kind of second blossoming tree, this time considered as an immaterial entity (i.e., image, datum, perceptum, ...) somehow hovering before or within consciousness as in a Dennettian Cartesian theater. Yet closer inspection of some of Husserl's own remarks on what the epoché is supposed to accomplish makes it clear that such an introspective reading is simply mistaken. Remarking on how that blossoming tree appears to consciousness after the epoché has been performed, Husserl (1983) writes

[...] everything remains as of old. Even the phenomenologically reduced perceptual mental process is a perceiving of "this blossoming apple tree, in this garden," etc., and, likewise, the reduced liking is a liking of this same thing. The tree has not lost the least nuance of all these moments, qualities, characteristics with which it was appearing in this perception, <with which $>$ it $<$ was appearing as > "lovely," "attractive," and so forth "in" this liking (p. 216).

Hence, the practice of phenomenological bracketing as originally intended by Husserl does not consist in a reflexive retreat from reality the better to focus on contents or 'qualia' that are found within the self-enclosed terrain of pure consciousness. Nevertheless, although everything after the epoché "remains as of old" (Husserl, 1983, p. 216), there is of course a sense in which the epoché, in Husserl's understanding, does reveal something that might have gone unnoticed before we put it to use. Again, Husserl (1970) remarks:

[...] through the epoché a new way of experiencing, of thinking, of theorizing, is opened to the philosopher; here, situated above his own natural being and above the natural world, he loses nothing of their being and objective truths and likewise nothing at all of the spiritual acquisitions of his world-life (...); he simply forbids himself - as a philosopher [...] - to continue the whole natural performance of his world-life (p. 152).

Two points are important in this rendition of the epoché.
The first thing to emphasize is that this new way of experiencing is not a matter of acquiring additional empirical information through further forms of experience, for example, by turning my introspective gaze from the world to my consciousness. This means that, with regard to the earlier example of Husserl's blossoming tree, the epoché is intended to enable a faithful attending and description of the original experience of the blossoming tree precisely as it appeared in that very experience, that is, without changing anything about all the moments and elements that were already implicit in that experience. So if in our straightforward experience of the blossoming tree, it appeared as 'actually existing' or 'real', mind independent in whatever sense, but also 'lovely', 'attractive, 'in this garden' and so forth, then these presuppositions, and basically all positions with regard to that tree, should be retained in our description.

Yet, secondly, in this reflexive elucidation of conscious experience through the epoché, not only does the focus shift from world to world-as-experienced, but so does the criterion for truth and error with regard to phenomenological statements that try to express descriptively what was going on according to experience. That is, by abstaining from taking any positions toward the conscious experience of, for example, spotlights changing color at a certain moment, we seem to be moving to what is at least a different sort of epistemological terrain when compared to the epistemic situation of empirical claims about the world (see Rosenberg, 2002). Yet, we should be careful as to the precise nature of the epistemic shift that, according to phenomenology, is at stake here.

Does such a claim, for example, imply some sort of "papal infallibility" (Dennett, 2007, p. 6) or incorrigibility with regard to phenomenological beliefs relative to the first-person perspective? Here is how Koch (1997) formulates such an idea:

We shall take the cogito only as a means of suspending objectivity claims and of thereby inducing infallibility in what remains of the objectivity claim after suspension. This last point is important. For every objective truth claim, in which I am invariably fallible, there is a corresponding trivial truth claim, in which I am infallible, a truth claim which is fulfilled by the sheer fact that I seriously and honestly claim so. For every objective, thick truth claim, that $\mathrm{p}$, there is a corresponding trivial, thin truth claim, that I think that $\mathrm{p}$ (or that it seems to me that p) (p. 73).

Hence, on Koch's reading (but also Dennett's, cf. infra), the epoché entails a movement from objectivity claims in which I am invariably fallible, e.g., the explicit judgment 'the spot changes color about halfway its trajectory', to a suspension of the same objectivity claim for which in that case I become infallible, 'it seems to me that the spot changes color about halfway its trajectory'. Moreover, the reason why such a transition from judgment to suspension implies infallibility is because in this case, according to Koch, the cogito "falls within its own scope" (1999, p. 72). What this means is that the cogito, represented by the expression 'I think that p' or 'it seems to me that p', cannot be iterated without becoming trivial since an additional deployment 
of the epoché would add no further relevant information beyond what can already be found after the first suspension: 'I think that $\mathrm{p}$ ' is logically equivalent to 'I think that I think that p' or 'it seems to me that it seems to me that $\mathrm{p}$ '.

However, it is highly questionable whether Husserl and other major figures in the phenomenological tradition would apprehend the outcome of the epoché and the suggested first-person incorrigibility in such an intellectualistic and Cartesian way. Here, the question is: should we understand the phenomenological transition from world to worldas-experienced as a suspension from objectivity claims to subjectivity claims in terms of a regression to the 'I think' of the Cartesian cogito? Husserl (1970), for one, does not seem to endorse this reading:

It is naturally a ludicrous, though unfortunately common misunderstanding, to seek to attack transcendental phenomenology as "Cartesianism", as if its ego cogito were a premise or set of premises from which the rest of knowledge (...) was to be deduced, absolutely "secured." The point is not to secure objectivity but to understand it (p. 193).

What is behind Husserl's quite explicit rejection of understanding phenomenology as another form of "Cartesianism"? Although much can (and has been) said about this (see e.g., MacDonald, 2000; Staiti, 2015), in the present context, the most important point to stress is that Husserl's and Descartes' projects are driven by fundamentally different questions. The relevant difference for our purposes is to be found in the opposition Husserl draws in the passage above between the Cartesian project of 'securing' and that of phenomenological 'understanding'. For Descartes, as is well known, given the rather unlikely but still imaginable possibility of my being deceived by a vicious demon, the crucial question becomes that of securing some 'fundamentum inconcussum' (involving the two figures of the cogito and a benevolent God) in order to ward off the skeptical threat of perpetual illusion. On a more formal level, Cartesian hyperbolic skepticism represents a passage from uncertainty regarding the truth of most of our convictions regarding the world and ourselves, to certainty with regard to the truth of believing itself (i.e., Koch's thesis above). How then is this different from Husserl's description of the task of phenomenology not to secure, but to understand objectivity? And how is this related to the issue of first-person incorrigibility and truth? Here is how Husserl (1989) specifies this task:

Its sole task and accomplishment is to clarify the sense of this world, precisely the sense in which everyone accepts it - and rightly so - as actually existing. That the world exists - that it is given as an existing universe in uninterrupted experience which is constantly fusing into universal concordance - is entirely beyond doubt. But it is quite another matter to understand this indubitability, which sustains life and positive science, and to clarify the ground of its legitimacy (p. 420).

So, on the one hand, Husserl would basically subscribe to Peirce's (1992) sobering advice not to "pretend to doubt in philosophy what we do not doubt in our hearts" (1992, pp. 2829 ), thereby denying that such a radical pretense is genuinely possible to begin with. Doubting, according to Husserl, is not a matter of simple decision or sheer will. In order to doubt something and to go beyond a philosophical play of mere make-believe, I need a relevant motivation to doubt and such motivation seems entirely lacking in the case of my experience of reality. The world, Husserl (1995) writes, stands before our eyes as existing "without question" (1995, p. 17); or, in Heidegger's (1985) words, it is there "before all belief" and never "experienced as something which is believed any more than it is guaranteed by knowledge" (1985, p. 216). Basically all phenomenological authors would concur on this basic point: rather than being the effect of what I believe it to be, my experience of reality, in its own characteristic way of appearing, determines and makes possible any beliefs I might form about it in turn (see also Merleau-Ponty, 2002, p. 44 et passim).

Yet this, according to Husserl, still somehow constitutes a problem. Again, however, one should avoid precipitously identifying this 'problem' with the Cartesian effort of trying to secure the world or any of its objects through some kind of miraculous deduction starting from the immanent sphere of consciousness. The main reason for Husserl's misgivings with regard to such an effort is not so much that it is a hopeless endeavor (although it is), but that it already betrays one's lack of a proper understanding of consciousness and world-experience. That is, within this Cartesian setup, conscious experience is already pre-understood as a matter of having 'subjective representations' or 'images' that may or may not correspond to the object as it is in-itself standing behind the veil of appearances, thereby opening up the skeptical challenge of knowing whether and how knowledge can extend beyond the prison-house of subjective-relative appearances. This conception of consciousness as some kind of 'bag' or 'container' where representational contents, to use Dennett's expression, "swim along" (1991, p. 44) is, in Husserl's (1999) view, a "fatal mistake" (1999, p. 35).

To give just one example of the 'mistake' Husserl is aiming at: when I visually perceive, say, a chair, almost no one (except, perhaps, some philosophers) makes the mistake of claiming that what we are actually conscious of is some sort of image, sense-datum or another mental representative of the chair. According to Husserl, being conscious of the chair through the presentational consciousness of some other chairlike simulacrum precisely does not count as a perception of a chair, even if this representative image somehow resembles the original chair. This is (but one limited way) how our ordinary experience of everyday objects immediately strikes us, as somehow presenting us with the chair itself. Yet most of us, Husserl included, would agree that objects don't appear before consciousness magically, as - in Sellars' idiom - "a seal on melted wax" (Sellars, 1981, p. 12): at least some sort of process is involved that makes the presence of the object - in the way that it is present - possible. It is precisely this possibility which Husserl, under the heading of his transcendental-constitutive analysis, wants to understand: not if conscious experience is involved with the world itself rather than its ghostly double, but how it is so. 
Now the 'fatal mistake' - of which Descartes was in Husserl's eyes a paradigmatic offender - occurs when we substitute some part of this process, i.e., that in virtue of which we are conscious of objects in the way that we do, for our consciousness of the object itself. In contemporary terms: when we confuse properties of what is represented with properties of the representing. To stick with the chair-example: as I visually perceive the chair, my experiences change in various detectable ways. What I perceive of the chair will, amongst other things, depend on my position relative to it. Yet, the chair itself does not appear to get bigger or smaller whenever I get nearer or back away from it, nor does it appear to turn black when I switch off the light. I perceive the chair as having one uniform color, size and shape, while the sensations in virtue of which I perceive those qualities can, and often must, vary with changes in my environment and condition. However, in straightforward perception I do not attend to these sensations, and they are not among the perceptual experience's object. As Husserl (2001) writes: "I do not see color-sensations, but colored things, I do not hear tone-sensations but the singer's song" (p. 99).

Although we won't go further in Husserl's detailed analyses of perceptual experience, Husserl's notorious quarrel with Descartes' theory of ideas on what it is like to perceive a world already reveals that there is nothing specifically 'incorrigible' about the phenomenological epoché and its turn to worldas-experienced. So unlike Koch's reading of Descartes, the phenomenological version of the epoché does not entail any sort of insularity thesis according to which first-person beliefs are immune to error as long as they are restricted to the principle of appearance qua appearance. Put yet another way: not how I think the world appears, but how it actually appears is the principal focus of phenomenological inquiry. And this is precisely what the phenomenological epoché, on Husserl's understanding, should enable us to do: no more and no less than to clarify the implicit sense of what is always already familiar and taken for granted in straightforward experience.

\section{Dennett's Heterophenomenology: Cartesianism without a Theater}

We seemed to have wandered needlessly into the historical vagaries of philosophical dispute between Husserl and Descartes in order to shed a light on an apparently trivial example like that of the phi-phenomenon discussed by Dennett. But, as pointed out endlessly by Dennett himself, seeming is not always being, and the triviality of the example stands in sharp contrast with the wider philosophical ramifications Dennett develops on a certain reading of the phenomenon for the very idea of consciousness and the first-person perspective. So what about this reading?

There is indeed a much simpler and parsimonious approach to the topic of subjective experience compared to the one we have been offering on our reading of Husserlian phenomenology. Dennett is a firm defender of the methodological principle that scientific theories, especially when it comes to such a contested field as consciousness, should avoid multiplying entities beyond necessity (1991, p. 134). By this he means primarily that if a certain gap should arise between how things stand in reality and how they 'seem' from the first-person perspective, one should avoid postulating what he famously calls 'the Cartesian theater': i.e., some kind of inner screen where shadowy representatives of an absent reality are henceforth really present before the inner eye of an equally shadowy observer. Yet, as Dennett points out, the idea dies hard and in order to dispel its seductive lure, it is not enough to avoid explicit reference to outdated forms of dualistic metaphysics by, for example, quickly replacing mind-talk with brain-talk. That is, even within the now dominant terms of neurocognitive materialism, the Cartesian specter tends to make its unholy reappearance - under the bastard idea of 'Cartesian materialism' - whenever a central point is presupposed where everything "comes together" and various brain processes present their final product to consciousness (Dennett and Kinsbourne, 1992 , p. 185). Such an idea is pernicious in a variety of ways: on the one hand, it usually makes for a sloppy functional analysis of how the brain is able to perform its various capacities because such an abstract center tends to clean up all our functional loose ends. On the other hand, wherever there is talk of something being finally presented to consciousness, we can be sure that the idea of a central observer appreciating and observing this product is never too far away. As Dennett (2007) points out with regard to the example visual consciousness:

We are making steady progress on this subpersonal story [...] and we can be confident that there will be a subpersonal story that gets all the way from eyeballs to reports and in that story there will not be a second presentation process with an inner witness observing an inner screen and then composing a report. As I never tire of saying, the work done by the imagined homunculus has to be broken up and distributed around (in space and time) to lesser agencies in the brain (p. 11).

This is the crux of Dennett's Multiple Drafts Model, specifically devised as an antidote to the crippling but tenacious legacy of the Cartesian Theater. However, what exactly does it mean to deny the existence of this central 'Oval Office' and to replace it it with "various events of content fixation occurring in various places at various times in the brain" (Dennett, 1991, p. 365) for our overall discussion on firstperson appearance? Did we, for example, not already see how Husserlian phenomenology left behind such a theater-conception of consciousness quite some time ago for an externalist understanding of consciousness as essentially world-involving? To appreciate in what way Dennett's proposal specifically diverges from the phenomenological tradition, let us see how this model works in vivo with the empirical example of the phiphenomenon.

In response to Goodman's question (cf. supra) for a possible explanation of the avowed experience of seeing the moving spot change color before it actually occurred, Dennett considers two possible hypotheses: an Orwellian and Stalinesque version, respectively. That is, either we concoct false memories of having seen the spot change color, though in fact we had no prior immediate experience of the change (this is the post-experiential 'Orwellian' revision, suggesting a kind of ex post facto rewriting of history); or else we really do have a genuine, albeit delayed, 
consciousness of the light moving continuously and changing color, due to a kind of unconscious rapid editing process that "fills in" the missing data and presents the finished product to the eye of the beholder (this is the pre-experiential 'Stalinesque' revision, reminiscent of the cooked-up evidence presented in communist show trials, which does in fact make a genuine appearance in court, despite its fraudulence). Common to both versions is the subject's belief in the conscious experience of the moving spot, although they seem to differ substantially in how that belief came about: due to false memories of a veridical experience in the Orwellian case, and accurate memories of a non-veridical experience in the case of the Stalinesque show trial.

Yet, in glossing over these two accounts of the phiphenomenon, Dennett's 'counterintuitive' proposal finally reveals its true color: according to Dennett, the intuition that one of the explanations must be correct to the exclusion of the other is, once again, a clear indication of our persistent captivity in the Cartesian Theater. Postulating a difference between a real experience above and beyond or, more properly, before or after what subjects believe they experienced is, in Dennett's functionalist idiom, "a difference that makes no difference" (1991, p. 132). Hence, in clear opposition to the phenomenological account, the conclusion Dennett wants us to draw from the numerous experiments discussed in his Consciousness Explained is that there is no difference between how things seem to us and how we think they seem. Bringing this all together, Dennett consequently dubs his Multiple Drafts Model as a first-person operationalism "for it brusquely denies the possibility in principle of consciousness of a stimulus in the absence of the subject's belief in that consciousness" (1991, p. 132).

Needless to say, such a conception of the first-person perspective as entirely constituted by subjective beliefs immediately carries some remarkable consequences for the scientific effort to devise a proper naturalistic account for this dimension. These become most salient in Dennett's own methodology of choice for approaching the scientific study of human consciousness, his heterophenomenology, advertised as an explicitly third-person approach to the issue of subjectivity (Dennett, 2003). On the face of it, this seems like a remarkable thing to do: subjectivity is traditionally regarded as occupying something rather like another dimension - the private, 'first-person', more or less self-consciousness sort of being in comparison with the privileged objects of 'third-person' methodologies like meteors, sound waves or bone density. This ostensible difference between meteors and minds has led some phenomenological authors, like e.g., Evan Thompson, to claim that phenomenology, as an explicitly first-person investigation, is in fact an inescapable prerogative for any naturalistic account because "any attempt to gain a comprehensive understanding of the human mind must at some point confront consciousness and subjectivity - how thinking, perceiving, acting and feeling are experienced in one's own case" (Thompson, 2007, p. 16, our italics; see also Gallagher, 2007). The reasoning behind such a claim is relatively straightforward and is meant particularly as a warning sign for Dennett's - but also others' - overambitious naturalistic inclinations: any explanatory scheme which departs so completely from first-person experience that it calls into doubt the very existence of such experiences can no longer claim to be elucidating that explanandum, since it has effectively 'eliminated' the very object it purports to be an account of. Yet Dennett is not impressed. In an essay addressing some misunderstandings concerning his apologia for his heterophenomenology with the little concealing title "Who's On First?", Dennett asks:

Can the standard methods be extended in such a way as to do justice to the phenomena of human consciousness? Or do we have to find some quite radical or revolutionary alternative science? I have defended the hypothesis that there is a straightforward, conservative extension of objective science that handsomely covers the ground - all the ground - of human consciousness, doing justice to all the data without ever having to abandon the rules and constraints of the experimental method that have worked so well in the rest of science (2003, p. 19).

Heterophenomenology is the method of choice whenever one wishes to take the first person point of view seriously that is, as seriously as it can be taken - while keeping the methodologically scrupulous requirements undergirding the same objective perspective that reigns in those sciences that aspire to explain different, but from a methodological point of view, no more daunting phenomena such as continental drift, biodiversity or the digestive tract. So what then, exactly, does Dennett's heterophenomenology commit us to? What precisely does it mean to take subjects seriously, but not too seriously?

\section{Return of the Cogito: Serious, All Too Serious}

Given that we have to adopt a strict third-person perspective, since as Dennett is keen to say, "all science is constructed from that perspective" (1991, p. 68), the only access to the phenomenological realm will be via the observation and interpretation of publicly observable data, including utterances and other behavioral manifestations. Furthermore, we will have to find a neutral way of describing these data - that is, a way that doesn't prejudge the issue - by adopting a special form of heterophenomenological abstinence. Such an abstinence likened by Dennett to a third-person version of Husserl's epoché (Dennett, 2003, p. 22) - brackets the issue about whether the subject is in fact a computer, a mere zombie, a dressed up parrot or a real conscious being. The only thing such a thirdperson epoché does commit us to is adopting what Dennett calls the intentional stance: we should interpret the vocal sounds emanating from the subjects' mouths as speech acts that express the subject's beliefs in order to compose a text of what that subject wants to say about his or her own conscious experiences. As Dennett (1991) explains:

People undoubtedly do believe they have mental images, pain, perceptual experiences and all the rest, and these facts the facts about what people believe, and report when they express their beliefs - are phenomena any scientific theory of mind must account for. We organize our data regarding these phenomena into theorists' fictions, "intentional objects" in heterophenomenological worlds. Then the question of whether 
items thus portrayed exist as real objects, events, and states in the brain - or in the soul, for that matter - is an empirical matter to investigate (p. 98).

Again, this merely seems like a fairly trivial rehearsal of the principle of scientific neutrality: from the fact that people believe all kinds of things, even when these things happen to refer to their own experience, we shouldn't immediately conclude that these things actually exist. As a case in point, take the example of visual experience. People often seem to believe that their visual experience represents the world in sharp focus, uniform detail and high resolution from the center out to the periphery, as a kind of snap-shot like picture of the world (Noë, 2004). Yet as Dennett points out, convincingly, such a view of visual experience as gap-free and wholly continuous is mistaken. Take the example of looking at a wall: while staring at it, it looks to you as if there is unbroken expanse of wall. However, this is not to say that it seems to you as if, in a single saccadic fixation, the whole of the wall's surface is presented in equally rich detail from the center out to the periphery, as if every part of the wall's surface is immediately presented to consciousness at once. Rather, as Husserl would say, the wall is "transcendent" to my experience insofar as it has more to it than what is revealed to me in any single phase of experience and, moreover, is precisely given or experienced (as opposed to inferred or deduced) as having more to it. So, as the example illustrates, we would do well to follow Dennett's advice by not taking everything a subject believes about his or her own experience at face value. On this account, taking subjects' reports and beliefs serious means that we take into account that they can be mistaken; if not, that is, if doubt with regard to conscious experience would be strictly speaking senseless, then as Wittgenstein (1958) famously said - so too would any assertion of knowledge (1958, p. 211).

However, despite Dennett's repeated insistence on our pervasive fallibility with regard to first-person experience as a central argument for the adoption of his heterophenomenological stance, the question is how this methodological modesty squares with his aforementioned first-person operationalism. How to reconcile the by all parties acknowledged fact that we can be wrong about first-order experience with Dennett's thoroughgoing fictionalization of subjectivity up to the point where we have "total, dictatorial authority over the account of how it seems to you, about what it is like to be you" (Dennett, 1991, p 96)? To put it in the language of Dennett's own cherished functionalism: is fallibility a difference that can make a difference for the defense of heterophenomenology when there is no possibility of consciousness in the absence of a subject's belief in that consciousness? It must be clear by now that it cannot, and furthermore, that this inability to make room for a distinction between appearance and reality within the field of conscious appearance is itself a remarkable and, as per the defense of heterophenomenology, undesirable consequence of what we would call Dennett's own doxastic Cartesianism. For if my subjective experience is entirely constituted by what I believe to be the case, or what I believe that seems to be the case, then there is of course - and as we made clear in our reading of Descartes - no 'case' about which I can be wrong either. Consequently, Dennett is confronted with the following paradox:

(1) Either make room for the distinction between experience and judgment in which case the plea for heterophenomenology can be saved but at the cost of first-person operationalism;

(2) Or retain the latter, but at the cost of being unable to countenance fallibility and hence of introducing an unavoidable return to the philosophical core of Cartesianism, although this time without a theater.

Yet secondly, apart from this general philosophical tension, a further problem for Dennett's doxastic account arises when we raise the further question about how it construes the relation between belief and experience. As we have seen, the central strategy of Dennett's heterophenomenology is to attribute a belief to the subject whenever he or she reports an experience, rather than the other way around. And indeed, it has been a traditional argument ever since Descartes and Kant that an 'I think' or 'I believe' accompanies, or at least in principle must be able to accompany, any experience I might claim to be having, for otherwise, as the famous quote from Kant (1996) continues, "something would be represented in me that could not be thought at all, which is as much as to say that the representation would either be impossible or else at least would be nothing to me" (1996, B131-132). Importantly, Dennett trades on this ineliminable occurrence of the 'I think' within reflective consciousness to advance his first-person operationalism and thus to deny the possibility that there could be any difference between beliefs and experience. Since, as Dennett's argument goes, if you have conscious experiences you don't believe you have - those experiences would be just as inaccessible to you as to the heterophenomenological observer. Conversely, if you believe you have conscious experiences you don't in fact have, it is your beliefs that need to be explained, not the non-existent experiences (Dennett, 2003, p. 21). Hence, the crucial question becomes: is it really necessary for a subject while enjoying or undergoing an experience, to immediately believe that he is enjoying or undergoing that experience?

It is safe to say that one of the grounding motives in the phenomenological works of most notably Sartre, Merleau-Ponty and Heidegger is a forceful critique of this intellectualistic idea. The claim has been that there are indeed conscious intentional experiences that a subject could have without immediately believing that he is having them. Even more, those experiences precisely depend on the subject's not having a belief about them: if the subject were to believe he was having the experience, instead of merely living it through, the experience would become impossible (see also Dreyfus and Kelly, 2007). Differently put: a necessary condition for those types of experience is precisely the absence of the Cartesian spectator. A famous example is of course the following one by Sartre (2004):

When I run after a streetcar, when I look at the time, when I am absorbed in contemplating a portrait, there is no I. There is consciousness of the streetcar-needing-to-be-overtaken, etc., and non-positional consciousness of consciousness. I am then 
plunged into the world of objects; they constitute the unity of my consciousness, they present themselves with values, with attractive and repellant qualities - but me, I have disappeared (2004, p. 32).

Central to such examples is that the subject, to put it in Lacanian terms, is 'internally excluded' from the experience while living them through: in keeping an appropriate distance while talking to people, in reaching automatically for the proffered handshake, laughing while listening to some amusing story, rapidly walking down the stairs or backing away from a painting to get a better view, there is a certain solicitation from the world to engage in various activities without us having to decide to do so. Moreover, reflexively deciding, contemplating or believing in such activities is the best way to lose all grips on what the situation calls for. Such an experience of spontaneous immersion or absorption "into the world of objects" only arises precisely when we are not looking for them; conversely, they would vanish immediately insofar I would try to think or believe them. Yet, pace Dennett, this does not mean that in those instances I momentarily become a zombie or unconscious machine; there still is something 'it is like' to be absorbed in these activities which set them apart from, say, a comatose condition, and the absence of belief is one example of its constitutive features. It is precisely this 'internally excluded' character of belief and experience in such phenomena which Dennett's doxastic Cartesianism cannot countenance.

\section{DENNETT AND PSYCHOANALYSIS: THE CURIOUS CASE OF THE "OBJECTIVELY SUBJECTIVE"}

Before we can begin to specify in what way psychoanalytic theory could bear on this debate between Dennett and phenomenology, some precursory remarks are in order. Because, first of all, it might not be entirely clear where, if at all, we should situate psychoanalysis, whether in its original Freudian formulation or in its Lacanian version, along Sellars' somewhat contrived, but perhaps still hermeneutically useful dichotomy. For in contrast to phenomenology's straightforward and programmatic insistence on first-person experience as an indispensable datum for any sort of naturalism, the claims and subject matter of psychoanalytic theory are in this regard, to put it mildly, somewhat more ambiguous. Of course, it might be argued that psychoanalysis is not really that interested in, nor in itself capable of, pursuing or resisting the naturalistic agenda of bridging the gap between neurocognitive and phenomenological accounts of blind sight or the rubber-hand illusion. And indeed, one could say, what would be further removed from psychoanalysis' basic insight into man's constitutive disadapted relation to its 'natural' environment than Dennett's talk of the design stance? Yet such a first and perhaps heartening impression is easily discarded when we shift the terrain to those phenomena, however, ill designed, that are considered to be at least more amenable to psychoanalytic elucidation, such as the nature of psychopathology, sexuality, language or desire. With regard to those, the question emerges whether or not psychoanalysis would simply join in with Dennett's deflationary tactics of reducing the several issues that may arise in the effort of articulating the intertwinement of subjectivity and language - for example, the relation a subject entertains with its own speech - or subjectivity and desire - for example, what it means to desire the desire of the other - to the austere categories of 'seeming' or 'fiction'? Presumably, the pre-reflexive answer would consist in a quick and resounding 'no'.

However, on the other hand, given Freud's departure from Brentano's views on intentionality and self-consciousness (see Seron, 2015, pp. 15-30; Bernet, 2002) or Lacan's critique of both Sartre's existential psychoanalysis (Lacan, 2006, p. 80) and Merleau-Ponty's bodily unconscious (Lacan, 1982-1983, p. 75), it is equally clear that the intellectual relation between phenomenology and psychoanalysis is complicated enough to avoid any easy wedding of psychoanalysis with manifest experience. Given this ambiguous position, a clarification of how psychoanalysis relates to the ongoing 'scientific disenchantment' along the terms set by Dennett's ingenious codification of the claims and methods of cognitive science, and conversely, to the phenomenological arguments that are being advanced against Dennett's proposal, indeed becomes a reasonable task.

\section{Freud and Lacan between Phenomenology and Cognitive Science}

To begin with some sweeping examples: what exactly is left of the once so seductive Freudian image of the three successive humiliations of man-in-the-world (Copernicus-Darwin-Freud) now that we can safely add a fourth one, -Dennett? As noted by several commentators (Gardner, 2000; Zizek, 2006), it seems that Freudian psychoanalysis, steeped as it is in the intentional language of repression, desires and negation - now finds itself amongst those traditional 'manifest' philosophies threatened by the more recent neurocognitive humiliations. And the reason for this clear: though, in the felicitous wordings of Freud, "psyche is extended; knows nothing about it" (Freud, 1938b, p. 300), there has never been a lack of critics pointing out that what it does not know is still suspiciously close to the philosophical problematic of intentional consciousness. And it is indeed striking and ironic, given psychoanalysis' original declaration of independence from any philosophy issuing from the cogito (see Freud, 1923, p. 13; Lacan, 2006, p. 75), that one of the standard ways of defending the unconscious today is precisely by referring to the properties of consciousness, of which intentionality is held to be pre-eminent. As Freud (1915) himself indeed pointed out:

All the categories which we employ to describe conscious mental acts, such as ideas, purposes, resolutions, and so on, can be applied [to unconscious mental acts]. Indeed, we are obliged to say of some of these latent states that the only respect in which they differ from conscious ones is precisely in the absence of consciousness (p. 168).

Turning to Lacan, we can discern the same manifest motives despite the latter's proto-cognitivist, structuralistic inclinations: even on the most cursory reading of the Ecrits, it would 
be difficult to avoid the perennial 'philosophemes' of subject, alienation, desire, Other and so on. But Lacan, of course, would try to avoid any quick philosophical (mis)recognition by reminding his readers to this subject is split, barred and divided by the signifier, therefore not the phenomenological subject of Jemeinigkeit, always already conscious of itself in its intentional involvement with the world. Nevertheless, however, split or deferred this subject might be, this failed or misfired cogito is still close enough to its Cartesian predecessor so as not to completely break with it. On the contrary, Lacan only ever wanted to think the unconscious, not as antithetical to consciousness, not as "a species that defines a circle in psychical reality of what does not have the attribute of consciousness" (Lacan, 2006, p. 830), but precisely as the implicit truth already contained in the Cartesian cogito me cogitare (see Dolar, 1998; Lacan, 2006). But this also means that this truth, whatever else it may be, is the truth of that same old Cogito, gained through a certain radicalization of that traditional aporia, confronted differently by Husserl, Fichte or Sartre, of conceiving subjectivity from and within its own terms. Therefore, in so far as phenomenology is susceptible to Dennett's heterophenomenological recasting of subjectivity in terms of a 'theorist's fiction', the same holds for Lacan's particular defense of the subject. And is it indeed not quite imaginable, for example, that Dennett's response to Lacan's notorious antihumanistic formula in Science and Truth according to which "science's man does not exist, only it's subject does" (2006, p. 730) would be the sobering "nor does it's subject, although it might seem to"?

On the other hand, however, it could be pointed out that we might have proceeded a little bit too quickly and carelessly in lumping together psychoanalysis with the manifest philosophies of intentional experience. And in fact, as is well known, both Freud and Lacan have been taken to task for neglecting and underestimating the accomplishments of phenomenology in a way that is, although not strictly equivalent, remarkably close to the contemporary phenomenological arguments raised against Dennett (see Schafer, 1976; Chalmers, 1995). Suffice to recall, in Freud's case, the succinct phenomenological critique of the psychoanalytic unconscious by Eugen Fink in the appendix to Husserl's Crisis:

This objection, which is raised in many variations against the so-called 'consciousness-idealism of phenomenology', is based on a fundamental philosophical naïveté. [...] The naïveté we refer to consists, before all theory-construction about the unconscious, in an omission. One thinks one is already acquainted with what the 'conscious', or consciousness', is and dismisses the task of first making into a prior subject matter the concept against which any science of the unconscious must demarcate its subject matter, i.e., precisely that of consciousness. But because one does not know what consciousness is, one misses in principle the point of departure of a science of the 'unconscious' (Husserl, 1970, p. 386).

Despite the shifting terminology, it's not too difficult to recognize in this depiction of psychoanalysis' 'naïvete' the same point of contention we already encountered in Dennett's case. That is, Freud is held to have tried to develop a naturalistic third-personal theory of mental functioning, couched in broadly functionalistic-energetic terms (the dynamic trinity of 'ego', 'id' and 'superego'; the energetic metaphors of cathexis, displacement, condensation, and so on), destined to explain various pathological phenomena, without, however, offering any explicit and sustained consideration of 'consciousness'. As noted by Tugendhat (1986, pp. 131-132) and Ricoeur (1977, p. 420 et passim.), Freud indeed never seems to talk about phenomenal consciousness and self-consciousness directly, but only and rather loosely in terms of the 'ego' which is portrayed as yet another homuncular-functional entity amongst others. A similar story can be told with regard to the notion of repression and other 'mechanisms' of defense of which Freud gives an extended account in terms of word- and thing-presentations, cathexes and so on, again strongly suggesting that these concepts designate sub-personal operations of some kind. Accordingly, repression, displacement, condensation and other similar notions, should not be conceived as first-personal actions, whether conscious or unconscious, operating within a normative framework of beliefs and desires, but as functionally specifiable processes requiring no agents, experiencers or observers whatsoever. In short: on this reading, psychoanalytic theory turns out to share roughly the same agenda as cognitive neuroscience in trying to offer a homuncular-functionalist top-down analysis of mental functioning in terms of various subsystems until we reach the level of non-intelligent functionaries that can be replaced by a machine (see Freud, 1938a, p. 144).

As for Lacan, although one of the remarkable features of his self-proclaimed return to Freudian orthodoxy is precisely the explicit avoidance of all those orthodox-naturalistic elements, this didn't necessarily seem to imply a return to a consideration of l'expérience vécue at the expense of Freud's naturalism. On the contrary, Lacan's structuralist-materialist reworking of Freudian metapsychology in terms of his 'logic of the signifier' appears to have been driven by an even more fierce ambition to finally establish psychoanalysis as a rigorous, because aspiring to the Koyréan ideal of mathematical formalization, scientific endeavor (see Milner, 1995; Johnston, 2012; Tomšic,, 2012). And indeed, after some years of flirting with phenomenological accounts, the famous 1953 Discourse of Rome can be seen as a veritable trumpet blast fiercely announcing the new footings on which to resurrect the psychoanalytic edifice as a "science of subjectivity" (Lacan, 2006, p. 235):

The form of mathematicization in which the discovery of the phoneme is inscribed, as a function of pairs of oppositions formed by the smallest graspable discriminative semantic elements, leads us to the very foundations that Freud's final doctrine designates as the subjective sources of the symbolic function in a vocalic connotation of presence and absence. And the reduction of any language (langue) to a group comprised of a very small number of such phonemic oppositions, initiating an equally rigorous formalization of its highest-level morphemes, puts within our reach a strict approach to our own field (Lacan, 2006, pp. 235-236). 
This is indeed a far cry from Lacan's earlier phenomenological declaration that "language, prior to signifying something, signifies to someone" (2006, p. 66). Here we are incited to the view that language, loosely defined in terms of the symbolic order as somehow pertaining to both the regulatory principles of social exchange and the material-phonetic level of 'pure signifiers' (on this equivocation, see Descombes, 2009), is "a form in which the subject is inserted at the level of his being" (Lacan, 1993, p. 179). In the Seminar on "The Purloined Letter" and The Instance of the Letter, gloomy images are being invoked to convey the radical nature of this 'insertion'. Lacan (2006, p. 21)) talks about "machines-that-think-like-men, subjects "more docile than sheep", lined up before the gripping effect of the signifying chain as "ostriches", determined by the signifier's displacement in their "acts, destiny, refusals, blindnesses, success, and fate." How all of this is supposed to be an effect of 'symbolic determination' is never really convincingly spelled out (Dennett's anti-mysterian concept of "wonder tissue" might be put to good use here; see Dennett, 2013, pp. 198-205), nor is it clear if and in what way Lacan's structuralistic remolding of Freudian concepts (e.g., metaphor/metonymy for condensation/displacement, repetition of the signifying chain for Wiederholungszwang, ...) is really an advance compared to the latter. Yet, for our present purposes, at least it is clear that on this reading Lacan's intent was to purify the Freudian unconscious even further from any remaining residues of metaphysical humanism and its associated anthropomorphic terminology. Hence, as we have noted in the case of Freud, Lacan's structuralistic rearticulation of the unconscious could therefore equally well be seen as a forerunner to the sort of materialist program better known today under the heading of cognitive science (see also Dupuy, 2000).

\section{Psychoanalysis' "Abominable Mess"}

Now this Janus-faced character of psychoanalysis has of course never slipped the attention of its various commentators, provoking blame and rejection from its critics; praise, confusion or silent endorsement from its defenders. On Sartre's diagnosis, for example, psychoanalysis is precisely founded on a systematic confusion of the personal and sub-personal levels and this constitutes its unavoidable yet inadmissible paradox: "I both am and am not the psychic facts hypothesized by psychoanalysis" (Sartre, 1958, pp. 50-51). In roughly the same way, Wittgenstein famously spoke of psychoanalysis' "abominable mess" (Wittgenstein, 1978, p. 316), premised as it is on a confusion between first-personal reasons and third-personal causes, imposing the former even if the patient doesn't accept them, resorting to the latter and being content with the patient's acceptance for their justification (Cioffi, 1998).

Similar accusations apply to Lacan's 'materialism of the signifier, as representing yet another confused effort to straddle both sides of this fence at once: the signifier being regarded as both amenable to a 'materialist' description in terms of its meaningless phonemic properties and an 'idealist' description in terms of its meaningful semantic properties. By cutting the cord between signifier and signified, and in the same move declaring the primacy of the former over the latter, Lacan thought to be able to transmute these 'pure signifiers' into causal forces operating in a mechanical way, yet responsible for the different meaning effects encountered in psychoanalytic practice. This is, for some, the very formula of magic (see Descombes, 2001, p. 93-101).

So what then are we to make of this confusion? There are of course some well-tried reconciliatory attempts which basically consist in either translating psychoanalysis into phenomenological terms ${ }^{2}$, or, embracing it precisely as a form of sub-personal psychology ${ }^{3}$ (see Gardner, 2000 for a detailed discussion), yet perhaps the more interesting thing to notice is the recurrent image from which such solutions spontaneously spring. By this we mean, as regards the present discussion, the very form in which the difference between Dennett and phenomenology is formulated: that is, in terms of 'fictional beliefs' (Dennett) and 'manifest experience' (phenomenology). In the following section, we will therefore try to explicate in what way psychoanalytic theory could distinguish itself from both these readings.

\section{Decentering Appearance: Belief in Belief}

Let us begin this section by recapitulating in a condensed form the core disagreement which stands behind the discussion between Dennett and phenomenology. Whether it is the topic of perceptual consciousness, imagination, sense of agency, the painfulness of pain or the problem of other minds, is not really that essential here: the crucial divergence already appears at the level of "the organization of the data" (Dennett, 2003, p. 9), that is, the way in which researchers should proceed whenever they set out to explain those phenomena of consciousness.

In his Who's on First? (2003), Dennett offers a clear summary of his position that can put the problem in sharper focus. "What", Dennett asks, are the "primary data" from which we ought to depart in order to arrive at "a science of consciousness" (p. 21), i.e.: (a) conscious experiences themselves; (b) beliefs about these experiences; (c) verbal judgments expressing those beliefs; or (d) utterances of one sort or another? Whereas, as we have seen, phenomenology vigorously opts for (a); Dennett's heterophenomenology is premised on the elimination of (a) in favor of (b) and (c). From this disagreement, it necessarily follows that the philosophical concepts of 'appearance' and 'seeming' function as a kind of shibboleth in the ensuing debate: designating 'immediate experience' in the case of phenomenology, 'beliefs about experience' in Dennett's account. Furthermore, it becomes obvious why the way in which arguments are being pressed for one position or the other, take on the form in which we have argued for some of the claims found in phenomenology: i.e., those cases that point toward a disjunction between belief and experience - that is, on the one hand, 'beliefs without experience' as in the discussion about the level of detail found in visual consciousness; on the other hand, 'experience without belief' as in Sartre's example of 'pre-reflexive immersion'.

From a psychoanalytic perspective, however, what should immediately strike us is not so much this manifest level

\footnotetext{
${ }^{2}$ This is indeed the proposal we can read in the works of Sartre and - even earlier - Politzer: to release psychoanalysis from its "mechanistic cramp" (Sartre, 1979, p. 32) or "abstract" and "realist" exigencies (Politzer, 1994) - for an excellent overview of Politzer's somewhat forgotten critique, see Bianco (2016).

${ }^{3}$ For a defense of this reading, see, e.g., Moore (1988); Kitcher (1992) and Livingstone-Smith (1999).
} 
of disagreement in terms of the difference between 'belief' and 'experience', but rather the implicit Cartesian agreement between Dennett and phenomenology on the concept of belief itself. To put it in Spinozistic terms, there is still, however, slightly, something sticking out as 'a kingdom within a kingdom' throughout this whole discussion, something which becomes most explicit in Dennett's response to some of his critics - Schwitzgebel (2007) and Noë (2007) - in his Heterophenomenology Reconsidered (2007). As before, the critique involves Dennett's seemingly incompatible insistence on both the essential fallibility of first-person accounts and some kind of Rortian incorrigibility with regard to "how it seems to them" (p. 263). In the same volume, Noë (2007) evokes the familiar Wittgensteinian theme on the logical limits of justification of first-person accounts which comes to an end rather sooner than we might think:

It [Wittgenstein's view on justification] applies to the special case where what is in question is how I take my own experience to be, what I take it to be like. I can be mistaken about the nature of my experience - about how I, in experience, take things to be. [...] But it would be a different kind of mistake for me also to be mistaken about how I take my experience to be. I can be wrong then about how things seem but not wrong about how I take things to seem (p. 244).

\section{Dennett (2007) wholeheartedly agrees:}

If somebody says her visual field seems detailed all the way out to the periphery, which lacks a perceptible boundary, there is no gainsaying her claim, but if she goes on to theorize about "the background" [...], she becomes an entirely fallible theorist, no longer to be taken at her word (p. 263).

So, at least when it comes to this notion of 'taking', of what I believe my experience 'is like', phenomenology and Dennett prove themselves to be something like an "epistemological pair" (Bachelard, 1949, p. 5). In short: whereas we can be wrong about 'seeming' understood in terms of experience, we cannot, however, be wrong about 'seeming' in terms of belief. Now the proper psychoanalytic questions that should arise in this context are the following ones: whence this sudden confidence? Which arguments are being advanced here to uphold this last inviolable sanctum of minimal infallibility with regard to this Cartesian theme of 'belief in belief'? Why is it so obvious that 'immunity to error' immediately ensues whenever we shift the terrain to the topic of belief itself? Is it because, in this case, the well-known phenomenological figure of the 'unbeteiligte Zuschauer' suddenly reappears on the scene? If so, why would that be? And why precisely at this point? Surprisingly, precious little can be found on these questions when we consult these various commentators.

Nevertheless, here, as everywhere else, it could be wise to stick to Althusser's famous "golden rule of materialism" to "not judge a being by its self-consciousness (Althusser, 1996, p. 115). Particularly interesting in this context are the analyses we can find in the works of Zizek $(1998,2006,2014)$ and Pfaller $(2014,2015)$ on the psychoanalytic concept of 'belief'. Elaborating on and extending Octave Mannoni's perspicuous theory of fetishism (see Mannoni, 2003, pp. 68-92), both these authors have drawn attention to a series of entirely common phenomena which nevertheless share some striking features that are directly relevant for our overall discussion. To start with some of these examples:

Imagine you're sitting in a bar reading a newspaper, waiting for a friend. The friend arrives. He says hello, and then continues: 'Excuse me, can I have a quick look at your newspaper? I know it's silly, but I just have to know the score from yesterday's game' (Pfaller, 2014, p. 1).

For reasons that are no doubt suspect, but hidden, I sometimes read the rather rudimentary horoscopes published in certain papers. It seems to me that I do not take much of an interest in them. I wonder how people can believe in them. [...] Once, last year, my horoscope said that "tomorrow will be an extremely favorable day for tidying up the house." This was not a spectacular prediction, except that I had long been planning to move on the day in question. I burst out laughing at so funny a coincidence. [...] I could say that I am not superstitious because I pay no mind to such things. But, to be precise, I should rather say: I know quite well that coincidences of this kind are meaningless, but I take a certain amount of pleasure in them all the same (Mannoni, 2003, p. 78).

What is common to these examples - and numerous others (see Zizek (1998); Pfaller (2014), for an extensive collection) is the paradoxical relation a subject seems to entertain with its belief (i.e., the importance of sports; the significance of horoscope predictions). In a way that is difficult to render conceptually transparent, these sorts of beliefs are never really believed in ("I know it's silly" - "I know quite well that these coincidences are meaningless"), yet in one way or another, they nonetheless exert a particular influence on their subjects (the compulsion to look at the paper - the pleasurable laughter). Moreover, as Pfaller argues, it is not so much their content that is primarily of interest here, but rather the form in which people refer to these beliefs. That is, as was already apparent from Mannoni's formula for these types of beliefs ("I know quite well ... but still"), its form is characterized by a complex coexistence of 'better knowledge' and 'belief'. The fidget sports fanatic knows quite well that yesterday's results are not important, but still he has to see them. Despite the better knowledge, and despite the gap this places between him and his silly practice, he nevertheless acts as if sports are of utmost importance. Similarly, horoscope predictions seem rather ridiculous to Mannoni, nonetheless, as he admits: "if the horoscope had said that "tomorrow will be an extremely unfavorable day for moving", "it would have made me laugh differently" (2003, p. 78.).

So in an initial approximation of the formal structure of this phenomenon, one should say that, on the one hand, these are beliefs that are never really one's own beliefs in the sense that one would claim ownership over them (à la "I believe in horoscopes, I really do"). The "better knowledge" is immediately invoked to signal such a subjective position of transcendence toward the belief. Yet, different from, for example, the Sartrean 
formula for transcendence - i.e., "To believe is to know that one believes, and to know that one believes is no longer to believe" (Sartre, 1958, p. 114) - such a better knowledge seems to be of little avail with respect to the efficacy of the belief in question. On the contrary, as Mannoni points out, one should even wonder if this position of knowledgeable transcendence does not somehow contribute to the maintenance of the disavowed belief? Such a claim would immediately contradict the seemingly incontestable principle according to which the dialectical relation between 'knowledge' and 'belief' is grounded in exclusion: on such an account, we (erroneously) believe (in the importance of sports, in the predictive validity of horoscopes, ...) precisely because we do not know (that sports are not important, that horoscopes do not possess predictive value, ...); conversely, better knowledge cancels out what we previously believed. Here, on the contrary, the dialectical relation between knowledge and belief would be based on the principle of necessary conjunction: only on the condition of better knowledge are we susceptible to those beliefs; conversely, in the absence of better knowledge, believing becomes impossible - as Mannoni succinctly puts it: "Evidently, the sole reason for the "but all the same" is the "I know well"” (2003, p. 71). If this principle is somehow sustainable (cf. infra for further argumentation), we can now proceed to advance a more precise formulation of this dialectic in terms of our general discussion: on a psychoanalytic account, the way things appear to me, that is, of what I "objectively believe" (cf. Zizek, 1989, p. 35) - as evidenced, despite myself, in my nonsensical behavior, spontaneous reactions and utterances (e.g., encouraging my car by means of little compliments when it won't start, wearing my 'lucky shirt' for an important interview which I did prepare for in a 'professional' way, ... . ) - as opposed to what I believe to believe, is structurally dependent on the self-reflexive movement of intellectual distancing through 'knowing that one knows'.

\section{Belief in the Uncanny or Uncanny Belief?}

Now, in order to substantiate this rather strong claim, what we seem to need is a methodological procedure closely resembling the phenomenological tool of "eidetic variation" (see Husserl, 1977, sec. 9a) in and through which, formally speaking, the necessary conditions of a certain phenomenon are established by 'varying' those conditions up to the point where the phenomenon itself would become (in)conceivable. Now it happens that a procedure of this kind is to be found implicitly in Freud's 1919 treatise on The Uncanny, a phenomenon which, moreover, bears some striking resemblances to the examples discussed above (see Dolar, 1991; Zupancic, 2005; Pfaller, 2006). Regardless of the wealth of literary examples and psychoanalytic concepts Freud employs throughout the article, this dense and, to a certain extent, inconclusive text, essentially revolves around one central effort: to circumscribe the "common core" which would allow us "to distinguish as 'uncanny' certain things which lie within the field of what is frightening" (Freud, 1919, p. 219). Freud's question is: how should one proceed in defining the common denominator in such a variety of examples as the mechanical doll Olympia, the obscene figure of the SandMan, the recurrent theme of the "double", the "repetition factor" or the Rat Man's "omnipotence of thoughts" - all taken as typical instances of the uncanny (Freud, 1919)? Why are they not simple examples of garden variety phobias such as the fear of heights or crowded places? What is it that sets them apart from the more epistemologically innocent logic of cognitive surprise or unfulfilled anticipation? And, finally, why should they even produce this peculiar affective response rather than none at all? As an instructive introduction for a further demarcation of the problem, Freud offers the following, general formula:

[...] an uncanny effect is often and easily produced when the distinction between imagination and reality is effaced, as when something that we have hitherto regarded as imaginary appears before us in reality [...] $(1919$, p. 242).

Accordingly, we seem to have three relevant conditions (1) the uncanny affect; (2) imagination; (3) appearance. First, the feeling of uncanniness should be distinguished from more common affective responses such as surprise, fear or mere indifference. Nor is it merely the univocal opposite of what is familiar, in the sense of 'homely', 'cozy' or 'intimate', since not everything which entails a negation of the familiar in this sense will provoke the feeling of the uncanny. As Freud argues, "something has to be added to what is novel and unfamiliar in order to make it uncanny" (1919, p. 221). Secondly, what it is that should be added seems to be contained in the two other conditions: appearance and imagination. Freud illustrates this point with an example taken from his case study of the Rat Man:

In the case history of an obsessional neurotic, I have described how the patient once stayed in a hydropathic establishment and benefited greatly by it. He had the good sense, however, to attribute his improvement not to the therapeutic properties of the water, but to the situation of his room, which immediately adjoined that of a very accommodating nurse. So on his second visit to the establishment he asked for the same room, but was told that it was already occupied by an old gentleman, whereupon he gave vent to his annoyance in the words: 'I wish he may be struck dead for it'. A fortnight later the old gentleman really did have a stroke. My patient thought this an 'uncanny' experience (1919, p. 239).

Here we have all the conditions combined: (1) the uncanny fearful experience, (2) the imagination pertaining to the obsessive wish and (3) reality appearing as if it immediately responded to what was "hitherto regarded as imaginary" (Freud, 1919, p. 242). At this point we can also introduce our previous dialectic between 'better knowledge' and 'belief'. Freud's first decisive move is to exclude Jentsch's hypothesis of intellectual uncertainty as an essential factor for the production of the Rat Man's uncanny experience and seemingly absurd guilt feelings. On such a cognitive account, the Rat Man would be struck by the uncanny precisely because he was, for a brief moment, a spontaneous theoretician of the 'omnipotence of thoughts', intellectually unable to rid himself from the illusion that 'wishes can truly kill'. And the reason for this is precisely because reality appears to correspond with was held to be impossible: 
better knowledge is suspended because of the qualities of the appearance. Conversely, lifting the veil of appearances would mean to break the spell of the uncanny. However, not only would this idea square rather badly with another of Freud's (1909, p.229) remarks on the peculiar epistemic position of the Rat Man as being different from "the superstition of uneducated people who feel themselves at one with their belief," it would also mean that, in the case of Hoffman's story, our uncanny experience would be due as well to our intellectual uncertainty as regards the true status of the Sand-Man. Yet, as Freud remarks, the story makes it quite clear that the Sand-Man is not really the Sand-man, nevertheless, "this knowledge does not lessen the impression of uncanniness in the least degree" (1919, p. 230). Furthermore, it can even be said that the logic of the uncanny is directly opposed to the logic of intellectual uncertainty. As Dolar (1991) points out, the most uncanny thing is not so much that we are kept uncertain as to the true nature of events, whether or not what happens is really due some unfathomable scenario. On the contrary, what is uncanny is that one knows in advance precisely what is bound to happen, even how and when it will happen ... and then, effectively, it really does happen. So here we seem to have attained a first step toward establishing our thesis: the uncanny is an experience that is not altered by a transcendent position of 'better knowledge'. The Rat Man knows quite well that 'wishes can't kill', that these absurd coincidences mean nothing at all, nonetheless, he is plagued by uncanny feelings and a mythical guilt strangely proportional to a disavowed belief in 'the omnipotence of thoughts'.

Now the second part of Mannoni's formula arises: could it be that the uncanny is not only impervious to 'better knowledge, but more strongly, that the latter should be seen as its enabling condition? This would mean that in the absence of better knowledge, whenever the distance between myself and the suspended belief disappears, the phenomenon of the uncanny would disappear as well. Again, Freud has noted this point in his subsequent effort, later on in the text, to shift the emphasis from his earlier material definition of the uncanny in terms of the content of the appearance, to a formal definition in terms of the subjective position of those afflicted by the uncanny toward that very same content. Why, for instance, would the prompt fulfillment of Polycrates' wishes induce an uncanny effect, while the very same appearance of immediate wish-fulfillment in the story of The Three Wishes produces none at all? Or whence the uncanniness surrounding the living doll Olympia in Hoffman's story, while again the same theme of coming-to-life of inanimate objects in most fairy tale stories remains without effect? If it is not the content of the appearance as such that seems to be responsible for the uncanny feeling when reading those stories, then, as Freud argues, we should consider the subjective position from which such stories are read (1919, pp. 245-246). What sets apart, for example, the aesthetic of Hoffman's story from that of fairy tales is that in the former, at the outset, we are invited to adopt the natural attitude of everyday life. Within this attitude, we know that such figures as the eye-robbing Sand-Man do not exist. In fairy tales, however,
[...] the world of reality is left behind from the very start, and the animistic system of beliefs is frankly adopted. Wish-fulfillments, secret powers, omnipotence of thoughts, animation of inanimate objects, all the elements so common in fairy stories, can exert no uncanny influence here [...] (Freud, 1919, p. 250).

Here, precisely, in the enchanted world of fairy tales where the existence of ghosts, resurrection of the dead, miracles and other gruesome plots is assumed, we have nothing to fear. And we have nothing to fear precisely because the difference between better knowledge and belief is temporarily suspended. On the other hand, only if we are invited to the enlightened position of better knowledge, only if we know that wishes are not causally responsible for certain outcomes in the world, do we spontaneously react to those outcomes as if we believed that things could have been different. Similarly, precisely because the Rat Man was "a highly educated and enlightened man of considerable acumen" and therefore "did not believe a word of all this rubbish" (1909, p. 229), did he react with a strange and compulsory form of credulity in the face of the most trivial coincidences. Hence, as Freud aptly notes, we must have "surmounted" certain beliefs in order to be susceptible to the effects of the uncanny (1919, p. 247).

\section{CONCLUSION}

To conclude our article, we will note three points that are particularly relevant for our discussion. First, as was the case in the examples discussed earlier, the logic of the uncanny should be understood in terms of a complex dialectic between better knowledge and belief. Within this dialectic, better knowledge does not form the disjunctive counterpart to belief, but should itself be considered as but one necessary element situated on the same "plane of immanence" (Deleuze, 2005) in conjunction with belief (see also Pfaller, 2014, pp. 41-43). Starting from this general principle, psychoanalytic theory therefore argues for at least two critical points: first, pace Dennett and phenomenology, we do not always know what we believe or how things seem to us; second, we misrecognize the true function of the alleged distance toward the belief that is expressed through "knowing better" (see Zizek, 1989, pp. 32-33; Pfaller, 2005, p. 118).

Second, this idea also enables us to put forward a further, finer distinction between psychoanalytic theory and the aforementioned phenomenological principle of 'appearance qua appearance' (cf. supra). According to this principle, beliefs are explained by the properties of the apparent object. Because reality appears in such a way as if, for example, it corresponds to the immediate fulfillment of my wishes, I (wrongly) believe that it does. Psychoanalytic theory, however, significantly departs from this picture: if, for instance, the uncanny appears uncanny and I strangely react, despite better knowledge, as if I believed in 'the omnipotence of thoughts', then this suspended belief is not primarily due to the properties of the presented object, but first of all to the act of presentation. More precisely: on a psychoanalytic account, the uncanny is uncanny not because I 
confuse appearance with reality, not because I succumb to the illusion and naively follow the appearance, but, on the contrary, precisely because I do not follow the appearance, because I am able to recognize the illusion as an illusion (or at least believe I can) and therefore picture myself as occupying a transcendent position of better knowledge. In short: exactly when - to put it in Husserlian terms - I do not confuse properties of what is represented with the act of representing. The illusion, therefore, is not situated at the level of the object, nor is it situated at the level of judgment toward that object, but in how this very act of judgment, and the reflexive self-consciousness of that judgment, contributes to what I 'objectively believe'.

Third and finally, this notion of 'objective belief' - i.e., beliefs that are suspended by 'better knowledge' - further allows us to confront in a distinctive way what may be considered as the defining gesture of Dennett's heterophenomenology: the rejection of "the bizarre category of the objectively subjective" (Dennett, 1991, p. 132). According to Dennett, this obscure philosophical notion of the "objectively subjective" should be disposed of because it is once again a clear expression of our obstinate belief in the Cartesian theater. It would correspond to that mythical moment of pure phenomenological 'givenness', where the 'given' is 'given' before being 'taken' in one way or another, in a theoretically unencumbered place where consciousness

\section{REFERENCES}

Althusser, L. (1996). Writings on Psychoanalysis. New York, NY: Colombia University Press.

Bachelard, G. (1949). Le Rationalisme Appliqué. Paris: PUF.

Bernet, R. (2002). Unconsciousness consciousness in Husserl and Freud. Phenomenol. Cogn. Sci. 1, 327-351. doi: 10.1023/A:1021316201873

Bianco, G. (2016). La Signification Du Concret. Psychologie, Philosophie Et Politique Chez Georges Politzer. Paris: Hermann (Hermann Philosophie).

Burge, T. (2010). Origins of Objectivity. Oxford: Clarendon Press.

Chalmers, D. (1995). The Conscious Mind. Oxford: Oxford University Press.

Cioffi, F. (1998). Wittgenstein on Freud and Frazer. Cambridge: Cambridge University Press.

Deleuze, G. (2005). Pure Immanence: Essays on Life. New York, NY: Zone Books.

Dennett, D. (1991). Consciousness Explained. New York, NY: Back Bay Books/Little, Brown and Company.

Dennett, D. (2001). The Fantasy of First Person Science. Available at: https://ase. tufts.edu/cogstud/dennett/papers/chalmersdeb3dft.htm.

Dennett, D. (2003). Who's on First? heterophenomenology explained. J. Conscious. Stud. 10, 19-30.

Dennett, D. (2007). Heterophenomenology reconsidered. Phenomenol. Cogn. Sci. 6, 247-270. doi: 10.1007/s11097-006-9044-9

Dennett, D. (2013). Intuition Pumps and other Tools for Thinking. New York, NY: W. W. Norton \& Company.

Dennett, D., and Kinsbourne, M. (1992). Time and the observer: the where and when of consciousness in the brain. Behav. Brain Sci. 15, 183-201. doi: 10.1017/ S0140525X00068229

Descombes, V. (2001). The Mind's Provisions: A Critique of Cogntivism. Princeton, NJ: Princeton University Press.

Descombes, V. (2009). L'équivoque du symbolique. Rev. Mauss 34, 438-466. doi: $10.3917 / \mathrm{rdm} .034 .0438$

Dolar, M. (1991). "I Shall Be With You On Your Wedding-Night": Lacan and the Uncanny, Vol. 58, Cambridge, MA: The MIT Press, 5-23.

Dolar, M. (1998). "Cogito as the subject of the unconscious," in SIC 2: Cogito and the Unconscious, ed. S. Zizek (Durham, NC: Duke University Press), 11-40.

Dreyfus, H., and Kelly, S. D. (2007). Heterophenomenology: heavy-handed sleightof-hand. Phenomenol. Cogn. Sci. 6, 45-55. doi: 10.1007/s11097-006-9042-y really happens. As Dennett notes, such a place might be a comforting image for some philosophers because it preserves the traditional distinction between reality and appearance at the heart of human subjectivity, "the seeming-a-certain-way over and above a believing-that-it-is-that-way" (1991, p. 133). Yet, the examples we discussed point out that this is perhaps not the only way in which "the objectively subjective" can be read. Indeed, instead of believing in "appearances" and not knowing whether or not they correspond to reality, "objective beliefs" display exactly the opposite structure: we know that they are not true, perhaps we even have a thoroughly adequate picture of reality, but the fact that we are nonetheless defined by them, that we act on them, remains undetected (Pfaller, 2014). Hence, from a psychoanalytic view, it is not so much the illusion of the "Cartesian theater", but the Dennettian theme of "belief in belief" considered as an exhaustive account of subjectivity that should be questioned.

\section{AUTHOR CONTRIBUTIONS}

JF confirms being a contributor to this work and approved it for publication. SV confirms being a contributor to this work and approved it for publication.

Dupuy, J. M. (2000). On the Origins of Cognitive Science: The Mechanization of the Mind. Princeton, NJ: Princeton University Press.

Freud, S. (1909). Notes upon a case of obsessional neurosis. Stand. Ed. 10, 153-318. Freud, S. (1915). The unconscious. Stand. Ed. 14, 166-215.

Freud, S. (1919). The "uncanny". Stand. Ed. 19, 219-256.

Freud, S. (1923). The ego and the id. Stand. Ed. 19, 12-66.

Freud, S. (1938a). An outline of psycho-analysis. Stand. Ed. 23, 141-207.

Freud, S. (1938b). Findings, ideas, problems. Stand. Ed. 23, 299-300.

Gallagher, S. (2007). "Neurophilosophy and neurophenomenology," in Phenomenology 2005: Selected Essays From North America, Vol. 5, eds L. Embree and T. Nenon (Bucharest: Zeta), 293-316.

Gardner, S. (2000). Psychoanalysis and the personal/sub-personal distinction. Philos. Explor. 1, 96-119. doi: 10.1080/13869790008520983

Goodman, N. (1978). Ways of Worldmaking. Indianapolis, IN: Hackett.

Heidegger, M. (1962). Being and Time. Oxford: Blackwell Publishers Ltd.

Heidegger, M. (1985). History of the Concept of Time. Bloomington, IN: Indiana University Press.

Husserl, E. (1970). The Crisis of European Sciences and Transcendental Phenomenology. Evanston, IL: Northwestern University Press.

Husserl, E. (1977). Phenomenological Psychology: Lectures, Summer Semester, 1925. The Hague: Nijhoff.

Husserl, E. (1983). Ideas Pertaining to a Pure Phenomenology and to a Phenomenological Philosophy. First book: General Introduction to a Pure Phenomenology. The Hague: Martinus Nijhoff.

Husserl, E. (1989). Ideas Pertaining to a Pure Phenomenology and to a Phenomenological Philosophy. Second book: Studies in the Phenomenology of Constitution. Dordrecht: Kluwer.

Husserl, E. (1995). Cartesian Meditations: An Introduction to Phenomenology. Dordrecht: Kluwer Academic Publishers.

Husserl, E. (1999). The Idea of Phenomenology. Dordrecht: Springer.

Husserl, E. (2001). Logical Investigations, 2nd Edn, Vol. 2. London: Routledge.

Johnston, A. (2012). "Turning the sciences inside out: revisiting lacan's "science and truth," in Concept and Form, Vol. 2, eds P. Hallward and K. Peden (London: Verso), 105-122.

Kant, I. (1996). Critique of Pure Reason. Indianapolis, IN: Hackett.

Kitcher, P. (1992). Freud's Dream: A Complete Interdisciplinary Science of Mind. Cambridge, MA: MIT Press. 
Koch, A. (1997). The limit of my world. Parabel 1, 70-82.

Kolers, P. A., and von Grünau, M. (1976). Shape and color in apparent motion. Vis. Res. 16, 329-335. doi: 10.1016/0042-6989(76)90192-9

Lacan, J. (1993). "The Psychoses," in The Seminar of Jacques Lacan: Book III 1955-1956, ed. J. A. Miller (London: Routledge).

Lacan, J. (2006). Ecrits. London: Norton.

Lacan, J. (1982-1983). "Merleau-Ponty," in Memoriam, trans. W. Ver Eecke and D. De Schutter (Atlantic Highlands, NJ, Humanities Press), 73-81.

Livingstone-Smith, D. (1999). Freud's Philosophy of the Unconscious. Dordrecht: Kluwer Academic Publishers.

MacDonald, P. S. (2000). Descartes and Husserl. The Philosophical Project of Radical Beginnings. New York, NY: SUNY Press.

Mannoni, O. (2003). "I Know well, but all the same," in Perversion and the Social Relation, eds M. A. Rothenberg, D. A. Foster, and S. Zizek (Durham, NC: Duke University Press), 68-92.

Merleau-Ponty, M. (2002). Phenomenology of Perception. London: Routledge.

Milner, J. C. (1995). L'Oeuvre Claire: Lacan, la Science et la Philosophie. Paris: Le Seuil.

Moore, M. (1988). "Mind, brain and unconscious," in Mind, Psychoanalysis and Science, eds P. Clark and C. Wright (Oxford: Blackwell), 141-166.

Noë, A. (2004). Action in Perception. Cambridge: The MIT Press.

Noë, A. (2007). The critique of pure phenomenology. Phenomenol. Cogn. Sci. 6 , 231-245. doi: 10.1007/s11097-006-9043-x

Overgaard, S. (2015). How to do things with brackets: the epoché explained. Cont. Philos. Rev. 2, 179-195. doi: 10.1007/s11007-015-9322-8

Peirce, C. S. (1992). The Essential Peirce, Vol. 1 and 2, eds N. Houser and C. Kloesel. Bloomington, IN: Indiana University Press.

Pfaller, R. (2005). "Where is your hamster? the concept of ideology in Zizek's cultural theory," in Traversing the Fantasy: Critical Responses to Slavoj Zizek, eds J. Glynos and M. Sharpe (Farnham: Ashgate Publishing Company), 198-216.

Pfaller, R. (2006). "The familiar unknown, the uncanny, the comic," in Lacan: The Silent Partners, ed. S. Zizek (London: Verso), 198-216.

Pfaller, R. (2014). On the Pleasure Principle in Culture: Illusions Without Owners. London: Verso.

Pfaller, R. (2015). “The althusserian battlegrounds," in Slavoj Zizek and Dialectical Materialism, eds A. Hamza and F. Ruda (London: Palgrave Macmillan), 23-42.

Politzer, G. (1994). Critique of the Foundations of Psychology. Pittsburgh, PA: Duquesne University Press.

Ricoeur, P. (1977). Freud and Philosophy: An Essay on Interpretation. New Haven, CT: Yale University Press.

Rosenberg, J. (2002). Thinking About KNOWING. Oxford: Oxford University Press.

Sartre, J. P. (1958). Being and Nothingness: An Essay on Phenomenological Ontology. London: Methuen.
Sartre, J. P. (1979). Between Existentialism and Marxism Situations VIII and IX. New York, NY: Morrow Quill.

Sartre, J. P. (2004). The Transcendence of the Ego. London: Routledge.

Schafer, R. (1976). A New Language for Psychoanalysis. New Haven, CT: Yale University Press.

Schwitzgebel, E. (2007). No unchallengeable epistemic authority, of any sort, regarding our own conscious experience - contra dennett? Phenomenol. Cogn. Sci. 6, 107-112. doi: 10.1007/s11097-0069034-y

Sellars, W. (1981). Foundations for a metaphysics of pure process. Monist 64, 3-90. doi: $10.5840 /$ monist 19816412

Sellars, W. (ed.). (1991). "Philosophy and the scientific image of man," in Science, Perception and Reality (Atascadero: Ridgeview Publishing Company), 1-40.

Seron, D. (2015). "L'équivalence entre "mental" et "conscient" chez Brentano," in Approches Phénoménologiques de linconscient, eds M. Gyemant and D. Popa (Hildesheim: Georg Olms Verlag), 15-30.

Staiti, A. (2015). On husserl's alleged cartesianism and conjuctivism: a critical reply to claude romano. Husserl Stud. 31, 123-141. doi: 10.1007/s10743-014-9164-y

Thompson, E. (2007). Mind in Life. Cambridge, MA: Harvard University Press.

Tomšič, S. (2012). Three notes on science and psychoanalysis. Filozofski Vestnik 33, 127-144.

Tugendhat, E. (1986). Self-Consciousness and Self-Determination. Cambridge, MA: The MIT Press.

Wittgenstein, L. (1958). Philosophical Investigations, 3rd Edn. NewYork, NY: Macmillan.

Wittgenstein, L. (1978). Lectures and Conversations on Aesthetics, Psychology and Religious Belief, ed. C. Barret. Oxford: Blackwell.

Zizek, S. (1989). The Sublime Object of Ideology. New York, NY: Verso.

Zizek, S. (1998). The Interpassive Subject. Paris: Centre Georges Pompidou.

Zizek, S. (2006). The Parallax View. Cambridge, MA: The MIT Press.

Zizek, S. (2014). Less Than Nothing. London. New York, NY: Verso.

Zupancic, A. (2005). Reversals of nothing: the case of the sneezing corpse. Filosofski Vestnik 26, 173-186.

Conflict of Interest Statement: The authors declare that the research was conducted in the absence of any commercial or financial relationships that could be construed as a potential conflict of interest.

Copyright $\odot 2017$ Feyaerts and Vanheule. This is an open-access article distributed under the terms of the Creative Commons Attribution License (CC BY). The use, distribution or reproduction in other forums is permitted, provided the original author(s) or licensor are credited and that the original publication in this journal is cited, in accordance with accepted academic practice. No use, distribution or reproduction is permitted which does not comply with these terms. 
OPEN ACCESS Jos Antonius Maria De Kroon, Psychiatrist Psychoanalyst Netherlands

Reviewed by: Stephanie Swales, University of Dallas, United States Raul Leon Moncayo, Mission Mental Health, United States

${ }^{*}$ Correspondence:

Thomas Lepoutre thomas.lepoutre@univ-amu.fr

Specialty section: This article was submitted to Psychoanalysis

and Neuropsychoanalysis, a section of the journal Frontiers in Psychology

Received: 20 April 2017 Accepted: 28 August 2017 Published: 15 September 2017

Citation:

Lepoutre T, Madeira ML and Guerin N (2017) The Lacanian

Concept of Paranoia: An Historical Perspective. Front. Psychol. 8:1564. doi: 10.3389/fpsyg.2017.01564

\section{The Lacanian Concept of Paranoia: An Historical Perspective}

\author{
Thomas Lepoutre ${ }^{1 *}$, Manoel L. Madeira ${ }^{2}$ and Nicolas Guerin ${ }^{1}$ \\ ${ }^{1}$ Department of Clinical Psychology, Aix-Marseille University LPCLS (EA 3278), Marseille, France, ${ }^{2}$ Institute of Psychology, \\ Federal University of Rio Grande do Sul, Porto Alegre, Brazil
}

This article seeks to reopen a major question raised by the Lacanian nosology of the psychoses, by looking closely at Lacan's formulations of what he never ceased referring to as "paranoia". While almost all classification systems of modern psychiatry, such as the ICD-10 and the DSM-5, have abandoned the specific category of paranoia, Lacan always viewed paranoia as a major category of "functional psychosis". He held that paranoia was a qualitatively different disorder than schizophrenia, and considered it to be the principal or exemplary form of psychosis. Furthermore, in the middle period of his work, Lacan thought of paranoia in much broader terms than those of the definition proposed by Kraepelin, which he revisited, point by point, developing his theory of Freud's concept of "Verwerfung" or foreclosure; the latter became the focal diagnostic criterion in his nosographic construction. Lacan's privileging of and evolving theoretical views on paranoia provide a structural approach to what he called the "resistant nucleus" of psychosis; his work serves as a counterpoint to the more descriptive neo-Kraepelinian approach of contemporary psychiatric nosology.

Keywords: DSM, foreclosure, Freud, Kraepelin, Lacan, nosography, paranoia, schizophrenia

\section{INTRODUCTION}

This article seeks to reopen a major question raised by the Lacanian nosology of the psychoses, by looking closely at Lacan's formulations of what he never ceased referring to as "paranoia".

The need for such a reopening arises because successive editions of the principal international classification systems have ceased to use "paranoia" to delineate a unique diagnostic category, to the point that it seems destined to "fade away," nosographically speaking (Prudent et al., 2016, p. 193). Lacan, on the contrary, used the concept intensively, so much so that he considered paranoia to be the prime example of psychosis. Has Lacan's approach become outdated? Could it, on the contrary, remain of interest today, at least on the condition that certain of its subtleties are not overlooked? We shall argue for the second option.

To this end, we need to consider, jointly and separately, the centrality of the place accorded to paranoia in Lacan's work and its increasing marginalization in contemporary nosography. We shall compare the slow incorporation of paranoia into the schizophrenia group (Marneros et al., 2012) with Lacan's paradoxical consolidation of the concept of paranoia, a concept to which he frequently appealed as the exemplary form of psychosis throughout his rethinking of that problematic.

\section{PARANOIA: CENTRAL FOR PSYCHOANALYSIS, MARGINAL FOR PSYCHIATRY}

Paranoia occupies an absolutely central place in Lacan's work. From Lacan's doctoral thesis on paranoiac psychosis written in 1932 (Lacan, 1975) and his first clinical publications in the 1930s 
(Lacan, 1931b, 1933/1988a, 1938/1988b), through his rereading of the Schreber case in 1955-1956 (Lacan, 1981/1993) and his programmatic text, "On a Question Prior to Any Possible Treatment of Psychosis," of 1959 (Lacan, 1958/1966/2006b), to his much later work in the 1970 s on knot theory, where it is reformulated and formalized in topological terms (Lacan, 2005/2016), paranoia was the clinical entity of reference for his approach to the clinical treatment of psychosis. Beyond its purely psychopathological denotations, psychosis is also the paradigmatic nosological form through which Lacan conceptualized a series of anthropological issues: the "hostile potentialities" that compose the social bond, for which the paranoid individual has an incomparable acumen (Lacan, 1975, p. 439); the problem of style in literary and artistic creation (Lacan, 1933); the "paranoiac structure of the ego" itself and the logic of analysis as a "guided paranoia" (Lacan, 1948/1966/2006a, pp. 93, 89); the recurring theme of "paranoiac knowledge" (cf. Lacan, 1947/1966/2006d, p. 150, Lacan, 1949/1966/2006e, p. 76); or again, in epistemological terms, what he called the "closure" of science (Lacan, 2017).

It is thus worthwhile to take a closer look at the reasons for Lacan's apparent nosographical privileging of paranoia, both to identify its historical grounds and to grasp its clinical value. This is especially the case since, as a countercurrent to the Lacanian approach, the complex history of the category of paranoia which has been at the heart of a certain number of terminological misunderstandings between European and American psychiatry (Pichot, 1997) - has led this term to be "overdiagnosed in the 19th century and underdiagnosed in the 20th" (Dowbiggin, 2000, p. 66). The shift in the frequency of diagnosis resulted from Kraepelin's introduction of the category of "dementia praecox," which Bleuler (1911/1950) soon renamed "schizophrenia"; this clinical entity came to absorb discussions of the "question of paranoia" or "Paranoiafrage" (Lewis, 1970, pp. 4-5) or to relegate them to the background. This led to Kraepelin's redefinition of paranoia "in the strict or narrow sense [im engsten Sinne]" (Kraepelin, 1899a, p. 170). As a result, while Lacan's writings attest to the centrality of paranoia for French psychoanalysts, modern psychiatrists, especially in North America, have tended to follow the opposite course, by underrating the nosological importance of paranoia and giving a hegemonic emphasis to schizophrenia (Kendler, 1982). The latter has been "broadened" and "expanded" (Andreasen, 1989, p. 520) to include paranoid forms, to the detriment of paranoia as a category.

Where does this sort of overrepresentation of paranoia in Lacan's work come from? How did Lacan make the seemingly anachronistic choice to focus on paranoia, at a time when his contemporaries in psychiatry were concentrating on schizophrenia?

To reply to this question, we shall reassess how the theme of paranoia is situated with respect to Lacan's theoretical path, which we view as being broadly organized into three major conceptual periods (Nobus, 2000; Vanheule, 2011). We shall concentrate on the first two of these, because they are decisive for the question of paranoia.

\section{EARLY WRITINGS: LACAN WITH KRAEPELIN, 1931-1952}

Although Lacan wrote several clinical articles about paranoia during the initial years of his work (Deloro, 2011), it is his doctoral thesis in medicine (Lacan, 1975), defended in 1932, that presents his first theoretical conception systematically.

In this thesis, Lacan referred to Bleuler, Kretschmer, and Jaspers to define paranoia as a "mode of reaction" (Lacan, 1975 , p. 49), rather than as a developmental anomaly or an organic process; he intended to draw out the direct connection between the "events experienced" by the patient (p. 101), the ensuing "internal conflicts" (p. 277), and the psychotic break [déclenchement], understood as "the subject's reaction to vital situations" (p. 77). His views were generally psychogenetic, and contrasted with the constitutionalist theories of Genil-Perrin and the organicist approach of Clérambault, which dominated psychiatry in France at the time. They also differed from Lacan's own later views, when his "return to Freud" (Lacan, 1981/1993, p. 71) led him a position that was diametrically opposed to his initial "comprehensive" approach (p. 316).

Although writers such as Cox-Cameron (2000) and Vanheule (2011) have highlighted the implications of Lacan's paradoxical and precocious early writings, it is noted less often that Lacan was also working to achieve a precise nosological definition and this led him to set out a lasting representation of the diagnostic concept of paranoia.

On this point, Kraepelin is the psychiatrist whom Lacan cites most frequently in his thesis, and whose work constitutes his major reference. After recalling the insoluble ambiguities and the "apex of the period of [nosological] confusion" around the Paranoiafrage, he concludes his history of the concept by noting, "Then came Kraepelin, at last, as it were, with the Germanic clarity of his conceptions"; for Lacan, Kraepelin's definitions marked the "maturity of the work of delimitation as applied to the notion of paranoia” (Lacan, 1975, p. 23).

As Lacan notes (Lacan, 1975, p. 23), Kraepelin's decisive move, which occurred in the sixth edition of his renowned Lehrbuch, consisted in "according a completely novel place to the concept of paranoia" (Kraepelin, 1899b, p. 430); in this, he diverged from traditional authors, who still associated paranoia with "a series of clinical pictures that no longer had any relation to the original concept, such as amentia, alcoholic hallucinations, and many other pathological states, which almost without doubt belong to dementia praecox or manic-depressive insanity" (p. 427).

This established the modern Kraepelinian concept (Kendler, 1988), to which those since Lacan have often returned, in which paranoia is limited to the "gradual development of a stable progressive system of delusions, without marked mental deterioration, clouding of consciousness, or disorder of thought, will, or conduct" (Kraepelin, 1899/1915, p. 423) - in opposition to the poor prognosis of the schizophrenia group.

Lacan refers to this "strict" Kraepelinian definition as "legitimate paranoia" (Lacan, 1975, p. 23). However, the definition, which is both the most orthodox psychiatric definition and one of the essential determining influences on how Lacan 
viewed paranoia, would be profoundly reworked in the course of his thorough rereading of Freud.

\section{THE RETURN TO FREUD: LACAN WITH SCHREBER, 1953-1962}

It is noteworthy that Lacan went on to revisit Kraepelin's original definition of paranoia. Given his formulations in his thesis, it is even surprising that, 20 years later, Lacan opened his seminar on the psychoses (Lacan, 1981/1993) by going back to his critical point of departure and reworking the canonical definition, which has rarely been called into question by later psychiatrists, not even by members of the Saint Louis school (Winokur, 1977; Kendler, $1980,1984)$ who instigated the neo-Kraepelinian revolution that inspired the DSM-III, DSM-IV, and DSM-5 revisions. Lacan actually repudiates Kraepelin's definition in its entirety, to the point of stating that, "There isn't a word of truth in it" (Lacan, 1981/1993, p. 17). He takes it apart point by point, casting doubt on each of its propositions successively: its supposedly gradual and continual development, the dependence of its etiology on purely endogenous causes, the illusory immutability of the system of delusions and the "total preservation of clarity and order in thought, will, and action" (p. 18).

Should we see in this apparent reversal a paradox in Lacan's approach? While it could be thought that Lacan is quite simply going back to a pre-Kraepelinian conception, which he had rejected unambiguously at an earlier point, the situation turns out to be more complex.

On the one hand, several of Lacan's criticisms had already been sketched out in his publications of the early 1930s. ${ }^{1}$ If he was able to express his criticisms more frankly in 1955, it might have been because his relation to psychiatry, and also to the rigors of pursuing a career within the hospital and university, was freer than it could have been in the 1930s. He could thus distance himself publicly from the authority figure of his thesis, and at a time when he had a robust conceptual framework that provided a new consistency to the different aspects of his critique of Kraepelin's definition.

On the other hand, despite his thoroughgoing criticism, Lacan continued to praise Kraepelin's conceptual prowess; this was still the case at the time of the publication of his Écrits in 1966, in which he reiterated his admiration for the German psychiatrist's "clinical genius" and his "faithfulness to the symptom's formal envelope" (Lacan, 1966/2006c, p. 52).

Nevertheless, alongside the methodical criticism intended to free the concept of paranoia from the "strict" psychiatric definition, Lacan's response - by directing attention to questions of structure rather than to symptoms alone - had the effect of reopening the semiological framework of paranoia, to include

\footnotetext{
${ }^{1}$ The discontinuous or episodic progress of the disorder was emphasized in Lacan's article on "schizography" (Lacan, 1931a); the basing of the etiology on external or social and intersubjective, rather than internal, causes, was developed in several works of the period (Lacan, 1931b, 1933, 1933/1988a) as well as in the 1932 thesis (Lacan, 1975). Lacan had also already begun to question the supposed "total preservation of clarity and order in thought" in his thesis, in relation to the case of Aimée and the retroactive reconstruction of the past imposed by the dynamic of the delusion on the subject's relation to her history.
}

"elementary phenomena" and the effects of "personal [...] meaning" (Lacan, 1981/1993, pp. 19, 54) as well as verbal and auditory hallucinations. Lacan considered these to be the paradigms of paranoiac functions, whereas Kraepelin found they occurred "only quite occasionally" (Kraepelin, 1901/1904, p. 145).

The relaxing of the Kraepelinian frame was certainly consistent with Lacan's overall conceptual development. Further, his emphasis on the structural analysis of "signifying effects" [effets de signifiant] in Freud's case histories, and especially in the case of Schreber, ultimately led him, in this period of his work, to identify a particular mode of defense that would provide psychosis with its own specific etiology: the "foreclosure of the Name-of-the-Father," which intervenes from the place of the Other (Lacan, 1958/1966/2006b, p. 477). The "failure of the paternal metaphor," which serves as both the "essential condition" of psychosis and "the structure that separates it from neurosis," has the necessary consequence of relegating the preoccupation with the nosography of paranoia to the background, for the sake of providing a clear characterization of psychotic structure as such (p. 479).

The downplaying of Lacan's initial interest in differential categories, if not his discarding of a nosographical definition acquired with great effort during his thesis, derives, for the most part, from his deepening of the Freudian approach, to the detriment of psychiatry. This approach was reinforced by the contributions of linguistic theory, a theory that finally enabled him to give an epistemological heft to the term "structure," which he had used more intuitively 20 years earlier.

Yet it is possible that Lacan was also taking his cues from another source. For a long time, Freud continued to privilege the earlier understanding of paranoia, rather than embracing the more modern dichotomy between paranoia and schizophrenia; this is shown by the many occasions in which he used these two terms as if they were interchangeable (Freud and Jung, 1974).

Freud did so because his deciphering of the clinical aspects of the psychoses was based on a pre-Kraepelinian nosography, with its broader and obsolete concept of paranoia. It can thus be noted that Freud's first diagnosis of paranoia, which would inspire Lacan's own concept of foreclosure, was explicitly corrected by Freud himself; once he had become aware of Kraepelin's dismantling of the concept, he came to view the case as one of "dementia paranoides" (Freud, 1896/1962, p. 174, note 1, added in 1924; Freud, 1925/1959, p. 60). He was thus late to recognize Kraepelin's revolution, for he only spoke of it in 1911: "I am of the opinion that Kraepelin was entirely justified in taking the step of separating off a large part of what had hitherto been called paranoia and merging it, together with catatonia and certain other forms of disease, into a new clinical unit..." (Freud, 1911/1958, p. 75). This rather laconic statement covers over a radical upheaval in the psychoanalytic nosography of the psychoses, through which it came to meet up with the modern psychiatric view that separates schizophrenia and paranoia, after long having allowed paranoia to occupy the nosological place of schizophrenia.

However, even after having imported Kraepelin's categories into his own nosography as of 1911, Freud continued to use 
the concept of paranoia in its more extended sense, and this is what Lacan encountered. The ambiguity of Freud's diagnosis of Schreber is a testament to this. Kraepelin, Bleuler, and Jung were unanimous in arguing that, as Jung put it, "Schreber's case is not a pure paranoia in the modern sense" (Jung, 1912/1916, p. 510, note 8), but rather a case of dementia praecox (p. 141); Freud nevertheless retained his anachronistic diagnosis of paranoia. Lacan would then follow in his footsteps, as if taking no heed of the ambiguity of the double diagnosis that appears in the full title of Freud's case history, which mentions both a "Case of Paranoia" and, parenthetically, "(Dementia Paranoides)".

We can thus understand why Lacan began his seminar on the psychoses by emphasizing Freud's privileging of paranoia:

In what has been done, is done, and is now in the course of being done concerning treatment of the psychoses the schizophrenias are much more readily explored than the paranoias, a much more lively interest is taken in them, and greater results are expected from this. Why then does paranoia, on the contrary, have a rather privileged position for Freudian doctrine - that of a knot, but also of a resistant nucleus? (Lacan, 1981/1993, p. 3).

What remains surprising is that, in noticing, supporting, and taking up this emphasis himself, Lacan fully recognizes the anachronism of that approach; he states expressly that he thinks that the historical reduction of the scope of paranoia had passed Freud by: "In this respect, as sometimes happens, Freud is not absolutely in step with his time. Is he way behind it? Is he way ahead of it? There lies the ambiguity. At first sight he is way behind it" (p. 4).

We see that Lacan was simultaneously emphasizing the central character of paranoia as a sort of historical scar and embracing it as a theoretical paradigm, as if he were hesitating between a purely historical privileging and a decidedly methodological preference.... In reality, Lacan was using what seemed to be a mere effect of history as a way of foreshadowing the structural framework that he was working to establish.

\section{CONCLUSION: LATER WRITINGS, 1962-1981}

In his clinical approach to paranoia during the last period of his teaching, Lacan ultimately drew out its structural traits, thereby fully revealing, within the generic conceptualization of psychosis, the inadequacy of the distinctions between schizophrenia and paranoia that had been proposed before then.

If his return to Freud was primarily under the auspices of the logic of the signifier and lent support to the broad definition of paranoia, Lacan's later work would focus instead on the limits of the symbolic, developing concepts related to jouissance and the object $a$. These concepts in turn had decisive effects on his

\section{REFERENCES}

Andreasen, N. C. (1989). The American concept of schizophrenia. Schizophr. Bull. 15, 519-531. doi: 10.1093/schbul/15.4.519 ensuing work on psychosis in the 1960s, allowing him eventually to arrive at a "more precise definition of paranoia, as identifying jouissance in this place of the Other as such" (Lacan, 1966/2001, p. 215).

This fully fledged definition, with its structural criterion that is both more precise and extensive than our contemporary "diagnostic criteria," also involves a complete parting of the ways between psychiatric and psychoanalytic nosographies. It does so by confirming the privilege of a definition that has been enlarged to cover all of what can be called the "elaborative psychoses," which go far beyond the "delusional disorders" described in recent editions of the DSM. On this point, this new gulf between the structural definition provided by Lacanian psychoanalysis and the definition given by "neoKraepelinian" psychiatry seems, in the end, to renew and extend an earlier gulf: the one that had originally separated Freud's initial broad definition from Kraepelin's "strict sense" of the term.

For Freud, for whom paranoia, as he said in a letter to Jung, "remains the [major] theoretical concept" (Freud and Jung, 1974, p. 47), and for Lacan, for whom it constituted the most vivid clinical form of the foreclosure of the paternal function, paranoia continued to be the "resistant nucleus". Perhaps psychoanalysis may be thought, in some sense, to play a similar role for clinical psychiatry.

\section{AUTHOR CONTRIBUTIONS}

All authors of this article certify that they each have provided substantial contributions to the conception or design of this work or the acquisition, analysis, or interpretation of data for the work; have participated in drafting the work or revising it critically for important intellectual content; have provided final approval of the version to be published; and agree to be accountable for all aspects of the work in ensuring that questions related to the accuracy or integrity of any part of the work are appropriately investigated and resolved.

\section{FUNDING}

This work was supported by the Aix-Marseille Université.

\section{ACKNOWLEDGMENT}

Translated by John Holland (ORCID: https://orcid.org/00000002-8518-7999).

Bleuler, E. (1911/1950). Dementia Praecox or the Group of Schizophrenias. New York, NY: International Universities Press.

Cox-Cameron, O. (2000). Lacan's doctoral thesis: turbulent preface or founding legend? Psychoanal. Perspect. 41/42, 17-45. 
Deloro, C. (2011). Caractère, constitution, structure. Lacan et le premier concept de paranoïa. Evol. Psychiatr. 76, 391-401. doi: 10.1016/j.evopsy.2011.06.006

Dowbiggin, I. (2000). Delusional diagnosis? The history of paranoia as a disease concept in the modern era. Hist. Psychiatry 11, 37-69. doi: 10.1177/ 0957154 X0001104103

Freud, S. (1896/1962). "Further remarks on neuro-psychoses of defence," in The Standard Edition of the Complete Psychological Works of Sigmund Freud, Vol. III, ed. J. Strachey (London: Hogarth), 159-188.

Freud, S. (1925/1959). "An autobiographical study," in The Standard Edition of the Complete Psychological Works of Sigmund Freud, Vol. XX, ed. J. Strachey (London: Hogarth), 3-76.

Freud, S. (ed.). (1911/1958). "Psycho-analytic notes on an autobiographical account of a case of paranoia," in The Standard Edition of the Complete Psychological Works of Sigmund Freud, Vol. XII (London: Hogarth), 9-82.

Freud, S., and Jung, C. G. (1974). The Freud/Jung Letters: The Correspondence between Sigmund Freud and C. G. Jung. Princeton, NJ: Princeton University Press.

Jung, C. G. (1912/1916). Psychology of the Unconscious: A Study of the Transformations and Symbolisms of the Libido. New York, NY: Moffat

Kendler, K. S. (1980). The nosologic validity of paranoia (simple delusional disorder). Arch. Gen. Psychiatry 37, 699-706. doi: 10.1001/archpsyc.1980. 01780190097012

Kendler, K. S. (1982). Demography of paranoid psychosis (delusional disorder): a review and comparison with schizophrenia and affective illness. Arch. Gen. Psychiatry 39, 890-902. doi: 10.1001/archpsyc.1982.04290080012003

Kendler, K. S. (1984). Paranoia (delusional disorder): a valid psychiatric entity? Trends Neurosci. 7, 14-17. doi: 10.1016/S0166-2236(84)80181-2

Kendler, K. S. (1988). Kraepelin and the diagnostic concept of paranoia. Compr. Psychiatry 29, 4-11. doi: 10.1016/0010-440X(88)90031-4

Kraepelin, E. (1899a). Psychiatrie: Ein Lehrbuch für Studirende und Aerzte, Vol. 1. Leipzig: Barth.

Kraepelin, E. (1899b). Psychiatrie: Ein Lehrbuch für Studirende und Aerzte, Vol. 2. Leipzig: Barth.

Kraepelin, E. (1899/1915). Clinical Psychiatry: A Textbook for Students and Physicians. New York, NY: Macmillan.

Kraepelin, E. (1901/1904). Lectures on Clinical Psychiatry. London: Baillière, Tindall and Cox.

Lacan, J. (1931a). Écrits “inspires”: schizographie. Ann. Med. Psychol. II, 508-520

Lacan, J. (1931b). Structures des Psychoses Paranö̈aques. Semaine des Hôpitaux de Paris 14. Available at: http://ecole-lacanienne.net/wp-content/uploads/2016/ 04/1931-07-07.pdf [accessed April 3, 2017].

Lacan, J. (1933). Le Problème du Style et la Conception Psychiatrique des Formes Paranoïaques de L'expérience. Minotaure 1. Available at: http://ecole-lacanienne. net/wp-content/uploads/2016/04/1933-06-01.pdf [accessed April 3, 2017].

Lacan, J. (1975). De la Psychose Paranoïaque dans ses Rapports avec la Personnalité. Paris: Seuil.

Lacan, J. (2017). Le Séminaire, Livre XIII?: L'objet de la Psychanalyse 1965-1966. Available at: http://staferla.free.fr/S13/S13\%20L'OBJET.pdf [accessed April 3, 2017].
Lacan, J. (1933/1988a). Motives of paranoiac crime: the crime of the Papin sisters. Crit. Texts 5, 7-11.

Lacan, J. (1938/1988b). The family complexes. Crit. Texts 5, 12-29.

Lacan, J. (1948/1966/2006a). “Aggressiveness in psychoanalysis," in Écrits: The First Complete Edition in English, ed. J.-A. Miller (New York: Norton), 82-101.

Lacan, J. (1958/1966/2006b). “On a question prior to any possible treatment of psychosis," in Écrits: The First Complete Edition in English, ed. J.-A. Miller (New York, NY: W.W. Norton \& Company).

Lacan, J. (1966/2001). “Présentation des mémoires d'un névropathe," in Autres Écrits, ed. J.-A. Miller (Paris: Seuil), 213-218.

Lacan, J. (1966/2006c). "On my antecedents," in Écrits: The First Complete Edition in English, ed. J.-A. Miller (New York: Norton), 51-57.

Lacan, J. (1947/1966/2006d). "Presentation on psychical causality," in Écrits: The First Complete Edition in English, ed. J.-A. Miller (New York: Norton), 123-158.

Lacan, J. (1949/1966/2006e). "The mirror stage as formative of the I function as revealed in psychoanalytic experience," in Ecrits: The First Complete Edition in English, ed. J.-A. Miller (New York: Norton), 75-89.

Lacan, J. (1981/1993). The Psychoses: The Seminar of Jacques Lacan, Book III, 1955-1956. New York, NY: Norton.

Lacan, J. (2005/2016). The Sinthome: The Seminar of Jacques Lacan, Book XXIII. Malden, MA: Polity.

Lewis, A. (1970). Paranoia and paranoid: a historical perspective. Psychol. Med. 1, 2-12. doi: 10.1017/S0033291700039969

Marneros, A., Pillmann, F., and Wustmann, T. (2012). Delusional disorders - are they simply paranoid schizophrenia? Schizophr. Bull. 38, 561-568. doi: 10.1093/ schbul/sbq125

Nobus, D. (2000). Jacques Lacan and the Freudian Practice of Psychoanalysis. London: Routledge.

Pichot, P. J. (1997). DSM-III and its reception: a European view. Am. J. Psychiatry 154, 47-54. doi: 10.1176/ajp.154.6.47

Prudent, C., Evrard, R., and de Tychey, C. (2016). La classification de la paranoïa dans la psychiatrie américaine contemporaine: une revue de la littérature. Evol. Psychiatr. 82, 191-216. doi: 10.1016/j.evopsy.2016.05.004

Vanheule, S. (2011). The Subject of Psychosis: A Lacanian Perspective. London: Palgrave Macmillan. doi: 10.1057/9780230355873

Winokur, G. (1977). Delusional disorder (paranoia). Compr. Psychiatry 18, 511-521.

Conflict of Interest Statement: The authors declare that the research was conducted in the absence of any commercial or financial relationships that could be construed as a potential conflict of interest.

Copyright (c) 2017 Lepoutre, Madeira and Guerin. This is an open-access article distributed under the terms of the Creative Commons Attribution License (CC BY). The use, distribution or reproduction in other forums is permitted, provided the original author(s) or licensor are credited and that the original publication in this journal is cited, in accordance with accepted academic practice. No use, distribution or reproduction is permitted which does not comply with these terms. 


\section{OPEN ACCESS}

Edited by:

Gertrudis Van De Vijver,

Ghent University, Belgium

Reviewed by:

Sandrine Detandt,

Fonds National de la Recherche

Scientifique, Belgium Jasper Feyaerts,

Ghent University, Belgium

*Correspondence: Yorgos Dimitriadis

dimitriadisyorgos@gmail.com

Specialty section: This article was submitted to

Psychoanalysis and

Neuropsychoanalysis,

a section of the journal

Frontiers in Psychology

Received: 17 April 2017

Accepted: 30 August 2017

Published: 21 September 2017

Citation:

Dimitriadis Y (2017) The

Psychoanalytic Concept of

Jouissance and the Kindling

Hypothesis. Front. Psychol. 8:1593.

doi: 10.3389/fpsyg.2017.01593

\section{The Psychoanalytic Concept of Jouissance and the Kindling Hypothesis}

\author{
Yorgos Dimitriadis* \\ Research Center for Psychoanalysis and Society, EA3522, UFR Psychoanalytic Studies, University Paris-Diderot \\ Sorbonne-Cité, Paris, France
}

This article aims to define the conceptual field of jouissance in Lacanian theory, and put forth the hypothesis of a relationship between certain neurophysiological mechanisms and specific clinical phenomena where jouissance is "kindled" and outside the control of the symbolic process. First, the author briefly introduces Lacan's notion of jouissance and the way it draws on Freud's theorization, and describes the preliminary stages of this conceptual field in Lacan's work. Then, the jouissance related to two other concepts: repetition, with its Freudian and Lacanian nuances, as well as the-exclusively - Lacanian concept of the object petit a. Lacan's later conceptualization of language as jouissance (the notion of lalangue) is then discussed in relation to Freud's early ideas ("Letter 52") on the different kinds of inscriptions that help form the mental apparatus. Finally, the author tries to formulate a hypothesis regarding specific neurophysiological mechanisms, based on clinical situations where jouissance becomes "kindled" and escapes the control of the symbolic processes through the neurophysiological mechanisms of conditioning, "kindling-sensitization" and "excitotoxicity." In these cases, jouissance can have a destructive effect on the body and can affect, among others organs, the brain-a process the author has previously described heuristically as the "psychosomatic diseases of the brain." This would be a special mechanism of automatism that would be triggered under the specific conditions of the fragility of the signifying chain (foreclosure of the Name-of-the-Father or solidification of the signifying chain) in combination with biological factors, including genetic factors. In this process, signifiers are reduced to signals, which in turn may be reduced to stimuli, with a tendency toward self-perpetuation, while affects are reduced to emotions and moods. Thus, conditioning and kindling-sensitization could also be understood in terms of a "semiotic reduction." Can we therefore consider that certain phenomena of automatism and certain deficits (delusional moods, schizophrenic apathy, etc.) could be seen as psychosomatic disorders of the brain? The phenomena in question might also serve-albeit at random - as a kind of shield to mitigate excessive jouissance.

Keywords: psychoanalysis, freud, lacan, kindling, sensitiztion, conditioning, psychosomatic disorders, brain 
Jacques Lacan, in his 1969 seminar The Other Side of Psychoanalysis (Lacan, 1969-1970, session of 11 February 1970), said that if analysis had one task to complete, it was to create a new field of energetics, the field of jouissance, which would require other structures than those of physics. He also expressed regret that this field would not be called, as he would have wished, the "Lacanian field," because with the little time he had left, he would not be able to even sketch out its basics. In the course of his teaching, Lacan designated seven versions of jouissance: of the Thing, of Being, of the Other (as subjective and objective genitive), of the body image, of the phallic image, sexual jouissance, and the jouissance of life. Things are quite different for Freud, who instead described different situations potentially referring to jouissance and including joy, pleasure, extreme pleasure, ecstasy, beatitude, sexual pleasure related to sexual satisfaction, the libido, and preliminary sexual excitement. The list already gives us an idea that jouissance is not pleasure, but rather, as Lacan announced in his lecture on Psychoanalysis and Medicine, pleasure is "what necessarily stops us at a certain point, at a respectful distance from jouissance" (Lacan, 1967, p. 46). In the same lecture, Lacan says that jouissance is "always of the order of tension, of forcing, of expenditure, even of exploit. Jouissance is undoubtedly there at the point where pain begins to appear" (Ibid).

\section{PRELIMINARIES AND THE BIRTH OF THE NOTION OF JOUISSANCE}

We will trace the trajectory of the concept of jouissance in Lacan, which not only has the status of the session of 5 March 1958 in his seminar The Formations of the Unconscious (Lacan, 19571958), where the term jouissance is introduced and contrasted with the notions of desire and the signifier. Two sessions later, on 25 March, Lacan says: "What we find at the basis of the analytical exploration of desire is masochism-the subject grasps himself as suffering; he grasps his existence of a living being as a signifier, i.e., as subject to desire," and later: "The subject does not simply satisfy desire, he enjoys desiring (jouit de désirer) and this is an essential dimension of his jouissance." Lacan will examine, while gradually revising it, this antithesis between jouissance and desire (but also between jouissance and the signifier) throughout the different stages of his teaching from 1957 to 1975, especially in his seminar R.S.I. Miller (1999) calls the first of the six consecutive examples of jouissance he finds in Lacan's work the "imaginarization" of jouissance, because the latter appears, he argues, as what resists symbolic elaboration, whether it is acting out, temporary perversions (e.g., in Seminar IV On the Object-relation), or the figure of the ferocious Superego. Following Miller's argument, we could say that, at this stage, Lacan's thinking about jouissance-which has not yet been named as such ${ }^{1}$ - remains linked to the "beyond of the symbolic elaboration, on the broken horizon of which appears the fantasmatic products of jouissance."

\footnotetext{
1 "A signifier in the Real of the analytic experience," he says on 30 May 1967, "a new term” on 14 June 1967, the year of his unpublished seminar on The Logic of Fantasy (Lacan, 1966-1967).
}

Aside from these preliminaries, the seminar where Lacan first develops the concept of jouissance is Seminar VII, The Ethics of Psychoanalysis (Lacan, 1959-1960a,b). Here he approaches jouissance through the prism of the impossible, linked to the notion of the Freudian Thing (Freud, 1950), das Ding, the subject's absolute Other. This is a "Real" as the subject's intimate exteriority, in other words, as what is most external yet closest to him. Likewise, the Thing is both the essence of Evil and the source of sublimation. The forbidden mother appears in this seminar as the incarnation of this absolute Other, i.e., of the Thing. Beyond the prohibition lies an impossibility-of the Real-announcing the divorce between jouissance and the signifier. The Thing is what cannot be found, due to not just prohibition but principal impossibility. The Oedipal prohibition therefore becomes a "mythical" version of this primordial impossibility. The jouissance of the Thing is impossible, hence Lacan's initial definition of jouissance as "the jouissance of the Thing as impossible." In the same seminar, Lacan tries to define the notion of jouissance as the satisfaction of the driverather than need-a definition that he later never repeats. The aim of the drive is not satisfaction but, to the contrary, the failure of satisfaction, which restarts its circuit. Consequently, if jouissance is to be the satisfaction of the drive, it is only insofar as any drive is ultimately the death drive, in other words, insofar as the drive can run jouissance through the chain of signifiers, thus historicizing the subject and, by the same token, bringing jouissance out of the exclusive circuit of the living.

\section{THE RELATION OF JOUISSANCE TO THE OBJECT PETIT a AND TO REPETITION}

In his seminar on Anxiety (Lacan, 1962-1963), during the session of 3 July 1963, Lacan says that for us, jouissance is not by nature promised to desire and that desire can only strive toward it. In the same seminar he speaks about jouissance via the operation of "subjective division" (Figure 1). In this division, the link between the signifiers and the desire of the Other is established (or not) through a process of subjectification, with anxiety as the intermediate level. The word "division" concerns the bar dividing $\mathrm{A}$, the big Other, by the subject, who is inscribed as a

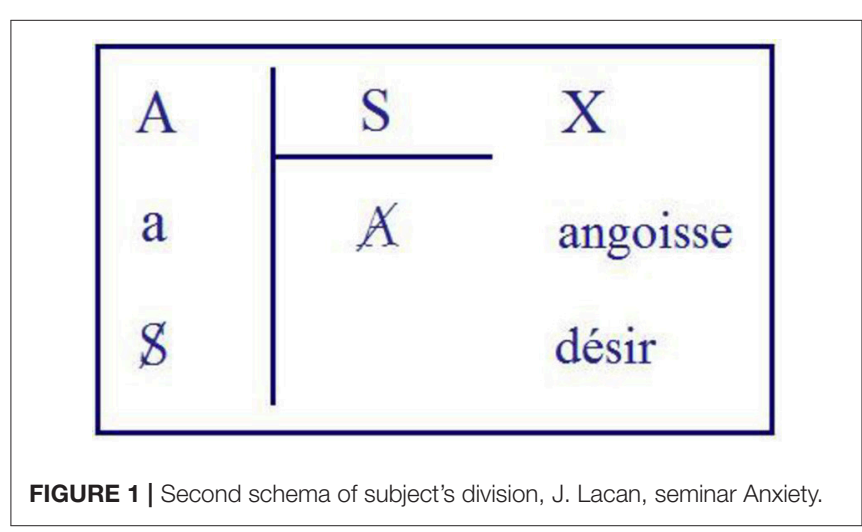


quotient. How many times can the $\mathrm{S}$ fit into the A? The first stage of this division is the stage of mythic jouissance ("jouissance of Being," marked as $\mathrm{X}$ in the schema of Figure 1) of the first undivided subject; this first relationship with A creates the liaison with the first signifier of the "desire of the Other." This raises the question of "what the Other wants from me" in saying this or that to me, a question that produces anxiety-hence Lacan calls this second logical moment the "moment of anxiety." It produces the inscription of jouissance as the object petit $a$, which is the remainder, the residue of this division. It is the subject who appears as petit $a$ for the Other, who wants something from him and who is thus lacking (barred). The result of this division is the barred Other, who consequently appears as lacking. The subject, after having moved through the position of the petit a for the Other, who is lacking, divides, in the rest of the process, the petit $a$ by the $S$, and at the same time is himself divided between the first signifier and the remaining signifiers coming from the Other. This is the logical moment of division, which creates the possible passage-via anxiety, as we have seen-from the subject's jouissance to his desire. The object petit $a$ is thus the cause of this desire. In the seminar, Lacan announces that "only love allows jouissance to condescend to desire" (p. 179), referring to the fact that the coincidence of desire and love, however contingent-through love-is not an indispensable condition.

In the following seminar, The Four Fundamental Concepts of Psychoanalysis (Lacan, 1964), Lacan further elaborates the link between the petit $a$ as an element of jouissance and the massive jouissance of the Thing it replaces. The petit $a$ is, on the one hand, an essential figure of the Thing, but, on the other hand, it is linked to the Other as the locus of signifiers. Its role is to mediate between the Thing and the Other. The object petit $a$ is an element and from this perspective resembles the signifier, which is also an element, namely because it is discontinuous. However, at the same time it has something to do with the essence, just like the Thing, in other words with the first bodily excitations and especially the body's orifices. Contrary to the Thing, the excitations of the object petit a have been subject to the desire of the Other, the Other who is lacking, as we have seen. This is because something in the structure of the body-in the functioning of the drives-is isomorphic to the structure of the unconscious. In this seminar, Lacan describes the unconscious as a dynamic system, rather than as a static series of repeating signifiers: it becomes a kind of edge that opens and closes, like an erogenous zone, like the mouth, and the anus. The lack of the signifier is articulated around the lack of the body. However, the latter is not the result of the signifier, rather it is natural and primary. Jouissance remains untamed as the jouissance of the raw body, of the living organism, yet it is also likely to become inscribed in the system of the signifiers of the unconscious, albeit never completely. In this seminar, jouissance is therefore not defined only negatively, as what is not assimilated by the Symbolic (the way we saw it in the seminar on Ethics). The link between jouissance and the signifiers of desire forms the condition for the relationship to something that exists outside the body and has to do with signifiers. In the 1970s, Lacan will name this type of jouissance-outside the body and related to signifiers"phallic jouissance ${ }^{2}$," because signification is always related to the Phallus $(\Phi)$. In The Subversion of the Subject and the Dialectics of Desire (Lacan, 1960b), he says that the phallic signifier is the signifier of jouissance and as such represents an exception in the signifying chain, because without it signifiers do not signify anything.

In the seminar The Other Side of Psychoanalysis (Lacan, 1969-1970) Lacan defines jouissance in relation to the notion of repetition. In this new conceptualization, it is jouissance that drives repetition, or, to put it otherwise, repetition strives for jouissance. Previously, the notion of repetition was related to the signifying chain and the regular return of certain signifiers. In this new version (Lacan, 1969-1970), Lacan tries to revise the notion by making use of the concept of "unary trait," a neologism introduced in different forms as early as in his seminar on Identification. It is based on Frege's set theory, but also and especially on Freud's term einziger Zug. In Group Psychology and the Analysis of the Ego (Freud, 1921, p. 107), Freud speaks about this "single trait" in the context of identifying with the group leader through the ego-ideal. In the same text, he has already mentioned identification through the symptom as the second version of this single trait. The classical example is Dora's hysterical cough, a characteristic trait she copies from her father and through which she identifies with him. Lacan prefers the neologism "unary trait", but when he speaks about it specifically with regards to jouissance, he says that it originates in the contingency of an encounter and instead of collectivizing, identifying the subject as in the other two cases, it characterizes him in a unique way and therefore is "distinct". He says:

What necessitates repetition is jouissance, a term specifically referred to. [...] As everything in the facts, in clinical experience, indicates to us, repetition is based on the return of jouissance. And what, in this connection, is well spelled out by Freud himself is that, in this very repetition, something is produced that is a defect, a failure" (p. 45-46). "Repetition is the precise denotation of a trait that I have uncovered for you in Freud's text as being identical with the unary trait, with the little stick, with the element of writing, the element of a trait insofar as it is the commemoration of an irruption of jouissance. (Lacan, 1969-1970, p. 77).

We have previously found this type of stigmata, as Soler (19911992) reminds us, in Freud's theory of the choice of the erotic object. Soler cites the example of the Wolfman, for whom, regardless of the reality of the primal scene-the coitus $a$ tergo between his parents that he witnessed sometime between 6 months and one-and-half year of age-what remains as a memory of jouissance is the scene, at two-and-half years, of the governess Grusha on her knees, scrubbing the floor, and of himself looking at her from behind and urinating, which translates the child's phallic jouissance. According to Freud, this jouissance is a trait we find throughout the Wolfman's life and, as Soler (1991-1992) puts it, it functions quasi-automatically in

${ }^{2}$ Later, in his seminar "Les non dupes errent" (Lacan, 1973-1974), he calls this type of jouissance "semiotic jouissance" (session of 11 June 1974). 
all its different metonymical displacements. In other words, the woman "placed" in this way on the floor is one way among others of "debasing" her (a moral degradation being another option) and from what Freud tells us, Sergei continued to feel attracted to not only maids in this position, but also to women of "loose morals." In other words, despite Freud's efforts to give this trait, as Soler says, an Oedipal meaning through the primal scene, "in reality, it has no meaning [sens]; it is a trait that stigmatizes the experience of jouissance. So, if we want it to have a meaning, this meaning is no other but jouissance" (Soler, 1991-1992, lecture of 13 May 1992). Which might help make the link, in a certain way, between, in this case, the choice of the erotic object-such and such type of woman in such and such situation-and the theme of jouissance, in this case phallic jouissance, in the form of urination. It is a simple way of thinking about the unary trait as a characteristic of the experience of jouissance, which repeats automatically.

But repetition is not simply the repetition of the unary trait. It is also one of the consequences that the existence of the trait has for jouissance. According to $\operatorname{Lacan}^{3}$, we need three moments in the repetition of the unary trait for repetition to function. The first moment is the encounter with an experience of jouissance, i.e., a moment in which the unary trait erects a "monument to jouissance," as he puts it. The second moment is the repetition of the trait, or rather an attempt at its repetition, because the striving for repetition results in what he calls an "immixtion of difference ${ }^{4}$." In other words, what is repeated is already different, giving rise to loss as the gap between the first jouissance commemorated by the monument and the jouissance that remains after the attempt at repetition. In terms of physics, this loss is entropy ${ }^{5}$. The difference and loss create a supplementary "subject" to be repeated. What the third moment then repeats is then as much loss as it is the element of the jouissance with a difference. The unary trait introduces the dimension of repetition in two ways: as the nostalgia of loss and the search for its retrieval. In this seminar, Lacan introduces the object petit $a$ as a "surplus jouissance" [plus de jouir], corresponding to Marx's notion of surplus-value [plus value]. The ambiguity of the term plus ["surplus" or "no more"] demonstrates that shutting down of jouissance is indispensable to the search for its "profit": the object petit a commemorates the "loss of jouissance." However, because it represents-as an object-the remainder of jouissance that has escaped the signifying process, Lacan calls it "surplus jouissance."

\section{LANGUAGE AS JOUISSANCE}

Three years later, in seminar Encore (Lacan, 1972-1973), it is the linguistic code itself that becomes understood as primarily

\footnotetext{
${ }^{3}$ See Lacan's Seminar ...ou pire (Lacan, 1971-1972) in Autres Écrits.

4 "It is this act which produces, anachronically, the immixtion of the difference brought into the signifier. What it had been, when repeated, it differs, becoming a subject to repetition." Lacan, Compte rendu avec interpolations du Séminaire de l'Éthique (Lacan, 1959-1960b).

${ }^{5}$ In his well-known book on repetition, Kierkegaard argues that repetition is always new and it is oriented toward the future rather than the past. For more details on precisely this question see Adam (2005).
}

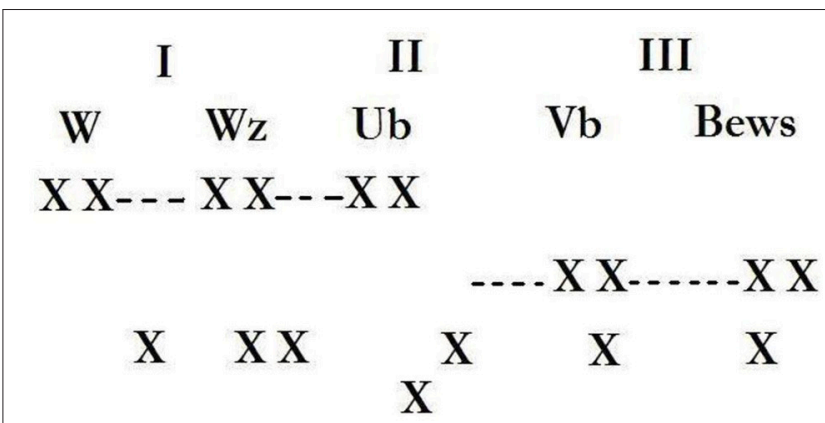

FIGURE 2 | Schema from S. Freud's letter no 112 (ex-52) to W. Fliess.

jouissance, i.e., its communicative value becomes secondary. To name this jouissance, Lacan uses the term lalangue, a neologism he created, as he explains in his Geneva Lecture on the Symptom (Lacan, 1989), from the word lallation, which refers to the sounds emitted by a newborn before he can articulate them as speech. The signifier becomes dissociated from the signified: the first refers to jouissance and the second to signification. The jouissance of speech, of the "bla bla," therefore acquires this dimension of the separation from the meaning of speech.

According to Braunstein (2003, p. 112), we find a prefiguration of the idea of the linguistic code as jouissance already in Freud's letter to Fliess from 6 December, $1896^{6}$ (Freud, 1896b, p. 207-214). The letter outlines three consecutive systems of inscription (Niederschriften) of perceptions (Wahrnehmungen) (Figure 2). In the first system (Wahrnehmungszeichen), perceptions are inscribed in no specific order, as sign-traces. Following Braunstein's commentary (Braunstein, 1994, p. 176) and using the Lacanian terminology, we could say that this logical time corresponds to the mythical jouissance, the "jouissance of Being" of the first subject, which precedes the arrival of the divided subject. The first codification happens at this moment through the notion of the trace (rather than the signifier) inscribed in the body (or rather in the flesh, which this very process of inscription transforms into a body) which Braunstein rightly situates as what the Freud of the second topography calls, at the time of the Mystic WritingPad (Freud, 1925), the "id" (das Id). In this first inscription, the experiences of the Real are written simultaneously and without any (chronological or logical) order ${ }^{7}$. We can say that the jouissance of lalangue is the jouissance of Being not yet dependent on the Other's signifiers, because even though it is related to them, there is not yet any separation from this Other and, as a consequence, this Other is not "perceived" in his dimension of otherness. The second system of inscription is that of the unconscious in the first topography (das Unbewusste), which according to Freud is not dominated by relations of synchrony, but by other, perhaps causal, relations, which lack the linear, syntactical and logical structuring of conscious thought. However, it is already a decoding, a decryption of the signs

\footnotetext{
${ }^{6}$ In the French context, this text is known as the "Letter 52"-Transl. Note. ${ }^{7}$ Lacan compares them to lotto tickets. See Lacan (1960a, p. 658).
} 
from the previously described first moment of inscription, and it follows the primary processes of the unconscious, which, governed by the metaphorical and metonymical processes, is structured like a linguistic code. The synchrony of inscription applies here as well and, like in the precedent system, there is no contradiction and no representation of death. On the other hand, these inscriptions are linked to the Other; jouissance is subject to the phallic signifier and to the-non-linear-logic of "deferred action." During the third moment of inscription, the unconscious thing-presentations of the previous moment are subject to the interpretation by the secondary processes of the preconscious, das Vorbewusste, and connected to wordpresentations. Diachrony and temporality-in the classical sense-are applied to this system of inscriptions, which is dominated by the rules of classical logic.

Closing this short parenthesis devoted to the Lacanian elaboration of the Letter 52, let us now return to Seminar Encore. In this seminar, the body [le corps] is paramount and, as Lacan points out, homophonically contained in its very title [En-corps]. There is no jouissance outside the living body. He says: "Isn't it precisely what psychoanalytic experience presupposes?-the substance of the body, on the condition that it is defined only as that which enjoys itself" (Lacan, 1972-1973, p. 23). In this sense, there is a dissociation between jouissance and the big Other, an absence of relationship. The fact that there is no sexual relationship is the leitmotif of this seminar. According to Lacan, sexual jouissance is an impasse, because neither sex derives jouissance from the Other. For both, jouissance is mediated by the Phallus. More specifically, Lacan says: "What is known as sexual jouissance is marked and dominated by the impossibility of establishing as such, anywhere in the enunciable, the sole One that interests us, the One of the relation "sexual relationship"” (p. 7). He later adds: "Jouissance, qua sexual, is phallic-in other words, it is not related to the Other as such" (p. 9). Subsequently, when he explains the notion of the Other in the terminology of this seminar, he says that it can only be the Other sex. His formulation of Woman and the feminine jouissance are also key elements of this seminar: this is the Other jouissance, known as the jouissance of the mystics, who too had access to it. Hence, women have access to "phallic jouissance," but their jouissance is not-all phallic, because, as Lacan says, "there is a jouissance that is hers, about which she herself perhaps knows nothing, if not that she experiences it" (p. 74). However, he explains that this does not happen to all women. This "Other jouissance" (which is not the "jouissance of the Other"-as Lacan has previously demonstrated, the latter is, by virtue of being the jouissance of the Other sex, impossible) is supplementary rather than complementary; the idea of complementarity would in fact create an illusion that the sexual relationship does exist.

The table of "writing" the sexual relationship-as a failurewhich we find in the Seminar Encore (Figure 3) suggests that men fail in their attempts to relate to the Other sex, because they are in a relationship with the object petit $a$ via fantasy. The body of the Other is thus reduced to the object petit a (written in the woman's part of the column) and all their jouissance is phallic jouissance, which contains its own limit through castration $(-\varphi)$. In any case, even in the sexual act, where we could say that

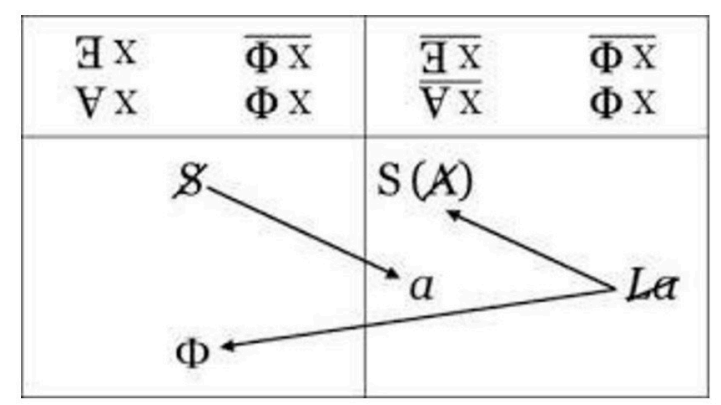

FIGURE 3 | The diagram of sexual difference, J. Lacan seminar Encore.

for the man the Phallus is momentarily embodied by the penis, the orgasm induces a refractory period that restricts jouissance; the latter remains a jouissance of the penis as an organ and not of the Other sex. On the other hand, for, the cause of her desire is the Phallus she does not have. This means that while in a sense she avoids the castration complex, she attaches herself to the Phallus, even if in order to do so she needs a man as her intermediary, for example by having a child.

In this case, her jouissance is also phallic, but it leaves her the possibility of accessing the Other, "supplementary" jouissance. This is why she is "not-all" and is marked as barred. In the schema of the formulas, two arrows are drawn starting from the barred Woman, one toward the Phallus, which we find in the man's part of the table, the other toward the S(A), which is the symbol used in the graph of desire (Figure 4) as the signifier of the lack in the Other. This signifier represents jouissance, because it replaces the phallic signifier, absent from the signifying chain. As Valas (1998) points out, the jouissance that is excluded from the place of the Other returns in the Real, especially in the body itself. The arrow pointing toward the $\mathrm{S}(\mathrm{A})$ remains in the column that concerns Woman, who is therefore not entirely phallic. As to love-and similarly to what we have seen in the seminar on Anxiety-here again Lacan says that "what makes up for [ce qui supplée] the sexual relationship is, quite precisely, love" (Lacan, 1972-1973, p. 45). We could say that in her relationship with a man, the woman gives what she does not have by representing the Phallus (which she does not have) for a man, and this gift is love, following Lacan's definition of it, namely as "giving what one does not have." After his reference to "feminine jouissance" in Encore, Lacan in fact never mentions it again. As a result, Lacan's belief is that the jouissances of the two sexes are "asymmetrical" and thus can never meet, which is another way of saying that the sexual relationship does not exist.

We will finish with the seminar R.S.I. (Lacan, 1974-1975) and Lacan's third lecture in Rome (Lacan, 1975) - usually referred to as La troisieme-where he makes a distinction between two types of jouissance: "phallic" jouissance and the "jouissance of the Other" in the sense of the objective genitive. We will not discuss this stage of his theorization of the notion of jouissance in great detail, because it would require an introduction to his use of the Borromean knot. We will only briefly mention that the object petit $a$ is "squeezed in" (Figure 5) between: 


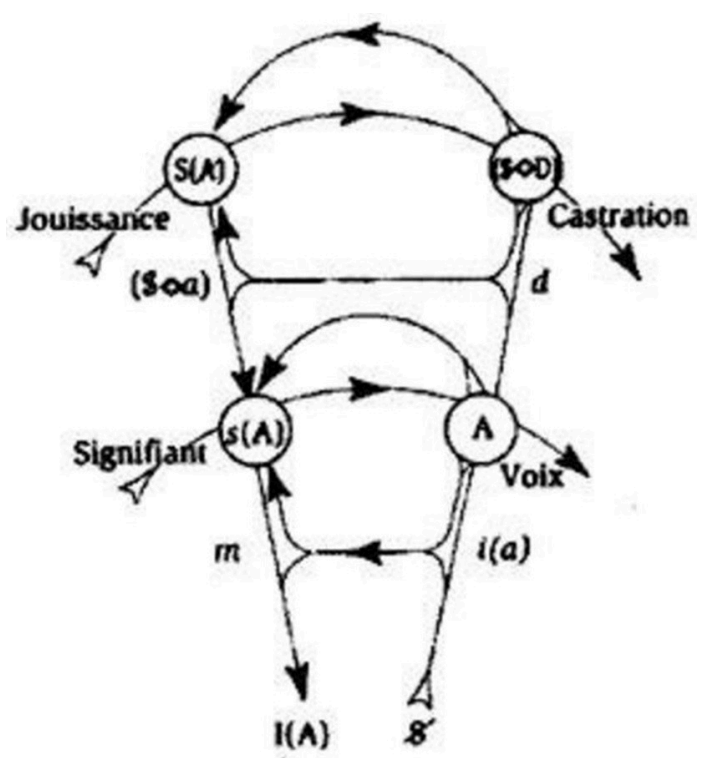

FIGURE 4 | The graph of desire-complete graph, J. Lacan seminar Desir and its interpretation.

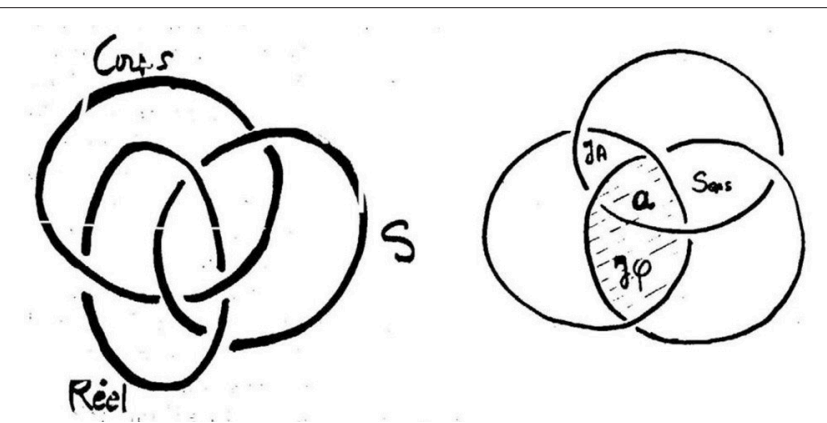

FIGURE 5 | The Borromean knot, J. Lacan, conference "La troisième."

(a) meaning, which forms the intersection between the Imaginary and the Symbolic;

(b) "phallic jouissance," which we find between the Symbolic and the Real;

(c) the "jouissance of the Other" (objective genitive), which is found between the Real and the Imaginary and thus outside language. Lacan also calls it the "jouissance of life," contrasting it to the "phallic jouissance," which is the "jouissance of death," because, as we have already said, it refers to the signifier and historicizes the subject, thus "helping" to kill, i.e., evacuate, other types of jouissance.

\section{THE POSSIBLE DESTRUCTIVE EFFECTS OF JOUISSANCE ON THE ORGANISM}

Having followed the different stages in the development of the conceptual field of jouissance in Lacan's teaching, we are now going to look at the specific question of the potentially destructive effects that jouissance can have on the human organism, i.e., the possibility that jouissance produces organic deficits, especially in cases where it is not limited by the phallic function and thus regulated by language. As we will see, this will allow us to make a link between the concept of jouissance and certain neurophysiological notions ${ }^{8}$. Yet before we speak about organic deficit, let us first look at the relationship between a deficit and a flaw [faille]. As Lacan's teaching progresses, the essence of the human condition in fact becomes articulated to an idea of a "flaw." In his commentary on Lacan's Presentation on Psychical Causality (Lacan, 1946) and critiquing theories that understand madness as a deficit, Jacques-Alain Miller argues:

A deficit can be identified in physical reality, and it is still the case that in order to treat a certain number of dysfunctions, we try to identify, via brain imaging, insufficient activity in this or that area of the brain. So these are fundamentally physical deficits. On the contrary, the flaw in question is a signifying fault, which Lacan understands as a split [faille] between the ego and the subject's being [...] (Miller, 2008, 30 January 2008).

Lacan therefore shifts the question from the deficit to the flaw and the subject will be considered by him as a gap between signifiers; the term "rift" [déchirement] was already present in all his early work on psychosis (Lacan, 1938, p. 842-843) and also in his article on the Mirror Stage (Lacan, 1949). In the course of his teaching, this same flaw will be located on the level of the Real as impossible, on the level of the "sexual non-rapport" and in the concept of "not-all."

The Lacanian theory, by way of its conception of the subject as a "flaw" (flaw because of the premature nature of the human being at the moment of his birth and, correlatively, because of its dependency to the Other of the language in regard to the formation of the organism itself, including the brain), allows us to clearly distinguish between the "subject" and the "brain of the person"; and this despite the tendency, in the last decades, toward the progressive cerebralization of personal identity ${ }^{9}$, as described by both anthropologist Vidal (2005) and sociologist Ehrenberg (2004). However, it is precisely the fact that the subject-as a flaw that enables the constitution of the human being-is separate from its brain that allows us to conceive the possibility, among other things, of the existence of psychosomatic affections, which affect the brain, and, consequently, the presence of deficiencies at that level.

Can Lacanian theory help us think about the appearance of an organic deficit? Lacan's reference to the Oedipal complex in Presentation on Psychical Causality (Lacan, 1946) makes it clear that what the establishment of the symbolic ternary prevents is precisely the processes of "sensitization." He writes: "I would not hesitate to say that one could demonstrate that the Oedipal crisis has physiological echoes, and that, however purely psychological its mainspring may be, a certain "dose of Oedipus" can be considered to have the same humoral efficacy as the absorption of a desensitizing medication" (Lacan, 1946, p. 149). Much later,

\footnotetext{
${ }^{8}$ Jadin and Ritter (2009) argues that the Project is in fact a text on the neuropsychology of jouissance.

${ }^{9}$ See also Dimitriadis (2012a).
} 
in his seminar The Other Side of Psychoanalysis, Lacan implicitly speaks about the potentially destructive power of jouissance over the living organism. We cite: "I have already said enough to you to know that jouissance is the jar of the Danaides, and that once you have started, you never know where it will end. It begins with a tickle and ends in a blaze of petrol. That's always what jouissance is" (Lacan, 1969-1970, p. 72). As he points out, the process of sensitization is physiological and even-if we adjust this to our current knowledge about the process-mostly neurophysiological (although there are some allergic and other physiologic mechanisms of sensitization that are not neurophysiologic); Besides, the term "sensitization" is quite similar to the term "conditioning" and according to Kandel (1991), who studied those mechanisms on aplysia, conditioning is a product of the sensitization mechanism.

\section{THE KINDLING-EXCITOTOXICITY HYPOTHESIS}

Taking Lacan's comments as our starting point, we can then pose the following audacious question: Can the mechanism of sensitization and its neurophysiological extensions of kindling and excitotoxicity account for the deficient phenomena affecting for example the brain ${ }^{10}$ ? In my previous work, we tried to show that the neurophysiological mechanism of kindling, which is related to the limbic system and has been described in psychiatry by Post $(1992)^{11}$, initially in the context of manic-depressive psychosis, lends itself very well to such hypothesis. Post (1992) formulated the hypothesis of the neurophysiological mechanism of kindling in order to understand certain phenomena of mood disorders and other psychiatric disorders. Concerning mood disorders, he argued that a manic depressive illness can progress from a reactive mode of functioning toward an automatic mode of functioning. This happens through a series of affective episodes, which at first become reactions conditioned by specific circumstances. At a later stage, if these episodes are repeated with sufficient frequency, they become autonomous, in other words automatic. We should note that automatism depends on a state of excitation that has a tendency to self-perpetuate, hence the term "kindling." According to Post et al., the mechanism of kindling could be linked to a certain type of genes.

Stahl (2002, from p. 385) argues that this neuronal excitation can even become toxic and destroy certain neurons. According to this author, in some clinical situations such as schizophrenia, depression, bipolar disorder, panic disorder, Alzheimer's disease, Parkinson's disease, and others, this excitotoxicity provokes neuronal apoptosis and makes these conditions irreversible, at least to some extent. Excitotoxicity is indeed a pathological process of neuronal alteration and destruction (or neurotoxicity)

\footnotetext{
${ }^{10}$ Surely, the jouissance affects not only the brain, but the whole organism, since, as Lacan remarked (Lacan, 1972-1973), the jouissance is a manifestation of life. As we suggested previously, the brain is nor the subject, nor the person, despite the nowadays tendency to identify it to the latter. This is the reason, according to our hypothesis, that it could be affected-like other organs-by psychosomatic affections.

${ }^{11}$ Concerning the neurophysiological mechanisms of sensitization and kindling, we refer the reader to our article on Post's work (Dimitriadis, 2012b).
}

through the hyperactivation of glutamic acid and its analogs. However, we can see that the last author creates an amalgam between neurological (Alzheimer's and Parkinson's diseases) and psychiatric diseases (schizophrenia, depression, bipolar disorder, panic disorder), a danger we are trying to avoid by using the concept of the psychosomatic diseases of the brain. How to avoid such a confusion? We can consider psychiatric diseases as states, which are related, although not in a constant manner, to neurophysiological disorders, or even to neuropathological diseases that occur in the form of psychosomatic afflictions, which affect the brain. In the same way we consider that one intestinal disease may have a purely somatic origin whereas another might have a psychosomatic one, we can by the same token consider that some cerebral networks may be affected by a purely organic cause (neurological diseases), whereas some others, as in the case of some psychiatric disorders, may be affected by psychosomatic processes, by way of the kindling mechanism and its possible ecxitotoxicity outcome. Sometimes, the same cerebral circuits could be affected either by purely somatic causes, or by psychosomatic processes, and in that case, we can obtain resembling clinical configurations as we have previously suggested (Dimitriadis, 2013a), for example some catatonic-like states of a purely organic origin (such as the neuroleptic's malignant syndrome) which nevertheless possess some characteristics that resemble those of psychotic catatonic syndromes.

\section{THE SEMIOTIC REDUCTION}

Beyond these questions about the neurophysiological mechanism of sensitization, the theory of psychosomatic phenomena put forth by Lacan in Seminar XI (Lacan, 1964) takes into consideration Pavlov's classical conditioning which is, according to Kandel, an elaboration of the sensitization mechanism. Specifically, Lacan argues that in cases where the signifying chain has become solidified, the dialectic of desire comes to a halt and, as a consequence, the "signifier of the desire of the Other" acquires a kind of opacity and becomes enigmatic. In this situation, it stops referring to another signifier and instead of reinitiating the subject's dialectic of desire it turns into an inductor, a signal, inducing disruptions to the needs of the soma. Thus, Lacan relates Pavlov's theory of conditioning ${ }^{12}$ to his own hypothesis of the solidification of the signifying chain in psychosomatic phenomena. In other words, he believes that there is an analogy between the solidified signifier and the signal of the experimenter (who rings a bell instead of showing the meat) in Pavlov's scenario, which is trying to condition a dog, a domesticated animal, i.e., one that is sensitive to the signs coming from the human other. This theorization allows us to correlate Lacan's psychoanalytic theory on psychosomatic phenomena, firstly to semiotics, and secondly to neurophysiology. As we said before, in this kind of process, the signal, thus produced, acquires an imperative "capacity" for the subject and conditions its soma;

\footnotetext{
12 According to Pavlov (1954), there is an intricacy between two systems of signaling in the human being: one related to the image (shared with animals), and another proper to the human language, the signals of the signals.
} 
consequently, it can cause a disruption of the functions, even lesions.

When we talk about needs, we refer not only to hunger or the need for exemption. It is a matter of several homeostatic circuits of the organism that can be disturbed by desire and drive. We believe that we contribute to this question by generalizing the Lacanian theory, i.e., by positing that, by way of such a semiotic process, the brain's homeostatic circuits may be affected as well. That is to say that, in our opinion, the signal can condition not only the homeostatic circuits of the peripheral soma, but also those of the brain. We named the reduction of the signifier into the signal, or even into stimuli that self-maintain themselves, "semiotic reduction process" (Dimitriadis, 2013b,c). The tendency stimuli have to self-maintain themselves may be explained by way of the kindling mechanism we referred to before. As we will see below, the circuits that regulate our mood might be, in that regard, a preferential target.

\section{THE SEMIOTIC REDUCTION PROCESS AND PHANEROSCOPY}

We believe that this reduction process, from the signifier to the signal or to the stimuli can be explained with the aid of Pierce's Phaneroscopy ${ }^{13}$ (the theory of phenomenology's categories) (Peirce, 1978), and its three categories: firstness, secondness, and thirdness. Firstness is "the mode of being of what is, as it is, positively and with no reference to anything else." Secondness is "the mode of being of what is, as it is, in relation to a second, but without considering any third one." Thirdness is "the mode of being of what is, as it is, by putting a second and third one in a reciprocal relationship." Firstness relates to the immediate sentiment, secondness to reaction and to current events, and thirdness to language, law, and representation. Thirdness would be the strictly human category. The semiotics of the human being is determined by these ternary dialectics since the dialectics of his desire, processes like the co-modalization of different sensory fluxes, shared attention, play pretend, the so-called metarepresentations, jokes, the structures of kinship etc. are all ternary processes. In the case of animals, it is the secondness of the signals that determine their semiotic systems.

According to ethologist Vidal (2011), "these registers of signals, of which anyone is in close relation with the stimulus it signals, to such an extent that it functions in the same way, are derived from dyadic links systems or from the secondness principle, whereas stimuli themselves act solely as "monads," according to the principle of firstness." For the signals, shifting is restricted to a relationship of synchronic presence (temporal or spatial contiguity, for example), and not to a (diachronic) relationship in reference to the absence of something, words for example. The function of language, according to Lacan (1956), is not to inform but to evoke. Therefore, the natural or conditioned reflexes, and more generally, the immediate reactions to a signal, belong to the secondness category. Stimuli do not even need another signal in order to be efficient; they act in closed-circuit

\footnotetext{
${ }^{13}$ Other authors have used Pierce's Phaneroscopy categories in the field of psychopathology (Roulot, 1992; Balat, 2000; Delion, 2000; Muller, 2000).
}

(as monads) and are thus able to self-maintain themselves. With the help of Pierce's Phaneroscopy, we therefore suggest that several psychopathologies are related to a gradual transition from thirdness toward states that fall under the secondness or firstness category, a transition toward more and more automatic states. More precisely:

- On the semiotic level, going from thirdness to secondness would mean going from the signifier to the signal, and on the clinical level, producing conditioning phenomena, and more generally, reaction phenomena. In this regard we have some classical psychosomatic phenomena like the conditioned anxiety crises, some conditioning phenomena in the case of drug addicts, reactive depressions or reactive manic states, the repetition syndrome in traumatic neuroses, certain "actionlike "symptoms" etc.

- The transition from thirdness or secondness to firstness would even go beyond this reduction "stage." We could maybe say that we go from the signifier or the signal to the stimuli themselves. In this event, we have even more automatic states, like automatic mood disorders: e.g., stable delusional mood or athymhormia in the case of schizophrenia, maniac, and depressive states that have become autonomous from their initial triggering causes, automatic states of panic, some psychosomatic phenomena that are automatic etc. In all of these situations, the signs do not come from the other, unlike conditioning where there is the signal from the other that is the triggering factor. In this case, stimuli in a way self-maintain themselves.

Needless to say that we do not maintain that there is continuity between animal and man on the basis of such an eventuality of semiotic reduction. Thirdness, even in case of these extreme situations, does persist, since it plays a constituent role for the human being, who cannot escape from it. In human beings, ternary structures subjugate (and in some way, "de-naturize") ethological signaling systems (signals and stimuli). The fact that when thirdness is compromised as was the case in the states previously stated the human body makes itself sick, can be regarded as a strong proof of such an assertion.

\section{LOGIC OF THE SIGNIFIER VS. LOGIC OF THE SIGN}

Independently of Pierce's Phaneroscopy, we can specify this semiotic reduction process in relation to the psychoanalytic concepts of "deferred action" and "repetition." The symbolic, i.e., the signifiers' network of a particular subject, is not an enclosed system. Each encounter with chance may modify the string of its signifiers. Each signifier can change the whole of the signifying chain of a subject. In the case of psychoanalytic therapy, isolation of the signifier (of a padding button) may allow the subject to provide a new, retroactive meaning of his whole history. If we consider that for a given subject some signifiers have played a special role, they can be assigned different meanings during different stages of the subject's life, but they never cease being of decisive importance to the 
subject. However, this recurring re-determination, around the different possibilities the symbolic dictates to the subject, in the same time opens up new dimensions, on condition that the subject manages to "admit" to himself his inscription in the symbolic, i.e., that he manages to accept the limit of the castration that his personal story dictates for him. This logic is diachronic and of recurring retroaction, in the sense that the end result can influence its own cause and change it after the fact ${ }^{14}$. On the other hand, the logic of the signal or that of the sign is a linear logic, valid for the reflexes, be they natural or conditioned, and entails an objectification, a certain universality of reactions. This logic also entails a synchrony and/or a spatial contiguity and determines the learning process in animals.

We may therefore consider the "semiotic reduction" also in relation to its consequences regarding the termination of the "padding" by the signifying chain. As we have seen, the end of the padding may occur in various situations. The padding buttoning dictates a subjective and diachronic assumption as far as it puts in relation through the signifiers. The padding is also an assumption of contingency, of whatever new happens to the subject. According to Lanteri-Laura's expression (Lanteri-Laura, 1992), it is therefore a creative automatism ${ }^{15}$. When the padding buttoning stops, the encounter with the signifiers of the desire of the Other, as we stated previously with regard to psychosomatic phenomena, acquires a certain objectivity and a certain reality of presence, the latter having the force of an order, in other words the characteristics of a signal. These frozen and "imperative" signifiers are pseudo-signifiers, "cut off" from the subject's history (diachrony). They are actually signals that can trigger psychosomatic processes. This is another way of conceiving the "actual neuroses," since the signals, unlike the signifiers, act in a synchronic and actual manner. At this stage, the jouissance in relation to the signification obtained in deferred action (of the mediation of the Other), that is to say the phallic jouissance (that has an out of body component), fades in favor of a jouissance of the body (of life) that is erratic and deregulated. Thus, the laws of life, in this case those of the human organism, can freely reveal themselves, instead of being subsumed and "de-naturized" by the effects of signification as before. And the physiological mechanisms (related, amongst others, to different processes like conditioning and kindling) can emerge spontaneously in the form of classical psychosomatic phenomena, various psychotic phenomena, panic attacks, addictive phenomena, posttraumatic phenomena, mood excesses, etc. More specifically, in the case of mood disorders the semiotic reduction (or the stop of the padding buttoning) might be that the affects, which are linked to the subject's signifiers-although in an indirect manner-lose that connection; they become estranged from the signifying function, thus transforming themselves into emotions (of secondness order) or into mood (of firstness order).

\footnotetext{
${ }^{14}$ Ansermet and Magistretti (2010a) have written about this operation, in connection to neuroplasticity.

${ }^{15}$ See also Dimitriadis (in press).
}

\section{THE DIALOGUE BETWEEN NEUROSCIENCES AND PSYCHOANALYSIS}

Alain Vanier begins the preface of a book (Dimitriadis, 2013b) with the following paragraph:

Ansermet and Magistretti (2011) distinguish between four possible positions in order to work toward an articulation of neurosciences with psychoanalysis.

- In the first place, that of an "absolute heterogeneity" which leads to neurology absorbing part of psychiatry, since it implies an exclusive alternative between psychical "or" neurological atiology; in other words, nothing more than the old antagonism between psychogenesis and organogenesis. They observe in this respect that the question of the subject remains unresolved.

- Another approach is "superposition," which favors an analogical model, this time without leftovers: this is the neuropsychoanalysis orientation.

- Thirdly, a "joining" model, which offers a potentially very rich perspective that, includes a certain idea of complexity.

- Finally, an approach that consists of a "crossroads of two heterogeneous orders" which is the subject of their studies (Ansermet and Magistretti, 2004, 2010b), with no hope of a "unified science," to use Pierre Fédida's words ${ }^{16}$ as quoted in the publication. An interdisciplinary approach then, in a perspective where neurosciences and psychoanalysis are two very distinct fields, presenting some intersection points from which we can question their respective limits (Dimitriadis, 2013b, p. 9-10).

We criticized the first position (Dimitriadis, 2013b), which is adopted, among others, by Zénoni (1998), when he sustains the abolition of the anatomical and the biological, as far as he considers those fields irrelevant in regard to the causality of the human body's behavior-and the radical separation from animal determinism. He states for example: "There is no clash between biology and psychoanalysis because there is no conflict of jurisdiction between them. A clinical phenomenon's causality falls within the jurisdiction of either psychoanalysis or biology, it never proceeds from the interaction of the two." We also criticized the second position (Dimitriadis, 2013b, 2015b), which can be found within the clinical-anatomical correlation method of Kaplan-Solms and Solms (2002), according to which the issue is to find anatomical connections between Freudian concepts and cerebral structures. The hypotheses presented in this paper, in regard to the concept of jouissance, fall under the fourth position. The intersection we have chosen is the concept of jouissance, in order to question the intricacy between the psychical factors and the purely organic ones-some genetic-within the development of some psychopathological phenomena, in relation to the potentially destructive effect of an excess of jouissance on the

\footnotetext{
16 "where comparative epistemology of the models and their critical theoretical functioning would play the deciding role into realizing their operative limits and their aptitude to be transformed reciprocally; in which case, the aim would be a mutual communication rather than the aspiration toward a unified science," Fédida (1992), p. 295
} 
organism, more particularly on the brain, although destruction can reach other organs and functions, even life itself.

This type of approach seems important given the importance biological psychiatry has nowadays acquired within the field of psychiatry, whose studies are mostly about the brain, all the more so as psychotropic drugs work mainly on that level. According, for example, to Morin (2017), it is reasonable to ask ourselves if some psychoanalytical postulates, like childhood amnesia, are compatible with what is actually known about the brain. The author, a neurologist and psychoanalyst who worked by means of her psychoanalytical listening with patients with cerebral lesions, speaks in the same book of the benefit of a non-integrative approach (between neurology and psychoanalysis) in the case of some of these particular patients; an approach which, according to the author, could instruct us as to the impact of the body's image in identifications.

The approach we have chosen might contribute to a new distinction between neurology and psychiatry ${ }^{17}$, because today several researchers ${ }^{18}$ are looking forward to a new integration of the two fields. It could be of help to the study and explanation of certain pathologies which are on the fringes of neuro-psychiatry (e.g., catatoniform phenomena, athymhormia, mental confusion... ${ }^{19}$ ). It could also boost the study of biological vulnerability-genetic or epigenetic amongst others-in relation to psychopathologies. There could be for example some kind of dialogue with the genetic studies of Crow $(2000,2002)$ who maintains that schizophrenia is the price man has to pay for the ability to speak. If we were to follow Crow's viewpoint, language and the schizophrenic being are two sides of the same coin; Lacan (1946) affirmed the same thing (even though from a point of view quite distant from Crow's) in his address at the Bonneval Colloquium when he maintained that the man cannot be understood without insanity.

This approach could be of help for the double "therapies," i.e., when a psychoanalytic cure is combined with the prescription of biological treatment by a medical doctor ${ }^{20}$, especially in defining the respective limits of those two oh so different approaches. It could also contribute to studies that look into the clinical effect of psychotropic drugs, as it can be perceived in transference ${ }^{21}$. This research begun in the 60's by some psychiatrists that worked also as psychoanalysts ${ }^{22}$, and is still ongoing ${ }^{23}$.

\section{FINAL REMARKS}

Can the term "kindling" be directly referred to the notion of jouissance? Such a claim would of course be unjustified and we have critiqued precisely this type of amalgamation of

\footnotetext{
${ }^{17}$ In France, these two specializations are considered distinct since 1968.

${ }^{18}$ See, for instance, Price et al. (2000).

${ }^{19}$ See Dimitriadis (2013a).

${ }^{20}$ See Dimitriadis (2014).

${ }^{21}$ Incidentally, the prescription of anti-epileptic drugs in the case of mood disorders has increased firstly because of some observations by Lambert et al. (1966) about Depamide $\AA$, and secondly in connection with Post's research concerning the kindling mechanism, which was initially conceived by Goddard (1981), in relation to epilepsy.

${ }^{22}$ See, for instance, Conté (1963), and Green (1961).

${ }^{23}$ See, for instance, Kapsambelis (1994) and Dimitriadis (2014).
}

concepts from different epistemic fields in my previous work (Dimitriadis, 2013b, 2015b). However, if we were to think about a neurophysiological mechanism that could account for the neurobiological support of jouissance-as a phenomenon of the living being-a mechanism of this kind (of reverse tolerance, like kindling) might be suitable. Bazan et al. (2016) have also suggested to instantiate jouissance physiologically, namely through the reward system of the mesolimbic pathway. This system can register a hypersensitivity for action that has previously been sealed by an experience of satisfaction and a jubilatory release of dopamine. However, the system also dissociates action from its results, which makes it structurally bound to produce derailments (the phenomenon of autoshaping), just like jouissance involves a derailment on the clinical level. In other words, it is the activation of the drive, a unique state of wanting and anticipation, that is intrinsically gratifying yet not pleasing - in the common sense of the termand this pleasure of the drive fits very well with the notion of jouissance. These authors refer to the works of Robinson and Berridge (1995), who suggested that the key change in addiction had to do with a hypersensitization, via the long-term adaptations in the circuits of the mesolimbic dopaminergic system. Their theory of "incentive salience" shows the malleability of the mesolimbic dopaminergic to historical imprints, i.e., the mark through which the drive insists and commemorates at the same time. The development of an addiction would then be a concrete example of this dissociation: a situation where the drug becomes an object of pathological want even though its appreciation continues to decline. Yet the authors do not try to create an equivalence between the theoretical corpus and a physiological circuit, because psychical regularities become autonomous from physiology, even though the body imposes certain constraints on the constitution of the psyche. We should point out that while we have worked a priori independently from these authors, we have come to similar conclusions with respect to the type of physiological mechanism (sensitization) which, rather than explain can "prepare the grounds" for the types of repetitive phenomena and even neuronal destruction that we have described as the psychosomatic phenomena of the brain ${ }^{24}$. More specifically, we have put forth a hypothesis (Dimitriadis, 2013b,c) of the "brain's psychosomatic participation" ${ }^{25}$, which could potentially also be applied to psychopathological contexts other than manic-depressive psychosis (e.g., schizophrenia ${ }^{26}$, addictions, depression ${ }^{27}$, catatonia ${ }^{28}$, repetitive panic attacks, traumatic neurosis, and others).

Why then not presume that under certain conditions, where there is a "foreclosure of the Name-of-the-Father" or the signifying chain becomes "solidified," the laws of the organismsuch as the processes of "sensitization" and "conditioning" — can

\footnotetext{
${ }^{24}$ It is perhaps also not a coincidence that among the first psychoanalytic works on the search for neuronal mechanisms-that could be related to certain psychic processes-we find Lawrence Kubie's work (Kubie, 1941) on the repetition in neurosis. According to some authors (for example, Le Roux, 2007), Lacan was familiar with Kubie's theory of "reverberating closed circuits."

${ }^{25}$ Silvano Arieti discussed this possibility as early as in the 1960s. For a review of the literature on the prehistory and history of this hypothesis, see Dimitriadis (2012a).

${ }^{26}$ See Dimitriadis (2013b,c, 2015a).

${ }^{27}$ See Dimitriadis (2014).

${ }^{28}$ See Dimitriadis (2013a).
} 
"switch on" and produce occasional deficits or even sequelae. As we have argued earlier, sensitization and conditioning could be considered as processes of "semiotic reduction." In this same way, why not consider that certain phenomena of automatism and certain deficits (delusional moods, schizophrenic apathy, etc.) in the context of the psychoses (but not only) could be seen as psychosomatic disorders of the brain. The phenomena in question could also serve-albeit in random ways-as a kind of shield that mitigates excess jouissance. Calling these "deficient phenomena" might appear somewhat pejorative; however, the "psychotic prognosis" is often pejorative as well. This does not prevent such phenomena from being able to facilitate a certain stabilization, as if in these cases the de-symbolized body, i.e., the soma, "treated itself", trying to pacify the excess of jouissance. In other words, if the Name-of-the-Father does not provide a "desensitizing medication" (as Lacan evoked in terms of Oedipus), the body can sometimes produce a condition that "functions" as this kind of medication via the psychosomatic suppléance, namely an illness of the brain that affects mood, motor skills and so on. Does this mean that in such cases we could speak about the suppléances of the Real of the body? In other words that, in the absence of another suppléance or compensation coming from the Symbolic, the Imaginary or the Real, the Real of the body self-mutilates and disconnects from the Other-and from his jouissance.

\section{CONCLUSIONS}

To sum up the "types" of jouissance discussed above, we could say that we can distinguish three aspects of jouissance in Lacan's teaching: (1) a jouissance that is linked to signifiers, i.e., "phallic jouissance," which is subject to castration and the Name-ofthe-Father; (2) a jouissance prior to the relationship with the (non-barred) Other, one that is below [en deçà] the level of the signifiers and refers to the first experiences with the Other, i.e., the jouissance of the "Freudian Thing" that is inscribed in the body as traces (and is therefore the jouissance of the body), but at the same time cannot be named and therefore remains a myth. This "jouissance of Being" can only be deduced retrospectively, following the subject's division by the signifier, but the subject can no longer access it and it is therefore impossible. Finally, (3) a jouissance beyond signifiers, beyond the functioning of the Phallus and the Name-of-the-Father. This is the supplementary "Other jouissance," accessible to women and mystics, which is

\section{REFERENCES}

Adam, R. (2005). Lacan et Kierkegaard. Paris: PUF.

Ansermet, F., and Magistretti, P. (2004). A chacun son cerveau: plasticité neuronale et inconscient. Paris: Odile Jacob.

Ansermet, F., and Magistretti, P. (2010a). “Quel inconscient?”, in Neurosciences et Psychanalyse, eds P. Magistretti and F. Ansermet (Paris: Odile Jacob), 195-199.

Ansermet, F., and Magistretti, P. (2010b). Enigmes du Plaisir? Paris: Odile Jacob.

Ansermet, F., and Magistretti, P. (2011). "Psychanalyse et psychiatrie," in Conférence inédite au séminaire Méthodologie et épistémologie (Paris).

Balat, M. (2000). Psychanalyse, Logique, Éveil de Coma: Le Musement du Scribe. Paris: L'Harmattan (coll. « ouverture philosophique 》). beyond language and which speaking beings cannot articulate in words, even though women can feel it, although not all women. However, this Other jouissance is logically conditioned by the phallic function, even though it lies beyond this function: it exceeds language, but is not exempt from it.

Nevertheless, the jouissance underneath language (prediscursive but not preverbal), the jouissance of the living, always remains subjacent, acting like a "parasite" toward other types of jouissance. It can have destructive effects on the body through physiological mechanisms that we tried to sketch out using the neurophysiological phenomenon of kindling, where the excess of excitation can produce toxicity, causing neuronal destruction. This kind of neuroplasticity, which we have described heuristically as the "psychosomatic disease of the brain" could affect, among others, brain structures related to affects, which would thus be reduced to emotions and moods. Through this same process, signifiers would be reduced, respectively, to signals, which in turn could be reduced to stimuli, with a tendency toward self-perpetuation. This would be a special mechanism of mental automatism, which could be triggered under the specific conditions of the fragility of the signifying chain (foreclosure of the Name-of-the-Father or solidification), in combination with biological factors, including genetic factors. Let us then give the last word to Freud, who writes, in Draft K (Freud, 1896a, p. 146): "I should say that heredity is an extra determinant in so far as it facilitates and increases the pathological affect-the determinant, that is, which in general makes possible the gradations between the normal and the extreme case. I do not believe that heredity determines the choice of the particular defensive neurosis."

\section{AUTHOR CONTRIBUTIONS}

The author confirms being the sole contributor of this work and approved it for publication.

\section{ACKNOWLEDGMENTS}

This work was supported by the Research Center for Psychoanalysis and Society, EA3522 and from the "UFR Psychoanalytic Studies, University Paris-Diderot Sorbonne-Cité, Paris, France." I would like to thank Ioanna M. Mastromina and Lyn J. Murphy for their help with manuscript preparation.
Bazan, A., Detantd, S., and Askari, S. (2016). Pour une physiologie de la jouissance. L'évol. Psychiatr. 81, 777-787. doi: 10.1016/j.evopsy.2015.06.002

Braunstein, N. (1994). La Jouissance, un Concept Lacanien. Paris: Point hors ligne. Braunstein, N. (2003). "Desire and jouissance in the teaching of Lacan" in The Cambridge Companion to Lacan, ed J.-M. Rabaté (Cambridge: Cambridge University Press), 102-115.

Conté, C. (1963). Psychoses délirantes et Neuroleptiques, Remarques sur le processus thérapeutique. Encéphale 7, 65-86.

Crow, T. J. (2000). Schizophrenia as the price that Homo sapiens pays for language: a resolution of the central paradox. Brain Res. Rev. 31, 118-129. doi: 10.1016/S0165-0173(99)00029-6

Crow, T. J. (ed.). (2002). The Speciation of Homo Sapiens. Oxford; New York, NY: British Academy. 
Delion, P. (2000). L'enfant Autiste le Bébé et la Sémiotique, lère Édn. Paris: PUF; (coll. « Le fil rouge 》).

Dimitriadis, Y. (2012a). Histoire d'un concept heuristique: Les affections psychosomatiques du cerveau. Psychiatr. Neurosci. Sci. Hum. 10, 63-76.

Dimitriadis, Y. (2012b). Les travaux de Robert M. Post sur le kindling (embrasement), la sensibilisation et le conditionnement. Ann. Méd. Psychol. 170, 296-298. doi: 10.1016/j.amp.2012.04.002

Dimitriadis, Y. (2013a). Sur certains enjeux du diagnostic de catatonie. Topique 123, 125-138. doi: 10.3917/top. 123.0125

Dimitriadis, Y. (2013b). Psychogénèse et Organogénèse en Psychopathologie: une Hypothèse Psychanalytique D'affections Psychosomatiques du Cerveau. Paris: L'Harmattan.

Dimitriadis, Y. (2013c). Le concept heuristique d'affection psychosomatique du cerveau. L'évol. Psychiatr. 78, 290-300. doi: 10.1016/j.evopsy.2012.09.007

Dimitriadis, Y. (2014). "Sur la problématique d'un éventuelle processus psychosomatique impliqué dans la dépression." Figures Psychanal. 28, 73-85. doi: $10.3917 /$ fp.028.0073

Dimitriadis, Y. (2015a). Sur une hypothèse psychanalytique d'intrication de facteurs génétiques, épigénétiques et acquises dans la transmission de la schizophrénie. Rev. Psychiatr. Psychanal. Soc. 3.

Dimitriadis, Y. (2015b). La dite neuro-psychanalyse est-elle une liaison dangereuse? Le Coq Héron 222, 64-71. doi: 10.3917/cohe.222.0064

Dimitriadis, Y. (in press). De l'automatisme du déficit à l'automatisme créateur. Ann. Méd. Psychol.

Ehrenberg, A. (2004). Le sujet cérébral. Esprit 11, 130-155.

Fédida, P. (1992). Crise et Contre Transfert, Paris: PUF.

Freud, S. (1896a). "Draft K. the neuroses of defense (a christmas fairy tale)," in The Origins of Psychoanalysis: Sigmund Freud's Letters-Letters, Drafts and Notes to Wilhelm Fliess (1887-1902), eds M. Bonaparte, A. Freud, and E. Kris (London: Imago), 146-155.

Freud, S. (1896b). "Letter from Freud to Fliess," in The Complete Letters of Sigmund Freud to Wilhelm Fliess, 1887-1904, ed J. Masson (Cambridge: Harvard University Press), 207-214.

Freud, S. (1921). Group Psychology and the Analysis of the Ego. Standard Edition, Vol. XVIII. London: Hogarth Press, 65-144.

Freud, S. (1925). A Note Upon the 'Mystic Writing-Pad'. Standard Edition, Vol. XIX. London: Hogarth Press, 225-232.

Freud, S. (1950). Project for a Scientific Psychology (1950 [1895]). Standard Edition, Vol. I. London: Hogarth Press, 281-391.

Goddard, G. (1981)., "The continuing search for mechanism," in Kindling 2nd Edn, ed W. J. Wada (New York, NY: Raven Press) 1-14.

Green, A. (1961). Chimiothérapies et psychothérapies, Problèmes posés par la comparaison des techniques chimiothérapiques et psychothérapiques et leur association en thérapeutique psychiatrique. L'Encéphale 50, 29-101.

Jadin, J. M., and Ritter, M. (2009). La Jouissance au Fil de L'enseignement de Lacan. Paris: Erès.

Kandel, E. (1991). "Cellular mechanisms of learning and biological basis of individuality," in Principles of Neural Sciences, 3rd Edn, eds E. R. Kandel, J. H. Schwartz, T. M. Jessell (New York, NY; Amsterdam; London; Tokyo: Elsevier).

Kaplan-Solms, C., and Solms, M. (2002). Clinical Studies in Neuro-psychoanalysis, Introduction to a Depth Neuropsychology. London: Karnac.

Kapsambelis, V. (1994). Les Médicaments du Narcissisme, Plessis-Robinson: Synthélabo, (coll. «Les empêcheurs de penser en rond 》).

Kubie, L. (1941). The repetitive Core of Neurosis. Psychoanal. Q. 10, 23-43.

Lacan, J. (1938). "Les complèxes familliaux," in Encyclopédie Française, tome VIII, Paris: La vie mentale, Société de gestion de l'Encyclopédie Française, 8.40-5/8.40-16-8.42-1/8.42-8.

Lacan, J. (1946). "Presentation on psychical causality," in Écrits: The First Complete Edition in English. Transl. by B. Fink (New York, NY: Norton), 123-160.

Lacan, J. (1949). "The mirror stage as formative of the $i$ function as revealed in the psychoanalytic experience," in Écrits: The First Complete Edition in English. Transl. by B. Fink (New York, NY: Norton), 75-81.

Lacan, J. (1956). "The function and field of language and speech in psychoanalysis," in Ecrits: The First Complete Edition in English. Transl. by B. Fink (New York, NY: Norton), 197-268.

Lacan, J. (1957-1958). Le Séminaire, Livre V, Les formations de Linconscient, Texte Établi Par Jacques-Alain Miller. Paris: Seuil, 1998.

Lacan, J. (1959-1960a). The Seminar, Book VII, The Ethics of Psychoanalysis (1959-1960). Transl. by D. Porter (New York, NY: Norton), 1997.

Lacan, J. (1959-1960b). Compte Rendu avec Interpolations du Séminaire de l'Éthique. Ornicar, Revue du Champ freudien. 28, Paris: Navarin, 7-18.

Lacan, J. (1960a). "Remarks on daniel lagache's presentation" in Ecrits: The First Complete Edition in English. Translated by B. Fink (New York, NY: Norton), 543-574.
Lacan, J. (1960b). "The subversion of the subject and the dialectics of desire," in Ecrits: The First Complete Edition in English. Transl. by B. Fink (New York, NY: Norton), 671-702.

Lacan, J. (1962-1963). The Seminar, Book X, Anxiety. Trans. by A. Price (Cambridge: Polity Press).

Lacan, J. (1964). The Seminar, Book XI. The Four Fundamental Concepts of Psychoanalysis. Transl. by A. Sheridan (New York, NY: Norton).

Lacan, J. (1966-1967). La logique du Fantasme. Unpublished seminar.

Lacan, J. (1967). Psychanalyse et médecine. Lettres de L'Ecole Freudienne 1, 34-61.

Lacan, J. (1969-1970). The Seminar, Book XVII, The Other Side of Psychoanalysis.

Transl. by R. Grigg (New York, NY: Norton).

Lacan, J. (1971-1972). “... ou Pire” in Autres Écrits. Paris: Seuil.

Lacan, J. (1972-1973). The Seminar, Book XX, Encore. The Limits of Love and Knowledge. Transl. B. Fink (New York, NY: Norton).

Lacan, J. (1973-1974). Les non Dupes Errent. Unpublished seminar.

Lacan, J. (1974-1975). RSI. Unpublished seminar.

Lacan, J. (1975). La Troisième. Lettres de l'École freudienne de Paris, 16.

Lacan, J. (1989). Geneva Lecture on the Symptom (1975). Analysis 1, 7-26.

Lambert, P., Carraz, G., Borselli, S., and Carbel, S. (1966). Action neuropsychotrope d'un nouvel anti-épilétique: le dépamide. Ann. Méd. Psychol. 1, 707-710.

Lanteri-Laura, G. (1992). "La notion de l'automatisme dans la médicine et dans la psychiatrie moderne," in Autonomie et Automatisme Dans la Psychose, ed H. Grivois (Paris: Masson), 7-29.

Le Roux, R. (2007). Psychanalyse et cybernétique. Les machines de Lacan. L'évol. Psychiatr. 72, 346-369. doi: 10.1016/j.evopsy.2007.04.005

Miller, J. A. (1999). Les six paradigmes de la jouissance. La Cause Freudienne 43, $7-29$.

Miller, J. A. (2008). Tout le Monde est Fou, Unpublished seminar.

Morin, C. (2017). L'homme et son Cerveau. Paris: Odile Jacob.

Muller, J. (2000). Hierarchical models in semiotics and psychoanalysis. Psychoanal. Psychiatry Hum. 15, 49-67.

Pavlov, I. (1954). La Raison, Numéro spécial, 8, Cycle de cours sur les Travaux de I.P. Paris: Pavlov.

Peirce Ch, S. (1978). Ecrits sur Le Signe: Rassemblés, Traduits et Commentés Par Gérard Deledalle. Paris: Seuil.

Post, R. (1992). Transduction of psychosocial stress into the neurobiology of recurrent affective disorder. Am. J. Psychiatry 149, 999-1010. doi: 10.1176/ajp.149.8.999

Price, B. H., Adams, D., and Coyle, J. T. (2000). Neurology and psychiatry: closing the Great Divide. Neurology 54, 8-14. doi: 10.1212/WNL.54.1.8

Robinson, T. E., and Berridge, K. C. (1995). The psychology and neurobiology of addictions: an incentive sensitization view. Addictions 2000, 91-117.

Roulot, D. (1992). "Secondéité pure et univers schizophrénique," in Signs of Humanity, Vol II, eds M. Balat, J. Deledalles-Rhodes, G. Deledalles, (Berlin: Mouton de Gryter), 1087-1096.

Soler, C. (1991-1992). Seminar at the Department of Psychoanalysis, Clinical Section, University of Paris VIII. Unpublished.

Stahl, S. (2002). Psychopharmacologie Essentielle. Paris: Flammarion.

Valas, P. (1998). Les di(t)Mensions de la Jouissance. Paris: Erès.

Vidal, F. (2005). Le sujet cérébral: une esquisse historique et conceptuelle Psychiatr. Sci. Hum. Neurosci. III, 37-48 doi: 10.1007/BF03006830

Vidal, J.-M. (2011). La tiercéité symbolique, fondement de la discontinuité psychique entre animaux et humains. Rev. Fr. Psychanal. 75, 17-51. doi: $10.3917 /$ rfp.751.0017

Zénoni, A. (1998). Le corps de L'être parlant. De L'évolutionnisme à La psychanalyse, 2éme Édn, Paris; Bruxelles: De Boeck.

Conflict of Interest Statement: The author declares that the research was conducted in the absence of any commercial or financial relationships that could be construed as a potential conflict of interest.

The reviewer, JF, and handling Editor declared their shared affiliation.

Copyright (c) 2017 Dimitriadis. This is an open-access article distributed under the terms of the Creative Commons Attribution License (CC BY). The use, distribution or reproduction in other forums is permitted, provided the original author(s) or licensor are credited and that the original publication in this journal is cited, in accordance with accepted academic practice. No use, distribution or reproduction is permitted which does not comply with these terms. 


\title{
The Lacanian Concept of Cut in Light of Lacan's Interactions with Maud Mannoni
}

\author{
Laure Razon ${ }^{1 \dagger}$, Olivier Putois ${ }^{1,2 * t}$ and Alain Vanier ${ }^{3}$ \\ ${ }^{1}$ Université de Strasbourg, SuLISOM EA 3071, Strasbourg, France, ${ }^{2}$ Department of Psychiatry, Mental Health and \\ Addictology, Strasbourg University Hospital, Strasbourg, France, ${ }^{3}$ CRPMS EA 3522, Department of Psychoanalytic Studies, \\ Paris Diderot University, Sorbonne Paris Cité, Paris, France
}

This article sets out to shed light on the Lacanian concept of cut (introduced in 1961-1962): it refers to the symbolic (i.e., linguistic) operation which produces the object $a$ and thereby enables separation, through which the subject emerges. To that effect, we show how this concept benefitted from Lacan's interactions with Maud Mannoni (1923-1998), who focused on clinical situations where implementing a cut in the subject's environment is the only way to enable a separation between the child and the Other. Lacan first drew on Mannoni's clinical elaborations about the retarded child's alienation to the maternal fantasy: when the mother's unconscious doesn't leave room for the cut, it prevents the separation through which the child could become a subject. Lacan generalized this in the late 1960s: he broadened Mannoni's alienation to the maternal fantasy to characterize a type of child symptom, where children become their mother's non-separated, de-phallicized object $a$. Then, in the 1970s, Mannoni proposed an original theoretico-clinical setting to address the configurations where the object a isn't separated: in the splintered institution, the team follows on projects of activities (professional, personal, etc.) outside the institution voiced by children who haven't previously encountered the symbolic cut, by helping them realize these external projects. By thus acknowledging their attempts at establishing a cut and giving them consistency, the splintered institution helps them psychically elaborate separation.

${ }^{\dagger}$ These authors have contributed equally to this work as co-first authors.

Specialty section: This article was submitted to

Psychoanalysis and Neuropsychoanalysis, a section of the journal Frontiers in Psychology

Received: 04 September 2017 Accepted: 29 November 2017 Published: 14 December 2017

Keywords: cut, psychosis, family, Lacan, Maud Mannoni, mental retardation, maternal fantasy, object a

\section{INTRODUCTION}

Lacan introduced the notion of cut in the early 1960s: its refers to the operation (broader than castration, both in scope and in nature) through which the infant's mothering figure (the maternal or primordial Other) enables psychical separation, by introducing the infant to a representation of him as symbolically distinct from her. Receiving this representation enables the infant to ultimately acknowledge his separation from her body; in Lacan's view, only then does the infant become a subject.

In this paper, we shed light on the theoretical and clinical fruitfulness of this concept of cut by addressing it from a specific perspective: that of the cases where the paradigm representation enabling the cut-the Name-of-the-Father, Lacan's rewriting of the Oedipus complex-isn't transmitted to the infant, thereby precluding the cut to be established in the child's psyche. How should one characterize such cases? Our hypothesis is that Maud Mannoni's clinical and theoretical 
elaborations on the psychotic dimension of such cases, which took place in a constant exchange with Lacan, provided him with crucial clinical material to conceptualize such situations and give the concept of cut its final shape. In return, she used Lacan's concept of cut in a very original fashion, by putting together a new type of institution trying to enable the emergence of the cut within the unconscious of children not heretofore presented with the Name-of-the-Father, by providing them with representations to implement the cut according to their structure (neurotic, psychotic, perverse, or autistic).

We first lay out the concept of cut as Lacan established it in the early 1960s, and insist on its paradigm conditionthe Name-of-the-Father. We then show how Lacan first drew on Mannoni's clinical elaborations about the retarded child's alienation to the maternal fantasy: when this fantasy doesn't leave room for a paternal cut, it prevents the separation through which the child could become a subject. He expanded on this in the late 1960s, in the first "Note on the Child:" the child can come to embody the object of the maternal fantasy and thereby become the mother's non-separated, de-phallicized object $a$-which these cases help characterize. Finally, we show how Mannoni, in the 1970 s, proposed an original theoretico-clinical setting to address the configurations where the cut hasn't been implemented due to a lack of paternal metaphor, and the object $a$ therefore hasn't been separated. The splintered institution is a therapeutic setting which assumes the cut by taking up desires of outside projects expressed by its young hosts: children are accompanied outside to participate in projects wherein they identify with a different representation of themselves, and thereby experience themselves as separated.

\section{THE CUT ACCORDING TO LACAN, IN THE EARLY 1960S}

\section{Alienation, A Precondition to the Cut}

The Lacanian concept of cut, or better the "function of the cut" (Lacan, 1998a, p. 206), refers to a structural sequence: it is not an event taking place at a determinate time in individual development, but a logical moment in the constitution of the subject. It is the result of the encounter between a real infant and the family and social configuration with which the infant is presented by the Other. (The term Other refer to the infant's primitive environment, the mother or the mothering adult).

The function of the cut is to enable the constitution of the subject through separation with the Other-we will come back to this point in detail. This separation has a prerequisite: the first sequence of the constitution of subjectivity, which Lacan calls "alienation" (Lacan, 1998a). Upon meeting the Other, the infant is exposed to language: in responding to his cries and behavior, the Other names him, he refers to him. In this exchange, the infant comes to realize that in order to become a subject, he must use what Lacan calls signifiers (characteristic of the symbolic order) - they are the discrete elements of language considered as different sounds, independently of their usual socially determined meaning. In particular, the infant gradually sees that in order to interact with the Other, he must endorse the signifier through which the Other designates him, called the primary or master signifier $\left(S_{1}\right)$ - the future object of primary repression. Lacan calls this operation « alienation 》 not only because the infant, generally speaking, receives the discourse of the Other through his speech, but most importantly because in this encounter with the Other, he receives a specific signifier $\mathrm{S}_{1}$, the assumption of which conditions his existence for the Other, and in particular communication with him. The signifier "functions as a signifier only by reducing the subject in question to being no more than a signifier, to petrify him in the same movement it calls the subject to function, to speak, as subject" (Lacan, 1998a, p. 207, mod. tr.).

The question then becomes, in order for the infant to become a subject properly speaking, to know what he represents for the Other, what the Other « wants from him 》(Lacan, 2014)— that is, what is the meaning of this $S_{1}$ which designates him? Since a single signifier, as such, has no meaning, $S_{1}$ can only acquire one by becoming part of a series of other signifiers coming from the Other (Lacan calls $\mathrm{S}_{2}$ the ensemble of these additional signifiers). In other words, alienation does not suffice to constitute the subject because, far from enabling the infant to gain access to a knowledge of what he is, it instead opens him to a never-ending series of equivalences between $S_{1}$ and $S_{2}$. It is this series of equivalences that enables the explorations of infantile curiosity (Lacan, 1998a, part 3), and more generally accounts for the effects of metaphor and metonymy through which formations of the unconscious can be interpreted.

\section{The Cut and the Desire of the Other}

It is at this very point, in these "intervals which cuts between the signifiers" $S_{1}$ and $S_{2}$ (Lacan, 1998a, p. 214, mod. tr.) that the second part of the structuring effect of the signifier on the subject comes to play: that is, the function of the cut. Endorsing $\mathrm{S}_{1}$ opens a $\ll$ Spaltung [splitting] in the subject 》 (Lacan, 1998a, p. 63): he becomes cut, « divided $\gg$ because the relationship between $S_{1}$ and $S_{2}$, far from being immediately obvious (since they both lack intrinsic meaning), only makes sense through metaphorical and metonymical equivalences within a specific network of signifiers which characterizes the constellation laid out by the Other specific to every subject. The unconscious effect of any $S_{1}$ will thus depend, for each subject, on the $S_{2}$ with which it is paired.

Thus, the constitution of the subject requires the cut in addition to alienation because the interval between $S_{1}$ and $S_{2}$, the repressed primary signifier and its equivalents in the discourse of the Other, draws on equivalences that are specific to the discourse of every particular Other, the desire of whom is the key to understand these equivalences. "It is in the interval between these two signifiers that resides the desire offered to the mapping of the subject of the discourse of the Other, of the first Other he has to deal with, let us say, by way of illustration, the mother" (Lacan, 1998a, p. 218). Thus the cut enables the constitution of the subject by leading the infant to wonder what the desire of the maternal Other is, what she wants from him (this question drives the analytic process, which will regressively lead to discover what one's $S_{1}$ is, as well as the ultimately arbitrary, contingent nature of its equivalences with $S_{2}$ ). "It is in so far as [the subject's] desire 
is beyond or falls short of what she says, of what she hints at, of what she brings out as meaning, it is in so far as his desire is unknown, it is in this point of lack, that the desire of the subject is constituted" (Lacan, 1998a, p. 218).

\section{The Fort-Da: Separation as an Effect of the Cut, and the Introduction of Object a}

Lacan believed that the subject's question about the desire of the Other, located in the cut between signifiers, can be paradigmatically illustrated by the sequence of the Freudian reel play (the $\ll f o r t-d a \gg$ ). This sequence illustrates the dependence of the subject's being on the desire of the Other.

In Beyond the Pleasure Principle (Freud, 2001, written in 1920), Freud describes how an 18-months infant-most likely his grandson Ernst-symbolizes the absences of his mother by playing with a reel attached to a string, thereby gradually enabling the introjection of the absented parent. Upon throwing the reel away from his cradle, he gives vent to a loud $\ll$ O-O-O-o $\gg$ (which means "fort" [away] in German), before pulling it back into view and hailing its appearance with a gleeful "Da !" (“There !”). In analyzing the infant's play, and in particular the substitution of the reel to the absent mother, Freud insists on the psychical achievement of becoming able to acknowledge her absence and to withstand it, by figuratively becoming the agent of this absence (in throwing the reel away).

But for Lacan, compensating for her absence by converting passivity into activity is "of secondary importance" (Lacan, 1998a, p. 62). He starts by pointing that the second step of the play (the "da!"), by introducing a phonemic alternation, represents the comings and goings through a pair of signifiers, $\mathrm{S}_{1}$ ("o-oo") and $S_{2}$ ("da!"). Thus, the fort-da play presents us with the paradigmatic example of the effect of the cut $\left(S_{1}-S_{2}\right.$ pair) on the subject-that is, separation. The physical disappearance of the maternal Other (endowed with a breast) can only become meaningful for the subject insofar as, by drawing on the "o-oo/da!" pair, he is led to wonder what type of object he is in the eye of this Other who keeps coming and going. In other terms, it is the phonemic opposition that enables the infant to wonder what takes place inbetween $S_{1}$ and $S_{2}$-which refer to absence and presence. Therefore, in throwing the reel, the infant stages this very question: the reel represents him as an object separated from the body of the Other-Lacan calls it "object $a$," a nonempirical object which causes the desire of the Other once it is separated from his body (Lacan, 2014). By thus staging the Other separating from the object (reel-baby) and then coming back to it, the infant understands the comings and goings of the Other as manifestations of her desire, on which the infant draws in order to and correspondingly become a desiring subject. For in this sequence, he realizes that he lacks what the desire of the Other can give him, namely the bodily part (especially the breast) experienced as separated from him, which in turn becomes a separated object $a$ for him (Lacan, 1998a, p. 62). Thus the fortda play, which draws on the function of the cut in its simplest expression ("o-o-o"/ "da!"), produces a separation by leading the infant to wonder what object $a$ he is to the Other and thereby to develop a desire echoing that of the Other (ibid.).
The question then becomes to know what conditions, on the side of the Other, the subject's access to the function of the cut, and the consecutive representation of a separation with the Other and the corresponding loss of the object $a$. To address this question, we start by examining the paradigmatic condition to access the cut (the paternal metaphor), and the corresponding version of the cut: castration.

\section{The Paradigmatic Condition of the Cut on the Side of the Other: The Paternal Metaphor, and Its Absence}

Since the function of the cut puts to work a relation of metaphorical and metonymical substitution between $S_{1}$ and $S_{2}$, the paradigmatic condition of its implementation in the infant's psyche is what Lacan calls the paternal metaphor (Lacan, 1966, 1998 b,c). This concept, which refers to Lacan's rewriting of the Oedipus complex, helps specify an Oedipal mode of representing oneself as separated from the Other and thereby as object $a$ of their desire.

The paternal metaphor is what enables the child to understand the mother's (or mothering figure's) absence as an Oedipal separation: this metaphor refers to the effect of the introduction, by the Other, of a specific signifier called the Name-of-the-Father (Lacan, 1966, p. 557). This signifier is meant to introduce the infant to the symbolic operation of castration, which entails two things. First, the Other's desire also has another object, referred to by this signifier (it can be the real father, but anyone can be in this position); therefore, the infant doesn't play the role of a phallus, that is of an object fully satisfying the mother's desire. And second, the Other's desire is nonetheless related to the infant, since its object stands in a symbolic relation of filiation with him. The presence of a Name-of-the-Father on the side of the Maternal Other thus conditions the infant's access to the Oedipus, and it plays a role even before the infant's birth by largely contributing to lay out the coordinates of his future subjective structuration. For if the Name-of-the-Father is no guarantee that the infant will be neurotic, it at least presents him with a triangular configuration which can protect him from depending exclusively on the desire of an almighty mother (with its potential arbitrariness), thanks to the presence of another object of desire on her part: her disappearance in the fort-da can be understood by the infant as a manifestation of her desire for someone else.

Thus, insofar as the Name-of-the-Father indicates both that the mother's desire has another object and that this object is nonetheless related to the infant, the presence of this signifier in the Maternal Other enables the child's primary identification to the father: by making it possible for the infant to acknowledge the presence of another object for the Mother's desire, this signifier enables him to becomes a representative of the Name-of-theFather (this is the positive side of symbolic castration for the infant: while he is no longer the mother's phallus, he becomes in exchange a paternal representative). Thereby, the Name-of-theFather crucially determines the content of the infant's $S_{1}$, and will thus help him investigate his origin in the Other, i.e., his $\mathrm{S}_{2}$ (constitution of infantile sexual theories, and of the primal scene fantasy). It thus becomes manifest that the function of the 
cut will paradigmatically rely on the paternal metaphor, and that castration is therefore to be understood as the Oedipal version of the cut: this metaphor will enable the subject to question the Other's desire with respect to him by establishing and binding the gap between $S_{1}$ and $S_{2}$ through metaphorical and metonymical equivalences, thereby grounding the discourse concerning the origin of the infant in the desire of a parental couple (This does not entail that the infant would access the Oedipal conflicts at the time of the fort-da or other absence/presence-staging playsroughly around 18 months-, but that the infant's experience of the fort-da as an introduction to an Oedipal structure will largely depend on the Oedipal structuration of the Other's psyche).

Hence when the Maternal Other's psyche presents the infant with the paternal metaphor, the effect of the cut (the separation of infant as object $a$ from the mother) is, so to speak, compensated for by the emergence of another bond between infant and Other: by being acknowledged by the latter as a result of the encounter between her desire and the Name-of-the-Father, the infant becomes phallicized. That is, he is desirable as a representative of her encounter with the Name-of-the-Father, and not only as an object of her own desire. From this moment on, separation also means conjunction: the infant hereafter exists as a subject embedded in a symbolic lineage, and no longer as the sole object of the mother's desire-this phallicization is thus the symbolic gain of the Oedipal version of the cut, to which castration refers.

Correspondingly, the Other's lack of acknowledgment of the Name-of-the-Father (and the consecutive lack of paternal metaphor in the discourse transmitted to the infant) will lead the mother to make him her sole object of desire. He becomes a non-phallicized object $a$, which does not depend on the desire of a couple-be it the psychical couple of the mother's Oedipus complex. In this configuration, the infant does not receive the Oedipal discourse-mediated representations which could enable him to access the function of the cut, and thereby separate himself psychically from the mother: her absence isn't understood against the background of an Oedipal triangulation, but as a definitive loss, experienced by the infant as a fragmentation of his own body (characteristic of psychotic anxiety). This type of psychical organization is characteristic of psychosis: the subject as object $a$ doesn't experience himself as separated from the Other's body. Lacan does not mean that a maternal Other who does not present his infant with a the Name-of-the-Father is psychotic, since many clinical configurations can prevent her from presenting a Nameof-the-Father to the infant (depressive breakdown, temporary depersonalization, effects of early mother-infant interactions in the context of neuronal or bodily conditions, etc.). But the subjective coordinates in which the infant is thus introduced are psychotic-like, since the $S_{1}$ through which the Other refers to him isn't paired with an $S_{2}$ representing an Oedipal discourse about his origin in the desire of a couple, giving him a specific, distinct position by separating him from an almighty maternal Other.

How can an infant be introduced to the function of the cut when he hasn't initially been presented with the paradigmatic symbolic condition of the cut-namely, the mother-transmitted paternal metaphor? Before examining how Maud Mannoni provided a theoretically and clinically original response to this question (Part 3), we will examine some of the subjective effects of the lack of an Oedipal $S_{2}$, in order to better understand both (1) what a subject not heretofore exposed to the paternal metaphor needs to access the function of the cut, and (2) what such a cut would amount to.

The lack of Oedipal $S_{2}$ can refer to a variety of specific positions attributed to the subject as object $a$ by the Other. The first part of Maud Mannoni's seminal contribution lies, in the 1950s and 1960s, in the clinical exploration of one of these subjective positions: namely, the one underlying what was then called mental retardation, or deficiency (we will use this terminology in spite of its connotations, as it was of common use at that time). Lacan, who was her analyst and encouraged her to publish her first book on the subject, underlined as early as in the Seminar 11 that the great merit of her work was to shed light on the "psychotic dimension" (Lacan, 1998a, p. 238) of mental retardation. This dimension comes from the "reduction" of the child to "being no more than the support of her desire in the most obscure term" (Lacan, 1998a, p. 237, mod. tr.): in the absence of paternal metaphor, the retarded infant, child, or adolescent is often caught up, as Mannoni phrased it, in the maternal fantasy. We will now develop this point.

\section{THE 1950S AND 1960S: FROM THE RETARDED CHILD TO THE MATERNAL FANTASY}

Before expanding on the role of the maternal fantasy, we will briefly recall the context of Mannoni's encounter with Lacan. He wanted her book to be the first in his newly inaugurated collection "Le Champ Freudien" (The Freudian Field) because it was showing, in the clinical domain of mental retardationheretofore quite neglected by psychoanalysts-the relevance of the Lacanian function of the cut, by focusing on the effects of the lack of an Oedipal cut (i.e., castration) on the constitution of the subject.

\section{Mannoni's Encounter with Lacan: The Psychotic Dimension of Mental Retardation}

Lacan noticed Mannoni's work in the 1950s, by attending conferences and reading papers mostly focused on psychoses, about which Françoise Dolto (Lacan's other famous child analyst pupil) hadn't done much work-focused as she was on the vicissitudes of Oedipal configurations. He immediately suggested that Mannoni undertake a cure with him; in parallel, an uninterrupted clinical exchange began: "he would give me all of his Seminars and I was 'transformed' by what he wrote" (DidierWeill, 2001, p. 174); "it was my clinical work he was interested in... he would keep asking about it to know more" (Didier-Weill, 2001, p. 172).

In this first period of their interactions, he encouraged her to share her clinical work on the unconscious family stakes of mental retardation and psychosis: "with his support, I wrote in one go The Retarded child and the Mother: a Psychoanalytic study" (Mannoni, 1988, p. 42), published in 1964. Lacan chose this book to open his newly established collection, "The Freudian Field" (Le 
Seuil editors); it would soon be completed by The First Meeting with the Psychoanalyst (1965).

Looking back at what she wanted to show, she wrote:

\begin{abstract}
"The child creates the psychotic response along with someone else; the more he will feel his environment approves of the seriousness of his 'condition', the more he will try and 'adjust' to the character in which he chose to alienate himself. Raised in the middle of an adult discourse focused solely on his case, the 'ill child' has no other solution but to disappear as a subject in order to fully become the illness with which he is equated" (Mannoni, 1970, p. 40).
\end{abstract}

Starting from the clinical hypothesis according to which "the child's unconscious is often to be sought after in the parent's unconscious" (Mannoni, 1981, p. 77), she notices that, in the psychotherapeutic care of so-called retarded children, psychiatric diagnosis can act as a screen with respect to the contribution of the "psychotic dimension" (Lacan, 1998a, p. 238) of the mothering parent's unconscious to the child's retardation. In other words, this diagnosis can be used as a family defensewith the other parent's frequent tacit consent-to ward off the question of whether the desire of the Other is aimed at a paternal figure, and replace it with a dual mother-infant relationship: the unconscious legitimization by the diagnosis prevents the implementation of the function of the cut and its separating effect. In this context, the child is cornered into adopting the subjective coordinates he is thus being offered, by endorsing this $S_{1}$ which reduces him to the status of dependency characteristic of mental retardation. The diagnosis qua $\mathrm{S}_{1}$ saturates the coordinates of the child's subjectivization possibilities: he remains alienated within a psychotic-like system of coordinates devoid of any symbolic cut which would enable the mother to view him as a separated being, by relating him to the Name-of-the-Father.

\footnotetext{
"When the symptom [of retardation, in the psychiatric sense of the word] has become the subject's only means of communication, he holds onto it. It is his language, and he wants it to be acknowledged as such" (Mannoni, 1998, p. 94).
}

This exchange with Lacan sheds light on Mannoni's characterization of her work in the 1950s and 1960s: "retardation and psychosis are alike" (Mannoni, 1981, p. 84). This intuition can be traced back to the clinical sensitivity derived from Mannoni's childhood experiences: her family reacted to the bewilderment and sense of loss she experienced upon leaving her beloved nurse in Sri Lanka (where her father was the consul of Belgium) by calling her "the retard" (cf. Razon, 2012). Her own subsequent personal trajectory, and her encounter with Lacan, would lead her to elaborate a therapeutic perspective to escape alienating family dynamics: helping retarded children to distance themselves from the position in which they are kept by their environment requires to investigate the psychotic dimension of the parental unconscious, characterized by a lack of cut.

But elaborating a therapeutic perspective doesn't mean that she sought to establish a parental or maternal causality (and thereby, responsibility) at the root of mental retardation-be it in her theorizing or in her clinical work. She tried to shed light on the dimensions of the family's psychical dynamics which prevent the child from developing as well as he can, and which can be influenced through appropriate therapeutic work focused on the establishment of a cut. She always refused to view the parents as guilty of their child's condition, as one of us (AV) has witnessed on a constant basis during 15 years of work alongside her.

Correspondingly, she did not neglect the importance of organic causality in accounting for the child's condition: speaking of a young patient, she writes that her retardation "seemed to have an undeniable organic basis" (Mannoni, 1981, p. 50). She thus remained faithful to Freud's legacy: in the Preface of the Three Essays, he draws on the notion of complemental series to stress that the biological dimension of the symptom should always be questioned, alongside the psychical. Therefore, Mannoni's view can be seen as belonging to what is nowadays called a multi-factorial approach to mental disability (cf. Golse, 2013).

Mannoni, in pointing out the psychotic dimension of the family unconscious, simply wished to claim that such an organic causality does not preclude a psychotherapy based on psychoanalytic principles-and that ignoring the unconscious processes emerging in a family upon encountering a child who resembles them so little will prevent his phallicization and thereby prevent the establishment of the cut.

\section{The Lack of Cut: The Retarded Child, Caught Up in the Maternal Fantasy}

Mannoni starts from the clinical observation according to which the psychologically handicapped child generally encounters a family configuration laden with a "psychotic dimension" (Lacan, 1998a, p. 238), i.e., lacking a Name-of-the-Father: "the handicapped child is rarely welcomed in a genuinely triangular situation" (Mannoni, 1981, p. 32)-that is, acknowledged by the mother as a representative of the father. Therefore, "the lack of a paternal signifier reduces the child to the status of object, without any hope of becoming a subject" (Mannoni, 1981, p. 52): if the mother does not view her child as representing his father (lack of Oedipal $\mathrm{S}_{2}$ ), he becomes a de-phallicized object $a$, not separated by the cut from the maternal Other's body.

The situation is partly related to the effect of the parents' encounter with the psychical handicap of the child. Of course, the extent of the parents' Oedipal organization-and specifically the mother's-plays an important role in the development of the handicapped child; but the effect of his handicap (as early as in ultrasound scans, etc.-cf. Potier, 2009) considerably weakens this organization, and increases the risk of de-phallicization. (The exponential rise of genetic and genomic sequencing nowadays makes this type of clinical configurations an everyday situation: the effects of de-phallicization need to be prevented, in particular, during the announcement consultation consecutive to genetic testing-cf. Potier et al., 2016). In other words, according to Mannoni, an important parental de-phallicization of the child, consecutive to the lack of cut, often occurs even when parents have a neurotic structure (cf. Vanier, 2012, p. 42-43). In these cases, the impact of the handicap on the parental bond is so deep that the mother doesn't relate the child to her desire for the father. It is this de-phallicization dynamics which Lacan aims to 
single out by using the expression "psychotic dimension" (Lacan, 1998a, p. 238): it does not refer to the specific psychical structure of the mother (or the parents), but to the type of de-phallicized configuration which frequently emerges in the context of a lack of cut characteristic of psychical handicap.

Raymonde, 14 years old, meets Mannoni because of a profound mental retardation and lack of motor coordination, with a "seemingly undeniable organic basis" (Mannoni, 1981, p. 50 sq., as well as all quotes in this paragraph). She rapidly shows a total lack of active resistance or aggressive behavior: everyone is "nice." All other siblings have a significant academic delay in the absence of mental retardation - and the father is an academic. Her mother is extremely rigid and anxious: she cannot stand the children's liveliness, which frightens her; all of them have personality disorders. Raymonde's mental retardation is a defense against her mother's rigid phobia: "she responds to her mother's demand to not cause any trouble by acting like a nice frightened girl, willing to be forgotten." The mother explains her severity in potty training by saying "I don't like it when I smell bad"anamnestic discussions clearly showed that, during pregnancy, she felt as though Raymonde "was part of her own body," just like "one of her own organs." This lack of the function of the cut comes from the situation surrounding her pregnancy: the father threatened to leave her in case the child was nonviable: this anticipated lack of acknowledgment from the father, inducing a massive de-phallicization, was assorted (for both parents) with a family structure where each parent's mother sought to exclude their child's partner. Therefore, their own psychical triangulations were already weakened: the father let the mother leave him aside, while she as well had little psychical space for him. This family constellation thus prevented Raymonde from accessing any kind of triangulation. Psychotherapy gradually led to unearth an important persecutory dimension (with spirits invading her body), echoing her mother's hypochondria and her experiences of bodily invasion. Working through these fantasies helped her regain a grip on her mental functioning and her body, which in turn led her to social and professional insertion (she became a gardener working with children). On the other hand, the gradual autonomization enabled by this psychoanalytic process, led Raymonde's mother to a massive disorganization and delusional confusion (Mannoni, 1981) because of her inability elaborate her object $a$ 's absence.

In these cases, the desire upon which the child depends is strictly the mother's, "in its most obscure term" (Lacan, 1998a, p. 237): the child is led to adopt the position conferred to him by the maternal fantasy, whatever the latter's precise naturewhile he can wonder what he represents as an object $a$ for the Other, he does experience the Other's desire as de-phallicized. This is what Mannoni refer to when she writes that in these cases, "as soon as it was conceived, the subject already plays a very specific role in the mother's fantasy; his fate is already sealed; he will be this desireless object whose sole function will be to fill in the maternal emptiness" (Mannoni, 1981, p. 84). This sentence plays on the word "conception": when the child was physically conceived, he didn't have this status (his handicap was unknown to the parents); but later parental unconscious formations show that, after discovery of the handicap, his conception was fantasmatically re-written into a completely dephallicized narrative, qualifying him as a non-phallicized object $a$ excluded from the couple's desire. "Unbeknownst to him, the child is so to speak 'caught up' in the mother's desire. (...) The child's illness will conceal the mother's" (Mannoni, 1981, p. 87). Being caught up means that it is the mother's difficulty to consider separation (this is the "illness") which often leads her to present her child's illness as the motive of an apparently legitimate care, thereby putting him in the position of an extension of her own body and thus precluding the cut from taking place.

Hereafter, this maternal "illness" (difficulty to consider separation) will lead her to equate separation with losing one's own being: the function of mental retardation "is to hide not only [the child's] lack of being, but what is felt as the mother's lack of being" (Mannoni, 1981, p. 170). A mother tells Mannoni: "since my child left, I feel an emptiness in myself, I don't know what to do with myself, I'm completely at a loss" (Mannoni, 1981, p. 101). For the mother, opening this closed mother-child circuit means self-annihilation: "any claim to autonomy on the part of the child is immediately experienced by the mother as the disappearance of this necessary support of her fantasy" (Mannoni, 1981, p. 86). Correspondingly, the unconscious of the retarded child echoes the mother's emptiness anxiety: "Mother's existence depends on me alone" (Mannoni, 1981, p. 105). This reminds us of the disorganizing effects of Raymonde's autonomization on her mother.

The fantasy refers to the coordinates of the relation to the object, and the object refers to a part of the Other's body, of which the subject must separate himself in order to come to existence. Therefore the term "emptiness" used by this mother can help specify the maternal fantasy wherein the retarded child is caught up: it is an archaic, cannibalistic oral fantasy, where the childobject is being devoured by the mother. Since the child is in a position of non-phallicized object, and is thus not protected from this maternal fantasy by a paternal cut, he experiences this fantasy directly in his body: he is afraid that the Other will snatch and devour him.

\footnotetext{
"Retarded and psychotic children respond to the threat of the Other with their body. Their body is directly subjected to panic: they lack the symbolic dimension which would help them situate themselves with respect to the Other's desire without risking to be snatched by him" (Mannoni, 1981, p. 198).
}

The cannibalistic fantasy of devouration had initially been described by Karl Abraham (1916) in the context of the cure of an adult patient; he mostly insisted on the fact that it expresses the infant's oral erotic drive. In the passage above, Mannoniafter Lacan (and Melanie Klein, who was partly trained by Abraham)-insists on the role of the Other in the structure of the fantasy, for two reasons. Firstly, oral drive is, to a large extent, experienced as coming from the Other because of the projective nature of archaic fantasies. And second, the presence of an infant does trigger cannibalistic fantasies in the Other: to some extent, a phallicized infant is protected from the excessive staging or transmission of such fantasies by the presence of the paternal metaphor in the mother's psyche-but in a de-phallicized context 
such as that of mental retardation, where the infant is experienced as part of her body, he is much less protected from them.

Mannoni points out, on the basis of such clinical material, that this fantasy is prevalent in these children because of the lack of what Lacan conceptualized as paternal cut. Our hypothesis is that, in thus spelling out that this fantasy is at work in the unconscious of mentally retarded children, Mannoni paved the way for Lacan's characterization of infantile symptoms in the late 1960s.

\section{The First "Note on the Child" (1986): Equating Lack of Cut with Alienation to Maternal Fantasy}

In 1964, in Seminar XI, Lacan gives, as the first example of lack of cut, the "psychotic dimension" pointed out by Mannoni in the unconscious of the retarded child caught up in the maternal fantasy. In 1969, when writing the two "Notes on the Child" (given to Jenny Aubry and published for the first time in Aubry, 1983), Lacan draws on Mannoni to generalize her results. From now on, he will describe the effect of a lack of cut in the maternal unconscious (the "psychotic dimension") with the terms Mannoni used to spell out the family dynamics at work in the background of mental retardation. From now on, the child as object of the maternal fantasy will refer to a type of child symptom, of which mental retardation becomes a specific case.

In the first "Note on the child," Lacan distinguishes two types of child symptoms, in the psychoanalytic sense of the term-that is, two types of difficulties the child encounters in order to become a subject. In the first case, the symptom can represent the truth of the parental couple, i.e., the encounter of their two Oedipus complexes. Drawing on the unconscious of both parents, it is the most complex case; but it is more open to psychoanalytical work as it relies on a cut-the Name-ofthe-Father is present in the mother's unconscious, which thus phallicizes the child. A typical example is Hans' horse-phobia, analyzed by Freud and later by Lacan (1998b): through this phobia, he was working through and gradually integrating the difference of sexes.

In the second case, this symptom is not mediated by the paternal function, i.e., by the Name-of-the-Father: just as with Raymonde's defensive use of her mental retardation, the symptom "stems from the subjectivity of the mother" (Lacan, 1986 , p. 13-14), in which case the child is concerned "directly as the correlative of a fantasy" (id.). The therapeutic goal then becomes to help the child separate from this dual relationship with the body of the maternal Other [Nowadays, we would most likely use Lacan's indications of two types of symptoms as a spectrum, with being caught up in the maternal fantasy on one end, and representing the truth of the parental couple on the other; or alternatively, as two interacting axes which should both be taken into account. Symptoms such as mental retardation should actually be dealt with drawing on both axes; clinical work with children with milder forms of mental retardation in the context of microdeletion 22q11.2 has made one of us (OP) very sensitive to the de-phallicisation caused by such symptoms. That is, the parental couple, and the subsequent phallicization of the child, can be partly put aside by the mother out of frustration at not having given an ideal phallicized child to her Oedipal father; which can profoundly impact the child's symptoms, in reaction to this disavowal of the importance of the couple].

Typical of this second case are psychosomatic disorders and psychical configurations such as mental retardation-which, for Mannoni, is essentially identical to child psychosis in its structure. Psychosomatic disorders share with mental retardation (and, more generally, psychosis) a lack of paternal metaphor, i.e., both belong to the "psychotic dimension" entailed in being the direct correlative of a maternal fantasy. This doesn't mean that mental retardation is a psychosomatic disorder, but that initially and prior to psychoanalytic work, psychosomatic symptoms are devoid of symbolic meaning: they are characterized by their lack of subjective signification and cannot be related metaphorically to the Oedipal narrative (Lacan, 1998a); as such, they are distinct from hysteric symptoms where bodily affections have an Oedipal signification.

One cannot but be struck to find in Lacan's words ("directly as the correlative of a fantasy") the exact characterization of the child's being the object of the maternal fantasy because of a lack of cut which Mannoni, partly nourished by her interactions with Lacan, had found in mental retardation when she wrote "the lack of a paternal signifier reduces the child to the status of an object, without any hope of becoming a subject" (Mannoni, 1981, p. 58).

Thus generalizing Mannoni's formulation then allows Lacan to spell out what is entailed in becoming the object of the sole maternal fantasy, and more specifically its de-phallicized object $a$ : insofar as the child isn't separated from the mother by the Nameof-the-Father, he "realizes the presence of what Jacques Lacan designates as the object $a$ in the fantasy" (Lacan, 1986, p. 1314) - that is, he appears to the mother as the surrogate to anything she could lack, i.e., she could have lost from the body of her own maternal Other. From this perspective, the mother's subjective structure, determined by a specific "mode of lack" (neurotic, perverse or psychotic), is secondary-the child will nonetheless be put in the position to "saturate" it (Lacan, 1986, p. 13-14), and thereby to conceal from her the truth of her own symptom. In this conception, Lacan takes into account the family dynamics pointed by Mannoni in the case of mental retardation: the child's symptom is the screen of the maternal symptom. Later, during the RSI seminar (1974-1975, unpublished), Lacan will refer to the mother's relation to the child saturating her lack with the expression "non-phallic jouissance."

How can these indications, born from the exchanges between Lacan and Mannoni, be put to work in order to make up for a lack of introduction to the cut by the maternal Other through the paternal metaphor-whether it has led to structures lacking this metaphor (schizophrenic, autistic, etc.) or to severely neurotic ones which somehow made up for this lack? And additionally, what would be a type of cut different from castration, which could be aimed at by psychoanalytic work with non-neurotic patients?

The first theoretico-clinical question was at the core of Mannoni's revolutionary institutional project: in the late 1960s, she founded Bonneuil's Experimental School. Embodying the theoretico-clinical organization of the splintered institution, this School also gave clinical elements toward 
answering the second question, by helping those of its nonneurotic hosts develop specific types of cuts differing from castration.

\section{BONNEUIL'S SPLINTERED INSTITUTION: ASSUMING THE CUT ON THE SIDE OF THE OTHER}

\section{The Splintered Institution: Assuming the Cut by Acknowledging Projects as $\mathrm{S}_{2}$}

When the mothering Other's unconscious hasn't exposed the child to the Name-of-the-Father, but has instead subjected him to her sole fantasy, the Other's comings and goings in the fort$d a$ cannot be understood by the child as manifesting a desire for someone else. Confronted with a maternal unconscious seeking to saturate her lack by reducing the child to the status of non-phallic object $a$, the child experiences separation as potential destruction of the Other - by fragmenting, exploding or emptying her body (cf. the $\ll$ emptiness $\gg$ feeling mentioned to Mannoni). Correspondingly, the infant identifies with this experience and fears his own explosion once separated from the other.

Clinical work with children not previously introduced to the cut through the paternal metaphor will thus have to make them feel that it is actually possible to separate from the maternal Other without destroying her-and thus, without risking their own life, for they are not part of her body. Insofar as their type of transference is-at least initially-dual (staging a faceto-face struggle with an almighty Other), Mannoni suggested an institutional therapeutic setting in order to provide, in material reality, a constant and permanent containment for their anxieties. But in order to prevent the institution (with its constant presence) from becoming the transferential replica of an almighty Other about to devour her child-object in a dual relationship, and instead to enable children to access the cut, she put forward a new type of therapeutic institution: the splintered institution, which assumes the cut and thereby makes separation possible on the part of the child.

\footnotetext{
"An institution is like a person feeding off of those who depend on her. It practically assumes an almighty position: it behaves likes the mother of a psychotic child, from whom the subject cannot separate without risking to explode. A different institution would, much like a scale, assume the cut and thereby make it possible for the subject to situate herself through his own speech-and to thus separate himself, cut himself off of the institution (...). The cut becomes possible, exactly as with a mother and her child. The cut is a symbolic phenomenon, which allows the subject to emerge and be acknowledged as such by someone else" (Mannoni, 1976, p. 53).
}

To prevent the establishment of a psychotic transference with respect to the institution-which would equate separation with mutual destruction-due to a lack of cut in the child's psyche, the strategy would be to take up any wish of the children for a project outside the institution (trip, activity, etc.), and consider it as an attempt at establishing a cut. "Assuming the cut," as
Mannoni put it, means that any expression of such a projectwish is to be "acknowledged" by the institution staff as a potential $\mathrm{S}_{2}$, i.e., as a symbolic representation of the child as bearing a different identity (taking-part-in-such-and-such-project) and thereby as implementing the function of the cut in their psyche, thus allowing them to withstand separation from the Other's body. By offering them the figure of a non-devouring maternal Other, who can bear separation by deliberately cutting herself from them in response to their project-wish, the institution reenacts the fort-da with a different outcome: physical separation in the course of the project doesn't amount to mutual destruction, as it is rather the implementation of the cut-i.e., the result of the symbolic acknowledgment by the Other of a new identity for the child, different from that of de-phallicized object $a$. Taking up the child's wish enables the institution to present him with a different desire of the Other with respect to him, and to represent himself as absent from him.

Mannoni proposes to call such an institution a "splintered institution" ("institution éclatée," in French-cf. e.g. Mannoni, 1973, p. 77): "splinter" explicitly refers to the psychotic fantasy (characteristic of what Lacan called the "psychotic dimension") which identifies loss of a bodily part with explosion and annihilation. By coining this expression, Mannoni wanted to stress that it should be the task of the institution itself to take up and overcome the Other's annihilation anxiety associated with loss of a bodily part, which children want to prevent by remaining attached to their status of his de-phallicized objects $a$, by responding positively to their expressed project-wishes (symbolic acknowledgment of the cut) and showing them that it can withstand their outcome (physical separation).

Mannoni's project of a splintered institution, which would "assume the cut," quickly became the motto of the Experimental School situated in Bonneuil-sur-Marne (just outside of Paris), founded in 1969 by Maud Mannoni and Robert Lefort, both students of Lacan's, with a couple of educators, Rose-Marie and Yves Guérin. The School is a place where children and adolescents live and take classes adjusted to their capacities; it also is a night shelter. Today, it is a daycare hospital and therapeutic night foster home. Schooling is in small groups, and goes along with creative activities supervised by educators; children do their part in the maintenance and daily chores.

The School rapidly became what Mannoni theorized as the splintered institution by considering the children's speech as wishes: far from being a technique, its organization revolves around the fundamental psychoanalytic tenet to start from what the subject says - that is, to always consider the person as a subject, and what they say as a manifestation of their subjectivity (see the section Conclusion below). The goal being to help children bear separation, it is a negative therapy of sorts, the goal of which is to constrain as little as possible. For example, in the early 1970s, an educator suggested to one of the adolescents, upon seeing his gift in bike repair, that he create a repair studio within the institution. The response was that he'd much rather work in a real bike repair shop (potential $S_{2}$ ), outside the institution. The adolescent's refusal, embedded within his transference on the educator, made it possible for him, first, to enact the rejection of an unconscious almighty Other. By taking up the educator's 
acknowledgment of his skills, he could then voice a true potential $\mathrm{S}_{2}$, to which the institution had to respond by allowing him to exist under this new identity; this gave a new meaning to this presence in the institution, as a moment embedded within his particular project. By acknowledging this new representation of himself, the institution helped him implement the psychical function of the cut and thus envision himself as physically separated from the Other: the fort-da could be undergone without anxiety of mutual annihilation.

"The Fort-Da play, this oscillation between a here and a there, is introduced in Bonneuil every time a child's stay involves an alternation with moments spent somewhere else" (Mannoni, 1976, p. 73).

In this light, projects such as going abroad are particularly interesting experiences: the immersion in a foreign language deepens the inscription in a new potential $S_{2}$, and allows for another representation of the desire of the Other.

With respect to families, the institution's whole clinical challenge then became to prevent the closure dynamics which can appear in response to the implementation of the cut in the child's psyche, because of the repetition compulsion which prevents them from letting the child escape his alienation to the Other's almighty fantasy and thus access a potential new $S_{2}$. Mannoni has the following exchange with the mother of a patient who cannot but try and thwart Bonneuil's dynamics:

“Julien's mother [JM]: Brittany does wonders for Julien.

Maud Mannoni [MM]: Yes, but it is of crucial importance that you do not settle here, or else we'll have to find him another place to escape the family...

JM: You think so ? I wanted to move here with his twin brother. MM: We've been lucky enough to find a place Julien likes, where he can enact his rejection of both his family and Bonneuil. It is his own place, where his mother and brother are absent. This is of the utmost symbolic importance; you're about to rob him of this.

JM: The host family had even agreed to accept his twin brother... MM: You are inducing a potential failure, here. You know too well that, when he's with you, the situation escalates very quickly.

JM: After fifteen minutes, he starts insulting me, while he's normal and composed with everyone else.

MM: And yet, it is this very hell that you seek to re-create.

JM: No, but why would he be normal with others and not with me?

MM: Why hunt him down to the place where he feels at peace, without his family?

JM: It's not on purpose that I knock everything down. I just can't help it" (Mannoni, 1976, p. 225).

Mannoni firmly tries to hold the symbolic function of the cut (by stressing that the project is Julien's own), in order to protect both mother and child from the sado-masochistic dual relationship which re-emerges when they are together. Mannoni expands on this symbolic function by stressing that the movement is to be understood as a variation of frames (a direct reference to the transferential setting), i.e., as a symbolic oscillation.

\begin{abstract}
"To offer another place is to build an alternative to the logics of rejection, to escape the deadlock of the inside-outside opposition with respect to the family or the institution, by favoring a movement between different places. By playing with different frames, we re-introduce a movement within the inside-outside opposition, and the subject can gradually reflect upon what he wants to become" (Mannoni, 1986, p. 106).
\end{abstract}

Distanced from the $S_{1}$ of his illness which feeds the fantasy of a devouring Other on which the child depends, the $\mathrm{S}_{2}$ acknowledged by the institution represents a discourse which can make up for the initial lack of paternal metaphor and implement a cut, thus leading the child or adolescent to withstand physical separation.

\section{Varieties of Cut}

The goal of the splintered institution is thus to make up for the initial lack of paternal metaphor, and subsequently of castration-the type of cut consecutive to this metaphor. But this doesn't mean that castration is the only type of cut that this type of institution sets out to enable by acknowledging children's projects. A potential $S_{2}$, being implemented as a function of the cut through institutional support will not necessarily amount to an Oedipal narrative; to that effect, the subject would need to be in the coordinates of a mostly neurotic structuration. This narrative is but one type of $S_{2}$ enabling the cut by representing the subject qua the object that the Other lacks, i.e., is separated from-and therefore desires. It is one way to symbolically account for the subject's physical separation from the Otherby drawing on triangulation, i.e., the presence of someone else as object of desire. As mentioned earlier, castration accounts for this specific type of cut because it binds the subject to the desire of the couple constituted by the Other and the bearer of the Name-of-the-Father.

In the splintered institution, the type of cut will depend on the psychical structure of each subject: an attempt as symbolically representing separation can use other means, such as delusion-a highly symbolic production. One need only think of Schreber's delusional narrative (Freud, 1958), structured around the fantasy of becoming God's wife $\left(\mathrm{S}_{2}\right)$, the object that the He needs to become complete. The cut from the Other that Schreber gradually elaborates is not symbolic castration, but it is nonetheless an attempt at building an alternative to the fantasy of being annihilated by an almighty Other, through becoming the phallicized object that He needs (and thus cannot annihilate).

To give an example of alternate type of cut encountered at Bonneuil (collected and synthesized by AV, a close collaborator of Mannoni's), work with autistic children revolved around helping them realize that their project, acknowledged as $S_{2}$ by the team, involved physical separation-which, in autism, amounts to death by annihilation, and is thus to be avoided at all costs. In other words, the focus of the function of the cut to be enabled by the institution was the acknowledgment of physical separation as such; it is the earliest type of cut being staged in the fort-da, 
prior to any narrative accounting for it. Taking up their wishes to go outside for various projects was successful in psychically implementing the cut when, upon coming back to Bonneuil from the countryside, they suddenly cried upon realizing that they had left behind their "family." Representing themselves as separated from them, that is as having been lost by them, could be used as a shifting point to be drawn upon in the gradual working through of physical separation at stake in the fort-da-which is quite different from the neurotic cut qua symbolic castration, mostly revolving around elaborating Oedipal issues.

\section{CONCLUSION}

We tried to show the fruitfulness of Lacan's concept of cut by addressing it from the perspective of the psychical configurations where it hasn't been implemented (with the child being put in the position of a de-phallicized object $a$ ). Maud Mannoni has explored these configurations extensively: therefore our goal was, in part 2 supra, to show how she has characterized some of them, which then helped Lacan define them in a systematic fashion. Finally, we wanted to lay out how Mannoni delineated a theoretico-clinical setting aimed at making up for a lack of cut, as defined by Lacan, and enabling it when subjectively possible (part 3 supra).

\section{REFERENCES}

Abraham, K. (1916). Untersuchungenüber die früheste prägenitale Entwicklungsstufe der Libido. Int. Z. Arztl. Psychoanal. 4, 71-97.

Aubry, J. (1983). Enfance Abandonnée: La Carence de Soins Maternels. Paris: Métailié.

Didier-Weill, A. (2001). Quartier Lacan. Paris: Denoël.

Freud, S. (1958). "Psycho-analytic notes on an autobiographical account of a Case of Paranoia (Dementia Paranoides) (1911)," in The Standard Edition of the Complete Psychological Works of Sigmund Freud. Volume XII (1911-1913), The Case of Schreber. Papers on Technique and Other Works, ed J. A. Strachey (London; Vintage: Hogarth Press), 3-82.

Freud, S. (2001). "Beyond the pleasure principle (1920)," in The Standard Edition of the Complete Psychological Works of Sigmund Freud. Volume XVIII (19201922), Beyond the Pleasure Principle. Group Psychology and Other Works, eds J. A. Strachey (London; Vintage: Hogarth Press), 7-65.

Golse, B. (2013). La place des psychothérapies dans la prise en charge des enfants autistes au regard du modèle polyfactoriel et des traitements multidimensionnels. Psychol. Clin. 36, 41-48. doi: 10.1051/psyc/201336041

Lacan, J. (1966). D’une Question Préliminaire à Tout Traitement Possible de la Psychose (1958) in Écrits, Le Seuil, 531-583. [English Transl. by A. Sheridan, On a Question Preliminary to Any Possible Treatment of Psychosis in Écrits: A Selection (1977)] (Tavistock: Routledge), 179-225.

Lacan, J. (1986). Notes Sur L'enfant (1969), Ornicar? 37, 13-14. [English Transl. by R. Grigg, Note on the Child, Analysis, 2, 1990: 7-8].

Lacan, J. (1998a). The Four Fundamental Concepts of Psycho-Analysis [Transl. by A. Sheridan]. London: Hogarth Press.

Lacan, J. (1998b). Le Séminaire 1957-1958, Livre, I. V., La Relation D’objet. Paris: Le Seuil.

Lacan, J. (1998c). Le Séminaire 1958-1959, Livre, V., Les formations de Linconscient. Paris: Le Seuil.

Lacan, J. (2014). Anxiety: The Seminar of Jacques Lacan, Book, X. Cambridge: Polity Press.
Mannoni's original use of this concept of cut in the splintered institution has been extended in an original fashion by one of us (AV) in the context of a hospital work with psychotic mothers and their infant; this led him to the idea of a "supposition of subject" (Vanier, 1989). The gist of it is that, in the presence of a psychotic type of mothering, the neonate's psychical development (and indeed, his effective survival) will compensate the mother's tendency to consider him as part of her body, by assuming the function of the cut and acknowledging him as a subject from the startthat is, as someone with a potential to be embedded in various $S_{2}$.

\section{AUTHOR CONTRIBUTIONS}

LR has provided much of the material concerning Mannoni, and has put forward the importance of movement; she has contributed to the structure of the paper. OP has provided much of the material concerning Lacan. He has organized the global structure of the paper, and has written the detailed version of the paper. AV has contributed to writing the paper (material concerning Lacan and Mannoni, structure of the paper, references). All authors read and approved the final manuscript.
Mannoni, M. (1970). Le Psychiatre, Son Fou et la Psychanalyse. Paris: Le Seuil. Mannoni, M. (1973). Éducation Impossible. Paris: Le Seuil.

Mannoni, M. (1976). Un Lieu Pour Vivre. Paris: Le Seuil.

Mannoni, M. (1981). L'enfant Arriéré et sa Mère (1964). Paris: Le Seuil. [English Transl. by A. M. Sheridan Smith: The Retarded Child and the Mother: A Psychoanalytic Study in 1973] (London: Tavistock).

Mannoni, M. (1986). Bonneuil, Seize Ans Après. Paris: Denoël.

Mannoni, M. (1988). Ce Qui Manque à la Vérité Pour Être Dite. Paris: Denoël.

Mannoni, M. (1998). Le Premier Rendez-vous Avec le Psychanalyste (1965). Paris: Gallimard.

Potier, R. (2009). L'imagerie cérébrale à l'épreuve de la psychanalyse. Res. Psychoanal. 1, 79-86. doi: 10.3917/rep.007.0079

Potier, R., Putois, O., Lyonnet, S., Weitzmann, J., and Villa, F. (2016). Regards croisés sur une pathologie développementale d'origine génétique. Réflexions épistémologiques et cliniques sur l'impact psychique du syndrome de microdélétion 22q11.2. Topique 2, 103-117. doi: 10.3917/top.135.0103

Razon, L. (2012). Maud mannoni et les écrivains: passion de l'être, passion de l'écriture. Topique 3, 153-160. doi: 10.3917/top.120.0153

Vanier, A. (1989). Quelques remarques à propos d'un travail avec les mères psychotiques et leur nourrisson. Psychol. Clin. 12, 39-50.

Vanier, A. (2012). L'enfant, objet a de Lacan. Fig. Psychanal. 2, 39-49. doi: $10.3917 /$ fp.024.0039

Conflict of Interest Statement: The authors declare that the research was conducted in the absence of any commercial or financial relationships that could be construed as a potential conflict of interest.

Copyright (c) 2017 Razon, Putois and Vanier. This is an open-access article distributed under the terms of the Creative Commons Attribution License (CC BY). The use, distribution or reproduction in other forums is permitted, provided the original author(s) or licensor are credited and that the original publication in this journal is cited, in accordance with accepted academic practice. No use, distribution or reproduction is permitted which does not comply with these terms. 
OPEN ACCESS

Edited by: Rémy Potier

Paris Diderot University, France

Reviewed by:

Daniela Flores Mosri,

Universidad Intercontinental, Mexico

Olivier Putois,

Université de Strasbourg, France

*Correspondence:

Beatriz Santos

sbeatriz@gmail.com

${ }^{\dagger}$ These authors have contributed equally to this work and co-first

authors.

Specialty section: This article was submitted to

Psychoanalysis and

Neuropsychoanalysis,

a section of the journal

Frontiers in Psychology

Received: 06 July 2017 Accepted: 14 December 2017 Published: 22 December 2017

Citation: Laufer L and Santos B (2017) Language and Vulnerability $-A$ Lacanian Analysis of Respect.

Front. Psychol. 8:2279. doi: 10.3389/fpsyg.2017.02279

\section{Language and Vulnerability-A Lacanian Analysis of Respect}

\author{
Laurie Laufer ${ }^{\dagger}$ and Beatriz Santos ${ }^{\star t}$ \\ Department of Psychoanalytic Studies, Center for Research in Psychoanalysis, Medicine and Society, Paris Diderot \\ University, Sorbonne Paris Cité, Paris, France
}

Lacan's original approach to language expands the reaches of psychoanalysis. Not limited to a set of technical instructions that guide "treatments of the soul," lacanian psychoanalysis can be seen as a theoretical toolbox whose utility is multidisciplinary. This paper contends that, by establishing a connection between (i) the idea that subjects are produced by language and bear the mark of the unconscious; and (ii) an approach to the production of symptoms that acknowledges the importance of their sense, lacanian theories enlighten discussions on the theme of vulnerability. We claim that Lacan's description of psychoanalysis as an apparatus that respects the person and (foremost) their symptoms generates evidence of the existence of a kind of recognition that takes into account the vulnerability of a given subject without assigning them to a fixed position of victim. This perspective enriches contemporary debates on the relationship between identity and vulnerability.

\section{Keywords: language, vulnerability, symptom, recognition, clinical practice}

\section{INTRODUCTION}

By referring to contemporary French psychoanalysts interested in the theme of symptoms, the present work examines how psychoanalytical theories on the relationship between language and subjectivity allow for a broader understanding of the concept of vulnerability. A lacanian perspective on respect and its importance to the development of psychoanalytical treatment stems from this discussion on vulnerability.

\section{LANGUAGE AND REALITY}

In Clarice Lispector's The passion according to G.H., at the end of an introspective quest that culminates in a Kafkaesque encounter with a cockroach, the main character finally understands what language is: "Reality is the raw material, language is the way I go in search of it-and the way I do not find it" (Lispector, 1964/1988). G.H. is a Brazilian middle-class woman who sets out to simply clean a room in her house but finds herself exploring the very origins of human communication. In doing so, she seems to comprehend language as that which allows one to seize the raw material that comes from an external reality (as opposed to psychic reality, in Freud's definition). In other words, G.H is able to experience the discontinuity between the available sensory information (the sense data) and what is captured and organized by our psychic apparatus. G.H's experience allows her to understand that this capture cannot happen without language.

As human beings, our very subjectivity is defined by language. As Emile Benveniste puts it, a separation between man on one side and the use of language on the other is not possible: even though we are inclined to imagine a primordial time when a man discovered another one and 
between the two of them language was worked out little by little, this is not what happened:

"We can never get back to man separated from language and we shall never see him inventing it. We shall never get back to man reduced to himself and exercising his wits to conceive of the existence of another. It is a speaking man whom we find in the world, a man speaking to another man, and language provides the very definition of man" (Benveniste, 1963/1967).

Benveniste insists on the idea that language is much more than an instrument that allows men and women to communicate. The main characteristics that defines language-its immaterial nature, its symbolic functioning, its articulated arrangement and the fact that it has content-set it apart from any instrument created by man: "to speak of an instrument is to put man and nature in opposition. The pick, the arrow, and the wheel are not in nature. They are fabrications. Language is in the nature of man, and he did not fabricate it" (Benveniste, 1963/1967).

This understanding of language as a given that simultaneously precedes and produces the subject proposed by Benveniste is also a main point in Lacan's description of human beings as subjects of language that are subjects to language. Throughout his work, Lacan will develop the notion of a subject who is able to talk because he/she is talked-that is, because he/she is inscribed in language as a preexisting structure. This is a fundamental shift in the understanding of the relationship between human beings and language: once seen as the actor responsible for the performing of acts of speech, the subject becomes, in lacanian theory, the product of such acts.

In "Position of the Unconscious" (1960), Lacan develops this idea of a subject subordinated to language through the affirmation that "the effect of language is to introduce the cause into the subject" (Lacan, 1960/2006). For Lacan, the subject is not what he imagines himself to be. We produce an imagean imaginary or specular illusion-of ourselves that protects us against the chaotic movement of our drives. This organized image, known as ego, differs from the subject: the lacanian subject is the subject of the unconscious, and is produced by the signifiers of language. The effect of language over the subject thus means that "he ([the subject] is not the cause of himself; he bears within himself the worm of the cause that splits him. For his cause is the signifier, without which there would be no subject in the real. But this subject is what the signifier represents, and the latter cannot represent anything except to another signifier: to which the subject who listens is thus reduced" (Lacan, 1960/2006).

The signifier allows the subject to occupy a place among all other beings, but does not encompass the totality of what a subject is. The subject is what the signifier represents; as the famous aphorism goes, the signifier is characterized by the fact that it represents a subject to another signifier (and to another, and to another, in an endless signifying chain, as Lacan will describe it).

\section{THE MEANING OF SYMPTOMS}

This understanding of the role played by language in the very constitution of a subject has important implications for the clinical work derived from lacanian theory. One of them is the appreciation of the importance of symptoms to the analytical cure. In his first Seminar, Lacan posits that the symptom initially appears to us as "a trace which will continue not to be understood (qui restera toujours incomprise) until the analysis has got quite a long way and we have discovered its meaning (son sens)" 1954. This means that, in psychoanalytical theory, the symptom is not simply seen as a manifestation associated to a disease. It is not the indication of a disturbance in the (healthy) condition of a person. Rather, it should be understood as a formation of the unconscious that the analyst should not strive to quickly extinguish since it was carefully (albeit unconsciously) produced by the subject-not unlikely a work of art.

We think of Freud's comparison of symptoms to cultural outputs, and to outputs produced by artists. In 1917, for instance, he mentions the importance of distinguishing the symptoms from the disease of his neurotic patients, and reminds us "that doing away with the symptoms is not necessarily curing the disease. Of course, the only tangible thing left over after the removal of the symptoms is the capacity to build new symptoms" (Freud, 1890/1942). This creative capacity may translate into the artist's ability of "turning away from reality" and transferring interests and libido to the elaboration of imaginary wishes. It also works as evidence that symptoms are not to be simply eradicated, but rather taken as an indication that there is work to be done. It is in this sense that Lacan describes the symptom as a trace in his early works: as a mark left by the presence of something that once was at a given place, like footsteps that reveal that someone has stood at a given spot.

What interests us regarding this way of looking at the symptom is the consequences to our approach of the psychoanalytical treatment. What does it mean, to treat someone, without getting rid of the symptom but focusing on its meaning instead?

French psychoanalyst Sidi Askofaré examines this matter on an article about what he sees as "the revolution of symptom" (Askofaré, 2005) — that is, as the action (by the symptom) of going round in an orbit. The symptom is found at the very beginning of a treatment as the reason why one seeks consultation with an analyst. It is also there at the very end of the analysis, albeit transformed. The trajectory it describes is not one of mere repetition nor of an eternal recurrence of events, but rather a revolution that conjoins a return to and a metamorphosis of events. In the unpublished Seminar from 1976, Linsu que sait de l'une-bévue s'aile à mourre, Lacan wonders if, in the end, it would be possible to understand psychoanalysis as synonym to identifying with one's symptom. Not understanding the meaning of the symptom or having it revealed by the analyst, but, as Askofaré puts it, taking ownership of the meaning of this symptom: "what is expected from the act of the analyst is that it brings the analysant to take ownership of (assumer) the meaning (sexual, phallic, or castration) of his symptoms."

Askofaré insists on the fact that this ability to assume or undertake the meaning of a symptom radically differs from the mere understanding or treatment of said symptom. In analysis, what happens to a subject is closer to an ethical experience that Lacan associates with the idea of respect. We believe that this specific understanding of respect broadens the use 
of psychoanalytical theory and contributes for contemporary discussions on vulnerability and politics.

\section{RESPECT, RECOGNITION, VULNERABILITY}

In his very first Seminar, from 1953 to 1954, Lacan studies Freud's articles about psychoanalytical technique. In a lesson concerning the concepts of resistance and defenses, he examines the criticism regarding Freud's supposed "authoritarianism" in relation to his patients-some of Lacan's students describe Freud's handling of the resistance as an act of conquering said resistances. Consequently, Freud is seen by these students as someone who is moved by a "strong will for domination."

But Lacan does not agree with his students' interpretation of Freud's technique. He posits that "if anything constitutes the originality of the analytic treatment, it is rather to have perceived at the beginning, right from the start, the problematical relation of the subject to himself. The real find, the discovery, in the sense I explained to you at the beginning of the year, is to have conjoined this relation with the meaning of the symptoms" (Lacan, 19531954/1988). This means that, rather than acting dominantly, the psychoanalyst works from a position of a certain vulnerability.

Indeed, when Lacan mentions "the problematical relation of the subject to himself," he is referring to the Freudian notion of Nebenmensch, "the fellow human being." In Freud's work, the (helpful) person capable of removing the distress of the child through a "specific action" also creates-via the same actiondependency and vulnerability. According to Freud,

"Let us suppose that the object which furnishes the perception resembles the subject-a fellow human-being (nebenmensch). If so, the theoretical interest taken in it is also explained by the fact that such an object was simultaneously the subject's first satisfying object and further his first hostile object, as well as his sole helping power. For this reason it is in relation to a fellow human-being that a human being learns to recognize" (Freud, 1895/1966).

In other words, it is by being vulnerable and by being exposed to the power and the hostility of another fellow human being that one develops his or her abilities of recognition. A moment of crisis and a critical environment are indeed the very conditions to the development of human's capacity to recognize others. This has a technical consequence that shall bring us back to the lacanian definition of the analyst as someone who gives up knowledge in the same way he/she gives up of his/her ideals.

In fact, Freud described in 1890 a menacing aspect inherent to all situations where help is involved (Freud, 1895/1966). Since the forces that work toward helping a subject necessarily impact the "autocratic nature of the personalities of the subjects," a common reaction in patients is to avoid asking for help of any kind (psychological, medical, or on a social context). The very idea of being helped elicits defenses. Consequently, the efficacy of psychoanalytical practice must rely on the fact that it differs from a psychological aid. It has to avoid what we could describe, from a lacanian perspective, as the imaginary trap (le piège imaginaire) of intersubjectivity. Rather, it should adhere to an unconditional recognition of the symptom of the subject, as well as of the "problematical relationship of the subject to himself" that the symptom imposes.

This unconditional recognition means questioning one's relationship to knowledge. The analyst behaves as a nebenmensch, a fellow human who cannot know what the analysant needs. One cannot, as an analyst, assume a position where prescribing attitudes or behaviors is a possibility. Rather, one must give up one's knowledge regarding his/her patients and the illusion of power that comes with it. By doing so, we rend ourselves more vulnerable. But we also move closer to the meaning of the symptoms.

We understand that this is the only way to keep psychoanalysis from either being dissolved into some sort of sentimental psychologisation that fails to take into account the submission to language described by Lacan; or into a medical way of thinking that tries to answer to normative ideals regarding treatments. One could describe this position concerning psychoanalysis as a certain style, neither intimate, nor extimate (as Lacan puts it), but proximate. As a practice, psychoanalysis remains vulnerable, situated between two spots, fragile.

In other words, the originality of the analytic treatment is to oppose something very simple to both an inquisitive style of the analysis of resistances and the mere eradication of symptoms: respect for the human being and for his or her symptoms. Lacan insists that:

"It is the subject's refusal of this meaning [of the symptom] that poses a problem for him. This meaning must not be revealed to him, it must be assumed by him. In this respect, psychoanalysis is a technique which respects the person-in the sense in which we understand it today, having realized that it had its price-not only respects it, but cannot function without respecting it" (Lacan, 1953-1954/1988).

From this perspective, respect means an idea of care for the other or for oneself that unties itself from a monolithic representation of who this other or this self should be. The lacanian understanding of respect allows for an idea of recognition that relies on a more variable (or less fixed) conception of the self.

This point of view seems to relate to the issue of the relationship between identity and vulnerability, as stated on the work of contemporary philosophers such as Judith Butler. In Precarious Life, Butler describes how "each of us is constituted politically in part by virtue of the social vulnerability of our bodies - as a site of desire and physical vulnerability." In other words, the author claims that, from a political perspective, being recognized as a subject implies a feeling of identity that is fundamentally related to an experience of vulnerability:

$\ll$ loss and vulnerability seem to follow from our being socially constituted bodies, attached to others, at risk of losing those attachments, exposed to others, at risk of violence by virtue of that exposure $\gg$ (Butler, 2004 p. 20).

Throughout her work, Butler has described how the act of being called a name paradoxically limits a subject and allows himself 
or herself to exist. When one receives a name-woman, man, transgender, Brazilian, heterosexual, gay, etc.-, one receives the possibility to exist socially at the same time that he or she is supposed to abide to the characteristics that allow for such a naming. Different characteristics lead to different designations and, consequently, to different degrees of vulnerability.

« one speaks, and one speaks for another, to another, and yet there is no way to collapse the distinction between the Other and oneself. When we say «we 》, we do nothing more than designate this very problematic. We do not solve it. And perharps it is, and it ought to be, insoluble. This disposition of ourselves outside ourselves seems to follow from bodily life, from its vulnerability and its exposure $\gg$ (Butler, 2004 p. 25).

The trouble with (any) identity, according to Judith Butler, lies in its variability and its diversity $-\ll I$ am a woman. Which woman? $\gg$. But this very trouble, this difficulty, is what allows us to understand how recognition cannot rely on an opaque, fixed, or monolithic representation of a subject.

\section{CONCLUSION}

These theoretical developments invite us to rethink what is at stake in the relationship between recognition and vulnerability. French psychoanalyst Jean Allouch argues that the psychoanalyst

\section{REFERENCES}

Allouch, J. (2014). Fragilités de l'analyse. Critique 800-801, 19-31.

Askofaré, S. (2005). La révolution du symptôme. Psychanalyse 4, 31-40. doi: 10.3917/psy.004.0031

Benveniste, E. (1963/1967). "Subjectivity in language," in Problems in General Linguistics, eds P. Verstraeten and N. Ruwet (Coral Gables, FL: University Miami Press), 223-230.

Butler, J. (2004). Precarious life. The Powers of Mourning and Violence. New York, NY; London: Verso Books.

Freud, S. (1890/1942). "Psychical (or Mental) treatment," in The Standard Edition of the Complete Psychological Works of Sigmund Freud, Vol. VII (1901-1905), ed J. Strachey (London: Hogarth Press), 281-302.

Freud, S. (1895/1966). "Project for a scientific psychology," in The Standard Edition of the Complete Psychological Works of Sigmund Freud, Vol. I (1886-1889), ed J. Strachey (London: Horgath Press), 283-295.

Lacan, J. (1953-1954/1988). Freud's Papers on Technique, 1953-1954. Transl. by J. Forrester. New York, NY; London: WW Norton \& Company. establishes a relationship to "variety as such"(le divers comme tel) which implies refraining from assigning a subject to a predefined clinical entity-or to a predefined name. In Allouch's words, this means that "oriented by variety, the psychoanalyst is bound to welcome anyone, and to do so by restraining from any identificatory action or thought" (Allouch, 2014). This means assuming a delicate position where one is perpetually thinking the subject without references to a knowledge of preexisting categories. And this ability to recognize variety without reducing it to rigid categories stems from this respectful attitude toward language, in the sense suggested by Lacan. Such an attitude is essential to the successful conduction of psychoanalytical treatments, and it may also enlighten discussions on vulnerability rising from other fields.

\section{AUTHOR CONTRIBUTIONS}

All authors listed have made a substantial, direct and intellectual contribution to the work, and approved it for publication.

\section{FUNDING}

The publication of this article has been funded by the Laboratory Center for Research in Psychoanalysis, Medicine and Society (CRPMS) at Paris Diderot University.
Lacan, J. (1960/2006). "Position of the unconscious", in Ecrits, ed J. A. Miller (New York, NY; London: W. W. Norton and Company), 703-722.

Lispector, C. (1964/1988). The Passion According to G.H. Transl. by R. W. Sousa. Minneapolis, MN: University of Minnesota.

Conflict of Interest Statement: The authors declare that the research was conducted in the absence of any commercial or financial relationships that could be construed as a potential conflict of interest.

The handling Editor declared a shared affiliation, though no other collaboration, with the authors.

Copyright (c) 2017 Laufer and Santos. This is an open-access article distributed under the terms of the Creative Commons Attribution License (CC BY). The use, distribution or reproduction in other forums is permitted, provided the original author(s) or licensor are credited and that the original publication in this journal is cited, in accordance with accepted academic practice. No use, distribution or reproduction is permitted which does not comply with these terms. 


\section{OPEN ACCESS}

Edited by:

Pierre-Henri Castel,

Centre National de la Recherche Scientifique (CNRS), France

Reviewed by:

Fabian Fajnwaks,

Paris 8 University, France Stéphane Thibierge,

Université Paris Diderot Paris 7.

France

${ }^{*}$ Correspondence:

Gertrudis Van de Vijver gertrudis.vandevijver@ugent.be Ariane Bazan ariane@ulb.ac.be

Specialty section: This article was submitted to Psychoanalysis and Neuropsychoanalysis, a section of the journal

Frontiers in Psychology

Received: 19 September 2017 Accepted: 11 December 2017 Published: 22 December 2017

Citation:

Van de Vijver G, Bazan A and

Detandt S (2017) The Mark, the Thing, and the Object: On What

Commands Repetition in Freud and Lacan. Front. Psychol. 8:2244. doi: 10.3389/fpsyg.2017.02244

\section{The Mark, the Thing, and the Object: On What Commands Repetition in Freud and Lacan}

\author{
Gertrudis Van de Vijver ${ }^{1 *}$, Ariane Bazan ${ }^{2 *}$ and Sandrine Detandt ${ }^{2}$ \\ ${ }^{1}$ Centre for the History of Philosophy and Continental Philosophy, Ghent University, Ghent, Belgium, ${ }^{2}$ Service de \\ Psychologie Clinique et Différentielle, Research Center for Clinical Psychology, Psychopathology and Psychosomatics, \\ Université Libre de Bruxelles, Brussels, Belgium
}

In Logique du Fantasme, Lacan argues that the compulsion to repeat does not obey the same discharge logic as homeostatic processes. Repetition installs a realm that is categorically different from the one related to homeostatic pleasure seeking, a properly subjective one, one in which the mark "stands for," "takes the place of," what we have ventured to call "an event," and what only in the movement of return, in what Lacan calls a "thinking of repetition," confirms and ever reconfirms this point of no return, which is also a qualitative cut and a structural loss. The kind of "standing for" Lacan intends here with the concept of repetition is certainly not something like an image or a faithful description. No, what Lacan wishes to stress is that this mark is situated at another level, at another place, it is "entstellt," and as such, it is punctually impinging upon the bodily dynamics without rendering the event, without having an external meta-point of view, but cutting across registers according to a logics that is not the homeostatic memory logics. This paper elaborates on this distinction on the basis of a confrontation with what Freud says about the pleasure principle and its beyond in Beyond the Pleasure Principle, and also takes inspiration from Freud's Project for a Scientific Psychology. We argue that Lacan's theory of enjoyment takes up and generalizes what Freud was after in Beyond the Pleasure Principle with the Wiederholungszwang, and pushes Freud's thoughts to a more articulated point: to the point where a subject is considered to speak only when it has allowed the other, through discourse, to have impacted and cut into his bodily pleasure dynamics.

Keywords: Freud, Lacan, repetition compulsion, jouissance, fort-da, beyond the pleasure principle, representation, dopamine

\section{INTRODUCTION}

It is well into his life as a practicing psychoanalyst that Freud wished to come to a firmer theoretical grounding of the clinical observation that people do not necessarily want to get rid of their suffering or their symptoms. Against therapeutic efforts of all kinds, people time and again repeat, even cannot not but repeat, what makes them suffer. This is what Freud means by Wiederholungszwang, the compulsion to repeat, situated, so he says, beyond the pleasure principle. In the text with the same name, Beyond the Pleasure Principle (Freud, 1920/1955), he explores the theoretical underpinnings of this clinical phenomenon. The idea he defends here is that the principle of 
repetition, and not the pleasure principle, is the most basic module of mental life, grounded in the drives. Freud is bold in his clinical affirmation - yes, the basic module of mental life is the compulsion to repeat, and not the pleasure principle ${ }^{1}-$ but he clearly does struggle to articulate the Wiederholungszwang in relation to the pleasure principle.

In Logique du Fantasme, Lacan (1966-1967/2017) invites us to consider that Beyond the Pleasure Principle constitutes a "conceptual intrusion" in Freud's work. He insists: "Do we really measure what is at stake here?" To him, the Wiederholungszwang, articulated in terms of jouissance, enjoyment, constitutes a genuine break with the pleasure principle, a contradiction even with what Freud would have thought until then to be the module of the functioning of the mental system, namely homeostasis, that holds that living substances always seek the state of minor tension. To Lacan, there is no doubt about the fact that the pleasure principle reissues homeostasis for mental life: the mental system, in as far as it is ruled by the pleasure principle, "echoes," "repeats," "redoubles" organic, homeostatic requirements. ${ }^{2}$

In this paper, we propose to clarify what is at stake in Lacan's diagnosis of a "conceptual intrusion" in Freud's text. We argue that Lacan's theory of the signifier and of enjoyment basically takes up and generalizes what Freud was after in Beyond the Pleasure Principle with the Wiederholungszwang, and that, notwithstanding the overt differences in style - Freud being more versed into biological metaphors and concepts, Lacan more into logical and topological formalizations - it is not the case that Lacan's theory of the signifier with its focus on formalization is far removed from the apparently more bodily concerns of Freud. On the contrary, Lacan pushes Freud consequently to the point where the act of speaking itself is shown to involve an ineliminable place of the speaking other, while also having a subversive impact on what constitutes the homeostatic bodily pleasure dynamics.

This paper has two parts. In the first part, we explain what Lacan means with the idea that we are thinking with the object. This is important to come to clarity about his account of the signifier as participating in the dynamics of pleasure and

\footnotetext{
${ }^{1}$ See, for instance, the end of II, where Freud speaks of tendencies beyond the pleasure principle, "more primitive than it and independent of it" (Freud, $1920 / 1955$, p. 17), or at the end of III, where he states that the compulsion to repeat is "more primitive, more elementary, more instinctual than the pleasure principle which it over-rides" (Freud, 1920/1955, p. 23). We note the unhappy translation of triebhafter into more instinctual - the translation of Trieb by drive would have been more accurate. Luckily, this is remediated in the new translation from the upcoming Revised Standard Edition, edited by Mark Solms. A critical and annotated version of Beyond the Pleasure Principle has meanwhile been published in Psychoanalysis and History (Freud, 1920/2015).

2"Quand Freud introduit pour la première fois, dans son Jenseits à lui, l'Audelà $d u$ principe du plaisir, le concept de répétition comme du forçage, $Z w a n g$, répétition, Wiederholung - cette répétition est forcée: Wiederholungszwang quand il l'introduit pour donner son état définitif au statut du sujet de l'inconscient, mesure-t-on bien la portée de cette intrusion conceptuelle? Si elle s'appelle 'au-delà du principe du plaisir', c'est précisément en ceci qu'elle rompt avec ce qui, jusque-là, lui donnait le module de la fonction psychique, à savoir cette homéostase qui fait écho à celle que nécessite la substance de l'organisme, qui la redouble et la répète et qui est celle que, dans l'appareil nerveux isolé comme tel, il définit par la loi de la moindre tension. Ce qu'introduit la Wiederholungszwang est nettement en contradiction avec cette loi primitive, celle qui s'était énoncée dans le principe du plaisir" (Lacan, 1966-1967/2017, séance XI, p. 134).
}

repetition. To this end, we draw on Freud's clinically interpreted anecdote of fort-da, and on Lacan's re-interpretation of it in his seminars The Four Fundamental Concepts of Psychoanalysis (Lacan, 1963-1964/1973) and La Logique du Fantasme (Lacan, 1966-1967/2017). In the second part, we clarify and critically discuss how the use of signifiers introduces a radical cut organized around the limit points of the pleasure principle. Here, we depart from the distinction Freud introduces in his Project for a Scientific Psychology between understanding and judging, having it correspond, respectively, with the realm of representational, grasping bodily movements and the functioning of the mark, seen as a precursor and initiator of the properly subjective realm, with, between both, a relation of fundamental contingency or arbitrariness that serves as the ground for the compulsion to repeat.

\section{TO THINK WITH THE OBJECT: FREUD AND LACAN INTERPRETING THE CHILDREN'S GAME "fort-da"}

In Beyond the Pleasure Principle, Freud re-discusses the fort-da children's game ${ }^{3}$ to make it clear that the compulsion to repeat is not just to be equated with the repetition of painful events. Both the compulsion to repeat and the repetitive children's games are related to the dynamics of excitations and their discharge, that is, to the pleasure dynamics. But they are so in a different way.

As early as Freud (1895/1966), proposes in his Project for a Scientific Psychology that homeostasis, the process that seeks the state of minor tension, is the default mode of mental functioning. This means that the mental system seeks in the first place to get rid of tension, that is, it is after the restauration of a previous state of less tension. Freud acknowledges of course that there is no mental functioning on that basis alone, because the mental apparatus also needs to be able to retain tension for a sufficient timespan, and it needs to be able to do this in organized ways, otherwise there would be no way of acting effectively in the surrounding world. ${ }^{4}$ The reality principle is what captures this requirement of retaining tension in order to adequately act and maintain oneself in the world. Both the pleasure principle and the reality principle, however, are eventually seeking a decrease in tension. ${ }^{5}$

${ }^{3} \mathrm{cf}$. Freud (1900/1953, The Interpretation of Dreams, p. 461) and Freud (1920/1955, Beyond the Pleasure Principle, II, pp. 14-17). The game concerns a young child (Freud's grandson) that used to play with his toys in such a way that he makes them disappear out of his sight, pronouncing then the long sound $o-o-o$. One day, while lying in his cradle, the child plays with his a bobbin, throwing it over the edge, pronouncing $o$-o-o again, and then, pulling the bobbin back in his little bed, triumphantly greets it with $a-a-a$. The two sounds are interpreted by Freud as expressing respectively fort and $d a$, away and back.

${ }^{4}$ That corresponds to the function of the ego. The ego cannot function but as a set of 'permanently activated neurons, i.e., neurons that can retain excitation "Thus the ego is to be defined as the totality of the $\psi$ cathexes, at a given time, in which a permanent component is distinguished from a changing one" (cf. Freud, 1895/1966, Project for a Scientific Psychology, p. 323).

${ }^{5}$ That is why they can be said to be both operating in function of the death drive, as Freud explicitly admits in Beyond the Pleasure Principle (Freud, 1920/1955), VII, pp. $62 \mathrm{ff}$. In "The economic problem of masochism" (Freud, 1924/1962), however, 
The question is, of course, how much tension the mental system will or should be capable of retaining, and why or how it will do so. This matter is at the core of the Freudian distinction between the pleasure principle and the compulsion to repeat. In discussing the fort-da game, Freud stresses that the child, by staging the presence and the disappearance of his toys, compensates for the anxiety and the pain that the absence of the mother is provoking in him. The game repeats the supposedly painful event, which suggests that there is no immediate relief of tension involved. Freud, however, does not hesitate to say that the indemnification at stake involves a direct benefit. It concerns a different kind of pleasure though, one stemming from another source (Freud, 1920/1955, p. 17). The difference, so Freud explains, has to do with the fact that the child succeeds in being less passively subjected to what he experiences, has found ways to actively master, that is, to bind excitations through the throwing away and pulling back of his bobbin and the repetitive "o-a," fort-da. In this way, discharge is enabled, while a distance is created with drive satisfaction. The use of "o-a" - that Lacan refers to as signs, marks - is what makes the mastering drive independent of whether the memory was itself pleasurable or not (Ibidem, pp. 16-17). ${ }^{6}$ However, even if the child's mental

Freud equates death drive with the Nirwanaprinciple, the pleasure principle and the reality principle as its modified form, with the representatives of libido.

${ }^{6}$ Several comments are in order here. Firstly, there is one clear passage in Jenseits in which Freud speaks of the importance of the trait (the $Z u g$ ) in relation to repetition: “This 'perpetual recurrence of the same thing' causes us no astonishment when it relates to active behavior on the part of the person concerned and when we can discern in him an essential character-trait (Characterzug) which always remains the same and which is compelled to find expression in a repetition of the same experiences." We are much more impressed by cases in which the subject appears to have a passive experience, over which he has no influence, but in which he meets with a repetition of the same fatality (Freud, 1920/1955, Beyond the Pleasure Principle, II, p. 22, italics original). While, in the context of the discussion of fort$d a$, Freud stresses in the first place "the use of the object" and talks of pleasure stemming 'from another source,' Lacan explicitly interprets the "o-a" as signs or marks, in line with the passage we mentioned [for instance in Logique du Fantasme (Lacan, 1966-1967/2017), XI, p. 136 (italics original)], where he writes: “(...) identité significante du 'plus' ou du 'moins' comme signe de ce qui doit être répété [character-trait (...) which is compelled to find expression in a repetition]," and also in The Four Fundamental Concepts (Lacan, 1963-1964/1973), V, p. 54, where he discusses automaton and tuchè: “(. . l) l'insistance des signes à quoi nous nous voyons commandés par le principe du Plaisir." That Lacan speaks of signs might be confusing, in as far as the sign here is purely formal and is defined in terms of oppositions. As such, it is what can be understood by the functioning of the signifier. Clearly, what Lacan intends is something different from more traditional (philosophical) accounts of the sign where it refers to something for someone (Peirce), or from cognitive views according to which the sign is what identifies stimuli on external grounds. With Lacan, following Freud, a sign or a mark is constituted by parameters or characteristics holding from within the subjective realm itself. As we explain further in this paper, Lacan speaks here of signs in reference to the Einzige Zug, which is the symbolic mark, the first signifier, that indicates that something was lost and cannot but be repeatedly searched for. By initiating that movement of repetition at the level of the signifiers, the little human being grafts himself upon the other, and inscribes himself in what Lacan calls le champ de l'Autre, the field of the Other (cf. Lacan, 1966-1967/2017, XVII, pp. 224-225/p. 136). Even if the distinction between the first and the second signifier, the Einzige Zug (the "sign") and the "proper" signifier can only be made from within the realm of "significance," the realm of the functioning of the signifier, it is nevertheless relevant to logically distinguish that first moment, the one in which something merely indicates that something was lost without being part of a differential system of signifiers. Of course, this is a mythical moment, set apart logically. Unless explicitly specified, we shall from here on speak of signifiers in order to avoid confusion between the philosophical use of the concept of sign and the psychoanalytical one. Secondly, to suggest that "another level" is initiated functioning is independent of the initial objects of satisfaction, even if the use of signifiers installs the pleasure dynamics at another level, at another place, there is in Freud's viewpoint on mental life still an "echoing," "repeating," "redoubling," as Lacan states, of organic, homeostatic requirements. The module of mental life is homeostasis, that is, the pleasure principle.

Lacan's (1963-1964/1973, p. 60) comments on the fort-da experiment in The Four Fundamental Concepts of Psychoanalysis are revealing for the questions that concern us here. Lacan is not siding with Freud's clinically based distinction between the repetition at stake in the children's game - still situated under the heading of the pleasure principle, albeit distinguished from mere drive satisfaction - and the "real" repetition he wishes to consider as lying beyond the pleasure principle, i.e., the compulsion to repeat. On the contrary, he considers the fort$d a$ game as an instantiation of what constitutes mental life at heart, ruled, that is, by repetition, and, therefore, not ruled by a pleasure principle that echoes homeostasis. In this sense, repetition, also coined as enjoyment by Lacan, is in his view not "natural," not obeying to what instincts or needs command in terms of pleasurable discharge. ${ }^{7}$ To Lacan, what counts in repetition, and what to him is illustrated in the fort-da game, is the attachment to that which stays the same, namely, the signifiers, "o-a," fort- $d a$, endlessly repeated. ${ }^{8}$ That the repetitive use of "o-a" takes place in an apparently signifying relation to a multiplicity of toys, in a variety of situations, is not what counts in the first place - it rather risks to distract us from its genuine significance. As a matter of fact, to consider the fort-da as a stamp of some or other event - the absence of the mother, for one, as Freud suggests - is too quickly complicit with a semantic-representational account and thereby misses the real point. ${ }^{9}$ According to Lacan, following here Wallon, the child is

when dealing with signifiers, or, with Freud, to talk of pleasure as stemming from "another source," is in agreement with the Freudian idea that memory and consciousness are two different and mutually exclusive systems: opening the possibility of using signifiers is opening the possibility of memory and immediately closes off their presence in consciousness. Thirdly, it is worth noting in passing that Freud speaks in the context of the use of signifiers, as in theater plays, of enjoyment, Genu $\beta$ (Freud, 1920/1955, p. 17) - the subject enjoys the commemoration of painful events in the play - a thing that will be of importance in the Lacanian viewpoint on enjoyment.

${ }^{7}$ The use of terms such as "natural" is never unproblematic. In this context, we take it that Lacan intends natural as opposed to cultural. We do not want to open the philosophical discussion on nature/nurture here, but we do want to stress that the opposition is perhaps less straightforward than Lacan seems to suggest. We will argue further on that even if the compulsion to repeat is seen to be categorically distinguished from the pleasure principle grounded in a homeostatic dynamics, this does not mean that there are no biological constraints to be taken into account. As a matter of fact, what we intend to show is that the compulsion to repeat, even if it does not follow homeostatic principles, does have a logic that can be said to be biologically anchored and is clearly linked to precise biological constraints (Bazan and Detandt, 2013).

${ }^{8}$ This is perfectly in line Freud's "perpetual recurrence of the same thing," stated in Jenseits, albeit not in the passage where we find fort-da. See footnote 6 for the full quote.

${ }^{9}$ The term representation (as well as meaning, content, ...) is extremely tricky. It is not the place here to unfold its various (mainly philosophical) traps and potentialities, but in relation to Lacan, it can be said that the representational realm mostly goes hand in hand with meaning, content, semantics, all of the imaginary order, against which he warns time and again. This is not per se the most adequate or the most interesting option though. We explain further on an alternative viewpoint on representation, one that is more radically embedded in 
vigilant for what it experiences as a lack exactly next to him, in his vicinity, not where the mother left the room and where he could expect her to come back. In other words, the child does not constitute its mental life on the basis of, for instance, a "representation" referring to the mother leaving the room, expecting that she will come back at some point through the same door. ${ }^{10}$ It is in the vicinity where the lack makes itself directly felt that the play with the bobbin and the utterance of "o-a" take place. As the bobbin, the "o-a" is actually the little thing that is detachable from him while being still retained, the little thing on the basis of which the infant explores and expands his universe in a movement of self-mutilation - throwing the thing, part of his own movements, away, and thereby bridging the abyss created by the absence of what was in his vicinity a moment before "It is with his object that the child jumps over the borders of his territory changed in wells and that he begins the incantation" (Lacan, 1963-1964/1973, p. 60, our translation). ${ }^{11}$ The little subject of the fort-da, successfully finding discharge through the act of repetitively pronouncing " $\mathrm{O}-\mathrm{a}$," is in the repetitive movements he initiates with his bobbin and covers with "o-a".

So, in sum, Freud grounds the pleasure principle in the possibility of discharge, and quite logically considers the child's game as a successful kind of discharge. What to him lies beyond the pleasure principle, has to do with those occasions where discharge appears to be problematic or radically impossible, such as in traumatic neuroses or in the phenomena of negative transference. To Lacan, however, this clinically observed distinction risks to miss the essential point, namely that in the

the dynamics of the body, and that understands representations as motor forms that correspond to the central imagery that arises from action intentions that did not completely lead to discharge (see Jeannerod, 1994, p. 201; Bazan, 2007, pp. 125-126). The point we wish to make in relation to the above passage, is that in repetition, it is not the content that counts, but the form. As Lacan indicates, the child jumps toward the "o-a" in a movement of bridging what appeared as a lack in his vicinity. To interpret this "o-a" as a "representation" referring to the mother leaving the room, expected to come back through the door, adds too much and too quickly elements of content. What Lacan wishes to indicate, clearly in line with Freud - who also, in Beyond the Pleasure Principle, notes that the child is not in panic at the moment the mother leaves the room - is that it concerns a throw and pull-movement, i.e., a movement of the acting subject, doubled, over-written by a phoneme sequence, "o-a," a signifier which is first and foremost a motor form. For more details (see Bazan and Van de Vijver, in preparation).

${ }^{10}$ Here, is an example of how tricky the term representation can be. It is here used between inverted commas to highlight its traditional philosophical sense, i.e., something that stands for something for someone: the child fears that the mother, whom he saw leaving through the door, will perhaps not come back. Following our viewpoint on representation, and following also Lacan and Wallon in the interpretation of the case, we would say that the activated motor-pattern of the eyes while the mother left the room constitutes the representational structure, formal in nature, and that it is exactly that pattern that is repeated in the play with the bobbin and the accompanying "o-a": the movement of throwing the bobbin away and pulling it back repeats the movement of something being at one point in the vicinity and at another point leaving a void in its absence.

${ }^{11}$ In line with Aristotle, Lacan will add here that man not only thinks with his object, he is, as a subject, where the object is put into practice This probably refers to Aristotle's (1984) idea that the mind is "none of the things existing in actuality before thinking" (De Anima iii 4, 429a24). In other words, thinking is nothing in actuality in abstraction of the form that thinks. Or still, our thinking is only with our objects of thought, that is, the forms. And that is precisely what is at stake here, and what we explain further on: "o-a" are formal objects that correspond to, or "stand for" actions tied together into motor packages that, in their opposite nature, organize what can be called subjective life. signifying procedures whereby the child, or any speaking being for that matter, deals with absence and presence, there is a structural loss, a structural impossibility that inescapably emerges with the use of signifiers, with the use of "o-a." This structural loss is not disconnected from the issue of discharge, and thus of pleasure, but does initiate another domain, obeying a different logics, a logics ruled by repetition. In order to make this clear, we have to explain how the use of the first signifier is connected to the pleasure dynamics, or rather, how it cuts with that dynamics and how it gives rise to the functioning of a new domain. To that end, we need to reconstruct and articulate in more detail how the child is caught into his movements, and how he finds an orientation on that basis.

\section{THE PLEASURE PRINCIPLE AND BEYOND}

\section{Understanding and Judging}

We know that pleasure is seen by Freud as discharge of tension; it is a temporary, floating, and partial suspension of displeasure. ${ }^{12}$ Tension - displeasure, if not trauma - constitutes the background against which pleasure has to be thought. We also know that as long as we live, there is, structurally, the encounter with unpleasantly high levels of tension (Freud, 1895/1963, 1895/1966; Lacan, 1963-1964/1981). Within this setting, the first air entering the respiratory system, the first milk entering the digestive system, can likely be called traumatic experiences. What exactly is at stake in these experiences?

What Freud writes in his Project for a scientific psychology is relevant here. Freud makes a distinction between understanding and judging, that he grounds in the idea that the complex of what surrounds the child, the fellow human being in the first place, falls apart into two components, one which "makes an impression by its constant structure and stays together as a Thing, while the other can be understood by the activity of memory that is, can be traced back to information from [the subject's] own body" (Freud, 1895/1966, p. 331, italics original). So, to understand, is to find relief in and through the proper bodily movements, that is, to succeed in grasping something (comprehensio), so that, by one's own means or not, an effective handle is found on the basis of which discharge becomes possible. To judge, on the other hand, refers to something that resists understanding, a thing that for that reason "stays together as a Thing" and impresses by its constant structure, and that is to be covered and bridged by other means, with what Freud refers to as traits or marks (Züge). To Freud, that is what judgment does: it corresponds to the impossibility of finding adequate movements that would lead to a grasp of the complex (understanding), and constitutes a cut with it by approaching the

\footnotetext{
${ }^{12}$ Freudian pleasure, then, is not an affect in the common sense meaning of the word (namely, a hedonic or agreeable feeling). Freudian pleasure is relief, not delight. Therefore, it is not concerned with valence as affects are. Without going into details, we are inclined to see affect, in the common sense, as far less determining and orienting for behavior than the drive system and as not organized around the adequacy of the act (for more details, see Bazan and Detandt, 2013, 2015; Bazan et al., 2016; Detandt, 2016).
} 
complex through a trait, a mark. A judgment is thereby "entstellt" with regard to understanding, it installs another realm, another domain. ${ }^{13}$

We propose to apply this schema to the dialectics between pleasure and displeasure and to what lies beyond. The potentiality of this move is twofold: on the one hand, it contributes to anchoring the functioning of the mark into the dynamics of pleasure and displeasure, approaching it, so to speak, "from below," and, on the other hand, it allows to ground the (f)act of speaking in the obstacles and the impossibilities the human being encounters specifically in and through the motor patterns and their potentiality to lead to discharge. Let us return to our examples, the entering of milk in particular.

\section{The Thing, the Mark, and Primary Judgment}

What happens in feeding, is that the child, most commonly, finds by itself the voluntary sucking movements that will contribute to the feeding. ${ }^{14}$ The act is what is first, with its motivational point - from where, why, for what reason it is undertaken - left unfathomable from within the system that undertakes it. ${ }^{15}$ As a consequence of the sucking movement, milk enters the system. That is, for the system, a surprise. That the movement of sucking, undertaken, so to speak, "out of nowhere," would lead to milk entering, was not foreseen and could not be foreseen. The first milk that enters the system comes as a surprise, and cannot but come as a surprise; it constitutes an event: the milk is an external, a priori hostile element entering the system. However proximate the entering of milk with the sucking movements is, both are, for the system concerned, disconnected, in the sense that there is nothing in the act of sucking that is connected with milk: their relation is contingent. Also the fact that the sucking brings a certain relief simply related to the sucking itself, is initially disconnected from the milk and does not diminish the surprising effect of the latter. The event of milk entering the system for the first time is inscribed as a mark, but it is not understood - the milk "stays together as a Thing." Our hypothesis is therefore that what is marked is first and foremost the event itself: the mark is the point, the punctual point expressing and inscribing the bodily surprise. ${ }^{16}$ The mark corresponds, in

\footnotetext{
${ }^{13}$ For a more extensive Lacanian discussion of the Thing, la Chose (see Lacan, 1959-1960/1986; Lew, 2014).

${ }^{14}$ Our schema is also applicable to what happens in breathing, but it is different in the sense that the child, most commonly, finds by itself, through voluntary breathing movements, the adequate act that creates a relief of tension. In breathing - in contrast, e.g., with feeding - there is no constitutive need to for a contribution of the other, nor is there a difference in timing between finding the grasping movement (the breathing movement) on the one hand, and the satisfaction of the drive. We chose for the example of feeding, because it allows us to more straightforwardly articulate the different moments we wish to distinguish here.

${ }^{15}$ This structurally missed step and the ways to retroactively recover it, whereby it is identified as the cause of our acting, is, actually, the ground for the hypothesis of the unconscious.

${ }^{16}$ This event is, so we think, beyond the mechanical part of it, the explosion of the sugar receptors in the mouth massively and suddenly highly activated. As we have discussed elsewhere, a physiological marker is proposed for this surprise in the form of a release of dopamine at the level of the nucleus accumbens, i.e., the dopamine peak indicating unexpected reward (Bazan and Detandt, 2013) but
}

our view, to what Freud called the "Triebrepräsentanz," 17 that is, the point where the subject allowed for the fact of "being taken by surprise" and that opens the possibility of returning to that point. We consider this "being taken by the event in the form of a mark" as the first step in the process of subjective positioning, the first or primary judgment, corresponding to what Freud calls "Bejahung," or what with Lacan becomes "Bejahung pure, primitive" (Lacan, 1955-1956/1981, p. 95) or “Bejahung primaire" (Lacan, 1966, p. 387). It does involve the position of the subject, albeit in a very preliminary and inviting sense: the fact that the trait was inscribed as a mark of the event, witnesses to a subjective choice - the little human let himself be surprised by the milk entering, it could as well have chosen not to drink. It therefore opens subjectivation as a task, an agenda. ${ }^{18}$ However, it is important to note that this logical time of being struck by surprise, is not exclusive to human beings, but, as we will explain further on, has to be supposed in vertebrates in general too.

What happens then with the undertaken movement that has made the entering of milk possible, and what about the relief to which it eventually contributed, or not? What role does it play in this "preliminary subjectivation"? Clearly, this movement, or cluster of movements, is of no help in understanding the event, but, being proximate, it gets linked to it, contingently but no less firmly. It is this link, inherently contingent but factually proximate, that, in our view, lies the ground for the further articulation of subjectivity, and of which Lacan will say that it is the ground for repetition.

What we propose here is that the adjacent movement, being only contingently linked to the ungraspable Thing of which the subject is factually experiencing the effects of surprise, this adjacent movement indicates and covers, "stands for," the ungraspable Thing. Freud himself is speaking of Vorstellungsrepräsentanz, a term that caused a huge confusion among psychoanalysts and scholars. ${ }^{19}$ Freud sometimes identifies the Triebrepräsentanz with the Vorstellungsrepräsentanz, and there is something understandable at this. We would be inclined to say that the first adjacent movement, contingently sticking to the mark, so to speak, also already belongs to another

also the dopamine release corresponding with disrupting, aversive and traumatic events (Bazan and Detandt, 2015), taken together as dopamine release 'marking' the unexpected event, independent of its valence (Bazan et al., 2016), and leading to a physiological registration known as 'incentive sensitization.'

${ }^{17}$ There can be a hesitation between Triebrepräsentanz and Triebrepräsentant, the first referring to the function of taking-the-place-of ("tenant-lieu"), the second to the taking-the-place-of itself. We wish to stress in the first place the notion of Repräsentanz. We shall see further on the delicate status of this point. For an extensive discussion of this concept (see Tort, 1966/2016), and for a subtle and pertinent "mise au point," primarily in relation to the functional interpretation of the Repräsentanz (see Lew, 1983).

${ }^{18}$ It would be possible and relevant to further elaborate on this issue in terms of alienation, as Lacan himself does all along in Logique du Fantasme. The subject (of the unconscious) is in "the part that is lost"; it is the subject of "je ne pense pas," and that part is what shows itself "by surprise." In relation to surprise, Lacan refers to Theodor Reik as the sole analyst having stressed its importance in relation to the unconscious (Reik, 1935/1976; cf. Lacan, 1966-1967/2017, VII, p. 92, Logique du Fantasme).

${ }^{19}$ It was for instance translated as "représentant représentatif" (Laplanche and Pontalis) or by Lacan as "tenant lieu de la représentation" (see Tort, 1966/2016; Lew, 1983, for a discussion). 
realm, namely the realm of movements that can become representational. The adjacent movement thus carries both sides: it refers to the Repräsentanz, with the mark taking the place of the Thing and having the potentiality to elicit Vorstellungen, representations - these two different logical moments reflect Freud's inaugural distinction between judgment at the one hand and comprehension at the other.

Beyond that first "sticky moment" where the Repräsentanz remains a pure potentiality - which is, actually, a logical moment, not a genetically identifiable moment ${ }^{20}$ - a call for other types of movements is launched, intentionally directed grasping movements this time, that are effectuated as a return to what escaped comprehension. Indeed, the first sucking is a sucking to discharge the sucking tension, but if it is followed by the event of the milk coming $\mathrm{in}^{21}$, and if it is thus given the weight of the mark, the subject can choose to have the next sucking as an intentionally directed movement, to grasp - i.e., to get - the milk. In this way, the Repräsentanz is what elicits representational i.e., mental - activity. This subjective representational work is a work of understanding, of com-prehension, or at least, it is an attempt to understand, to grasp. This work is constituted on the basis of the marked adjacent movements - marks that are, as we have argued, the marks of a non-understanding, of a limit to understanding, that is, a limit to the possibility of grasping something, a limit to making that something (the milk entering as a surprise) into an object.

Very much in line with this, Lacan will consider the mark as the first signifier, S1, corresponding to Freud's unitary trait, the "Einzige Zug," the symbolic mark that constitutes an event by indicating a cut with the level of what is being marked (Lacan, 1966-1967/2017, p. 135). The S1 enables the primary judgment that has the form of an affirmation (Bejahung): it marks that there was an event that struck the body. However, to Lacan, the S1 has to be called symbolic already: in order to be called a mark at all, it intrinsically demands to be deployed and ever re-deployed through the articulation of representations that engage with other signifiers. ${ }^{22}$ If the mark would not have elicited the subject to a return, it would not be an Einzige Zug, an S1. S2 then stands for the chain of signifiers that aim at a return to the first signifier in an attempt to grasp or understand the initial moment of surprise, and in this sense corresponds to the representational activity which Freud refers to as the com-prehensio. Lacan speaks here of a "thinking

\footnotetext{
${ }^{20}$ It is certainly not a genetically identifiable moment, as it is a moment of historization, indicating the registration of the contingency of a subject's history in the form of a marked event. We do however think (as indicated in footnote 16) that there is a physiological correlate to this marking, in the form of a dopamine release, probably a dopamine spike. Note that if biological correlates can be situated at precise moments, their mental realization is dynamic, hence the use of the term 'logical moment' instead of 'chronological moment' (see also Bazan and Detandt, 2017).

${ }^{21}$ See footnote 16 .

${ }^{22}$ Here, we easily jump from representations to signifiers. However, we propose that both are logically equivalent. Indeed, a representation (see footnote 7) is thought as a motor activation rest of an action intention that could not be discharged in actual motor activation; a signifier, then, is merely the application of this logic to the act of speaking, i.e., to articulatory phoneme motor patterns. Both representations in general, and signifiers specifically, are thus motor potentialities, i.e., forms, without any determined content or meaning.
}

of return," a "thinking of repetition" (Lacan, 1966-1967/2017, p. 135). ${ }^{23}$ The articulation of this representational realm, its structuring, is properly symbolic, constituted of representations, but it is, meanwhile, very much anchored in the body, determined by what is, along a subjective history, being "accepted and inscribed" as a mark and what is contingently adjacent to it as an undertaken movement. In other words, what initiates the repetition of these actions is not the possible reward or relief they might bring about. What causes repetition is the fact that the action is being linked to the event, the event being constituted by surprise. Note that the marking, with an adjacent movement being contingently linked up with it, is independent from whether the event was painful (first air coming into the lungs) or rewarding (first milk entering the mouth cavity). In other words, the fact that milk enters the digestive system and eventually brings relief is secondary to the effect of the event as such - and it is the latter, not the former, that induces the repetition. $^{24}$

What has to be further elaborated, therefore, is what this movement of "thinking of return" exactly involves, how it is marking specifically the human being as a speaking being, with representations becoming genuinely signifiers, and what, if anything, constitutes, in this context, the difference with the compulsion to repeat. In order to further unfold this, we need to turn to the status of the object, its relation to the possibility and the meaning of discharge, as well as to the role of the fellow human being in this fabric of pleasure and enjoyment.

\section{The Signifier Inscribed in a Basic Non-attunement of Actions and Needs: The Role of the Other}

Let us return once more to the question of what happens in the deployment of directed actions by the subject, knowing that it must have been historically struck by the event, accompanied by the experience of the adjacent movement contingently linked to it. We know that all vertebrates capable of action have to cope with an initial non-attunement of actions and needs. The reason for this is structural. Vertebrates are characterized by a double body: an inner, invertebrate sack-like body with all the big vegetative systems (respiration, digestion, excretion, etc.) and a "newly invented" outer body constituted by a skeleton and striated muscles (see Bazan, 2007). While needs arise in the inner,

\footnotetext{
${ }^{23}$ See here Lacan's discussion of the children's play with "o-a." To Lacan, from the moment the child uses "o" (S1), we cannot but add to it the differential "a" (S2), revealing the moment of $\mathrm{S} 1$ in isolation as a mythical, logical moment. He calls therefore the S1 symbolic, and states that there is from thereon no grounding to be looked for in the similarities or differences between objects such as toys, bobbins, mothers, to identify what a mark is. Nothing of this sort is hidden in the plays of Freud's grandson that would justify the use of "o-a," as nothing of this sort would justify the marked surprise effect in the child. According to Lacan, a unitary trait identifies something - in our interpretation, an event - but it is only through the repetition, in the differential play with other signifiers, that an event genuinely becomes a subjective event.

${ }^{24}$ The first events in life frequently lead to the repetition of actions crucial for our survival, but our intuition is that this is at the bottom of it a matter of chance, not of teleology. E.g., a pigeon that made a wing movement before receiving a grain (Skinner, 1948), will from then on also repeat that wing movement because it had been registered as what had to be repeated, even if it had nothing to do with its survival chance (https://www.youtube.com/watch?v=8uPmeWiFTIw).
} 
invertebrate body, the specific actions for the satisfaction of these needs are outer body actions. The structural non-attunement between actions and needs resides in the fact that it is not $a$ priori clear what outer body action could constitute a response to what the inner body needs. Even if this gap is less prominent in most vertebrates as compared to humans (e.g., little horses get on their feet and move toward the mother nipple in the span of hours after birth), the idea is nevertheless that, even in animals, this instinct-encouraged movement has to be sanctioned by a mark (a dopamine-release) to be registered as a movement with a high potential for repetition, and that therefore, independently of instincts, the body registers the history of (contingent) events. Once a specific action has been linked to an event, what drives to repeat this action, is disconnected from the drive satisfaction itself. Indeed, the relief caused by the satisfaction of an internal body need is only contingently connected to what the external body succeeded to develop as an action. The relief, as the tension itself, is a serendipitous addendum, a by-product, important for survival, but not determinative for what drives repetitive behavior. No matter what the outcome, the child will not stop the endless repetition, the sucking, or, as Freud stressed, the endless uttering of "o-o-o" and then "a-a-a." From the moment the child accepted and marked the event, it is driven by the repetition compulsion to grasp. So, it is from within the repetition compulsion that relief of tension becomes possible - it is not the relief of tension that is the ground for repetition.

It is often said, from within a psychoanalytical setting, that what drives the human being is not the satisfaction of needs. We agree with this. In line with what we elaborated in relation to higher vertebrates, however, we consider that the structural non-attunement of needs and actions holds in the same way for human beings, and that it is intrinsically related to the way in which vertebrate bodies are constituted. This allows us now to address the question of the specificity of the human being, as a speaking being, from a slightly different angle. It is true, indeed, as Freud already highlighted in his Project for a Scientific Psychology, that the human child is born in a configuration of helplessness, which implies that the fellow human being plays a role that is structurally of the utmost importance in the constitution of his subjective world. Let us return to our example of the milk. Up until this point we have brought the scenario as if what is crucially at stake for the child is the sucking. However, due to his helplessness, the repetitive action of the sucking is, per force, supplemented by other actions, e.g., crying, vocalizations, that contingently, but crucially, contribute to realize the conditions within which relief becomes possible. Again, what drives the child to act and repeat its actions is not the possibility of relief in itself, it is the attempt to grasp what initially escaped, namely the surprising event. And in this grasping attempt, the other, as a speaking being, is once more an ineliminable factor. Indeed, a bunch of contingent movements, situated primarily in the realm of vocalizations, that, by surprise, out of nowhere, made a difference (i.e., brought the mother, the milk, relief), doubles, in a far more whimsical fashion, the logically first contingency of the sucking movement. Indeed, a mother, with far more fierceness than, e.g., milk, resists objectification, stays together as a Thing. More correctly, it is to the extent that the other "stays together as a Thing" and resists understanding, that the child is launched, here again, for an endless 'thinking of return', a re-elaboration of his first vocalizations, in an attempt to grasp after all that which entered his system as a surprising event and with regard to which it did not succeed in articulating the appropriate adequate actions.

We therefore agree with Lacan when he states that the child thinks with his object, which means that he subjectivizes through the handlings with his object. We also agree with him (cf. his reading of "o-a"), that the use of signifiers, and the linguistic, signifying practices at large have to be understood along the same lines: a signifier is handled as an object, the object perhaps, on the basis of which the child explores and expands his subjective universe. We have explained in the previous part how these handlings are articulated in terms of a failure in grasping the Thing, how the marks in a sense "take over," or at least initiate a new realm of being, the realm properly constituted by signifiers (which is the Other, in Lacan's terms). We remind here that the signifier is a form, a motor-pattern, only contingently linked to what brings discharge - indeed, it marks precisely what was not understood and could not be brought back to memories of the proper body.

Repetition or enjoyment, a "thinking of return," as Lacan calls it, is therefore, for the human being, intrinsically bound up with the nature of the signifier. The child, in the same movement of adopting the signifier that is offered to him as a formal potentiality by the other, inscribes himself in a universe of vocalizations where it is structurally impossible to grasp the Thing. It is from there on condemned to run after the Thing, to commemorate what can be called, perhaps, a moment of exquisite subjectivity - the structurally escaping moment of having been struck by surprise. By structurally missing this point because of the fact that the Thing is situated at another level and cannot be brought back to bodily understanding, the subject endlessly, repetitively, runs after "the facts": it repeats the marks in themselves, and strives for understanding after all, attempts to make the Thing into an object, to bring it back to proper and directed body movements that bring discharge. Both realms, however much intertwined they are, are disconnected realms, only contingently bound up. As we saw with the "fort-da" game, the child produces the first signifiers "out of nowhere," or at least, these signifiers cannot be grounded in the distinctions between his toys, between the mother or the father being absent or present. There is no way back from signifiers to meanings ${ }^{25}$ : the relation between form and content is neither innately, nor naturalistically grounded. As we saw with the first mark, the Einzige Zug: signifiers emerge at the point where a "naturalistic" grounding - an adequate grasping of the object, leading to discharge - reaches a limit. Or perhaps more correctly: the use of the signifier indicates that a limit was reached, indicates that the bodily movements were inadequate.

What both Freud and Lacan note in relation to this repetitive dynamics, a thing that follows logically here, but needs to be

\footnotetext{
${ }^{25}$ This is an ironic reference to Russell's (1905) “On Denoting," where he says, albeit from a different angle, but with, in our view, the same stakes at play, that there is no backward road from denotations to meanings.
} 
stressed time and again, is that the action does not at all need to be adequate to be repeated. This is quite generally what clinical experience confirms: it may be certified that praying or singing does not stop the earthquake - it is nevertheless repeated. The child's repetitive "o-a" does not impact on the leaving and the return of the mother, but it is joyfully and victoriously repeated nevertheless. We have defended elsewhere (Bazan et al., 2016) that even if the act is not adequate in grasping the thing, it still is better than sideration or bewilderment; it is the execution in itself that brings relief. Freud will say it is relief "from another source"; Lacan will consider that it radically concerns another domain, the domain of signifiers to which the child finds entrance. And in this domain, the other, the Other, occupies an ineliminable place: without the other/the Other, there would be no "significance," no functioning of the signifiers. It is a space where contingency, or rather, arbitrariness between form and content reigns: the exchanges between the child and the other, in as far as they are based in signifier exchanges, are firstly formal exchanges, content being realized in the historical interweaving between those forms, the adjacent bodily movements and the web of directed and intentional actions deployed in their wake.

\section{The Object as a Coherent Motor Package and the Experience of Satisfaction}

What is there to say then about the object? We would be inclined to consider an object as a coherent motor package, a bounded set of grasp movements that opens the possibility of discharge. We already said that the Repräsentanz ${ }^{26}$ "stands for" the event: it might be considered as a crystallization of movement parameters into a solidary whole. It is different from what philosophers are traditionally inclined to call an object, though, as it is a contingent whole of movements arbitrarily cut out of a sequence and has no intentional directedness. However, as argued, the motor pattern has the potentiality to launch for a return under the form of directed actions. These actions produce what we would call in the proper sense "mental" representations of what first intruded the system and stayed together as a Thing. It are then these "mental representations" that, when executed, can lead to discharge, however partial and temporary that is, and which can, in our view, be genuinely called objects. In other words, the mental, representational inscription amounts to an objectification. As this is likely to be the most delicate point of our argumentation, we dare to insist. Firstly, what we call an object or a representation is first and foremost a motor pattern, a motor intention, as Jeannerod calls it (Jeannerod, 1994; Bazan, 2007): it is the motor form within which something can be grasped. To address the question of the object, is therefore in the first place to ask for the formal arrangement of the space of possible motor patterns. What serves as a filling up in that space - content, meaning, ... - is secondary, and does not inform about the arrangement of the space itself. In other words, questions about

\footnotetext{
${ }^{26}$ The difference between Repräsentanz and Repräsentant can once more be brought forward here: however frozen or crystallized the motor pattern is (Repräsentant) it is nevertheless a motor-pattern, hence formal, potentially ready to receive different contents, and thus it is also functional in nature (Repräsentanz).
}

representations corresponding more or less adequately to some or other object out there, are missing the point. A representation is an object, is a motor pattern, and the articulation of the space of motor patterns, being a constraining space, is at the meantime the enabling condition for what counts as an object: the constraint is the possibility. ${ }^{27}$

This account of the object enables us to address (i) the typically Lacanian idea of the object as bound up with a structural loss - the fact of launching comprehending grasp movements is indicative of, rests on, a step being missed, as we have shown, the step corresponding to a non-understanding, covered by the mark - with the object $a$ that theoretically indicates this ever missed object, (ii) the issue of objective reality, that here refers to successful grasping movements, i.e., movements leading to discharge. Clearly, the issue of discharge is crucial in the constitution of the object. As a matter of fact, only that which can give rise to discharge has a chance to lead to objectification. Along these lines, Lacan states that it is impossible to understand what an object is without the dimension of satisfaction, a thing that, to him, largely escaped the philosophical tradition. ${ }^{28}$ There is, however, a potential confusion in the way in which Lacan uses the term satisfaction, at least in as far as we take it to refer to the satisfaction of needs. We have indeed argued that there is a contingent, arbitrary relation between what brings satisfaction of needs and what is constituted as an object through motorpatterns. We have also argued that object-constitution happens on grounds radically cut from what brings satisfaction of needs. We are indeed speaking of another level, of pleasure "from another source" as Freud states, of objects of enjoyment, as Lacan calls it. In other words, objects of pleasure are not situated at the level of the satisfaction of needs ${ }^{29}$ ! We propose therefore to reserve the term satisfaction for the level of needs, to talk of objects of pleasure when we are aiming at the object constitution that is related to what brings relief, diminution of tension, and of

${ }^{27}$ The resemblance with Kantian epistemology is straightforward. Kant's dictum that "the Thing in itself is not knowable" serves as the starting point for his epistemology: from the moment we talk about objects and objectivity, we talk about what there is "for us," in our words, what is within the range of the graspable through our motor patterns. Another way of saying the same thing, from within the formalistic tradition in philosophy (Frege in the first place) is that the grasping space is a functional space - in line with Kant's philosophy that articulates the functionalism of Reason. It is from within the functional space that the place is prepared, delineated, circumvented, of what can come to satisfy the function. That place within a functional space, that is the object. In our words: that motor pattern ready to grasp something, that is the object. The formal discussion that is relevant in this regard, is the one on the relation between intension (that defines the function) and extension (that satisfies the function). Lacan works with these distinctions frequently, not in the least in his Seminar XII, Problèmes Cruciaux pour la Psychanalyse (Lacan, 1964-1965/2003).

${ }^{28}$ There is no way, dixit Lacan, to conceive of an object without the dimension of satisfaction. With regard to the homeostatic, organic account, he says: "Rien, dans tout cela, qui pousse à la recherche, à la saisie, à la constitution d'un objet. Le problème de l'objet comme tel est laissé intact par toute cette conception organique d'un appareil homéostatique. Il est très étonnant qu'on n'en ait pas jusqu'ici marqué la faille. Freud ici, assurément, a le mérite de marquer, que la recherche de l'objet est quelque chose qui n'est concevable qu'à introduire la dimension de la satisfaction" (Lacan, 1966-1967/2017, p. 156).

${ }^{29}$ It is even questionable whether we can speak of objects of satisfaction; the term "experience of satisfaction" seems more adequate, even if it also demands to be further unfolded, certainly in light of the meaning of the term "experience" in the philosophical tradition. 
enjoyment to indicate the impossibility of relief that the subject is desperately holding on to.

It is in relation to this that the exchanges with the fellow human being have to be investigated. Of course, the fellow human being is essential for what is to be called the constitution of objects of pleasure. In providing for the essential means of discharge carrying out the specific acts - the other structurally intervenes in the temporality of excitation and discharge of the child, codetermines the identification of what counts as an object of pleasure, and in this way also co-determines what lies beyond in terms of enjoyment. That this has its implications for what counts as an experience of satisfaction is evident, but the important thing to note is that it is not the satisfaction that determines the constitution of the objects of pleasure or of enjoyment. Rather, the satisfaction of the need, in this new scheme, is over-written or replaced by the possibility of discharge through grasping movements leading to objectification, a possibility that was opened up as a return to the marked event covering that which stayed together as a Thing. The space of satisfaction of needs is thereby subverted into a space whereby the subject is endlessly and repetitively demanding to be recognized at another "level," the one of subjectivity, expecting from the other to tell him the answer, that is, to bring (to be), for him, the object of relief.

\section{CONCLUSION}

In Beyond the Pleasure Principle, Freud seeks to describe and articulate the functioning of the psychic apparatus in situ, that is, anchored in the ways in which human beings sense, move and act. In discussing the issue of Wiederholungszwang, Freud, here perhaps more than anywhere else, starts from the clinical observation of quantities of excitation of which it is not easy, not possible even, for the subject to get rid. That is where to him the disjunction between pleasure and repetition finds entrance: at the point that cannot be silenced through understanding, the point where pleasure, the possibility of decreasing tension, has come to a limit, the point that in its insistence searches other ways out. Freud's overt biological phrasing is certainly not a matter of looking to ground the psychical in the biological; it is a matter of cutting the psychical at the correct joints. And this cutting cannot but start from the embarrassment in relation to the body, that is, from the moments and the points where something does not obey the logics of pleasure and lies beyond it as a compulsion to repeat.

In line with this viewpoint, and taking up Lacan's revisiting of it in terms of enjoyment, we have argued (i) that the insistence with which subjects repeat is to be grafted upon the structural disconnectedness between what articulates behavior and what satisfies needs, (ii) that this structural disconnectedness, this nonattunement, is to be linked to the bodily make up of vertebrates at large, with the basic distinction between an internal body as a source of excitation and an external body as a motoric means of responding to this excitation in an attempt to diminish it, (iii) that it is relevant to introduce here the Freudian distinction between understanding and judging, and to identify understanding with the articulated motor-patterns of the external body that aim at grasping (com-prehending), and the judging with a dynamics of the mark, in which it is indicated (marked) that something stays together as a Thing exactly to the extent that it is not understood, not grasped through adequate motor-patterns, (iv) that mental representations (signifiers), understood as phonemic motor packages, are inscribed into this bodily dynamics of non-attunement, which means that they are particular motorforms attempting to grasp that from which they are initially and structurally disconnected (the Thing), (v) that this distinction between understanding and judging, combined with the idea that signifiers or mental representations are motor-patterns, provides us with a basis to identify processes of repetition (Wiederholungszwang) in terms of repeated attempts situated at the level of the marks, structurally disconnected from what is satisfying at the level of needs, (vi) that the initial helplessness of the infant, together with the subtlety of language, with its (small and flexibly recombinable) phonemic motor-packages offered by the other/the Other, is the means through which the categorical difference between humans and other vertebrates can be made clinically relevant, and finally, (vii) that the representational grasping movement corresponds to objectification, whereby the object expresses the formal readiness of the representational space, a readiness that can be, in secondary instance, filled up in various ways, but that, due to the initial non-attunement in which it is grounded, is structurally missing the Thing that it initially marked, leading to an endless compulsion to repeat, without which? There would be no humanity, no culture, no subjective life.

In sum, we have argued for the inscription of the dynamics of signifiers in the structural non-attunement that already exists between actions and needs in mammals, leading to the repetition of actions independently from their being useful or not. Our purpose thereby was not at all to diminish the specificity of the human condition as a speaking condition. On the contrary, our purpose was thereby to show that we are tempted, time and again, to interpret human behavior too quickly as guided by intentional, consciously guided principles and mechanisms. Signifier repetition is the basic human condition, not intentional behavior! That is what Lacan stresses over and again, linked to the nature and the functioning of the signifier. In this way, Lacan's viewpoint operates, more explicitly than Freud's, a categorical shift from the idea that man is or should be guided by what brings satisfaction to his needs, to the idea that man is driven to repeat what was structurally missed. In speaking of a "conceptual intrusion" in relation to the compulsion to repeat, Lacan focuses on what constitutes the mental as a specific kind of object. In this, he wishes to "ensure," "faire valoir" Freud (Lacan, 1966$1967 / 2017$, XIII, p. 280) in what he was eventually after - the subject of the unconscious - and that is exactly the mental apparatus with as a module the compulsion to repeat.

\section{AUTHOR CONTRIBUTIONS}

$\mathrm{GVdV}$ is the main author of this article. She launched the core-idea of applying Freud's distinction between judging and understanding to the process whereby a signifier is for the first time accepted in a dynamics that was until then a homeostatic 
pleasure dynamics. The articulation of this idea happened on the basis of already well-advanced research in neuropsychoanalysis on the signifier and on jouissance by $\mathrm{AB}$. She is then second main author. The collaborative work between both these authors

\section{REFERENCES}

Aristotle. (1984). "De anima," in The Complete Works of Aristotle, Vol. 1, ed. J. Barnes (Princeton, NJ: LXXI).

Bazan, A. (2007). Des Fantômes Dans la Voix. Une Hypothèse Neuropsychanalytique Sur la Structure de Linconscient. Collection Voix Psychanalytiques. Montréal, QC: Liber.

Bazan, A., and Detandt, S. (2013). On the physiology of jouissance: interpreting the mesolimbic dopaminergic reward functions from a psychoanalytic perspective. Front. Hum. Neurosci. 7:709. doi: 10.3389/fnhum.2013.00709

Bazan, A., and Detandt, S. (2015). Trauma and jouissance, a neuropsychoanalytic perpective. J. Cent. Freud. Anal. Res. 26, 99-127.

Bazan, A., and Detandt, S. (2017). The grand challenge for psychoanalysis and neuropsychoanalysis: a science of the subject. Front. Psychol. 8:1259. doi: 10.3389/fpsyg.2017.01259

Bazan, A., Detandt, S., and Askari, S. (2016). Proposition pour une physiologie de la jouissance. Evol. Psychiatr. 81, 777-787. doi: 10.1016/j.evopsy.2015.06.002

Detandt, S. (2016). De la "Jouissance " au "Wanting " Dans Une Population de Fumeurs: Etude Empirique sur les Tenants des Assuétudes à Linterface des Approches Clinique et Expérimentales. Doctoral dissertation, Université Libre de Bruxelles, Bruxelles.

Freud, S. (1895/1963). "On the grounds for detaching a particular syndrome from neurasthenia under the description 'anxiety neurosis," in The Standard Edition of the Complete Psychological Works of Sigmund Freud, Vol. 3, trans. J. Strachey (London: The Hogarth Press).

Freud, S. (1895/1966). "Project for a scientific psychology," in The Standard Edition of the Complete Psychological Works of Sigmund Freud, Vol. 1, trans. J. Strachey (London: The Hogarth Press).

Freud, S. (1900/1953). "The interpretation of dreams," in The Standard Edition of the Complete Psychological Works of Sigmund Freud, Vol. 5, trans. J. Strachey (London: The Hogarth Press).

Freud, S. (1920/1955). "Beyond the pleasure principle," in The Standard Edition of the Complete Psychological Works of Sigmund Freud, Vol. 18, trans. J. Strachey (London: The Hogarth Press), 1-64.

Freud, S. (1920/2015). "Beyond the pleasure principle," in Psychoanalysis and History, Vol. 17, trans. M. Solms (London: International Psycho-Analytical), 151-204.

Freud, S. (1924/1962). "The economic problem of masochism”, in The Standard Edition of the Complete Psychological Works of Sigmund Freud: The Ego and the Id and Other Works, Vol. 19, trans. J. Strachey (London: The Hogarth Press), $155-170$. was intense and the result can be called a common result. SD contributed with her doctoral research on jouissance and the compulsion to repeat, part of the research background that served as a basis for this reflective article.

Jeannerod, M. (1994). The representing brain: neural correlates of motor intention and imagery. Behav. Brain Sci. 17, 187-245. doi: 10.1017/S0140525X00034026

Lacan, J. (1955-1956/1981). Les Psychoses, Le Séminaire III, éd. M. Jacques-Alain. Paris: Seuil.

Lacan, J. (1959-1960/1986). L’Ethique de la Psychanalyse, Le Séminaire. Livre VII. Paris: Seuil.

Lacan, J. (1963-1964/1973). Les Quatre Concepts Fondamentaux de la Psychanalyse, Le Séminaire XI, éd. J.-A. Miller. Paris: Seuil.

Lacan, J. (1963-1964/1981). The Four Fundamental Concepts of Psychoanalysis, Book XI, trans. A. Sheridan. New York, NY: W.W. Norton \& Company.

Lacan, J. (1964-1965/2003). Problèmes Cruciaux pour la Psychanalyse, Le Séminaire XII, éd. M. Roussan. Paris: Association Freudienne Internationale.

Lacan, J. (1966). "Réponse au Commentaire de Jean Hyppolite " in Ecrits. Paris: Seuil, 369-399.

Lacan, J. (1966-1967/2017). La Logique du Fantasme, Le Séminaire XIV, éd. M. Roussan. Paris: Éditions du Seuil.

Lew, R. (1983). « La représentance ». Analytica 34, 121-129.

Lew, R. (2014). La «Chose » en Psychanalyse, Cahiers de Lectures Freudiennes. Paris: La Lysimaque.

Reik, T. (1935/1976). Der Überraschte Psychologe. Über Erraten und Verstehen Unbewusster Vorgänge; Le Psychologue Surpris. Deviner et Comprendre les Processus Inconscients, (trad. Denise Berger). Paris: Denoël.

Russell, B. (1905). “On denoting," in Logic and Knowledge, ed. R. C. Marsh (London: George Allen and Unwin), 41-56.

Skinner, B. F. (1948). Superstition' in the pigeon. J. Exp. Psychol. 38, 168-172. doi: $10.1037 / \mathrm{h} 0055873$

Tort, M. (1966/2016). « A Propos du Concept Freudian de 'Représentant' (Repräsentanz), Concept and Form: The Cahiers pour l'Analyse and Contemporary Thought. Available at: http://cahiers.kingston.ac.uk/vol05/ cpa5.2.tort.html

Conflict of Interest Statement: The authors declare that the research was conducted in the absence of any commercial or financial relationships that could be construed as a potential conflict of interest.

Copyright (c) 2017 Van de Vijver, Bazan and Detandt. This is an open-access article distributed under the terms of the Creative Commons Attribution License (CC BY). The use, distribution or reproduction in other forums is permitted, provided the original author(s) or licensor are credited and that the original publication in this journal is cited, in accordance with accepted academic practice. No use, distribution or reproduction is permitted which does not comply with these terms. 


\section{OPEN ACCESS}

Edited by:

Jos Antonius Maria De Kroon, Independent Researcher, Eindhoven,

Netherlands

Reviewed by:

Rik Loose,

Dublin Business School of Arts, Ireland Marjorie Roques,

Normandie Université, France

${ }^{*}$ Correspondence: Olivier Ouvry 1@oouvry.fr

Specialty section:

This article was submitted to

Psychoanalysis and Neuropsychoanalysis,

a section of the journal

Frontiers in Psychology

Received: 23 April 2017 Accepted: 18 December 2017 Published: 06 February 2018

Citation:

Ouvry O (2018) Lacan and Adolescence: The Contemporary Clinic of the "Sexual Non-rapport" and Pornography. Front. Psychol. 8:2299. doi: 10.3389/fpsyg.2017.02299

\section{Lacan and Adolescence: The Contemporary Clinic of the "Sexual Non-rapport" and Pornography}

\author{
Olivier Ouvry* \\ UTRPP Laboratory (EA 4403), Department of Psychology, University of Paris-Sorbonne-Cité, Paris, France
}

This article explores two clinical phenomena-pornography and conspiracy thinking - that are highly relevant today and can be observed specifically among adolescent boys in the early stages of post-puberty: conspiracy thinking and the viewing of pornographic videos. It shows that the Lacanian concepts of the Real (of puberty) and the sexual non-rapport help us understand the psychopathological aspects of these two phenomena. Watching pornographic material becomes equivalent to a conspiracy theory about the sexual non-rapport; both in fact deny the effect of what puberty introduces as radically new.

Keywords: conspiracy thought, pornography, the adolescent boy, adolescence, the Real of puberty, the other jouissance, sexual non-rapport

\section{INTRODUCTION}

In our clinical experience, the two phenomena, which we are going to handle-pornography and conspiracy thinking ${ }^{1}$ - can mostly be observed among post-pubertal boys. The already high and apparently growing occurrence of these manifestations seems troubling and often gives rise to highly controversial views ${ }^{2}$. What does this tell us? How do we understand these phenomena and deal with them? And should we indeed be worried or should we dismiss them as banal, given how widespread they currently are?

Our hypothesis is that these two phenomena, observed at teenagers not presenting known psychological disorders, are in fact interlinked through an underlying mechanism, which has to do with the dread of the other of the Other sex ${ }^{3}$. However, to arrive at this conclusion, we must first make a few preliminary remarks.

\footnotetext{
${ }^{1}$ A conspiracy theory is an explanation of an event or situation that invokes an unwarranted conspiracy, generally one involving an illegal or harmful act carried out by government or other powerful actors. Conspiracy theories often produce hypotheses that contradict the prevailing understanding of history or simple facts. The term is a derogatory one (Ayto, 1999). According to the political scientist Barkun, conspiracy theories rely on the view that the universe is governed by design, and embody three principles: nothing happens by accident, nothing is as it seems, and everything is connected (Barkun, 2003). Another common feature is that conspiracy theories evolve to incorporate whatever evidence exists against them, so that they become, as Barkun writes, a closed system that is unfalsifiable, and therefore "a matter of faith rather than proof" (Barkun, 2003, 2011).

${ }^{2} \mathrm{~A}$ new work brings a point of view different from ours as for the adolescence and the pornography. It is complementary in the fact that he proposes the festive point of view of the use of the porn (Bidaud, 2017).

${ }^{3}$ The judicious article of Janin (2015) addresses this issue from a complementary angle, namely shame, hatred and pornography, whereby the first two terms can be related to the rapport of the Other sex.
} 


\section{BACKGROUND}

We can begin with the fact that these phenomena are observed mainly among boys. Hence, there is a gender division. We know that Freud saw the period of infantile sexuality as radically different for girls versus boys, and even located their Oedipal entrance and exit points as mirror images of one another. However, what happens to this difference in puberty?

For the boy, the end of the Oedipal period is marked by castration, which is experienced as a possibility when the reality principle of the existence of two sexes sets in, i.e., a reality that contradicts the infantile sexual theories that had previously kept it at bay. Anatomically, we are (born as) girls or boys, rather than becoming either sex (Beauvoir, 1949). This realization makes the imaginary register of the infantile sexual theories obsolete and replaces it with a logical order guaranteed by the father as the bearer of the organ that gives meaning to what makes difference in language (the Symbolic and the Real). It is through the articulation of the reality of the difference of the sexes to the lack in Other that the function of the phallus (the signifier of the lack in the Other one) find its validation in language.

For the little boy, the end of the Oedipus complex is therefore characterized by a change in the reference framework. This is why Freud speaks about the boy's dissolution of the Oedipus complex (Freud, 1924) rather than simply its repression. In this new world, everyone has their place as either a man or a woman-and everyone is asked to position themselves clearly.

However, the little girl does not follow the same path. When she sees the difference between the sexes, she does not prevaricate and decides that she does not have a penis (Freud, 1925). Prior to extending this destiny to all other girls, including her motherand hence realizing how things are-during the pre-Oedipal stage the girl is in exactly the same position as the boy, as emphasized by Freud: they share the same sexual object (the mother) and the same erogenous zone (the clitoris-equated with the penis). The shift from the mother to the father as the sexual object is therefore produced via castration, introducing the Oedipal complex, which represents the first difference with the boy's trajectory ${ }^{4}$ (the girl does not keep the mother as her sexual object). From the father, she expects to receive the penis she does not have (like her mother), and which she converts, through a symbolic "equation" (Freud, 1925), into having a child from him.

This means that the girl enters the Oedipal stage precisely through the castration complex-i.e., by taking the reality of sexual difference into account-contrary to the boy, to whom the same realization provides a way of exiting and dissolving the Oedipus complex. For the girl, not only is there no defined exit from the Oedipus complex (she is not concerned by the threat of castration, see Freud), but also, importantly, her new logical position is that of seducing the father, who is a man, in order to unconsciously fulfill her wish of having a child with him.

${ }^{4}$ We should stress, as Freud also does, that the girl's trajectory through the preOedipal stage and then through puberty can only be tracked via the differences from the boy's position. Freud writes: "In conformity with its peculiar nature, psycho-analysis does not try to describe what a woman is-that would be a task it could scarcely perform - but sets about enquiring how she comes into being, how a woman develops out of a child with a bisexual disposition." (Freud, 1933).
This position of seduction, which the little girl acquires already as a child, has to be related to what Freud says in Narcissism: An Introduction, when he describes the "fundamental differences" between the male and female approach to love, in his text obviously speaking about the situation post-puberty. He writes:

A comparison of the male and female sexes then shows that there are fundamental differences between them in respect of their type of object-choice, although these differences are of course not universal. Complete object-love of the attachment type is, properly speaking, characteristic of the male. [...] A different course is followed in the type of female most frequently met with, which is probably the purest and truest one. With the onset of puberty, the maturing of the female sexual organs, which up till then have been in a condition of latency, seems to bring about an intensification of the original narcissism, and this is unfavorable to the development of a true object-choice with its accompanying sexual overvaluation." (Freud, 1914)

Thus, the difference between the girl's and the boy's position, already observed by Freud during the infantile period, reappears again after puberty. The boy's object choice is anaclitic with an overvaluation of the sexual object and can in fact turn into a paralyzing infatuation, akin to the courtly love of the Middle Ages, where the "object is elevated to the dignity of the Thing," as Lacan puts it (Lacan, 2013). As for the girl, she sides with the Thing, presenting herself as inaccessible, taking a narcissistic position of seduction. She turns herself into an object impossible to grasp and thus provokes the boy's predatory greed. The arrival of a child, as Freud stresses, can later give her access to attachment-type love, similar to the choice made by the boy.

We understand that the girl's narcissistic position of seduction is a continuation of what she had already experienced toward the first man of her life, the father of early childhood-which is the opposite of what we see in the boy. For him, the new situation of puberty appears as a radical discontinuity. It corresponds to what we have described, in another work, as the emergence of the Feminine (Ouvry, 2001)-Feminine with a capital F, to mark its impossible inscription in what existed before its arrival, i.e., the infantile.

This emergence of the Other sex (again, for the same reasons, with a capital $\mathrm{O}$ ), which did not exist in the infantile period [see Freud's discussion of the displacement, prior to puberty, of the erogenous zone from the clitoris to the vagina (Freud, 1933)] constitutes the second difference between the girl's and the boy's trajectories. This appearance is an effect of the Real, the "Real of puberty" (Ouvry, 1999), in other words an experience that cannot be inscribed in the infantile phallic organization, in language; it is a discovery of something radically new and unprecedented: The Feminine. This is what Lacan tries to express through his famous aphorism: "There is no sexual relationship"5. In other words, there is no relationship between the sexes in the structure

\footnotetext{
${ }^{5}$ This aligns with Freud's lecture on Femininity (see Note 4). In the same text, he also stresses that there is no specifically feminine libido, which is another way of putting of what he has said previously, namely that nothing in language could express what a woman is, and thus we have no means to describe a feminine trajectory or feminine libido. His words are later echoed by Lacan's formulations (the Woman does not exist, or no signifier exists for a woman's sex)—or rather, to be precise, Lacan's commentary renders Freud's argument more legible.
} 
of language, because there is only one signifier for both sexes: "There is no signifier of the Woman's sex."

The boy's new position is therefore very far from where he stood before puberty. The world has been transformed, and before he can adjust this new reality to a figuration that is socially feasible (i.e., the other of the Other sex), there is a certain delay ${ }^{6}$. Time is needed to take on the social rules of relating to the other outside the incestuous framework of Oedipus (of the infantile). This intermediary period is also where we situate the phenomena of porn consumption and conspiracy thinking.

But before we discuss these phenomena, we would like to look at the logical consequences of what we have just said, specifically in relation to the girl's situation and trying to understand the higher prevalence of this behavior among boys.

For the girl, the emergence of the Real of puberty in fact happens at a later moment, when she discovers the Other jouissance of which she is the potential bearer. This discovery is made the first time she feels this jouissance during sex. The importance of this moment seems to be confirmed by a significant clinical fact, namely that certain young men can suffer a psychotic break when they first make a woman orgasm, due to the change in the woman's status. Until this moment, during the infantile period, it was the father who knew something about sexuality. And now it is the girl who finds herself the bearer of this knowledge, via her Other jouissance (effect of the Real of puberty). In psychosis, where the Name-of-the-Father has not been symbolized (foreclosure), the boy's summoning of the father of the infantile at this very moment necessarily has consequences. Contrary to the neurotic, where the effect is a certain deposition of the father (a fall of the great Other and the appearance of the $\mathrm{S}(\mathrm{A})$ ), for the psychotic it is instead the hole of the Real that is suddenly revealed, setting off a cascade of effects that culminate in a delusional state (Lacan, 2006).

\section{DISCUSSION}

We have thus defined the two stages that characterize the first period post-puberty: for the boy, it is situated between the immediate experience of the Real of puberty and its "dressing up" by the other of the Other sex, which necessarily happens at a later stage; for the girl, it runs from the first physiological changes of puberty to the discovery of the Other jouissance, when she first has sex. When we visualize these two positions, we see that they are, just like for Freud during the infantile period, mirror images of one another: the woman's immediate and the man's delayed position of seduction; the experience of the Real of puberty, which is immediate for the boy and delayed for the girl.

Pornography and conspiracy thinking correspond to this intermediary phase $^{7}$, specifically among boys. Both

${ }^{6} \mathrm{Cf}$. Choudhury et al. (2006) "Changes in social behavior are driven by both social and biological factors. During adolescence, it is likely that peer interactions and societal influences as well as genetically determined hormonal milieu influence social behavior. However, since the recent discovery that the brain matures considerably during adolescence, evidence has emerged pointing to the role of neural maturation in the development of social cognition during adolescence."

${ }^{7}$ Cf. Marty F., La violence comme expression du mal-être à l'adolescence, Adolescence 2009/4 ( $\left.\mathrm{n}^{\circ} 70\right), 1007-1017$. manifestations are de facto reactions to the Real of puberty, in terms of both its truth effect and the absence of knowledge linked to it (there is no signifier for the woman's sex). They can be related to each other using the following equation: pornography is to the sexual relationship what conspiracy thinking is to truth, or, pornography is the conspiracy theory of the sexual non-rapport ${ }^{8}$. What do we mean by this?

The effect of the Real of puberty bores a hole in the infantile knowledge guaranteed by the father. This is Lacan's there is no sexual relationship we are already familiar with. And it is indeed knowledge that conspiracy thinking wants to question": "They are hiding something from us", the argument goes, and these secrets belong to the domain of truth, in this case the truth of not knowing. However, what is the truth that puberty suddenly reveals, if not precisely the truth linked to jouissance-which, by definition escapes knowledge? Conspiracy thought is evidence of the adolescent's inevitable dilemma: "Should I accept the new situation of puberty, at the cost of revealing the non-knowledge that the Oedipal fiction helped conceal? Can I really leave the world of childhood so easily?"

On the other hand, pornographic images revive, as a kind of resurgence of the infantile, the knowledge about sexuality that was there to be had, the knowledge of the Oedipal promise, which is guaranteed by the father-the imaginary father of the infantile period, the father of the infantile phallic stage. In this case, this knowledge [savoir] is obtained by "seeing it [ça voir]"-in other words, by seeing the sexual relationship as if it indeed existed, as if there really was something to see, even though it radically escapes representation, again and again ${ }^{10}$. In today's society, this strategy is greatly facilitated by the internet, which offers a whole new range of viewing possibilities ${ }^{11}$.

The idea that knowledge should somehow be preserved (that the infantile theory should be "saved," like data on a disk) echoes the approach of the conspiracy thinker, his quest for a true knowledge that would give meaning to the official discourses, be they journalistic, historical and/or academic. These same discourses are in fact trying to circumvent the idea of a total

\footnotetext{
${ }^{8}$ Rob Brotherton, Suspicious Minds, Bloomsbury Sigma, 2017-01-03, 304 pages, ISBN-10: 1472915631, quoted by Lynne alcolm, http://www.abc.net.au/ radionational/programs/allinthemind/the-psychology-of-conspiracy-theories/ 7177962,17 February 2016: “This is something that we all suffer from, not just in the context of conspiracy theories, but we all want to feel like we have control over our circumstances and that we understand what's going on around us. When that feeling of control is stripped away for whatever reason... then we look for other sources of control, what is called compensatory control."

${ }^{9}$ Cf. Sander van der Linden (London School of Economics and Political Science, Grantham Research Institute on Climate Change and the Environment), What a hoax, Scientific American Mind 41, September/October 2013 (Mind.ScientificAmerican.com): "A strong distrust of authority would be one such overarching ideological lens. In a belief system in which authorities are fundamentally untrustworthy, alternative-even outlandish and contradictoryexplanations for troubling events can seem plausible, as long as they are consistent with a skepticism toward the powers that be."

${ }^{10}$ Like those who engage in watching pornography and always repeat the same scene-desperately fleeting, desperately empty.

${ }^{11}$ There is of course nothing new about this phenomenon: just think of Antoine Doisnell in 400 Blows (Truffaut, 1959), when he and his friend are looking at the photographs in mail-order catalogues, where scantily-clad women become the subject of laughs, looks, research and frustration.
} 
knowledge, precisely by surfing on the non-knowledge they have embraced. They can dress up the current events or history or any other knowledge through a discourse of semblances, a semblant of truth that, as they know, by nature escapes them. In this way, they express what the other of the Other sex has come to conceal for them, namely the effect of the Real of puberty that we have discussed, which remains inaccessible to knowledge.

And this is what conspiracy thinking refuses and rejects, calling instead for a total knowledge that would be the truth. This "underground" knowledge could unmask the truth of the semblant, i.e., what psychoanalytic theory identifies as castration.

I will use a clinical vignette to illustrate my argument. It concerns a teenager with an interest in conspiracy theories, whose a family configuration where the mystic father blocker by a phallic mother has deprived him, since his childhood, from access to the symbolic phallic function, thus preventing him from discovering the Other jouissance of puberty. By resorting to watching porn videos, he is able to maintain an infantile auto-erotic sexuality through masturbation, while women in fact remain a source of dread.

\section{CONCLUDING REMARKS}

With "seeing it" [ça voir] and knowledge [savoir], we have two valences of the same principle: applied to sexuality

\section{REFERENCES}

Ayto, J. (1999). 20th Century Words. Oxford: Oxford University Press.

Barkun, M. (2011). Chasing Phantoms: Reality, Imagination, and Homeland Security Since 9/11. Chapel Hill: University of North Carolina Press.

Barkun, M. (2003). A Culture of Conspiracy: Apocalyptic Visions in Contemporary America. Berkeley, CA: University of California Press.

Beauvoir, S. (1949). The Second Sex. London: Vintage.

Bidaud, E. (2017). Psychanalyse et Pornographie. Paris: La Musardine.

Choudhury, S., Blakemore, S. J., and Charman T. (2006). Social cognitive development during adolescence. Soc. Cogn. Affect. Neurosci. 1, 165-174. doi: $10.1093 /$ scan/nsl024

Freud, S. (1914). On Narcissism. London: Hogarth Press.

Freud, S. (1924). The Dissolution of the Oedipus Complex. London: Hogarth Press.

Freud, S. (1925). Some Psychical Consequences of the Anatomical Distinction between the Sexes. London: Hogarth Press.

Freud, S. (1933). Lecture XXIII: Femininity. New Introductory Lectures On PsychoAnalysis. London: Hogarth Press.

Janin, C. (2015). Shame, hatred, and pornography: Variations on an aspect of current times. Int. J. Psychoanal. 96, 1603-1614. doi: 10.1111/1745-8315.12417 (pornography) and to truth (conspiracy theories). Both attest to the same refusal of the emergence of the Other jouissance, the same attempt to avoid non-knowledge, non-sense, non-truth (the truth is a lying truth, Lacan said) - an attitude that in fact assumes a destitution of being ${ }^{12}$, of the being of truth that is the father of the infantile period.

Both these valences must be transitory, marking simply a stage in the complicated passage of the boy-and of some girls, who assume the masculine sexual position. Only clinical analysis can identify situations where there is a true risk of pathological fixation. At a time of hardening attitudes and growing fears (which after the attacks of 2015 are of course legitimate), we must remain even more rigorous in our clinical approach, which alone can help us contain our emotions and not become overwhelmed by them, a risk that easily leads to premature warnings and false alarms.

\section{AUTHOR CONTRIBUTIONS}

The author confirms being the sole contributor of this work and approved it for publication.

${ }^{12}$ Lacan, J. (1973-1974). Les non-dupes errent (Unpublished): "Real is the reason for the lying truth. If only because it is variable. What do we call the Real? It is what cannot be said otherwise than in lying, what is reluctant to the truth, reluctant to say that it is true.
Lacan, J. (2006). On a Question Prior to Any Possible Treatment of Psychosis. New York, NY: W.W. Norton.

Lacan, J. (2013). The Ethics of Psychoanalysis 1959-1960: The Seminar of Jacques Lacan. London: Routledge.

Ouvry, O. (1999). "Le réel pubertaire," in Problématiques Adolescentes et Direction de la Cure, eds D. Lauru, D, C. Hoffmann and C.-N. Pickmann (Paris: Erès), $113-120$.

Ouvry, O. (2001). Le Féminin Comme Nouveauté Pubertaire. Paris: Erès.

Conflict of Interest Statement: The author declares that the research was conducted in the absence of any commercial or financial relationships that could be construed as a potential conflict of interest.

Copyright (C) 2018 Ouvry. This is an open-access article distributed under the terms of the Creative Commons Attribution License (CC BY). The use, distribution or reproduction in other forums is permitted, provided the original author(s) and the copyright owner are credited and that the original publication in this journal is cited, in accordance with accepted academic practice. No use, distribution or reproduction is permitted which does not comply with these terms. 
OPEN ACCESS

Edited by:

Rémy Potier,

Paris Diderot University, France

Reviewed by:

Kazushige Shingu,

Nara University, Japan

Raphael Minjard,

Lumière University Lyon 2, France

*Correspondence:

David Schrans

david.schrans@ugent.be

Specialty section:

This article was submitted to

Psychoanalysis and

Neuropsychoanalysis,

a section of the journal

Frontiers in Psychology

Received: 16 August 2017

Accepted: 11 April 2018

Published: 15 May 2018

Citation:

Schrans D (2018) The Individual and the Collective: Sociological Influences

on Lacan's Concept of the Relation

Subject-Other.

Front. Psychol. 9:614

doi: 10.3389/fpsyg.2018.00614

\section{The Individual and the Collective: Sociological Influences on Lacan's Concept of the Relation Subject-Other}

\author{
David Schrans*
}

Department of Psychoanalysis and Clinical Consulting, Faculty of Psychology and Educational Sciences, Ghent University, Ghent, Belgium

In this conceptual analysis we discuss the sociological influences on Lacan's conceptualization of the relation between the subject and the other. In his writings predating World War II Lacan defines this relation in terms of identification. However, from 1953 onward he defines it in terms of the subject of speech and the Symbolic Other. It is a popular notion to characterize this change in terms of a radical breach, influenced by the reading of Lévi-Strauss. However, through a close reading of both Lacan's early writings and their Durkheimian influences we will demonstrate that what has changed, is Lacan's conceptualization of the relation between the individual and the collective. This change was gradual rather than sudden. Moreover, it can be situated within the theoretical evolution of the contiguous fields of sociology, anthropology and psychoanalysis. Thus we reject the idea of a breach within his own thought and with what came before him. We will establish our point through a summary of how the relation between the individual and the collective was theorized before Lacan. Durkheim conceptualized this relation as dual: the individual and the collective are radically separated. Mauss attempted to unify the field of anthropology through the holistic concept of the total man. In Lévi-Straus's formalization the individual becomes a function within a structured, Symbolic system. Finally, a reading of Lacan's publications concerning the notion of the logic of the collective will testify to his attempts at formulating a notion of the subject that asserts itself against this collective while at the same time retaining its nature of a logical function. This is the conundrum that Lacan will confront time and again throughout his teachings. Lévi-Strauss merely provided him with the methodological tools of structural anthropology that helped him refine the interrogations that he had already begun.

Keywords: Lacan, individual, collective, Durkheim, Mauss, Lévi-Strauss, subjective assertion, family complexes

\section{INTRODUCTION}

A popular notion among Lacanian scholars is the occurrence of a radical shift from a Lacan preoccupied with the Imaginary order to a Lacan focused on the Symbolic. Where the former is centered around his theory on the mirror stage (Lacan, 2006 [1949]), the latter has come about through his reading of the anthropologist Claude Lévi-Strauss (Zafiropoulos, 2001; Zafiropulos, 2010 [2003]) and is inaugurated by his presentation entitled The function and field of speech and language in psychoanalysis in 1953 (Lacan, 2006 [1953b]). 
In this paper we reject the notion of a radical shift from the Imaginary to the Symbolic. What is more, we defend the idea that Lacan's evolving conceptual framework can be situated within a broader intellectual history of anthropological and sociological thought concerning the relation between the individual and the collective. Hence, we neither accept a breach within his own thought, nor with what came before him.

The relation between the individual and the collective has occupied psychoanalysis since Freud's writings on group psychology (Freud, 1955 [1921]) and has been carried on by psychoanalysts such as Bion and Rickman, both of whom have influenced Lacan (2001 [1947]). However, it has also been one of the tenets of sociology and anthropology. The notion of individuality and the influence of the collective is central in Durkheim's work, which ended in an impasse where both were radically separated. Marcel Mauss attempted to resolve this impasse with his notion of the total man and Lévi-Strauss formalized this notion and its implications. In this paper we will focus on the period between Lacan's writings on the family, where this relation is based on identification and heavily influenced by Durkheim, and his writings on the Symbolic, where it is based on language and heavily influenced by Mauss and Lévi Strauss.

\section{DURKHEIM AND LACAN ON THE FAMILY}

As both Freud (1955 [1921]) and Lacan (2001 [1938]) noted, the foundations for man's social life, and thus his relation to the collective, are laid down in the family. Zafiropoulos (2001) states that Lacan was influenced by Durkheim in his writings on the family. We will therefore subject Durkheim's teachings on the family to a close reading and compare it with Lacan's paper on the family complexes. Finally, we will confront our reading with Zafiropoulos' interpretation, which states that Lacan eventually diverted from Durkheim through a new interpretation of the notion of the father inspired by Lévi-Strauss.

\section{Durkheim on the Contraction of the Family}

Durkheim stated that the family is a social institution subject to a cultural evolution, with the conjugal family as its final conclusion. It is not merely a biological affair, but has moral and judicial implications which are protected by the collective in which the family is embedded. The evolution of the institution of the family is determined by what Durkheim (1975 [1892]) calls the law of contraction: throughout history the number of relatives which constitute a family has progressively diminished. The historical starting point of the family is the clan. In this social structure a totem or alleged forefather is responsible for the creation of society and forms the center of family life. Members of a clan were both relatives and fellow citizens (Lamanna, 2002). In these societies there was no notion of an individual and the different members of the group were hardly distinguished from one another. Only when the clan ceased to be nomadic and started to attach value to the territory on which it lived, did family and clan become two separate entities. A broad, amorphous family system became distinguished from a political and territorial clan organization (Durkheim, 1984 [1893]). Families with a patrilineal or matrilineal structure originated within the clan (Durkheim,
1975 [1892]). A further contraction was realized by the agnatic families, which were smaller and more egalitarian than the totem based families. These families were centered around shared possessions, rather than religion and could be either patrilineal or matrilineal.

This differs from the Roman, patriarchal families, which were strictly patrilineal and governed by the principle of patria potestas. The father represented the group and his authority over its members and possessions was absolute. This contrasts with the German paternal family where paternal dominance was less strict. The son could emancipate himself and leave the family on his own accord.

The conjugal family is the family structure discerned by Durkheim in French society of his day. It is a further contraction of the paternal rather than of the patriarchal family as the latter was too strict to allow for any further contraction. The only permanent elements within this system are husband and wife, although secondary zones of kinship (i.e., relatives up to the sixth degree), as remnants of the previous structures, still existed. A child is dependent on its father until it is married. As Zafiropoulos (2001) correctly points out, with the contraction of the family the disciplinary rights of the father have greatly diminished. However, the interference of the state has increased. In France as of 1889 the father can even be set out of this paternal rights by the state. According to Durkheim, state intervention was a necessary prerequisite for the existence of the conjugal family. Whereas kinship relations in societies constituted by patriarchal families could only be broken off under the authority of the father, in the case of those based on the conjugal family the state must provide its approval in cases of divorce or adoption. Durkheim warns us however that with the contraction of the family, individuality and the pursuit of purely individual goals have increased. When the individual "looks for his purpose within himself, he falls into a state of moral misery which leads him to suicide" (Durkheim, 1975 [1892], p. 236). Yet, according to Lamanna (2002) Durkheim is not necessarily pessimistic where it concerns the increase of individuality and the decrease of paternal authority. The former gave rise to individual freedom and the latter consolidated the ties between the members of society through state intervention.

\section{Lacan on the Family Complexes}

According to Zafiropoulos (2001) Lacan was heavily influenced by Durkheim's writings on the family when he wrote his own contribution on the family complexes (Lacan, 2001 [1938]). Lacan states that the process of subjective development is structured by three fundamental complexes which center around three imagoes: the weaning complex with the imago of the mother, the complex of intrusion with the imago of the rival and the Oedipus complex with the imago of the father. The structuring of these complexes takes place within the family as a historically determined institution. However, in our modern, Western families (for which Lacan uses the term "conjugal families") the father has become progressively absent due to the "contraction of the institution of the family" (Lacan, 2001 [1938], p. 27). As a consequence the Oedipus complex in Western society has started to falter, which explains the burgeoning 
of modern forms of psychopathology such as the character neuroses.

The first complex the human infant encounters, the weaning complex, is "the most primitive complex in psychic development" and "forms the basis of the most archaic and stable sentiments uniting the individual and the family" (Lacan, 2001 [1938], p. 30, trans. Cormac Gallagher). This complex originates from the separation of the infant from the womb, which, for man, is always a premature separation. The repercussion of its prematurity is the universally shared call of the young human for the social group, and in the first place the family, which is in fact a call for some sort of social function which meets the needs emanating from this vital insufficiency of the first years. The first form this social connection with the outside world takes on is the imago of the mother as a sublimation of the mother, a bringing into form and recognizing her as an answer to the vital insufficiency. It is the first connection to the other the infant makes. It is also the connection upon which all the consecutive connections with the other will be made. A successful transition of the weaning complex is therefore paramount to social development.

As important as the imago of the mother is, it is marked by a strange ambivalence. The longing for the maternal imago can become a longing for the state before birth, and as such instigate the death drive. Because of this ambivalence the lure of death, of a return to the tranquil, inanimate state of life before birth, remains present in the ambiguous form of the imago of the mother. The complex of intrusion offers a solution to these summons of death through a confrontation with the double, archetypally represented in the form of the brother. This complex roused by the first realization of the presence of a sibling, and of the feelings of jealousy concerning the mother this provokes. Lacan cautions us that we must not confuse human jealousy with biological rivalry. For at its most fundamental, jealousy presupposes mental identification. Lacan considers identification as primary, the aggressiveness it provokes as secondary. Lacan's description of the complex of intrusion is an early form of his theory on the mirror stage (Lacan, 2006 [1949]). He states that through the recognition of its own image in the mirror the human infant regains the unity it once experienced in utero.

At the same time the body is experienced as unity, the world, which was equally perceived as fragmented, is organized by reflecting the forms of the body. Consequently, Lacan declares the mirror image to be a good symbol for the reality as it is experienced at that moment in human development. The world in this phase is a narcissistic world in which the image of the double is central and there is no place for others (as truly "other"). Indeed, the experience of the other as a mirror image does not help the subject to break through the affective isolation caused by its prematurity. However, as the formation of the ego through identification with an external image occurs, the drama of jealousy and sibling rivalry is being played out. Identification with the unweaned sibling provokes aggressiveness because it triggers the maternal imago and thus the desire for death. This is why Lacan states that aggressiveness is secondary to identification: the identification with the other awakens the primary masochism (i.e., the death drive) of the weaning complex. However, this primary masochism can be overcome if it is transformed into sadism in the form of rivalry. Through identification the infant can fix one of the poles of primary masochism and turn it into aggressiveness toward the unweaned sibling. "Thus the non-violence of the primordial form of suicide engenders the violence of the imaginary murder of the sibling" (Lacan, 2001 [1938], p. 40, trans. Cormac Gallagher). Consequently the other is recognized as truly other. This is why Lacan states that jealousy is the archetype of all social sentiments. However, the complex of intrusion can also end in an imaginary impasse where the ego and the alter-ego are not distinguished. This can lead to serious forms of psychopathology (e.g., paranoia).

Finally, the Oedipus complex installs two fundamental, psychological instances: repression and the Ego-ideal. Contrary to Freudian doctrine, which recognizes the father as the primary agent of castration, Lacan states that the original cause for repression stems from the lure of death present in the imago of the mother. The sexual desires of the Oedipus complex reactivate the desire for the mother and thus the ancient death drive which is thereupon repressed. The father, as the one who opposes this desire for the mother, figures only as a secondary source for repression. As such, repression paves the way for yet another form of identification with the rival, but this time as an Ego-ideal: "the ideal of virility in the boy, and in the girl the ideal of virginity" (Lacan, 2001 [1938], p. 56, trans. Cormac Galagher). However, Lacan remarks that not every society accords the same place to the father and its successful development depends largely on the extent to which both the repressive and the sublimatory functions are united in the imago of the father. In the Trobriand of Melanesia, for example, the repressive function is attributed to the maternal uncle, the sublimatory function to the biological father. The effect is a relative absence of neurosis and a great rigidity on the level of cultural productions. In our Western society "the father [...] is always lacking in some way or another, whether he be absent or humiliated, divided or a sham" (Lacan, 2001 [1938], p. 61, trans. Cormac Galagher) and the reason for this Lacan finds in "the same social progress that makes the family evolve toward the conjugal form [and] increasingly submits it to individual variations" (Lacan, 2001 [1938], p. 74, trans. Cormac Galagher). When this happens the dialectic of sublimation is negated and libidinal energy exhausted, which eventually leads to character neurosis.

Zafiropoulos (2001) states that Lacan's views betray a Durkheimian influence because he links the degradation of the Oedipus complex to the contraction of the family. The author claims that Lacan is strictly non-Freudian as long as he is influenced by Durkheim. In Totem and Taboo Freud (1953 [1912]) stated that human society commenced with the murder of the primal father. As such, the degraded, dead father is at the foundation of every human society and not a historical contingency. Only with the discovery of structural anthropology through the writings of Lévi-Strauss would Lacan be able to recognize the structurally lacking father function and commence his return to Freud. Although we acknowledge the presence of Durkheimian influences in Lacan's text from 1938, we find Zafiropoulos' arguments on his transition from Durkheimian/non-Freudian to structuralist/Freudian to leave a lot to be desired. First, although he cites Lévi-Strauss' work as 
being responsible for this sudden change in Lacan's thinking Zafiropoulos never actually demonstrates how this work led to an interpretation of the father as structurally lacking. When discussing this change, his main reference is French writer Paul Claudel and his play Le père humilié. Second, we have seen that with the contraction of the family there has been a shift in authority from the father to the state. Even if Durkheim writes about the degradation of the father, he takes into account other forms of authority and law. When discussing Durkheim's views on the relation between the individual and the collective, we will see that this shift can be explained by an evolution in this relation. And last but certainly not least, we have difficulty accepting that such a slow and arduous process as the evolution of one's thinking, Lacan's in this case, is marked by sudden revolutions. During an analysis something can befall the patient and create a new insight-but every analyst knows that revolutions are very rare in the consulting room. There is always the process of working through to take into account. Therefore, it is more interesting to look at the historical development that links Durkheim to Lacan through Lévi-Strauss, because the latter wouldn't have been possible without Durkheim. In what follows, we will present the reader with the evolution of the conceptualization of the relation between the subject and the Other (in sociological terms: between the individual and the collective) from Durkheim to Lacan. This point of view will better allow us to link the gradual evolution of Lacan's thinking to the developments in sociology and anthropology that preceded him.

\section{DURKHEIM AND THE OPPOSITION BETWEEN INDIVIDUAL AND COLLECTIVE}

In The Division of Labor in Society Durkheim (1984 [1893]) describes two forms of relation between the individual and the collective: mechanical solidarity, a relation based on similarity, and organic solidarity, a relation based on difference. Between these two forms he describes an evolution. Primitive societies are primarily based on mechanical solidarity. The members of these societies are hardly differentiated. This form of solidarity is represented in "the totality of beliefs and sentiments common to the average members of a society" which then "forms a determinate system with a life of its own" (Durkheim, 1984 [1893], p. 39). This system is the collective or common consciousness, which cannot be located within a single physical substratum but is present in its entirety in every member of society. Nevertheless, it exists independent from these individuals: "Individuals pass on, but it abides" (Durkheim, 1984 [1893]). It does not change from one generation to the other, but links the different generations to each other. The origin of the collective unconscious lies in the confrontation of shared feelings and representations. Central to Durkheim's theory on the collective consciousness is the notion of vitality. Consciousness, whether it be individual or collective, derives its force, its vitality, from strong representations. The confrontation of shared representations within a society gives these collective representations a greater vitality, which largely surpasses the vitality of individual representations. This way of conceptualizing consciousness has several consequences. First, Durkheim concludes a split within the human mind between an individual and a collective consciousness where the latter appears as "an echo resounding within ourselves of a force that is alien, one moreover superior to that which we are ourselves" (Durkheim, 1984 [1893], p. 56). Second, because of its greater vitality the collective consciousness appears as a moral force. It is also the strongest form of authority. When a certain representation or act goes against these collective representations, against the moral order and greatest authority, this provokes a heavy emotional response from the group. Therefore, Durkheim states that penal law is the most common expression of the collective consciousness. Last, it also implies that this authority is not a social function, which receives a relative importance according to the society in which it occurs, but represents the society as a whole. For example, in the Roman, patriarchal families the father did not incarnate a specific social function but represented the group and its moral ascendancy as such.

Whereas mechanical solidarity is based on similarity, organic solidarity is based on difference and specialization. More specifically, it is based on what Durkheim calls the "division of labor." As a society grows larger and more complex the functions the different members fulfill become more diversified. This in turn increases the degree of individuality within that society. This radically changes the relation between the members because now they all depend upon one another (like the organs that constitute a body), whereas in societies based on mechanical solidarity there was virtually no differentiation and every member could easily be replaced by any other. According to Durkheim the standard expression of this form of solidarity is not penal law, but contractual law. The relation between the members of these societies are consolidated through contract. However, this does not mean that such societies are merely based on free exchange where relations are fleeting and exist only for the duration of the contract. The state regulates and harmonizes the different (professional, domestic, etc.) relations between the individuals by offering a legal framework within which contracts can be made. Moreover, the state is as dependent on the different members of society as they are on it and on each other. Society no longer treats its members as things over which it has rights, but as cooperating members on which it depends and with regards to whom it has certain obligations. Thus Durkheim explains the degraded authority of the father, on which Lacan based his theories on the Oedipus complex in 1938, through a change in the nature of the relation between the individual and the collective. In the patriarchal societies of yore, members were hardly differentiated and the father represented the group as a superhuman authority. In modern societies based on the division of labor this authority shifts to the state as a governing instance which is as dependent on the individuals as they are on the collective. That is why Durkheim states that "each time that we find ourselves faced with a mechanism of government endowed with great authority we must seek the reason not in the particular situation of those governing, but in the nature of the societies that they govern" (Durkheim, 1984 [1893], p. 143-144). 
Even though he discerns an evolution toward individuality, Durkheim continues to stress the importance of the collective representations and their effect on the individual. In a paper written with his nephew, Marcel Mauss (Durkheim and Mauss, 1903), he describes the impact of social morphology (i.e., the composition and structure of a society) on the classification systems used by the members of a given society. Whether it is a primitive classification of plants based on an animistic belief, or a scientific classification based on genetics, man categorizes the world that surrounds him in representational systems that have a certain structure and hierarchy. Durkheim states that these systems of classification are shaped by a process influenced by all sorts of external elements, the most fundamental of which is the social organization of a society. Therefore, many of the primitive classification systems reflect the morphology of the society from which they originate. However, once these representational systems have gained their independence from the social structures from whence they sprung, they function according to their own logic.

In conclusion we can state that Durkheim's collective consciousness contains its own collective representations, has its own vitality and functions according to its own laws. What is more, Durkheim (1924 [1898]) maintains a strict separation between the collective and the individual. The collective conscious exists both as an independent entity and resides in its entirety in every individual, albeit in an unconscious form. He deduces this from the fact that the collective representations appear to come from outside the individual and impose themselves in a coercive manner, under the form of moral obligations.

Karsenti (1997) states that Durkheim's conceptualization brings sociology in an awkward position. He has materialized the collective (chosification), made it into a collective consciousness that is unconscious on an individual level. As such, sociology can only study the social in the light of this irreducible dualism, where the collective has a certain ascendancy over the individual. This is due to the fact that for Durkheim a representation can only exist if it represents something to somebody. In order to allow for the idea of an unconscious representation he has to dissociate the notion of representation and individual consciousness. Subsequently, he postulates the existence of a collective consciousness that exists alongside the individual consciousness, because only then the collective representations can be unconscious for us individuals but not as such. It is only afterwards that these collective representations appear, not as the product of some impersonal subject, but as the effect of their insertion on the level of the limited, individual consciousness. Thus the notion of representation lead Durkheim into an impasse where the individual and the collective are strictly dissociated.

\section{MAUSS AND THE TOTAL MAN}

Mauss will furnish sociology with a new object: the total man (l'homme total). In a shift from sociology to anthropology, which studies man in all his aspects (social, individual, biological, etc.), he will rectify Durkheim's decentering of the individual and reunite the individual and the collective. The social forms but a single aspect of this total man. Maus's is no longer a dualistic approach, but one that focuses on the complex and dialectical relation between the individual and the collective in an effort to expose its underlying rules and structures, rather than its representations. Mauss defends the notion of a gradual difference between individual and collective. Individual representations can permeate the collective and vice versa. Every individual possesses a fragment of the totality of collective representations, which are moreover marked by the singularity of the individual.

He finds one of the most convincing examples of these transitions between collective and individual in the physical and psychological effects on the individual of the collective suggestion of death. Mauss (1950 [1926]) describes how in certain primitive cultures in Australia and New-Zealand individuals die because of magical or moral causes suggested by collectively shared beliefs. The individual dies not because of some physical disorder or any personal conviction or deed, but because of the way in which the collective manifests itself on an individual level—or, which comes down to the same in Mauss' view, the way in which the individual positions itself within the collective. Subjective consciousness and the will to live pale in comparison to the collective necessity to die. However, this is not, as it would be in a Durkheimian logic, because the collective representations act on the individual as an external cause, but because the individual assumes a given position within the social structure of the tribe. Hence, this state often coincides with a breach of community. Through magic or the committing of a crime the individual breaks off with those forces which had up until then supported it. For example, the Wakelbura who eats prohibited game will become sick, consume himself and eventually die while gasping out the sounds of the animal in question ${ }^{1}$.

According to Mauss the destructive effect of this collective suggestion takes place on the joint between man's social and biological nature, albeit minimally mediated by his individual consciousness. Karsenti (1997) states that this is only possible if one supposes that the collective resides within the individual, alongside the individual will to live. Mauss explains this phenomenon with the assumption that psychological, physical and social forces coincide in the individual, and rejects the idea of a strict dissociation between the collective and the individual. As such, this phenomenon is structured along these three axes: (1) an individually experienced conviction to die responds to (2) a collectively shared suggestion to die, upon which (3) a physical event follows.

Contrary to Durkheim, who took the collective representations to be the primary object of sociology, Mauss wants to study the total individual through anthropology. He defends a return to man in his most concrete form. This is

\footnotetext{
${ }^{1}$ Lévi-Strauss (1963 [1949]), in his paper on "The Effectiveness of Symbols," gives an interesting pendant of this phenomenon. He explains how a shaman cures a woman experiencing difficulties during labor by connecting her symptoms with the collectively shared mythology, which has an effect on these physical symptoms. This paper has heavily influenced Lacan in his interpretation of the Symbolic Order (Zafiropulos, 2010 [2003]).
} 
a psychological and biological individual who appropriates a fragment of the collective in a process called socialization. Man is totally individual and totally collective. Moreover, both orders are subject to the same logic and the same laws. This totality can equally be found in language. Sociology and anthropology would benefit from adapting the methods of linguistics, because they form a science that studies a phenomenon that is both physiological, psychological and social. Lévi-Strauss will be the one who takes up the challenge and applies the methods of linguistics to social structures.

\section{LÉVI-STRAUSS AND THE SYMBOLIC FUNCTION}

For our discussion of Lévi-Strauss' elaboration of Mauss' symbolic framework, we will rely heavily of his Introduction to the work of Marcel Mauss (Lévi-Strauss, 1987 [1950]). In this succinct analysis of the latter's body of work, Lévi-Strauss addresses the question of the subjective implication of the anthropologist in his observations of other societies, which we consider to be a specific formulation of the question with regard to the relation between the individual and the collective. Mauss' concept of the total man implies that the anthropologist, as an observer, is of the same nature as his object of observation. Not only does he approach this society as an object of study, he also participates as a subject in this so-called object. Moreover, he has to externalize his subjective experience in order to present it in a formalized manner. This task would be impossible if the subjective and the objective would not meet at a given point.

Lévi-Strauss is prompted to formulate an answer to this question by an incongruity he perceives in Mauss' essay on the gift (Mauss, 2011 [1925]). In this seminal work, Mauss describes the principles of the exchange of gifts in different cultures. The study yields several observed principles, which can be found among very differing cultures across the globe: the obligation to give, to receive and to reciprocate. Moreover, many cultures formulate an explanation for these principles in terms of their own systems of belief. For example, the Maori of New Zealand refer to the hau. This is a spiritual essence which follows the gift wherever it goes and has the tendency to return to its origins. Therefore, if A offers a gift to B, and B passes this gift on to C, then $\mathrm{C}$ has to reciprocate to A for the hau present in the gift needs to be returned to its original source. However, Lévi-Strauss points out that we should never take these indigenous explanations at face value. A concept such as the hau is an element within a given symbolic system governing the exchange of gifts and as such should be scrutinized as to its function within this system.

He compares the hau and similar concepts with algebraic notions, which represent an undefined value of meaning but are themselves completely devoid of meaning. Their function is to reconcile the gap between signifier and signified. They are an attempt to restore a previously lost unity. As such, they do not represent an affective value, as Mauss arguments, but have a logical function and are to be situated on the same level as the relation they attempt to construct, which is a symbolic level. Whether something, an object, belongs to one person or the other is but a derivative of the original, relational character of the underlying reality. Indeed, according to Lévi-Strauss and in line with Mauss' own holistic approach of the total man, the underlying reality of these obligations and their uniting principle of the hau is the totality of the exchange. This totality is reflected in certain linguistic expressions used by some primitive cultures where giving and receiving, or borrowing and lending, are designated by one and the same word. As in any form of communication, the different terms implied (i.e., sender, receiver, gift, or message) are but secondary elements which divide an underlying, unified reality.

Lévi-Strauss stresses the relational character of the symbolic. Through the use of discrete elements it attempts to differentiate this previously undifferentiated reality. Terms such as subject and object, individual and collective, I and other, are differentiated through the use of the symbolic system. This is especially palpable in the principles present in the exchange of gifts. However, in such a system there is hardly any place for an individual separate from the collective. Indeed, Lévi-Strauss stresses the fact that in Mauss' study of the notion of the person (Mauss, 1938) the individual is relegated to a logical function within the symbolic system-which can only be collective.

\section{LACAN: THE LOGIC OF THE COLLECTIVE AND THE ASSERTION OF THE SUBJECT}

We have already discussed Lacan's approach of the relation to the other in terms of identification, which is ubiquitous in his paper on the family complexes. However, the events of World War II have brought the dire effects of identification to Lacan's attention (Roudinesco, 1997 [1993]). Moreover, a visit to England in 1947 acquainted him with the approach of Rickman and Bion in working with groups of mental patients during the war. Their views of group therapy were based on a conceptualization of the group in terms of horizontal identification (Bion and Rickman, $1943)^{2}$.

In 1953 Lacan wrote a letter to his ex-analyst, Rudolph Loewenstein, where he claims he has reached a point where he feels himself "a man more certain of his duties and his destiny" who has a growing assurance of what he has to say on "an experience of which only the last few years have permitted [him] to recognize the nature" (Lacan, 1976 [1953a], p. 132, our translation). This also marks the year of his Rome Discourse (Lacan, 2006 [1953b]), a text in which Lévi-Strauss' influence can all but be denied. However, in the years preceding it we see Lacan as a seeker, attempting not only to conceptualize a relation between the subject and the other that does not merely rely on identification, but also to formalize this relation in a logical system. Traces of his quest can be found in his papers on the logic of the collective (Lacan, 2001 [1945-1946], 2006 [1945]).

In a rare and rather dense paper Lacan (2001 [19451946]) presents us with a mathematical riddle which reveals the principle of a logical connection between a group and the

\footnotetext{
${ }^{2}$ This contrasts with the Freudian point of view, where the vertical identification with the leader takes precedence over the horizontal identifications between the members of the group (Freud, 1955 [1921]).
} 
individuals that constitute it. We are offered 12 visually identical coins, amongst which one can be discerned on grounds of its weight. We do not know whether this coin, the "bad coin," is lighter or heavier than the others. Its quality does not concern us, the only thing that concerns us is the notion of its absolute difference. Furthermore, we have at our disposal a classic pair of scales. Our task is to discern the "bad coin" with a maximum of three separate weighings. We lack the space to expound the complete solution to this riddle (an excellent translation of Lacan's article can be found on-line). We will content ourselves with a brief summary of Lacan's proceedings and his conclusions.

After he has illustrated the solution to the problem as it is presented, Lacan ups the ante by adding another coin to the collection. Can we still solve the riddle if we have to discern the "bad coin" among 13 coins? This can indeed be done, provided that we use another procedure than the one applied to a collection of 12 pieces. Moreover, this new procedure permits Lacan to elaborate a formula that allows one to find the "bad piece" among a maximum amount of coins with the aid of a minimum amount of weighings. One merely has to follow three simple principles: first, one has to isolate a piece that is free of any suspicion; next, one brings about a discord in the distribution of suspicion (e.g., the amount of coins that is suspected to be lighter than the others is greater than the amount that is suspected to be heavier); finally, one discriminates between the remaining pieces until one has found the "bad piece."

Without the complete solution at one's disposal this will undoubtedly sound complicated-and it is. However, the important thing to retain is the fact that this collection cannot be defined with the aid of any external criterium. There is no unifying characteristic other than the uniformity of the collection. The only way we can discern the "bad coin" is through a comparison with the other coins. Even when, in the first step, we isolate a coin that serves as a norm with which to compare the other coins, this is done through a comparison with the coins already present. In other words, the absolute difference that constitutes the individual in this collective can only be reached through a comparison with the others. Moreover, this relation between the individual and the collective can be formalized through a logical formula. As such, Lacan can sustain the notion of a separation between the individual and the collective (which was too radical in Durkheim's case) while at the same time formalizing this relation as a logical function (which was Lévi-Strauss' aim). In a paper that chronologically precedes this one, but which logically forms its consequence, Lacan (2006 [1945]) formulates how the subject asserts itself against the collective.

Lacan presents us with yet another riddle. Three prisoners are summoned by the warden who promises to grant one his freedom if he successfully stands a test. He presents them with five disks: three white and two black. Each prisoner will have a disc attached to his back such that he himself cannot see the color of his own disc, but can perfectly observe the disks the other two are wearing. Moreover, they are not allowed to communicate. The purpose of the test is to infer what color disc one is wearing based on logical reason. Thereupon, the warden distributes the white disks among the prisoners. After staring at each other for some time, all three prisoners head for the warden. What happened ${ }^{3}$.

In the ideal solution one prisoner, $\mathrm{A}$, starts from the hypothesis that he is black. Within this condition another prisoner, $\mathrm{B}$, could make the same hypothesis and easily come to the conclusion. If he were indeed black, the third prisoner, C, would see two black disks and leave at once. However, $\mathrm{C}$ does not move at once. Therefore, B can conclude that he is not black and leave. Yet, B does not leave either. Thus, A can only conclude that his initial hypothesis ("I am black") was false. And because in reality all three prisoners followed the same path of reasoning, they all leave once they have reached this conclusion.

Lacan is hard pressed to point out the sophistic nature of this solution. For if they all leave at the same time, they all must doubt their initial conclusion which was based on the fact that the others remained standing still. Therefore, after they have all left, their doubts will make them all pause. This scenario is reminiscent of Achilles and the tortoise, and one can wonder whether they will ever reach the warden. Lacan arguments that they will, and that they only need two stops to come to an absolute, logical certainty. For the first halt objectifies B's conclusion: if $\mathrm{C}$ had seen two black disks, he would never pause. The second stop objectifies A's conclusion: if B pauses a second time, that means the first pause was not conclusive for him (which it would have been had A been black). Thus, Lacan concludes, these temporal hesitations are a necessity in order to arrive at a logically sound argument.

The introduction of time in order to arrive at a logical conclusion does not agree with the spatial nature of classical logic, which is based on the universality of certain forms. One does not need time: either one sees the solution or one does not see it. However, Lacan states that in this logic of the collective three logical times can be discerned. The first is what he call the instant of the glance. The riddle would be limited to this time if two black disks were distributed, its solution summarized in the following statement: "Being opposite two blacks, one knows that one is white," (Lacan, 2006 [1945], p. 167). The subject of this statement is the impersonal "one" of every logical statement. This is also the subject present in Durkheim's mechanical solidarity: the "one" that represents the collective consciousness and is expressed through penal law. Indeed, according to Durkheim the latter does not imply that "I do not perform a certain act because it is punishable," but rather that "it is punishable, because one does not perform such acts." However, this subject is also present in the reasoning of Mauss and Lévi-Strauss as it can be compared to notions such as the hau. It merely serves a logical function within a closed, symbolic system. Yet Lacan has something different in mind, namely a subject that asserts itself against the collective. In order to arrive at this assertion, the subject has to encounter the other.

Indeed, the situation where one prisoner sees two black disks does not present itself. Therefore, a second time is inaugurated with the following (intuitive) statement: "Were I a black, the two whites that I see would waste no time realizing that they are whites," (Lacan, 2006 [1945], p. 168). In this time, one

${ }^{3}$ We will only scratch the surface of this text. For a thorough discussion of the riddle, its solution and implications, see Hoens (in press). 
prisoner ( $\mathrm{A}$ in our example) makes himself the object of the gaze of the other two and puts himself in their position. In this case, time is necessary for the other two to reach a conclusion because it is based on the fact that the other stands still (which is interpreted as a hesitation). Lacan calls this the time for comprehending. The subject of this time is a subject determined by the reciprocity of the other. The relation between these subject is of an imaginary nature, meaning that the prisoners mirror each other (Aucremane, 1985).

The time for comprehending also puts every subject under a logical pressure. Indeed, how long does this comprehending take? If A hesitates to come to a conclusion and the other two precede him, he will never ever be able to reach any sound conclusion because it can only be based on their standing still. Therefore, a necessary moment of concluding interrupts the time for comprehending through the following statement: "I hasten to declare myself a white, so that these whites, whom I consider in this way, do not precede me in recognizing themselves for what they are," (Lacan, 2006 [1945], p. 168). This statement is the subjective assertion. The time for comprehending leads to a conclusion, but only if the subject anticipates the certainty of his conclusion and seizes it in a moment of urgency.

Lacan operates a shift from spatiality to temporality, from a subject seized by an intersubjective logic to a subject that asserts itself in an act based on a judgment that lacks sufficient logical ground. This subject is the personal subject, the one that pronounces "I" (in French: "je"). It can only exist on the condition that it has assumed the other forms of subjectivity (i.e., the impersonal "one" and the reciprocal subject). The assertion of this subject is different from the subject as a mere function of the symbolic system-and yet, Lacan states that this subject also has a logical form and stems from a logical process.

According to Lacan the temporal logic of this riddle can be applied to group of undefined size, given that there is always one black disc less than there are prisoners. As in the case with the 13 coins, the group is not constituted by a common trait. The trait is retroactively defined by the group through the assertion of the subject. The collective is founded on the reciprocity of the difference. As such, the collective logic can be expressed according to the following principles: "(1) A man knows what is not a man; (2) Men recognize themselves among themselves as men; (3) I declare myself to be a man for fear of being convinced by men that I am not a man," (Lacan, 2006 [1945], p. 174). Thus

\section{REFERENCES}

Aucremane, J. L. (1985). 'Le Temps Logique': trois temps de la subjectivité. Quarto $22,20-22$.

Bion, W. R., and Rickman, J. (1943). Intra-group tensions in therapy. Their study as the task of the group. Lancet 242, 678-682.

Durkheim, E. (1975 [1892]). "La famille conjugale," in Textes 3. Fonctions Sociales et Institutions, ed V. Karady (Paris: Les éditions de minuit), 35-49.

Durkheim, E. (1984 [1893]). The Division of Labor in Society. New York, NY: The Free Press.

Durkheim, E. (1924 [1898]). "Représentations individuelles et représentations collectives," in Sociologie et Philosophie, ed E. Durkheim (Paris: Alcan), 1-48.
Lacan formalizes the relation between the individual and the collective. In this formalization the individual is a subject and as such a function within a logical process. However, through the anticipation of its truth it can assert itself against this collective and escape the reciprocal relation in which it was captured.

\section{CONCLUSION}

Lacan's views on the relation between the subject and the other gradually change between 1938 and 1953. Initially this relation is conceived of as strictly based on the principle of identification. Such was the case in his paper on the family complexes, where the process of socialization is described as a series of consecutive identifications. From 1953 onward Lacan conceptualizes the Other no longer as an image with which to identify, but as a symbolic system governed by the laws of language. This new conceptualization is realized through the tools handed to him by Lévi-Strauss' structural anthropology. In this paper we have demonstrated that between 1938 and 1953 Lacan attempted to formulate the individual as a function, the subject, within a logic of the collective. Thus, although Lévi-Strauss handed him the methodology, this encounter does not constitute a radical breach in Lacan's work-it is merely a refining of the work he had already started.

Moreover, we have demonstrated that Lacan's statements on the logic of the collective can be situated within a broader frame of reference. Whereas Durkheim ended in a situation where individual and collective are radically separated, Mauss and Lévi-Strauss relegated the individual to a mere logical function within a collective, symbolic system. Lacan on the other hand conceptualized a subject that can assert itself against the other while still remaining part of a logical system. This is the conundrum that Lacan will confront time and again throughout his teachings and needs to be taken into account when one wishes to study the further influence of Lévi-Strauss on Lacan. The subject, a logical function within the Symbolic, speaks and asserts itself.

\section{AUTHOR CONTRIBUTIONS}

The author confirms being the sole contributor of this work and approved it for publication.
Durkheim, E., and Mauss, M. (1903). "De quelques formes primitives de classification: contribution à à l'étude des représentations collectives," in Année Sociologique, Vol. VI, 1-72.

Freud, S. (1953 [1912]). "Totem and taboo," in Standard Edition, Vol. 13, ed J. Strachey (London: Hogarth), 1-161.

Freud, S. (1955 [1921]). "Group psychology and the analysis of the ego," in Standard Edition, Vol. 18, ed J. Strachey (London: Hogarth), 69-143.

Hoens, D. (in press). "Logical time and the assertion of anticipated certainty: A new sophism," in Lacan's Ecrits: A Reader's Guide. 1: Between the Imaginary and the Symbolic, eds C. Neill, S. Vanheule, and D. Hook (New York, NY: Routledge).

Karsenti, B. (1997). L'homme total. Sociologie, Anthropologie et Philosophie chez Marcel Mauss. Paris: Presses Universitaires de France. 
Lacan, J. (2001 [1938]). "Les complexes familiaux dans la formation de l'individu. essai d'analyse d'une fonction en psychologie," in Autres Écrits, ed J. A. Miller (Paris: Seuil), 23-84.

Lacan, J. (2006 [1945]). "Logical time and the assertion of anticipated certainty," in Ecrits, Transl. by B. Fink (New York, NY: W. W. Norton \& Company), 161-175.

Lacan, J. (2001 [1945-1946]). "Le nombre treize et la forme logique de la suspicion," in Autres Écrits, eds J. Lacan and J. A. Miller (Paris: Seuil), 85-99.

Lacan, J. (2006 [1949]). "The mirror stage as formative of the $i$ function as revealed in psychoanalytic experience," in Écrits, Transl. by B. Fink (New York, NY: W. W. Norton \& Company), 75-81.

Lacan, J. (1976 [1953a]). "Lettre de jacques lacan à rudolph loewenstein," in La Scission de 1953. La Communauté Psychanalytique en France I. Supplément au Numéro 7 d'Ornicar? eds J. A. Miller (Paris: Le Champ Freudien), 120-135.

Lacan, J. (2001 [1947]). "La Psychiatrie Anglaise et la Guerre," in Autres Écrits, eds J. Lacan and J. A. Miller (Paris: Seuil), 101-119.

Lacan, J. (2006 [1953b]). "The function and field of speech and language in psychoanalysis," in Écrits, Transl. by B. Fink (New York, NY: W. W. Norton \& Company), 197-265.

Lamanna, M. A. (2002). Emile Durkheim on the Family. Thousand Oaks, CA: Sage Publications.

Lévi-Strauss, C. (1963 [1949]). "The effectiveness of symbols," in Structural Anthropology (New York, NY: Basic Books), 186-205.

Lévi-Strauss, C. (1987 [1950]). Introduction to the Work of Marcel Mauss. Transl. by F. Baker. London: Routledge.
Mauss, M. (2011 [1925]). The Gift: The Form and Reason for Exchange in Archaic Societies. Transl. by W. D. Halls. New York, NY: W. W. Norton \& Company.

Mauss, M. (ed.). (1950 [1926]). "Effet physique chez l'individu de l'idée de mort suggérée par la collectivité," in Sociologie et Anthropologie (Paris: Presses Universitaires de France), 313-332.

Mauss, M. (1938). Une catégorie de l'esprit humain: la notion de personne celle de “moi”. J. R. Anthropol. Inst. 68, 263-281.

Roudinesco, E. (1997 [1993]). Jacques Lacan. Transl. by B. Bray. Cambridge: Polity Press.

Zafiropoulos, M. (2001). Lacan et les Sciences Sociales. Le Déclin du Père (1938-1953). Paris: Presses Universitaires de France.

Zafiropulos, M. (2010 [2003]). Lacan and Lévi-Strauss or the Return to Freud (1951-1957). Transl. by J. Holland. London: Karnac Books.

Conflict of Interest Statement: The author declares that the research was conducted in the absence of any commercial or financial relationships that could be construed as a potential conflict of interest.

Copyright (C) 2018 Schrans. This is an open-access article distributed under the terms of the Creative Commons Attribution License (CC BY). The use, distribution or reproduction in other forums is permitted, provided the original author(s) and the copyright owner are credited and that the original publication in this journal is cited, in accordance with accepted academic practice. No use, distribution or reproduction is permitted which does not comply with these terms. 


\title{
The 'Real Without Law' in Psychoanalysis and Neurosciences
}

\author{
Adriano Aguiar* \\ Mental Health and Family Medicine, Institute of Psychiatry, Psychiatric Center of Rio de Janeiro, Federal University of Rio de \\ Janeiro, Rio de Janeiro, Brazil
}

In this article, we will examine some of Lacan's concepts on the relation between psychoanalysis and science. The difference that Lacan states between the real for science, which would be entirely governed by laws, and the real for psychoanalysis a 'real without law' - risk to lead to an irreducible separation between the two fields. However, as the article shows, that separation between psychoanalysis and science is not the position defended by Freud and Lacan. Indeed the latest discoveries in the field of neurosciences challenge the traditional conception of the real for science, bringing it closer to the real 'without law' that characterizes psychoanalysis. Conceiving the real for science as a real that is opened to contingencies and not entirely governed by laws, is the first necessary step for a new alliance between psychoanalysis and

OPEN ACCESS

Edited by: Rémy Potier,

Paris Diderot University, France

Reviewed by:

Liviu Poenaru,

In Analysis, Revue Transdisciplinaire de Psychanalyse et Sciences,

Switzerland

Daniela Flores Mosri,

Universidad Intercontinental, Mexico

${ }^{*}$ Correspondence:

Adriano Aguiar aguiarad@gmail.com

Specialty section:

This article was submitted to Psychoanalysis

and Neuropsychoanalysis, a section of the journal

Frontiers in Psychology

Received: 23 October 2017 Accepted: 11 May 2018

Published: 26 June 2018

Citation:

Aguiar A (2018) The 'Real Without

Law' in Psychoanalysis and Neurosciences.

Front. Psychol. 9:851. doi: 10.3389/fpsyg.2018.00851 science.

Keywords: psychoanalysis, neurosciences, Lacan, real, second nature, cognitive science

\section{INTRODUCTION}

Since the 1990s some important neuroscientists, such as Gerald Edelman, V. S. Ramachandran, Antonio Damasio and others, began to express their interest in approaching psychoanalysis and neurosciences. The studies conducted by these scientists led to the creation of the Neuropsychoanalysis Association, an international network of non-profit organizations that support the dialog between neurosciences and psychoanalysis.

Even if those more involved with Lacanian psychoanalysis tended to be more suspicious about an approximation between psychoanalysis and neuroscience, this scenario has been changing in the last decade since some Lacanian psychoanalysts and philosophers have done quite fruitful theoretical dialogs between some experimental findings in the fields of genetics and neurosciences and some theoretical concepts from Lacanian psychoanalysis (Ansermet and Magistretti, 2004; Zizek, 2008; Johnston, 2013).

This article seeks to contribute to the debate between Lacanian psychoanalysis and neurosciences, discussing a specific point of the conceptual underpinnings of Lacanian theorizations about science. If the difference that Lacan states between the real for science, which would be entirely governed by laws, and the real for psychoanalysis - a 'real without law' - risk to be seen as the basis for an irreducible separation between the two fields, we tried to show that the complete separation between psychoanalysis and science was never the position defended by Freud and Lacan. We argue that the latest discoveries in the field of neurosciences challenge the traditional conception of the real for science, bringing it closer to the real 'without law' that characterizes psychoanalysis, what makes possible a entirely new kind of dialog between the two fields, since the idea of the real that arises from contemporary neurosciences is a real that is opened to contingencies and not entirely governed by laws. 


\section{PSYCHOANALYSIS AND NATURAL SCIENCES}

The development of psychoanalytical theory by Freud was often associated with some concepts or metaphors that he took from the natural sciences, which exerted a strong influence in his thinking. Otherwise, Lacan's inspiration in Levi-Strauss and Saussure's structuralism, contributed decisively to give Lacanian psychoanalysis its own epistemological vocabulary that moved away from naturalistic influences (Bezerra, 2013). Although Lacan had been interested in animal behavior and biology in the early days of his teaching, this interest was in the opposite direction of the naturalism present in some post-Freudian psychoanalysts thinking. Differently from the adaptationist perspective present in the naturalistic inspiration of most postFreudian authors, for Lacan human subjectivity is something that emerges as the effect of the symbolic order, constituting a break from the immediate plan of nature.

However, if Lacan's teaching was clearly marked by an antinaturalistic perspective, we could not say that he sustains that psychoanalysis should have an anti-scientific stance. We know that Freud thought that the worldview (Weltanschauung) of psychoanalysis should be no other than science's one. At the end of the conference The question of a Weltanschauung Freud states that: "In my opinion, psychoanalysis is incapable of creating a Weltanschauung of its own. Psychoanalysis does not need one; it is part of science and can adhere to the scientific Weltanschauung" (Freud, 1933 p. 89).

In the same direction, Lacan is emphatic in reproving those who claim that psychoanalysis should stand in a position of exteriority regarding the scientific field: "We say, contrary to what was invented on an alleged breaking of Freud with the scientism of his time, that it was this same scientism (...) which led Freud, as is shown in his writings, to open the way that will forever have his name. We say that this way has never left the ideals of this scientism since it is called like that and that the mark it brings form it is not contingent, but essential" (Lacan, 1966/1998, p. 871).

For Lacan, the relationship between psychoanalysis and science rests on the epistemological discontinuity produced by the emergence of modern science which promoted a radical transformation in the modern conception of the subject that was essential for the emergence of psychoanalysis. The Cartesian cogito is considered by Lacan a key correlate to the emergence of modern science, which he characterizes as a moment of rejection of all traditional knowledge in order to establish a "grounding in being" for the subject. A subject, emptied of knowledge, devoid of content and representation, without substantial density, which only exists in the act: "I think, therefore I am." This is the subject of science. And for Lacan this subject is none other than the subject upon which psychoanalysis itself operates: "That is why it was important to promote, first and foremost, and as a fact to be distinguished from the question of whether psychoanalysis is a science (if your field is scientific), just the fact that its practice does not imply another subject than the subject of science" (Lacan, 1966/1998, p. 878).

\section{THE REAL FOR SCIENCE AND THE REAL FOR PSYCHOANALYSIS}

For Lacan, psychoanalysis would not be possible without the advent of modern science. Following Koyré (1957/2010), Lacan thinks that science is always based on the assumption that there is "knowledge in the Real". The "laws of nature" implies that there is something like an articulated network of "signifiers" that are present in the Real, and, at least in the early part of his teaching, Lacan searched for a rapprochement between psychoanalysis and the scientific field based on this assumption that characterizes the foundation of science: that there is knowledge in the Real. Indeed, at the beginning of his teaching, Lacan seeks an alignment between psychoanalysis and science via structuralism. According to Jacques-Alain Miller (Miller, 2002a), Lacan wandered of being able to suspend the segregation of psychoanalysis by science trying to translate the tragic aspect of human experience into the mathematics. That's why Lacan was so attracted to some kind of mathematization of psychoanalytic experience. In this perspective, the unconscious is constituted by signifiers organized according to the laws of language, which operate independently of the subject's consciousness. The subject itself is an effect of the functioning of these laws. That is why the analyst can rely on the Freudian free association. It certifies that for psychoanalysis there is the assumption that there is a certain "knowledge in the Real". This is a deterministic assumption of psychoanalysis: speak the patient whatever she says, the unconscious signifiers will emerge in her speech, for there are laws of language that determine the unconscious functioning. In this sense, we could say that there is a kind of "knowledge in the Real" which is present in the analytical experience, it's not just about hermeneutics or narratives (Miller, 1989).

Towards the end of his teaching, Lacan will gradually replace the causal language that marked his beginnings to isolate a break in the chain of determination, stating that the real with which we deal in the analytic experience is a real that conveys the absence of law - a "real without law". It is a real that is not based on the positive axiom that for Lacan characterizes science - "there is knowledge in the real" - but a real that rests in contingency and in the absence of sexual relation ("il n'y a pas de rapport sexuel"): "Throughout his teaching, ready to confront the discourse of science on their own ground, he [Lacan] adopted a causal language. Until he found a break in the causality, a break in determination, finding, synthesizing - why not say that? - certain results under the species of: "there is no sexual causality". He said "relation". But he said relation meaning that there is no causality. There is no law of the relation between the sexes. He thought that by this way he could oppose to the real for science - which is a real containing knowledge - to the real of psychoanalysis under the species of a real that does not contain a knowledge and that would convey the knowledge of the unconscious. It would convey, first of all, especially the absence of law, precisely the hole in this knowledge. "There is no sexual relation" is the notion of the absence of law. The sexual law cannot be written. It is then that the term contingency becomes the master word, rather than cause" (Miller, 2012). 


\section{PSYCHOANALYSIS AND SCIENCE: THREE LOGICAL MOMENTS}

In separating these two conceptions of the real, the real for science and the real for psychoanalysis, Lacan highlights the specificity of psychoanalysis, which can then definitely give up the aim of being recognized as part of the scientific field. On the other hand, this doesn't imply that we should believe that psychoanalysis and science are two completely separated fields, with nothing to say to each other. According to Miller (2011), we can divide into three logical moments the relationship between psychoanalysis and science in Lacan's teaching. In the beginning, Lacan states that psychoanalysis depends on science, putting scientific knowledge as a condition of possibility for the emergence of psychoanalysis. In a second stage, Lacan moves a little from this perspective, understanding that psychoanalysis finds its place out of a failure or incompleteness in the discourse of science. Miller (ibid) notes that in the Italian Note (Lacan, 1973/2003), Lacan says that the very functioning of the discourse of science tends to produce an effect of reaction or protest that Lacan calls "humanist." This reaction aims to highlight that the knowledge in the real does not account for everything and that what is essential in the humankind is not the scientific objectivity, but rather something that always escapes from the scientific knowledge. The "humanist protest" claims for what Lacan qualifies as "docta ignorantia" (learned ignorance) against the scientific knowledge and, in a certain way, psychoanalysis finds its place in this humanism protest since she seeks to reintroduce the dimension of the subject that the discourse of science tends to suture. Psychoanalysis then appears as a "waste product" of the discourse of science and the psychoanalyst is called to challenge the discourse of science reintroducing the dimension of the subject.

Miller (2011) retakes this proposition of Lacan to show that he didn't stop there and to state that the position of psychoanalysis in relation to science should not stay in this humanist protest neither refuse the scientific knowledge. Miller points out that, still in the Italian Note, by introducing the desire to know that characterizes psychoanalysis, Lacan would point to a third logical moment in this circuit, in which psychoanalysis is not situated in the field of humanistic protest against science, but embodies the return of the science in the field of the learned ignorance. The desire to know that characterizes the position of the psychoanalyst, should not be confused with the learned ignorance, neither with the scientific knowledge. Psychoanalysis deals, otherwise, with something that is transmitted from science when the scientific desire enters the humanistic field of the learned ignorance. The desire to know that characterizes psychoanalysis thus entails a paradox: it is an effect of science without being, however, according to the scientific desire. It is an unprecedented desire to know that has its roots in science, but should not be confused with the scientific desire either with the denial of the scientific knowledge. The psychoanalytical stance is not a scientific one, but this doesn't imply that it refuses the knowledge in the real. It's a position that takes in charge the issues of "truth" with the means of science.

For Miller, the core of Freud's ambition is the return of the question about the truth within the scientific field: "We note that for the defenders of the scientific discourse, far from being distinguished from the learned ignorance, [psychoanalysis] is mistaken for it. Psychoanalysis may seem a reprint of the learned ignorance, which was as Lacan showed her for a while. On the other hand, for the learned ignorance partisans, the humanists, psychoanalysis seems to be attached to the values of science. This dual position led Lacan to assert that science (he said this with the best reason in the world, that is, with the example of Freud) inspired in some dissatisfied with the learned ignorance, with the humanistic knowledge, the desire to treat the truth in an unprecedented way. Lacan then speaks of a desire to know, which is the transformation of the desire of science when it finds what was excluded and foreclosure: the problem of truth" (Miller, 2011, p. 414).

\section{FROM THE PSYCHOANALYTIC PROTEST TO A NEW ALLIANCE WITH SCIENCE}

The discovery of the hysterical symptom by Freud was made in the context of the scientific discourse, it had incidence over a real in the scientific sense, a Galilean real, a real that accommodates knowledge. But Freud introduces something new there, postulating that there is a sense in the real, that the symptom has a meaning. For this, Miller (2005) states that psychoanalysis has emerged as a "corruption of scientific knowledge," as for science there is knowledge in the real, but it doesn't mean to "say" anything. Postulate that there is sense in the real implies that it means something, that there is something like a certain "intentionality" of the symptom which is the condition of possibility for analytic interpretation: "the meaning in the real is the support of the symptom in the analytical perspective" (Miller, 2005, p. 15).

Throughout the twentieth century, it was widely accepted this conception of the symptom - the analytic symptom. The symptom was seen as a mental symptom, as an unconscious symptom, a symptom that has a meaning to be interpreted. Nowadays, however, the situation has changed. After the DSM-III and the strong influence of biology in the mainstream psychiatric discourse (Aguiar, 2004), the symptom has been seen, in this perspective, as a sign of some disorder of the brain, as something absolutely meaningless, whose physiological causes neurosciences would explain.

How to answer to this from a psychoanalytic point of view? Miller (2005) states that there are three answers today: first, there are those who wish to adhere to the knowledge in the real, that is, those who believe that psychoanalytic concepts could be translated into the language of the neurosciences. Then there is the opposite position, the psychoanalytic protest which, according to Miller, is appealing, but in vain. This protest consists in refusing the knowledge in the real. For Miller, however, Lacanian's position can't be the refusal of the scientific knowledge. Lacanian psychoanalysts must admit that there is knowledge in the real, but at the same time, formulate that there is a hole in this knowledge, that sexuality makes a hole in the knowledge in the real. In this sense, Miller proposes a 
position that is more compatible with a certain alliance with science, a "new alliance" with science that takes into account the real at stake in psychoanalysis: "We can say that here we find the index that points to what Lacan brings and that doesn't consist absolutely in a refusal of the scientific real and of the knowledge in the real. Because deny the scientific real and refuse the discourse of science is a road to perdition that opens the way to all intrigues in the 'psi' field. Intrigue is not an injurious term. Do not refuse that knowledge, admit that there is knowledge in the real, but at the same time formulate that in this knowledge there is a hole, that sexuality makes a hole in this knowledge. It is a transformation of Freud, no doubt. It's a new alliance between psychoanalysis and science, if I dare to say, that rests on the non-relation. The non-relation gives the site of Lacanian practice. This should be understood as follows: the "sexual non-relation" is what makes a balance with the statement that says that "there is knowledge in the real". It is sexuality that makes an objection to the omnipotence of the discourse of science" (Miller, 2005, p. 16).

Miller doesn't say much more about how could be such new alliance between science and psychoanalysis. This seems to be a task to be done, with which this article aims to contribute. But it is important to notice that he writes these lines after pointing out the shift in the prevailing conception of the symptom in the contemporary era since the neuroscientific discourse became hegemonic. So when he speaks about science here, he doesn't seem to be talking about physics or mathematics as is more usual within the Lacanian field, but about the natural sciences and more specifically the neurosciences.

In another passage of the same text - which is the transcript of one of Miller's conferences at the Congress of the World Association of Psychoanalysis in 2004 - Miller draws the attention of the psychoanalysts, saying that one should not "insult the future" and proposes a certain openness to what happens in the field of neuroscience and cognitive sciences: "Freud's metapsychology showed signs of weakness, in the second half of the twentieth century. And we could say that Lacan proceeded a logical-linguistic translation of that metapsychology. He himself acknowledged having to go through this in order to give a breath of life to psychoanalysis. So it is not absurd, a priori, to try to give a neurocognitive translation of the metapsychology. We can say that it will be judged by its results" (Miller, 2005, p. 11).

We propose to take seriously these indications from Miller: how to think about a new relationship between psychoanalysis and neuroscience that rest on the non-relation? How to conceive the relation between psychoanalysis and neuroscience in a way that doesn't deny the scientific knowledge, without ever losing sight of what makes a hole in this knowledge?

Jean-Claude Milner, which is another important reference in the field of Lacanian psychoanalysis, especially regarding the relationship between psychoanalysis and science, proposes in one of his recent books (Milner, 2011), that to think about the relation of Lacanian psychoanalysis with the science of today, you may need to move away from Koyrés classical perspective that privileges the mathematization of the real. According to Milner, when Galileo wrote that nature was written in mathematical letters, the strong word should be "letter" and not mathematics. Because the essence of the Galilean turn would be, in Milner's opinion, the literalization, of which mathematics is just one way among others.

According to Milner, the position of Lacan with respect to science was deeply marked by the science of his time, which was a science dominated by the physics of Newton and Einstein. Today, however, for Milner that physics is dead, and to approach the new paradigms of science one would have to consider genetics and the biological sciences instead. And for Milner, the current biological science is not mathematized but literalized. The type of literalization scientists dedicated to the transcription of the genetic code held, for example, may even involve certain calculations, but do not constitute a mathematization. According to Milner, a kind of literalization of the living is emerging in biological sciences, and take it seriously would compel the Lacanian position in relation to science to change, especially as regards the reference to Koyré: "On the back cover that he wrote to the book Autres Écrits, Jacques-Alain Miller acknowledged in the decoding of the genome a 'promise of new marriage of the signifier with the living'. But overall, I have sometimes the impression that we don't take into account the passage of the years. In 1965, in The science and the truth, Lacan could write that 'Koyré is our guide'. Almost half a century has passed, the epistemology and the history of science have changed, and repeated offensives against Koyrés model were done, which the most decisive ones were not always recognized; as Foucault's in The Order of Things. Determinate what remains of Koyré should be a matter to consider. I didn't judge opportune to express myself in detail - neither on what remains or not from Koyré in general, nor on what in Lacan could be affected by an eventual obsolescence of Koyré. In L'oeuvre Claire I had put myself where it was placed by Lacan himself, namely, in a space where the supreme science is the mathematical physics. I haven't addressed the question of biology" (Milner, 2011, p. 19).

In 1984, Prigogine and Stengers (1997) had already pointed out that the classical model of science, as Koyré interpreted it, implied a conception of nature as an "automaton nature", entirely governed by mechanical laws accessible to human's rationality through the laws of mathematics. In fact, much of the natural phenomena respond to this model, as the dynamics of celestial bodies and the law of gravity, which obey the laws that mathematics succeed to identify. But the scientific discoveries of the twentieth century require a transformation in our conception of nature that has not been fully assimilated into the culture, which implies a perception of nature not as something stable, fully governed by predictable and immutable laws, but as a nature that is open for transformation: "Modern science was established as a product of a culture, against certain dominant conceptions of this culture (Aristotelianism in particular, but also the magic and alchemy). One could even say that it was constituted against nature itself because it denied her complexity and becoming on behalf of an eternal and knowable world ruled by a small number of simple and immutable laws" (Prigogine and Stengers, 1997, p. 4).

As stated by these authors for over 30 years, today's science is no longer the classical science, and those who continue to conceive nature as an automaton governed by mechanical and predictable laws are losing sight of what matters most to the 
science of our time, i.e., not the continuities and stable situations, but developments, crises and instabilities, which require another conception of naturalism.

We understand that to conceive of a "new alliance" between psychoanalysis and science, which rests on the "non-relation," i.e., to conceive a relation between psychoanalysis and science that take into account the "real without law" (Miller, 2002b) that guides the practice of Lacanian psychoanalysis, one must examine what is happening in the field of contemporary natural sciences, particularly in the field neurosciences, so that you can seek in this field if it's possible to find some openings for the contingent real (Miller, 2008) which is proper of psychoanalysis.

\section{NEUROSCIENCES AND THE REAL WITHOUT LAW}

In the book The Dappled World: A Study in the Boundaries of Science (Cartwright, 1999), the philosopher of science Nancy Cartwright shows that anyone who looks clearly and honestly at the current state of science will come across with the fact that we can no longer accept the often assumed equivalence between scientific realism and universality of the laws. The author notes that in the various domains covered by science we are increasingly faced with the fact that we can't establish universal laws: "The kind of knowledge we can defend from our impressive scientific successes does not point to a unified world from of a universal order, but to a dappled world of stained objects" (Cartwright, 1999, p.10).

As Adrian Johnston (Johnston, 2011) argues, it is not necessary to go down into the world of quantum physics to give scientific status to the indeterminacy that is characteristic of human subjectivity. According to Johnston, a veritable avalanche of current research in genetics and neuroscience reveals that brains and human bodies are much less determined by preestablished rules than we previously thought. The biomateriality of nature establishes a relatively small number of limiting parameters for the living being. It hardly functions as something that determines all the details of life. The biologist Francisco Varela and his collaborators (Varela et al., 1991), for example, describe the ontogenetic and phylogenetic unfolding of living beings as satisfactory/sufficient processes that work only to achieve what is good enough to survive, for long enough to reproduce. Evolution doesn't compel the production of what would be Ideal, allowing the arising of a great diversity at all levels of interaction with the environment, and may even permit the persistence of highly dysfunctional gaps in life: "The second step, then, is to analyze the evolutionary process as having a solution that is satisfactory rather than optimal: in this perspective [natural] selection functions as a broad survival filter that admits any structure that has enough integrity to persist. In this point of view, the focus of the analysis is no longer directed at the characteristic features, but rather at the patterns of organisms, via their life history. Another metaphor recently suggested for this post-Darwinian conception of the evolutionary process is evolution as bricolage, the joining of parts and elements into complex matrices, not because they fulfill some ideal project, but simply because they are possible. Here the evolutionary problem is no more like forcing a precise trajectory of the requirements of ideal aptitude; it is rather how to prune the multiplicity of viable paths that exist at any point" (Varela et al., 1991, p. 196).

The French philosopher Catherine Malabou (2008) develop the philosophical issues that arise with the discovery of neuroplasticity. For her, this discovery entails that we have to acknowledge that human brain is organized and reorganized "dialectically," continually suffering multiple oscillations between its "malleable flexibility" and its "resistant fixity." Catherine Malabou states that we have not yet fully assimilated the results of the revolutionary discoveries made by neurosciences in the last 50 years. In particular, we have not yet assimilated the importance of the constitutive historicity of the brain, which is implicated in the discovery of brain plasticity: "Our brain is plastic, and we do not know it. We are completely ignorant of this dynamic, this organization, and this structure. We continue to believe in the "stiffness" of a fully genetic brain" (Malabou, 2008. p. 4). For Malabou, the relatively recent discovery of brain neuroplasticity should change our conception of the brain as entirely predetermined by the laws of nature, allowing us to see the brain as something modifiable, "formable" and formative at the same time. Malabou identifies three levels in which cerebral neuroplasticity operates: (1) in the modeling of neural connections during embryonic and childhood development; (2) in the modification of the neuronal connections that occur through the plasticity of the synaptic modulation to lifelong learning; and (3) the ability to repair after some kind of injury.

In the book Le cerveau intime (Jeannerod, 2002), Marc Jeannerod argues that if a synapse belongs to a circuit often used, it tends to increase in volume, permeability, and effectiveness. On the contrary, if a synapse is poorly used it tends to become less effective. According to Jeannerod, it is a biological mechanism of individuation that makes each brain unique: "The theory of synaptic efficacy allows us to explain the gradual molding of a brain under the influence of individual experience, to the point of it is possible for us in principle to account for the individual characteristics and particularities of each brain. We are dealing here with a mechanism of individuation that makes each brain a single object, despite its adherence to a common model" (Jeannerod, p.63).

The psychoanalyst François Ansermet and the neuroscientist Pierre Magistretti also emphasize this aspect of brain plasticity as a biological indicator of the uniqueness of the brain, which is shaped by experience. In the book, A chacun son cerveau (Ansermet and Magistretti, 2004) these authors argue that the recent discoveries of neurobiology demonstrate that the plasticity of the neural network allows the inscription of the lived experience in the brain. The traces are inscribed, associated and modified throughout life through the mechanisms of brain plasticity. Plasticity would thus be the mechanism by which each brain is unique, giving place for a materiality of singularity. They note, however, that the traits left by the lived experiences can be lasting or even permanent. Plasticity, according to the authors, is not synonymous with flexibility or permanent adaptability, it 
also constitutes a certain determinism that gives each individual a destiny that is his own.

The cognitive scientist Stanovich (2004) describe in the book Robot's Rebellion: Finding Meaning in the Age of Darwin, that the evolutionary processes that gave birth to humans reached such a high degree of complexity, especially neural complexity, that two interrelated results occurred: first the brain was modeled in a highly elaborated anatomical differentiation, from a plurality of constituent elements that are not synchronized with each other, often leading to intracerebral conflicts, in which different parts present incompatible functions. Secondly, these intracerebral conflicts - understood as a materialized result of the sedimentation of several distinct periods of evolutionary history in the human central nervous system - make possible something unique to humans, which Stanovich calls "rebellion" against nature, insofar that it makes us humans prone to evolve against genetic and evolutionary determinism. According to Stanovich's perspective, the evolution shaped human beings as vehicles capable of transmitting genetic material, with incredibly elaborate and flexible intelligence, also involving a sensitive and receptive plastic brain, so that evolutionarygenetic deterministic control, in our case, would have been relatively loosened to the point of producing creatures that escaped the control of genes in a completely unpredictable way. From the perspective of genes as "blind" replicators, the high complexity of the human body/brain system, is a kind of double-edged sword: while it allows replication strategies that are broader and more sophisticated than those of other living beings, the exceptional complexity of humans gives birth to biological processes that are disruptive to the natural dictates of evolution as they are transmitted by genes.

The neuroscientist Antonio Damasio (Damasio, 2010), also assumes a perspective quite similar to Stanovich's, formulating that in man, the emergence of consciousness and the creation of culture are a radical novelty in the history of evolution, for these often offer imperfect or even "rebellious" responses, many of which go against the dictates of nature's own laws: "If nature can be considered as indifferent, unpredictable, unpredictable, then human consciousness creates the possibility of question the ways of nature. The emergence of human consciousness is associated with evolutionary developments in the brain, behavior, and mind that ultimately lead to the creation of culture, a radical novelty in the movement of natural history. The emergence of neurons, with the emergence of the diversification of behavior and the paving of the path to the mind, is a momentary event in the great trajectory. But the appearance of the conscious brain, capable of self-reflection, is the next great moment. It is the opening of the way to a rebellious and imperfect response to the dictates of a careless nature" (Damasio, 2010, p.287).

As Adrian Johnston argues, the biological sciences need to be able to detach themselves from the idea of organicity (in the sense of a complete and harmonic whole) to conceive the brain in a way that is more compatible with the richness and complexity of human beings as speaking beings, as beings carrying within themselves something more than the organic. For him, to do justice to the rich and unpredictable kind of subject humans beings are, life sciences should complement the worldview of their spontaneous organicism with the notion that there is something more in the organic than the organic itself (Johnston, 2013). However, this non-organicity of the human brain should not be understood simply as equivalent to the inorganic. Johnston proposes that we call "anorganic" this non-organicity that is distinct from the inorganic. Unlike the inorganic, the term anorganic, as Johnston conceives it, designates the flaws in the organic structure and the dynamics engendered in and by the non-whole biological systems. For Johnston, scientific findings as those described above, show that the biomaterial substance of evolution seems to reflexively negate its own controls and causal influences, giving rise to beings whose complex plasticity escapes governance evolutionary-genetic nature.

\section{CONCLUSION}

Since the 1990s psychoanalysis has been constantly criticized for having moved away from traditional methodologies of scientific investigation and, more specifically, from the emerging neuroscientific field. Lacanian psychoanalysis, which is very influential in the psychoanalytic field nowadays, tend to have a more critical position regarding the neurosciences, although some Lacanian psychoanalysts have done very interesting works in the interface between psychoanalysis and neuroscience.

One important conceptual underpinning for the rarity of debates with neuroscience in Lacanian psychoanalysis is the notion that psychoanalysis and sciences deal with different conceptions of the real. Lacan developed from Koyré the conception that the real with which science deal is a real entirely governed by the laws of physics and by the end of his teaching he states that the real for psychoanalysis is a real that conveys the absence of laws for sexuality - a "real without law".

We tried to show in this article that a new conception of the real is emerging from contemporary neurosciences, making possible new perspectives for the dialog between Lacanian psychoanalysis and neurosciences. A famous phrase from Ansermet and Magistretti state: "the individual can be considered biologically determined to be free, that is, to constitute an exception to the universal that carries him" (Ansermet and Magistretti, 2004, p.10). This only can happen because nature itself is fragile, vulnerable, subject to failures in its own materiality. This perspective challenges the most common intuitive view, in which nature is conceived as an omnipotent monolithic block composed of elements perfectly connected and controlled by deterministic laws. The more recent discoveries of life sciences, and neurosciences in particular, makes possible to conceive the materiality of nature as prone to contingency, error, and complexity, which is a vision of the real that is closer to the Lacanian idea that the real is without law, that nature and brain are less deterministic than science previously thought. This opens up an ontological and epistemological space for new debates between Lacanian psychoanalysis and neurosciences. 
When the proposal for an approximation between psychoanalysis and neurosciences was initially proposed in the 1990s, some authors saw this approach as a project that aimed to adapt psychoanalysis to traditional methods of empirical investigation and sought to integrate psychoanalysis into science. I tend to agree with Bazan (2011) when she says that psychoanalysis owes to clinics its fundamentals and originality, and it is from this position that psychoanalysis can contribute to the neuroscientific debate about the fundamentals of consciousness and subjectivity, endowed with its different but nevertheless elaborated and systematized theory. As Bazan says this should also constitute a fundamental basis to be taken seriously. But answering to those who are skeptical about this approximation and who ask what would be the gain for

\section{REFERENCES}

Aguiar, A. (2004). A Psiquiatria no Divã. Entre as Ciências da Vida e a Medicalização da Existência. Rio de Janeiro: Relume-Dumará.

Ansermet, F., and Magistretti, P. (2004). A Chacun Son Cerveau. Plasticité Neuronale et Inconscient. Paris: Odile-Jacob.

Bazan, A. (2011). The grand challenge for psychoanalysis - and neuropsychoanalysis: taking on the game. Front. Psychol. 2:220. doi: 10.3389/fpsyg.2011.00220

Bezerra, B. Jr. (2013). Projeto para uma Psicologia Científica: Freud e as Neurociências. Rio de Janeiro: Civilização Brasileira.

Cartwright, N. (1999). The Dappled World: A Study of the Boundaries of Science. Cambridge: Cambridge University Press.

Damasio, A. (2010). Self Comes to Mind: Constructing the Conscious Brain. New York, NY: Pantheon.

Freud, S. (1933). "New introductory lectures on psycho-analysis," in The Standard Edition of the Complete Psychological Works of Sigmund Freud, Vol. XXII, ed. J. Strachey (New York City, NY: Norton), 1932-1936.

Jeannerod, M. (2002). Le Cerveau Intime. Paris: Odile Jacob.

Johnston, A. (2011). "Second natures in dappled worlds: John McDowell, Nancy Cartwright, and Hegelian-Lacanian materialism," in $\operatorname{Umbr}(a)$ : The Worst, eds M. Rigilano and K. Fetter (Buffalo, NY: State University of New York at Buffalo), 71-91.

Johnston, A. (2013). Drive between brain and subject: an immanent critique of Lacanian neuropsychoanalysis. South. J. Philos. 51, 48-84.

Koyré, A. (1957/2010). Do Mundo Fechado ao Universo Infinito. Rio de Janeiro: Forense Universitária.

Lacan, J. (1966/1998). “A ciência e a verdade,” in Escritos, ed. J. Zahar (Rio de Janeiro: Jorge Zahar).

Lacan, J. (1973/2003). "Nota italiana," in Outros Escritos, ed. J. Zahar (Rio de Janeiro: Jorge Zahar).

Malabou, C. (2008). What Should we do with Our Brain? New York, NY: Fordham University Press. psychoanalysis with this kind of approach, Bazan's response seems perfect to me: "I do not know. There is no agenda for what there is to win, nor, for that matter, for what there is to lose. Rather, it is the game itself, the sole faithfulness to something that is happening, which should be decisive. Something is happening, which clearly and loudly summons psychoanalysis to respond; as said, how to respond, is not a priori clear, but a non-response would imply a certain loss." (Bazan, 2011, p. 3).

\section{AUTHOR CONTRIBUTIONS}

The author has researched and wrote the article.

Miller, J.-A. (1989). "Las respuestas de lo real," in Aspectos del mal Estar en la Cultura, ed. J. Zahar (Buenos Aires: Manantial).

Miller, J.-A. (2002a). A Ex-Sistência. Opção Lacaniana. São Paulo: Edições Eólia, 33.

Miller, J.-A. (2002b). O Real é sem lei, Opção Lacaniana. São Paulo: Edições Eólia, 34.

Miller, J.-A. (2005). Uma Fantasia. Opção Lacaniana. São Paulo: Edições Eólia, 42.

Miller, J.-A. (2008). A Merci de la Contingence. La Lettre Mensuelle $n^{\circ} 270$. Disponível em: http://www.causefreudienne.net/a-la-merci-de-lacontingence/

Miller, J.-A. (2011). El Banquete de los Analistas. Buenos Aires: Paidos.

Miller, J.-A. (2012). Do Neurônio ao nó. Revista aSEPHallus, Rio de Janeiro. Disponível em: www.isepol.com/asephallus

Milner, J.-C. (2011). Clartés de Tout. De Lacan à Marx, d’Aristote à Mao. Paris: Verdier.

Prigogine, I., and Stengers, I. (1997). A Nova Aliança: Metamorfose da Ciência. Brasília: Universidade de Brasília.

Stanovich, K. (2004). The Robot's Rebellion. Chicago, IL: The University Chicago Press.

Varela, F., Thompson, E., and Rosch, E. (1991). The Embodied Mind: Cognitive Science and Human Experience. Cambridge, MA: MIT Press.

Zizek, S. (2008). A Visão em Paralaxe. São Paulo: Boitempo.

Conflict of Interest Statement: The author declares that the research was conducted in the absence of any commercial or financial relationships that could be construed as a potential conflict of interest.

Copyright (c) 2018 Aguiar. This is an open-access article distributed under the terms of the Creative Commons Attribution License (CC BY). The use, distribution or reproduction in other forums is permitted, provided the original author(s) and the copyright owner are credited and that the original publication in this journal is cited, in accordance with accepted academic practice. No use, distribution or reproduction is permitted which does not comply with these terms. 
OPEN ACCESS

Edited by:

Gertrudis Van De Vijver,

Ghent University, Belgium

Reviewed by:

Jasper Feyaerts,

Ghent University, Belgium

Olivier Putois,

Université de Strasbourg, France

*Correspondence:

Laure Westphal

laure_westphal@hotmail.fr

Thierry Lamote

thierry_lamote@yahoo.fr

Specialty section:

This article was submitted to Psychoanalysis

and Neuropsychoanalysis,

a section of the journal

Frontiers in Psychology

Received: 22 November 2017

Accepted: 25 July 2018

Published: 22 October 2018

Citation:

Westphal $L$ and Lamote $T$ (2018) The Clinic of Identifications in the Different Processes of Metamorphosis Into Woman. Front. Psychol. 9:1463. doi: 10.3389/fpsyg.2018.01463

\section{The Clinic of Identifications in the Different Processes of Metamorphosis Into Woman}

\author{
Laure Westphal* and Thierry Lamote* \\ Department of Psychoanalytical Studies, Center for Research in Psychoanalysis, Medicine and Society (EA-3522), University \\ of Paris Diderot-Paris-7, Paris, France
}

This article examines, from a psychoanalytical perspective, the function of identification in the relationship between the subject of the unconscious and his body, his body image, and the other. To this effect, the article leans on the clinic of the metamorphosis into a woman in psychosis, both in the way that it is presented by patients in the context of treatment, and in the form of testimonies extracted from literature. It demonstrates how specular identification allows the subject to unify himself, so long as there is an avoidance of possible deformations of the psychical body, including for example the delusion of transforming into a woman. It also turns its attention to the second logical moment of identification, when identification becomes sexed and organizes a certain relation to the other. A failure in this process sometimes leads the subject to opt for an identification of a gendered look, so as to stabilize himself. Indeed, transsexualism, which does not derive from any biological or sociological determination, and which can be observed in all subjective structures, is a possible way for the psychotic subject to problematize his relation to the body and to the other by identification with the woman, now that progress in science and law have enabled this.

Keywords: phallic function, identification, jouissance, push-to-the-woman, psychosis, mirror stage, transsexualism

\section{INTRODUCTION}

This article looks at the function of identification as conceptualized by Lacan in the logical moments that constitute one's subjective construction. We will look at the role of self-identification in the mirror, its stumbling in the delusion of transformation into a woman, and then the correlative pitfall of sexed identification at the moment of the Oedipus complex. Could it be possible for a subject, who lacks structuring identifications, to opt for identification with a gendered look, in order to inscribe himself into the collective?

Our development will be in four phases. First, we will show how identifications reorganize the subject's relation to jouissance, in order to establish, secondly, the effects its failure produces on paranoid delusion. Thirdly, we will see that transsexualism is not the privilege of neurosis, since certain psychotic subjects adopt it to resolve their psychical impasse. Fourthly, and lastly, we will 
discuss more specifically in which conditions transsexualism represents, for the psychotic subject, a new way of inscribing himself subjectively into the collective.

\section{IDENTITY, THE RECOGNITION OF THE SPECULAR IMAGE, AND THEIR DISORDERS APPROACHED ON THE BASIS OF LACANIAN THEORY}

During a group therapy session, Ferhat, a teenage patient, told us about a scene from childhood that remained deeply enigmatic to him. One day, when he was in the restaurant that his parents owned, he went to the toilet and fell into a state of stupefaction when faced with the image reflected in the mirror: "Just in front of me, in the mirror, I saw something horrible ... I don't know what it was, it didn't look like anything I know..." He immediately slipped into a sort of somnambulism, left the restaurant, and walked for hours. What happened to Ferhat? What exactly had appeared to him in the mirror that day, in place of his specular image? Let us follow the thread of Lacan's elaborations touching on specular recognition.

The recognition of the specular image is, according to Lacan, crucial not only for the subject's identification - the acquisition of his identity - but also for the construction of the "reality" in which he will move. Henri Wallon was the first to pay attention to the moment when a child discovers the image of his body unified in the mirror. Moreover, Wallon shows an immediate intuition concerning the connection between body image and language. He says that specular recognition is "the prelude of the symbolic by which the mind manages to transmute what is given in sensibility into a universe" (Wallon, 1931). However, pertinent the link that Wallon intuitively establishes between image and language, we must note that he states it by inverting its terms: it is not recognition of the image that allows the symbolic function to be established, but the opposite. The prior marking of the child by the symbolic is what creates the condition not only for any recognition of his specular image, but also for the love of this body image, namely what Freud called "narcissism." Indeed, how does the passage from autoeroticism to narcissism come about? By what modalities are the transmutation of the jouissance of the body (invaded by the disorderly chaos of the partial drives) into self-love (through the attachment of libido to the image of the body) produced? The mechanism of this tipping-point often appears very mysterious in psychoanalytical literature. Freud indicates: "There must be something added to autoerotism - a new psychical action - in order to bring about narcissism" (Freud, 1914, 77). But what "psychical action" is at work here?

In “Group Psychology and Analysis of the Ego," Freud (1921) distinguishes identification, by which the subject enriches himself with the properties of the object, from the love bond, which, on the contrary, causes the subject to empty himself in favor of the object. Indeed, the subject's narcissistic libido is drained by the act of love, whereas in identification, "the object becomes volatile and disappears in order to feed on the ego." Here, the object has from the start "been lost" (Lacan, 1956-1957, 172-173). The relation to the object is established in accordance with two movements: one, identification, which is a movement of incorporation; and second, the love relation, which produces a loss in favor of the object. But these two modalities of connection to the object are, if one reads Freud attentively, conditioned by an older double operation. Such operation, he tells us, is primary, prior to the appearance of the object: the primordial identification with the father, which appears in Freud as the phase that precedes the affective bond with the mother. More precisely (in Freud, the ambiguity remains), primordial identification with the father and the bond with the mother would be almost simultaneous: they would take place in a highly condensed sequence, in a flutter. Everything happens as though identification with the father (by which the subject incorporates something of which the father is the support, namely the symbolic order) was concomitant with a loss materialized by the love bond with the mother (because in love, the subject empties himself, loses something, in favor of the other party). This sequence will be resumed and rearticulated by Freud some years later in "Negation" (Die Verneinung).

In 'Negation' (Freud, 1925), we find one of the rare Freudian articulations of primary repression and a description of the "mythical moment" (Lacan, 1956, 319) of the subject's emergence, of the appearance of language, and of the upsurge of "reality." Here, Freud postulates - in a phase that dates from before the distinction between inside and outside, between subjective and objective - the existence of an original "pleasure ego," which introjects (Bejahung) into itself "all that is good," while rejecting (Ausstossung) the bad and leaving it on the outside. The inaugural Freudian intuition, which holds that the subject's reality is elaborated in accordance with a process of re-finding the lost object, encounters a new foundation here: the objects that constitute the subject's reality only exist inasmuch as the primordial object has been lost. In other words, not only does subjectivity result from a fundamental loss of inside and outside, but, furthermore, it is around this lost object, whose absence will be the motor of the subject's desire, that what we call reality will be constituted. What does Bejahung consist of? What is introjected at that moment, through a loss? Bejahung, as JeanClaude Maleval has reminded us, is "an admission in the symbolic sense" (Maleval, 2000, 48): it is the primordial symbolization with which the symbolic order is established. This concerns the mythical moment when, through primordial identification with the father, the subject's capture in the discourses is produced. In this moment, the subject, consenting (Bejahung) to inscribe himself into the order of language, accepts its essential condition, namely the loss (expulsion, Ausstossung) of an object, which Lacan will notate as "object $a$." This mechanism of primordial repression, whereby the body is emptied of its jouissance (object a), while the subject becomes equipped with the symbolic, will likewise condition the process of specular recognition defended by Lacan in the "mirror stage" (Lacan, 1949).

We should recall that this "stage" brings the young child into presence, given his image reflected in the mirror, along with a third party (father, mother, or another) as witness to the scene. What happens during this stage? The subject, still an infant, 
recognizes his own image in the mirror. This recognition, Lacan tells us, must be understood as an identification, "namely, the transformation that takes place in the subject when he assumes an image" (Lacan, 1949, 76). Until then, the infant only perceived his body as scattered, disjointed elements (a hand, arm, or foot that appeared in the visual field and which he might try to grab as though it were a foreign object). Suddenly, in the mirror, what were mere fragmentations become a unified image that he recognizes as his own. At this instant, identification is produced, creating the foundation of the subject's identity (the matrix of any speech act in the first person, "I") through the articulation of the three registers of real, imaginary, and symbolic. Indeed, the subject knots into one unified instance the specular image, his bodily sensations (the register of the real), and the naming (symbolic) of the image reflected by the Other observing the scene. Many consequences arise from this founding moment of identity. The first is to ground the recognition (of the body image) and ego upon an error. Indeed, the bodily unity perceived in this image is falsified by specularity: the image returned by the mirror is false, inverting the body's coordinates. Next, we must conceive how this anchors the ego in the otherness of the mirror: the ego does not coincide with itself, it stems from the register of the other (it imposes the detour via the mirror) for the subject, who finds therein the most ordinary experience of his division. Furthermore, the body image returned by the mirror locates and inscribes the locus of the other, where the ego is not only housed, but also the same others, the subject's alter-egos (peers). Finally, the same holds for a disjunction between real and imaginary: this body that is unified and autonomous, and which is reflected by the mirror (the imaginary register), doesn't accord with the lived experience of body incoordination, of impotence, and of Hilflosigkeit (the real register), where the infant is found. The image observed in the mirror is thus inscribed in the form of a developing fiction, because it anticipates a state to come in relation to the real state in which the subject is found. Here, we can see the function of the specular image: the image (i) veils, covers the real (a). Moreover, this is precisely what Lacan formalized in the matheme of the body image, $i(a)$, where " $i$ " represents the image, and "a" the real object, the lost object, rejected outside the symbolic, whose absence supports the image and ensures its consistency. Let us briefly summarize the two phases that condition the recognition of the specular image: first of all, in the initial phase, primary repression has to be produced, which allows for language access (Bejahung) by means of loss (Ausstossung) of the object (a). It is on the grounds of this initial loss that the mirror stage will be elaborated, the matrix of recognition (of the body image and reality), which is established through articulating specular image (i), the real (object $a$ ), and the symbolic (naming by the Other). The whole, as we can see, falls under the dependence on primary repression, that is, loss of the primordial object: if the lost object (the object $a$ ) is no longer lacking, if it reappears in the weave of the image, we will be dealing with a series of clinical phenomena that we will approach later. For now, we will look at how these two phases inscribe their effects into the subjectification process, by virtue of the retroaction phase triggered by the Oedipus complex.
The Oedipus complex confirms the loss of the primordial object and opens a resolution to the dead-end in which the subject is precipitated. We may recall that after a phase of reciprocal illusion (when the infant could derive comfort from the illusion of completing the mother, while she could also sustain this illusion of a harmony between herself and her child) the young child suspects that something is not right: the mother's comings and goings hint toward maternal castration, indicating that she too lacks, i.e., that she desires and seems to find elsewhere (beyond the subject) the object to satisfy her desire. The child, exposed to what initially appeared as something stemming from pure whim, is then caught in an anxiety-provoking alternative, sketched out in accordance with the coordinates of his (oral) libidinal development: either he has the means to fulfill the mother, and in this case risks being devoured by her; or he lacks these means, and risks being abandoned, left in the lurch. The father's intervention, through what Lacan named the "paternal metaphor" (Lacan, $1958,463-4 ; 476 ; 479)$, traces the path of a resolution to this dead-end, which cannot be resolved in the imaginary register (where the mother/child relation is located). The Name-of-theFather is the signifier that allows the mother's desire to be named and for the subject to be positioned in a genealogy, that is, at a place whereby the mother is forbidden. The result of this Oedipal operation is threefold. On one hand, it inscribes the coordinates of the symbolic order (which Lacan named the Other, the treasure of the signifier), which are founded upon the law of language (the word is the death of the thing: once the object is lost, the subject only encounters its semblances through the intermediary of signifiers representing them). On the other hand - we will return to this in detail - it allows for the production of the phallic signifier, which symbolizes the loss of the object of jouissance: the phallus tallows the loss to be metabolized. Without the phallus, this loss would prove intolerable. Finally, inscribed at the resolution of the Oedipal process is what Lacan called the fundamental fantasy, which allows for the positioning of the lost object $(a)$ in a certain relation to the subject $(\$): \$ \diamond a$. The fundamental fantasy is not a little fiction that the subject recounts to himself so as to be cut off from reality; on the contrary, not only will it orient the subject's desire, but it will also provide reality with its frame. Indeed, desire is oriented by the quest for the lost object. We have seen that this is the condition of the appearance of all the objects that present themselves to the subject, in other words, all the objects around which what we call reality is arranged. Should the fundamental fantasy vacillate, reality itself careens.

Identity in Lacanian theory is, therefore, a three-phase process. In the first phase, primary repression engages the process of subjectification, placing its dependence on the loss of the primordial object; in the second phase, this inaugural loss is felt again during the mirror stage, when the lost object serves to support the specular image, covering it by connecting it to the symbolic; finally, in the third phase, the entire sequence is stabilized during the Oedipus complex, when the fundamental fantasy is established, which comes to frame and localize the object $a$. Accidents arising during one or more of the phases of this process will generate a set of phenomena touching on identity. The cause of the inability to recognize the image of the 
self can be located in cases of early autism (Lefort) or serious child psychosis (Maleval, 1981). These incidents arise during primary repression: when Ausstossung (primal expulsion) has not occurred, the specular image, un-ballasted by the lost object, is struck with a strangeness that prevents the recognition processes. How are we to tackle the passing disturbances that affect specular recognition, like when the young Ferhat saw an object of horror appearing in the mirror? What happened at that moment, in the locus of his face, was nothing other than the object $a$, without its imaginary covering and devoid of symbolic armature. In other words, the misadventure recounted by this young adolescent shows us another consequence of the foreclosure of the Name-of-the-Father: when the paternal metaphor has not been produced, the object $a$, being neither localized nor framed by the fundamental fantasy, threatens at any moment to reappear directly in the weave of reality, which it suddenly unravels, leaving the subject in a state of stupefaction. We will now turn to another series of disorders, likewise conditioned by the foreclosure of the Name-of-the-Father: the psychotic subject's disturbances of sexed identity. Let us examine this with the case of Schreber, which will allow us to distinguish disturbances affecting the coordinates of specular recognition (implying the object $a$ ) from what Lacan names "push-to-the-woman" (where the question of Other jouissance arises).

\section{DISTURBANCES OF SEXED IDENTITY, OTHER JOUISSANCE, AND TRANSSEXUALISM: THE EXAMPLE OF SCHREBER RE-READ BY LACAN}

Daniel-Paul Schreber was a German jurist. In 1884, shortly after failing in the Reichstag elections, he underwent a psychotic episode that led him to the rest home of Dr. Fleichsig to be treated for hypochondria with suicidal ideation. He only spent a short time there, after which he spent " 8 years [...], on the whole quite happy ones, rich also in outward honors" (Schreber, 1903, 46): indeed, in the interval, he had become president of the Freiberg tribunal (1889), before exercising a mandate following his election as local representative in the constituency where he had been defeated in the 1884 elections (Devreese et al., 1986, 156). Around October 1893, when he was promoted to the presidency of the Supreme Court of the Dresden district, he had another psychotic episode, more serious this time, to the point that after some months, bombarded by multiple hallucinations, he was relieved of his functions and placed under provisional tutelage (1895). After a long efflorescent period of his delusion, he drafted his memoirs to plead his case before a tribunal. He won his lawsuit in 1902, left the asylum, and published his Memoirs of My Nervous Illness (1903). Some years later, in 1907, a new psychotic episode returned him to the asylum, where his state rapidly deteriorated. He died there in 1911. Freud drew on Schreber's Memoirs to establish the bases of his theory of psychosis (Freud, 1910). Lacan made it the guiding thread of his 1955-1956 Seminar, The Psychoses, before making it the base of his own theory founded on the notion of "foreclosure of the
Name-of-the-Father" in his text "On a Question Prior to Any Possible Treatment of Psychosis."

Following the trail of Freud and Lacan, we will turn our attention to the second psychotic episode (1893). Schreber explains that when he was notified of his promotion in June 1893 by the Minister of Legal Affairs - "Dr. Schuring in person" (Schreber, 1903, 46) - he had dreams foretelling the return of his illness. One morning, he adds, a "sensation" (rather than a dream) imposed itself, striking him "as highly peculiar: it was the idea that it really must be rather pleasant to be a woman succumbing to intercourse" (Schreber, 1903, 46). He took up office in the following weeks; but faced with the heavy burden of work, he says that he quickly "overtaxed [himself] mentally" (Schreber, 1903, 47). He started to hear crackling noises, before a fresh "nervous breakdown" occurred, accompanied by troubling physical symptoms. He writes: "the blood had gone from my extremities to the heart," while his mood was "gloomy in the extreme" (Schreber, 1903, 49). Dr. Fleichsig quickly admitted him into the care home. Schreber soon fell into catatonic states, became delusional and confused, with hallucinations. Both Freud and Lacan looked, in particular, at the initial sensation, which had arisen on the brink of the phenomena, that of being a woman succumbing to intercourse. For both, the entire cycle of the illness - from the virile protest at the start when first faced with this idea, through to the final reconciliation (Versohnung) with God, that is, with the father (Freud, 1910), via the delusional labor itself - finds its cause in this inaugural instant. Indeed, the entire delusional movement leads Schreber to rearrange reality, not to make it "more beautiful" (Freud, 1910), but simply to make it compatible with the initial intuition. According to his system, the world order had been decomposed, endangering the whole universe; the only recourse to avoid catastrophe entails putting himself in a feminine position in relation to God: once transformed into a woman, he will give birth to a new humanity, formed of the "Schreber spirit." Only then a certain calm appeared, according to his testimony: after the terrifying experiences of the first phases - composed of invasive hallucinations, a sense of the world ending, and unspeakable bodily happenings - a respite emerged, concomitant with the acceptance of womanly transformation, allowing him to begin serenely entertaining the various procedures he would undergo to leave the asylum and put an end to tutelage. At the end of the delusional process, he maintains his conviction of transforming into a woman. He says he had observed his specular image at length: "I venture to assert flatly that anybody who sees me standing in front of a mirror with the upper part of my body naked would get the undoubted impression of a female trunk, especially when the illusion is strengthened by some feminine adornments" (Schreber, 1903, 248). What can be said of this movement toward feminization, in the way that Schreber describes it, and which in some way we feel relates to the specular image? Is it transsexualism?

In his book Clinique de l'identité (2009), Thibierge notes that in psychosis, the dimension of recognition or of the image proves to be fundamentally defective, to a point that, "upholding an image or a meaning always turns out to be precarious and under threat. [...] This is why, in a psychosis - regardless of the 
apparent solidity of certain delusional edifices, where there is an attempt to suture this fault- a complete collapse of the subject's imaginary coordinates is always liable to occur, that is, a complete collapse of what we call recognition" (Thibierge, 2009, 23). The most enlightening example of this fragility of the specular register is given by the Fregoli delusion, described by Courbon and Fail (1927). The patient of the original case said that her persecutor, the actress Robine, embodied multiple personalities, like the Italian actor Fregoli. She identified her persecutor, in disguise, in any person she met, and from whom she received "influxes" of other sensory phenomena. Robine was "always there under the variety of rags" (Thibierge, 2009, 13). In this syndrome, "the other party is always the same person," which indicates a problem where name and image are not joined: "The name names something the image fails to cover, to represent, in short, that it doesn't allow one to recognize: it is something else" (Thibierge, 2009, 13). Indeed, the name is no longer articulated to the image, but rather designates an object, "an $x$, which is always the same, which in coming to the fore reveals an inconsistency, even the collapse of the image and the imaginary in the field of recognition" (Thibierge, 2009, 13). This object, which shows through behind the image to the point of unjoining it from the name in order to become prevalent, is of course the object $a$, which is always at risk of appearing again in psychosis (because it is no longer framed by the fantasy). Let's specify the three interconnected aspects of this disintegration in the coordinates of specular recognition. First, the object a reappears in the foreground, because the primordial rejection (Ausstossung) specific to primary repression hasn't been consolidated during the retroactive phase of the Oedipus complex, for want of any paternal support. Thereafter, this prevalence of the object modifies the function of the proper name, instead of identifying the object in a differential way, that is, through mere difference from other names (without any direct link between name and object named). The name here is conjoined to the object, raising itself to the real that it names. Consequently, the Image either joins itself to the named object (allowing it to appear behind each mask), or separates itself from it during moments of fragmentation (Thibierge, 2009, 20). Within this framework, we may tackle transsexualism in the case of the psychotic subject. The psychotic transsexual claims to have a "feminine" appearance, but this appearance does not fall within the remit of the usual register of the image, which always participates loosely in semblance; what the subject targets in this naming is a being excluded from all divisions and contingencies: "Femininity is thus the name it gives to an absolutely real substance that is non-sexed" (Thibierge, 2009, 27). When he asks for his appearance and civil status to be modified, the psychotic transsexual targets an absolute identity designated by the name of the woman, which he has the conviction he embodies "more really than women" (Thibierge, 2009, 28). Thibierge writes: "Although he claims he has a feminine image and often makes this claim, [what the psychotic transsexual aims at] is much rather what he finds himself identifying in this image, which he regularly mentions when we question him: the real of a jouissance that he appeals to and sometimes experiences, a cutaneous jouissance of the envelope, the matrix, and completeness" (Thibierge, $2009,28)$. This variant of the problem was observed in the
Fregoli delusion, where the autotomizing and the foregrounding of the object $a$ disintegrate the representational function of the proper name. The name is then joined to the object like the image, which becomes its simple mask, and is always identical. In transsexualism, the foregrounding of the object (a real, which bears a jouissance of the envelope) is joined to a name (the woman), and compels the subject to modify his appearance and his civil identity in order to adhere to the real. In the case of Schreber, are we looking at this process of the disintegrating coordinates of recognition? We think not: to grasp what distinguishes the Schreber case from cases of transsexualism in psychosis, we must relocate it through to the question of "jouissance."

The concept of jouissance is central in Lacanian theory, so much so that it has displaced the question that remained unsolved for Freud: "What does a woman want?" Lacan asks instead, what would create feminine jouissance.

Freud organized his theory of libido around the question of the phallus; why is so much attention focused on the male organ? Quite simply because "the female genitals [in the child's fantasmatic view] never seem to be discovered" (Freud, 1923, 145): sexed division of being is organized around the fact of having, or not having, a penis. On the man's side, sexuality revolves around the organ, the penis, offering an imaginary hold on the phallic signifier, the signifier of lack, the one bearing the mark of castration. Male jouissance, which Lacan named "phallic jouissance," is entirely subject to the laws of language, which is, sifted by castration; it is thus limited, circumscribed, and regulated. Conversely, due to the late discovery of the female organ, the unconscious lacks a signifier that would circumscribe women with a definition. Female jouissance is hence only partially ordered by the phallic signifier, that is, it only passes partially through castration. Feminine jouissance is "not all" submitted to masculine jouissance. A woman also has the possibility of gaining access to "Other jouissance," a bodily jouissance both crazy and enigmatic. This Other jouissance is testified to in particular by mystics: since they are "not all" constrained in phallic signification, they know, in their privileged relationship with a consistent Other (God, the Beloved), ecstasies that give a glimpse of this objectless bodily jouissance by which the rift in the Other is indicated, that is, the powerlessness of words to check it. Saint Teresa and Saint John of the Cross left superb testimonies of these bodily phenomena, ranging from the most "acute" suffering to summits of ecstasy. Saint Teresa, regarding the case of a person she says she had known in this state, writes: "although of short duration, [this state] left the body absolutely broken; the pulse was so slow it seemed the soul was on the brink of being surrendered to God, no more nor less. The body loses its natural heat; but the inner fire that consumes the soul is so ardent that were it to increase just a little, God would place it at the height of its desires" (Marie-Eugène de l'EnfantJésus, 1988, 777). Saint John of the Cross also dealt with these phenomena of "breakings and collapses under spiritual action," (Marie-Eugène de l'Enfant-Jésus, 1988, 777), and spoke at length of "ravishings, ecstasies, dislocations of the bones, that are always produced when the communications are not purely spiritual" (Marie-Eugène de l'Enfant-Jésus, 1988, 777). These afflictions 
can be followed, in accordance with regulated procedures and asceticism, by other forms of divine response. Here is how Saint Teresa describes this out-of-the-ordinary experience: "a line of fire so ardent [...] I thought I might die. I didn't know how to explain it. It is as if an invisible hand had plunged full into the fire. Ah! What fire and what sweetness at the same time. I burned with love and felt that $1 \mathrm{~min}, 1 \mathrm{~s}$ more, and I would not have been able to bear this ardor without dying" (Marie-Eugène de l'Enfant-Jésus, 1988, 845).

Despite the spectacular aspect of the ecstasies described by Saint John of the Cross and Saint Teresa, the feminine position they speak of remains regulated by the Name-of-the-Father, just like the masculine position: indeed, both positions are situated in relation to the phallic signifier, a heritage of the paternal metaphor. Their flights of ecstasy thus conserve a link with the symbolic order, and this is why these great mystics can testify to this, in richly descriptive metaphors. This is very different from the psychotic's position, whose jouissance is not disciplined by the phallus, which can give rise to bodily sensations that are otherwise terrifying, and which, moreover, are very often tempered only after a long delusional labor. This is what President Schreber did, mobilizing a heavy symbolic apparatus to construct a delusion apt to raise the jouissance that was harassing him to the level of the signifier (thereby absorbing it). Henceforth, we must distinguish this modality of push-to-the-woman from the modality that manifests itself in the transsexual clinic.

To begin, we will note that the jouissance Schreber experienced doesn't stem from a cutaneous jouissance, or a jouissance of the envelope, as mentioned by Stéphane Thibierge. The pivotal moments of his unmanning are inscribed in the same way as the inaugural sensation of feminine jouissance, which surprised him at the beginning of his illness: throughout his book, Schreber testifies to these bodily sensations that gave him a "definite foretaste of female sexual enjoyment in intercourse" (Schreber, 1903, 239). He explains that all the barriers that curb the ravishing and voluptuousness of men within certain limits, for him "no longer exist, indeed in a certain sense the reverse applies" (Schreber, 1903, 249). This ecstatic state sustains his illusion that the beatitudes he has passed through stem from a subjective position that was emancipated from the humiliating phallic signification that usually bounds masculine jouissance (and feminine jouissance too, albeit to a lesser extent). This ecstatic state will also lead his delusion down the path of what Lacan called "push-to-the-woman," a feature of the ordinary clinic of psychosis, namely the spontaneous slope, for numerous "psychosed" subjects, to give body (through delusional elaborations) to The All Woman, that is, to a version of woman totally liberated from castration.

Likewise, the surface of his body, its superficial envelope, was not touched by the miraculous paths, but rather the real of the internal organs, the space inside the body, which is inaccessible to the gaze. Schreber describes at length, "the miracles that enacted against the organs of the thoracic and abdominal cavities." Likewise, his conviction of being transformed into woman didn't come from the image in the mirror, but from organic sensations, namely that "there were marked indications of an actual retraction of the male organ; frequently, however, particularly when mainly impure rays were involved, they manifested themselves in the form of a softening, approaching almost complete dissolution" (Schreber, 1903, 142). It was also the physical sensation of "a contraction of the vertebrae and possibly of my thigh bones," and not the (visually) perceived image of the contours of his body, that convinced him of "a change in my whole stature (diminution of my body size)" (Schreber, 1903, 142). We can see that the critical period when the conviction of unmanning was established unfolded against the backdrop of the tenacious "impression" (again, physical, not specular) that his "body had become smaller by about six or eight centimeters." (Schreber, 1903, 142).

Let us now try to discern, using Schreber's testimony, what distinguishes the paranoiac version of the push-to-thewoman from the transsexual form it might take, even if not all transsexualism derives from the push-to-the-woman. In this article, we will limit ourselves to the clinic of psychosis. The paranoid subject, meanwhile, treats, by means of (symbolic) delusion, the invasive jouissance that perturbs the real of the organism; the imaginary, notably the imaginary that concerns their identity and bodily surface, does not play a minor role here: Schreber didn't see, strictly speaking, the modifications that occurred in his body. He felt them, from the inside, and moreover he was fully conscious that the mirror (the image) couldn't flesh out this real (which is why he disguised it: not in order to sustain a failing identity, but in order to sustain his delusion). Despite this, and contrary to transsexual psychotics, he did not change his civil status to conjoin his identity to the jouissance he felt (at no moment did he make a claim for obtaining a female identity, except at the terminal point of his delusion when he imagined himself eventually coupling with God in order to engender a new lineage). However, the psychotic subject who chooses feminine transsexualism spares himself the delirium via the modifications brought to his name (symbolic) and his appearance (imaginary).

\section{THE CLINIC OF FEMININE TRANSSEXUALISM ACCORDING TO LACAN}

By looking at Schreber, Lacan (1955/1956) identified the pushto-the-woman in its delusional version, without knowing that 20 years later, he would meet psychotic subjects in his practice suffering from this phenomenon in the form of transsexualism.

Let us reinforce that in using Lacan's theory, we are interested in transsexualism as it appears in psychosis. In this article, we address uniquely the many forms of expression in the metamorphosis into woman, in psychosis. We can neither infer, from our observations, the subjective outcomes of transsexualism in a "normal" or neurotic condition, nor infer a biological or social existing cause, from any possible example. We cannot pathologise, on a psychological level, such a subjective choice. Consequently, in the case of psychosis, it would be inappropriate to stigmatize the transsexual phenomenon, especially when we see (we will demonstrate this mostly in the fourth part of the article) how it allows the subject to avoid the deployment of a delirium. 
Let us go back to 1976, where, during his clinical presentations at the Sainte-Anne clinic, Lacan interviewed a biological man, whose psychosis left him in no doubt that he was a woman and should become one physically by means of endocrinal and surgical treatments. Even though Lacan then qualified transsexualism as pathological, he was also reworking the concepts of jouissance and identification, deepening the trench separating the delusion of metamorphosing into woman from transsexualism. Let's turn now to the patient dubbed "Michel H."

Michel H. was hospitalized at Sainte-Anne in 1976, after having tried to hang himself. He recalls, in speaking to Lacan, the taste he had developed in childhood for stroking and dressing in women's clothing, beginning with his sisters' clothes, whose femininity he envied. He would have liked to "be a girl" like them. He initially wore women's clothes hidden from the gaze of others, saying they were "soft on his skin," "warm on [his] body" and gave him a feeling of well-being that would have otherwise been inaccessible. He specifies that this had always given him intense satisfaction "on a sentimental level" and he counts among his qualities the fact of being "soft and gentle." At the time of the interview, Michel H. still cross-dressed and did what he could so that his bodily appearance would convey his impression of being a woman. He shaved closely, wore makeup, and altered the texture of his skin to arouse a soft look. He modified his appearance, striving to make it more feminine by obtaining looks of approval from the Other.

But Michel H.'s insistence on living as a woman in the relation to the Other does not explain what kind of jouissance he experienced. Moreover, on the subject of his sexuality, he said that he was considerably perplexed. At twenty-two years of age, he had attempted relationships with men and women, to see which would suit him best, and concluded that neither one nor the other attracted him (Lacan, 1976, p. 314). With women, he did not feel like a man; even if penetration did procure for him a physiological pleasure that he qualifies as "masculine," leading him to go "through to the end," he reported that something stronger than him contradicted him, and justified him pushing his partner away. Furthermore, he tried to have sexual relations with two male childhood friends, but limited himself to timid caresses because he couldn't manage to feel like a woman in the arms of a man. Shortly afterward, he attempted suicide.

Was the inability for him to feel that he was of the opposite sex to another partner a result of repressed homosexuality, as Freud first suggested with regard to Schreber (Freud, 1910), or did it result from a latent push-to-the-woman that Michel $\mathrm{H}$. had not yet deciphered? In support of this second hypothesis, Michel H. said he had to negotiate the femininity that imposed itself upon him, just as much as he had to struggle against the sense of being abused. He gives an example of a time when he started to cross dress in public, and men shouted at him in the street and pushed him around. He felt he was approached in a similarly humiliating manner each time he met people who he knew; some of them would speak amongst themselves, point at him, or else try to get to know him better and go out with him. According to him, these people laughed at having unmasked him and seen that he was a man. So, he decided to stay shut at home and "disguise" himself while taking small quantities of drugs "so as to feel [his] way into the character a bit better." By doing so, he managed to see himself as a "woman dressed as a woman," unified and coherent, until the impression of being a transvestite man exhibiting a lie imposed itself on him again (Czermak, 1996). In these circumstances, the feeling of wanting to get rid of himself could surge up within him just as quickly, and he deflected it by breaking the mirror in which he was looking at himself. Another time, he had tried to "castrate himself" by cutting off his penis with a razor blade. He could only touch the skin due to the pain, which was too intense.

Michel $\mathrm{H}$. adds to the feeling of being a woman, the sense of being objectified in relation to the Other, depersonalized and compelled to get rid of what he feels as an excess of the drive of jouissance. When he tried to castrate himself, he seemed to be responding less to a demanding paternal Ego Ideal, and more to the urge to create the lack that symbolic castration had not inscribed in him. In order to understand this, we should revisit with Lacan (Lacan, 1972-1973) the myth of Totem and Taboo (Freud, 1913), according to which a whole only assumes value if it is contradicted by an exception. For the neurotic, the exception is the imaginary father he has killed and whose guilt-ridden memory forces him to renounce incest, maternal jouissance, in favor of phallic jouissance. In the opposite case, in which the subject has foreclosed the symbolic father, he lacks this exception in order to subscribe to the phallic universal and to singularize himself there. He is thereby exposed to maternal jouissance, to a sardonic push-to-the-woman and to an anxiety of fragmentation, which can lead him to hope to remedy this through self-mutilation in order to create a lack.

But why, in order to mutilate oneself, does one choose the penis among all the other organs? At the start of life, there is nothing phallic about the penis for the subject, who takes himself rather as a whole for the Other's phallus. Only under the threat of castration and by inscribing the signifier of the Name-ofthe-Father at the heart of his subjectivity does he phallicize the penis and turn it into the signifier of desire, the phallus. In other words, the subject gives up his status as the Other's phallus by becoming phallic himself, and by granting the phallus, beyond its status as a signified, with the status of a master signifier of the discourse about sex. By endowing it with this added value, he commits the "common error" (Lacan, 1971/1972a,b, 311) to which all subscribe. Among other effects, this phallic masquerade immunizes the subject against the perception of a sexual organ that is a disgusting deformity to be denounced as an "error of nature." This is the case of the psychotic subject who has equally refused, along with the paternal metaphor, phallic jouissance. Such a subject experiences the penis as a part of the body even more threatening than the others, one that targets sexual jouissance and everything depersonalizing about it. To the extent that the subject has not established their distinction, he rejects the penis so as not to be taken for the phallus (of the Other) and, to this effect, he may equally emasculate himself (Donnelly-Boylen, 2016) and take the surgeon for a castrating father.

Does the subject's attempted ordering of the invading jouissance imply a particular relation to identification? Freud underscored that the anatomical difference between the sexes had psychical consequences in the matter of sexed identification (Freud, 1905). Lacan adopted this idea and identified three logical 
phases that allow the subject to opt for a sexed identification (Lacan, 1973/1974). The first phase corresponds to the mythical real of the anatomical difference between the sexes that, in reality, only takes on its value in the second phase, where the subject adheres to the sexual discourse and interprets the given data with the aid of signifiers of phallic criteria. During this second stage, nature succumbs under the weight of symbolic castration and of the signifier of the phallus, allowing the subject to subjectively differentiate the sexes. Only then the third phase can take place, and the subject chooses to identify himself sexually on either the masculine or feminine side.

If the subject does not subscribe to the phallic function during the second phase of sexualization, he will not be able to refer to the phallus as the base for organizing his jouissance and choosing a sexed identification. For example, without having subjectively assented to phallic signification, Schreber (1903) was passively inhabited by the phallic signifier. He showed this through his virile protestation (Morel, 2000), which dwindled in favor of the progressive feminization of his body and his subjectivity. As for Michel H., he averted the painfulness of a body that was incoherent with his feminine experience by physically becoming a woman through gathering information on the progress of medicine. Notably, he learned that one is able to "get oneself castrated," to "have breasts through hormonal treatment," and to truly manage to "metamorphose into a woman." Reinforced by these discoveries, he asked plastic surgeons to modify his face and considered similar steps in order to be castrated and to modify his secondary sexual characteristics. The idea of "taking oneself for a woman" gave him the hope of no longer experiencing the "anxieties of being a man" and of "falling out of character." Even though Lacan said that psychoanalysis could not hope to modify Michel H.'s projects, does this mean they are deleterious to him?

The recent homologation of transsexualism in different cultures allows the psychotic subject to envisage an unprecedented way of establishing a link between jouissance and identification. Michel H. hints to this by saying that nearly all of his romantic relationships had failed except the one in which he behaved as a woman. This was his most recent attempt with a woman who also had the particularity of "admitting" that he was a woman: "I was always dressed as a woman," he says, "even during penetration, and I felt that I was a woman during sexual intercourse." By way of consequence, he managed to forget that he was a man and lived together with her "like two dykes." We will conclude from this that Michel $\mathrm{H}$. was suffering from a gender dysphoria that afflicted his relations with men as well as his relations with women, except when the nature of the relation allowed him to feel like a woman. Could the jouissance that was being sought out be the jouissance of the identification with the woman, and this alone? It seems so, and this identification would be existential for Michel H., who affirms that since he was very young he has lived only to be a woman. Furthermore, he says that he prefers to sacrifice his life and not have children, to have nothing but to be a woman.
When Michel H. chooses the signifier "woman" to describe his sensorial jouissance, and wishes to take on the appearance of a woman, he is different from Schreber, who elaborates a delusion in order to justify the term of "unmanning" (Schreber, 1903). On the contrary, he constructs a project of real metamorphosis and asks for authorization from society, from medicine, demanding that the insane source of the drive, his penile organ, be removed. The psychotic subject who opts for transsexualism strives to engage in the raison d'être of the other sex thanks to an appearance and feminine social codes with which to stabilize himself in the relation to the Other. All in all, for Schreber, the signifier "woman" justified a devastating imbalance in the drive, whereas for Michel H., it is destined to regulate and to humanize jouissance. The psychotic transsexual subject privileges the delusional imagining of the symbolic inscription of his body in the relation to the Other, which is nothing less than the definition that we give to supplementation.

Nevertheless, the primal mark of symbolic inscription in psychosis continues to have its effects. Not having singularized himself, the subject still feels himself to be the element of a whole devoid of exteriority and experiences it in the form of anxieties of fragmentation. In this way, he is able to tame his tendency toward the "push-to-exception" (Morel, 2000) and to invent singular solutions whose clothing is contingent upon an era or upon a culture. One can be, like Schreber, the woman that men are lacking, or, like the transsexual psychotic subject, the one who denounces the order of nature as not being in conformity with the being of exception that he embodies. This second eventuality allows the subject to appropriate his push-tothe-woman subjectively, and to make a claim for an exceptional destiny by wanting to become even more of a woman. Freud had identified and qualified psychotic feminization as asymptotic (Freud, 1910), which Lacan (Lacan, 1958, 572) took into account in the "push to" of the "push-to-the-woman" (Ménard, 2011).

The push-to-the-woman proceeds from a real dimension, because jouissance is attested in the body, from an imaginary dimension - which manifests itself through the subject's fascination with the image - and even from a symbolic dimension, once one has mapped out the position of exception to which the subject aspires as an avatar of the Ego Ideal. When this clinical phenomenon is integrated into a paranoiac construction, the subject creates a new world order around the law of his being and seeks to rejoin the signifier of "woman" by means of a delusion that is proportional in intensity to the jouissance that he is seeking to absorb. Schreber exemplified this by delaying his transformation into a woman under the pressure of the delusion's work-in-progress, until he endowed the woman that he would embody with a character that was so exceptional that he could couple with God and generate a new lineage.

As for Michel H., he explains (as other psychotic transsexuals also do), the destiny of the singular exception that he covets. After 2 weeks of hospitalization, he says he finds it hard to bear only being allowed to wear his women's clothes at night and that this privation makes him nervous during the day, except when he dreams of his project of metamorphosis. He specifies that this consists of becoming a woman of exceptional beauty, as has been promised him by numerous scientific articles that he 
has read on the subject, in which a man could be much more slender, much more beautiful, and much gentler, than a true woman. Michel H. turns the signifier "woman" into the point of exception that he lacks in order to create a new order of jouissance, and thus generates the conditions in which his sexual jouissance is tamed. Lacan's conceptualization of the knotting between Imaginary, Symbolic, and Real clarifies this even though the psychoanalyst himself was against exploiting it for the subject of transsexualism.

\section{FEMININE TRANSSEXUALISM AS A SOLUTION}

Very early in his teaching, Lacan turned his attention to the dimensions of the real, the imaginary, and the symbolic that organize subjectivity. He spoke about them between the lines of his thesis on the case of Aimée (Lacan, 1932) and then reconsidered their dialectic again on the occasion of the three significant periods that marked his approach to the psychoses. In the first period, which occurred at the same time as the Seminar that he dedicated to them (Lacan, 1958), Lacan maps out how the conditions of the psychical structure and its points of fracture are determined by a psychical, logical, and linguistic causality. In psychosis, the foreclosure of the Name-of-the-Father prevents the symbolic from absorbing the imaginary. During a second period, he ventures into an analysis of Schreber's Memoirs (Lacan, 1958) and puts the emphasis on the jouissance of the Other, namely the Real against which the psychotic subject can sometimes defend himself by identifying a persecutor. Lastly, he opens up a third and final period (Lacan, 1975/1976) in which he turns his attention to the way in which the psychotic subject can compensate the fragile articulation between the Real, the Imaginary, and the Symbolic.

To understand this, we may recall that at birth, the child begins by struggling against maternal jouissance, the Thing or das Ding, and does no more than babble a subjective claim. By turning to the father, the infant subsequently allows the Real, the Imaginary, and the Symbolic to be organized (Bousseyroux, 2011). He consolidates his subjective structuration by taking the name of his father, who names him, a step which produces a symptom at the same time. In neurosis, the symptom is thus correlative to the nomination relative to the sinthome (Lacan, 1975/1976). However, in psychosis, the subject does not have the paternal reference to constitute for himself a symptom, thus it is all the more necessary for him to fabricate a sinthome $a$ posteriori, a name, in such a way that that the equilibrium of the structure will hold together. This step must circumscribe jouissance (the Real), arrange the body in the relation to the Other (the Symbolic), and exorcize the uncanny that is linked to the Imaginary. When the Name-of-the-Father is lacking, the sinthome does not replace it, but rather allows subjectivity to become organized.

After having conceptualized the sinthome, Lacan did not return to his work on transsexualism in psychosis, nor did he have any occasion to, because medicine and law were far less sympathetic to transsexuals than they have been in recent years (Bonierbale et al., 2005). In 1976, transsexualism was often considered morbid, whereas today, regardless of one's subjective structure, one can more easily solicit medicine to modify his secondary sexual characteristics and proceed to "sex reassignment." That is to say, a transsexual can legitimately request that the error of nature from which he suffers should be the object of reparation. A legal system has been put in place in numerous countries offering him the possibility of changing civil status and of taking a first name of the new sex to which he asserts to belong. Science and society taken as a whole have supported the project of transsexuals'. But what does this specifically allow the psychotic subject to do? In which conditions does it stabilize him or not?

Contrary to the delusion of metamorphosing into woman, feminine transsexualism (Stoller, 1968) in psychosis proceeds from the subject's election of the signifier "woman" in order to attach the body to it. That is to say, he resolves his perplexity with regard to his body and language by overinvesting the signifier "woman" which gives the Real a meaning and offers a cartography of the drive that is more sensible. For him, this signifier performs at the same time as an advent of the body and an advent of signification (Hubert, 2007). By knotting bodily jouissance to the signifier, the subject obtains the sense of coherence that he was lacking, turning the upsetting penile into the final obstacle before reaching harmony. It is quite natural that he should thereafter request that it be cut off (Chiland, 2011).

Michel H. mentions this when he recounts a childhood nightmare in which he was terrified of a blond woman who cut off legs and bodily members in a veritable bloodbath. In order to protect himself against this woman, who "cut [also] the members of the family," he would sleep alongside his parents in their bed. Michel $H$. thinks that he had discarded this nightmare by cross dressing, and yet he underlines that he has since colored his hair blond, and has also worn a blond wig. He makes a comparison between the blond woman and his own blondness. Furthermore, he remembers that this woman had aging facial features that gave her a hollowed appearance, more like a man, and that she was very unkind. He concludes that perhaps it related to the pain he inflicted on his parents by cross dressing, because in his dream, this woman always spared him by doing his parents harm. For his part, he rejects the harm that he could do to them by thinking of getting castrated far away from them, in a clinic in Morocco.

The psychotic subject often has a body that persecutes him at the level of the drive, except when he manages, as does Michel H., to turn the image perceived from the outside into the very thing that supports him. This step is uncertain, because if the Other does not consent to it, for example when the Other unmasks, mocks, or rejects the subject, the subject experiences with fright the impression of being the wasted object of the Other from which he struggles to detach himself (Czermak, 1996). He feels again the impression of having been let go, of being "fleetingly improvised" as Schreber put it (Schreber, 1903) and of risking subjective death. But if the Other authorizes him to identify himself with a woman, the subject annuls the mortifying identification with the phallus and extracts himself from the maternal jouissance. He succeeds by reaching a sensual and 
scopic jouissance of which he wants to be the exclusive agent. Only when he was dressed as a woman did Michel H. say his body experienced a satisfaction: "I truly find my personality, my character, and my gentleness.”

In transsexualism, where metamorphosis into woman is not delusional but requested, the subject aspires to give meaning to the excess of jouissance by qualifying it as feminine and to support himself to this effect in the eyes of the Other. The subject strives to re-knot with his ideal Ego in a pacified manner by looking at himself in the mirror that has never reflected unity. When he dresses as a woman, Michel $\mathrm{H}$. says that he regains his gentleness. He completes this observation in the following way: "You can see it. My gestures are different, and my behavior, too." Outside of him, the double being contemplates himself from the outside and becomes the person that should have been looking at him and recognizing him. Additionally, Michel H. says he has written a poem entitled "Léternelle-La femme blonde" ["The Eternal One-The Blond Woman"] in which he describes Corinne, the female character he has forged for himself, and to whom he bears a singular veneration. He addresses her as though it were not he, but an idealized version of himself. This pacified way of living through the schism is possible at those moments when he manages to "forget that he's a man" and when he makes any sense of discordance disappear behind an image that he overinvests.

But this is not all. It is not only a matter of looking like a woman (Serrano, 2007), but also a matter of being a beautiful woman, with this highly particular relation to the exception. Indeed, feminine transsexualism has the peculiarity, as opposed to its male counterpart, of worshipping this appearance in a singular fashion and of wanting to exhibit a remarkable beauty. Alone in front of the mirror and dressed as a woman, he sublimates what he perceives as a waste object, this phallus that has not been detached. With a look that is subjugated by the artifices that he models, he anticipates the body that was primarily experienced as deformed (Czermak, 2001). If he obtains a look of admiration from the Other, this represses his anxieties of fragmentation. When speaking of the blond woman, Michel $\mathrm{H}$. says that he very quickly forgot that he had cross-dressed. For him, the scopic pleasure represses the obscenity of the body and allows whatever surrounds it to be invested in, in particular, the clothing that is destined to give the Ego a consistency. With the mask that he wears, the subject admires himself in the Other's look, which subtracts the jouissance of the organ and attenuates the persecution of the look.

The scoptophilic aspect of the transsexual (Safouan, 1974) is often associated with a tendency toward exhibitionism, even to being a star. This comes from the desire to ward off the annihilating look of the Other in order to be, instead, sustained by the latter through a highlighting of the body. Etymologically, "advent" refers back to the question of dignity (Castel, 2003), which is to be underlined as central to the transsexual procedure. First, alone in front of the mirror, and then in public, the psychotic subject re-actualizes the specular experience lost to him due to not having been named at the moment of appropriating the image in the mirror. By harmonizing the body and jouissance in the Other's look and the look from his fellow peers, he asks for their authorization so as to finally appropriate the image. He lies in wait for the look and the words of the Other to function as a unary trait, as a testimony that the egoic assumption can take place. From this perspective, losing the organ would allow everything to take shape around it. Furthermore, to be inscribed subjectively in the collective is correlative with an assumption of identity.

Ordinarily, during the specular stage, the subject not only discovers his image, but also discovers that it will not be enough to correspond with his being to the others. This is connected to a symbolic hole that is traumatic for every single subject. This pushes us to absorb the gap between these two images, and this is what the first name (Ginestet-Delbreil, 2003) facilitates by repressing the image of the body. But when the subject fails to be named, he is unable to appropriate the scopic image capable of repressing the bodily drives and must get by with a body that has not been anchored to the signifying order. Could it be that cultivating two other distinct images, whether an obscene image or a feminine image, would allow him to re-actualize the process and to provide the Other with a new opportunity to recognize him subjectively? The subject who looks at himself for the first time in the mirror has not benefitted from the assent of the Other, but it gives him the opportunity to make up for it and to validate, beyond the feminine seeming, the feminine being.

Wearing the feminine mask allows the psychotic subject to knot in a different way the dimension of the drives, the image, and the signifier "woman." This signifier does not have the function that the signifier of the phallus holds, that of sexualizing desire, but rather the merit of differentiating the masculine and the feminine without making any appeal to the father and facilitating the subject's subscription to a classifying identification (Morel, 2000). In this sense, a transsexual subject stripped of filiation and of origin proceeds to an auto-engendering that he would like to see validated, and chooses for himself an identification of sexed appearance that holds the value of a primordial identification. Let us underscore that this identification is the source of subjectification because the transsexual, psychotic subject who has not been able to say "my name is..." and "I'm a boy," can now say "I'm a woman" and proudly introduce his new first name through the signifier "Mrs." This is an experience of signifying reassignment that has a performative scope, unlike the delusion of metamorphosing into woman.

During subjective construction, the child frees himself from the gaze thanks to the name he is given, which he accepts and uses to mark out the imaginary by means of the symbolic. The transsexual follows the same path, as Michel H. demonstrates in choosing for his poem three first names in the guise of a signature: "Michel," "Michelle," and "Corinne." First, he feminized his first name, then changed it for another that represented the woman he wants to become. As for his choice of the name Corinne, Michel $\mathrm{H}$. explains that it refers to a childhood memory of a young girl called Corinne: "it's a first name that I'm fond of, so I gave it to myself." According to Ginestet-Delbreil (2003), the act of naming oneself is symbolic, because, in this way, the subject replaces the unconscious image of the body with the specular image to which he gives a meaning. The transsexual psychotic subject requests an inscription of his new first name in civil status, and re-launches 
the aborted process of articulating the Real and the Imaginary by means of the Symbolic.

In summary, we must distinguish, in the realm of psychosis, the delusion of metamorphosing into woman from transsexualism, where the conviction of being a woman functions for the subject as a project of inscription into the field of the Other and fellow beings. While surgery is counterindicated for the former (where the delusion needs to be contained), in the latter, it allows the transsexual subject to refuse to be the Other's phallus by inscribing himself into the symbolic order. Indeed, the transsexual wards off the effect of his foreclosure of the phallic function with the aid of a new sexual discourse, with which he replaces sexed identification. Moreover, he defends his image in the Other's look and supports it by means of an authentic claim for subjectivity. He knots the Symbolic to the Imaginary and no longer expects the Real of the body to confirm him by demanding his anatomical sex be modified (Millot, 1983). In this sense, the transsexual symptom functions as a supplementary device to the Name-of-the-Father, in other words, as a sinthome (Cavanagh, 2016).

Before concluding our theoretical and clinical journey on the function that feminine transsexualism takes in psychosis (for instance, the exemption of a delirium), we wish to add that we could have offered the reader a historical, anthropological, or even sociological approach to the phenomenon. However, this was not out intention, as it would have deviated from the strictly clinical aspect of this article. Psychoanalysis, based on the teachings of Lacan, must observe the choices of the subject and the outcomes of the subject's ethics, particularly, that of not giving up his desire, obviously including when it is related to a choice of gender and/or sexual object.

\section{REFERENCES}

Bonierbale, M., Michel, A., and Lançon, C. (2005). Le corps transformé. Inf. Psychiatr. 81, 517-528.

Bousseyroux, M. (2011). Au Risque de la Topologie et de la Poésie. Elargir la Psychanalyse. Toulouse: Eres.

Castel, P.-H. (2003). La Métamorphose Impensable, Essais sur le Transsexualisme et Lidentité Personnelle. Paris: Gallimard.

Cavanagh, S. (2016). L. “Transsexuality as Sinthome”. Stud. Gend. Sex. 17, 27-44. doi: 10.1080/15240657.2016.1135681

Czermak, M. (2001). Passions de l'objet. Études Psychanalytiques des Psychoses. Paris: Association Freudienne.

Chiland, C. (2011). Changer de Sexe, Illusion et Réalité. Paris: Odile Jacob.

Courbon, P., and Fail, G. (1927). Syndrome d'illusion de Frégoli et schizophrénie. Bull. Soc. Clin. Med. Ment. 15, 121-125.

Czermak, M. (1996). Sur l’identité Sexuelle. A Propos du Transsexualisme. Paris: L'Association Freudienne Internationale.

Devreese, D., Israëls, H., and Quackelbeen, J. (1986). Schreber Inédit. Paris: Seuil.

Donnelly-Boylen, K. (2016). Gender dysphoria, serious mental illness, and genital self-mutilation: a case report. J. Gay Lesbian Ment. Health 20, 376-381. doi: 10.1080/19359705.2016.1209395

Freud, S. (1905). Three Essays on the Theory of Sexuality, in S.E, Vol. 7. London: Hogarth, 123-245.

Freud, S. (1910). Psychoanalytical Notes on an Autobiographical Account of a Case of Paranoia S.E, Vol. 12. London: Hogarth, 1-82.

Freud, S. (1913). Totem and Taboo in S.E, Vol. 13. London: Hogarth, 1-161.

Freud, S. (1914). On Narcissism, in S.E, Vol. 14. London: Hogarth, 67-102.

\section{CONCLUSION}

In the first part of this article, we proved that after the subject has gone through the logical moment of the mirror stage, he constitutes for himself an egoic identity. If, on the other hand, he does not appropriate his image with the help of an other that names him, his jouissance instrumentalizes him and the body fragments. Our re-reading of Schreber allowed us to observe that the excess of jouissance can in this context take on a feminine sense for the subject and feed a delusion of metamorphosing into woman. But, the structuralist approach (Redmond, 2013) allows us to better understand the classical delusions. This way of distinguishing the different types of jouissance, in accordance with the identification that is at stake for the subject, also sheds light on the way that transsexualism in psychosis can be presented as a solution. Indeed, not all transsexualism falls within the field of psychosis, but when it imposes itself within this subjective structure, it allows the subject who is not in the throes of the delusion of metamorphosis, but who is grappling with the jouissance of the Other, to subscribe in a different way, via the phallic function, to classifications of gender. It thus facilitates the subject's inscription of his body and subjectivity in the collective, if the surgeon and lawmaker consent to it. Henceforth, he can sustain himself in a relation to the Other whose recognition previously failed him.

\section{AUTHOR CONTRIBUTIONS}

LW and TL wrote the article.

Freud, S. (1921). "Group Psychology and the Analysis of the Ego" in S.E. Vol. 18, London: Hogarth, 65-144.

Freud, S. (1923). "The Infantile Genital Organization" in S.E, Vol. 19. London: Hogarth, 139-145.

Freud, S. (1925). "Negation", in S.E, Vol. 19, London: Hogarth, 233-239.

Ginestet-Delbreil, S. (2003). Du désaveu à l'errance. Un Préalable à la Perversion et à D’autres Phénomènes. La Riche: Diabase.

Hubert, H. (2007). Transsexualisme: du syndrome au sinthome. Clin. Méditerr. 76, 255-270. doi: $10.3917 / \mathrm{cm} .076 .0255$

Lacan, J. (1932). De la Psychose Paranoïaque Dans ses Rapports avec la Personnalité. Paris: Seuil.

Lacan, J. (1949). “The Mirror Stage as Formative of the Function of the I," in Écrits. London: Tavistock, 1-7.

Lacan, J. (1955/1956). Le séminaire III, Les Psychoses. Paris: Seuil, 1994.

Lacan, J. (1956). "Response to Jean Hyppolite's Commentary on Freud's 'Verneinung'," in Écrits in English. New York, NY: Norton, 318-333.

Lacan, J. (1958). "On a question prior to any possible treatment of psychosis," in Ecrits: The First Complete Edition in English, eds J.-A. Miller and B. Fink (New York, NY: W.W. Norton \& Company), 445-488.

Lacan, J. (1976). "Entretien avec Michel H," in Sur Lidentité Sexuelle. A Propos du Transsexualisme, eds M. Czermak and H. Frignet (Paris: AFI).

Lacan, J. (1956-1957). Le séminaire IV, La relation d’objet. Paris: Seuil, 1994.

Lacan, J. (1971/1972a). Le séminaire XIX, ... ou pire. Paris: Seuil.

Lacan, J. (1971/1972b). Talking to Brick Walls. Cambridge: Polity, 2017.

Lacan, J. (1972-1973). Seminar XX, Encore. New York, NY: Norton, 1998.

Lacan, J. (1973/1974). Le séminaire XXI, Les non-dupes errent. Paris: Seuil.

Lacan, J. (1975/1976). Seminar XXIII, The Sinthome. Cambridge: Polity. 
Maleval, J.-C. (1981). Folies Hystériques et Psychoses Dissociatives. Paris: Payot, 2007.

Maleval, J.-C. (2000). La forclusion du Nom-du-Père. Paris: Seuil.

Marie-Eugène de l'Enfant-Jésus, P. (1988). Je Veux Voir Dieu. Venasque: Carmel.

Ménard, A. (2011). Le pousse-à-la femme dans la psychose. Cah. Clin. Nice 6, 133-140.

Millot, C. (1983). Horsexe, Essai sur le Transsexualisme. Paris: Point Hors Ligne.

Morel, G. (2000). Ambigüités sexuelles. Sexuation et psychose. Paris: Anthropos/Economica.

Redmond, J. (2013). Contemporary perspectives on Lacanian theories of psychosis. Front. Psychol. 4:350. doi: 10.3389/fpsyg.2013.00350

Safouan, M. (1974). Etudes Sur l'Edipe. Paris: Seuil.

Schreber, D.-P. (1903). Memoirs of My Nervous Illness. New York, NY: NY Review of Books, 2000.

Serrano, J. (2007). Whipping Girl: A Transsexual Woman on Sexism and the Scapegoating of Femininity. New York, NY: Seal Press.

Stoller, R. (1968). Recherches sur Lidentité Sexuelle. Paris: Gallimard.
Thibierge, S. (2009). Clinique de Lidentité. Paris: PUF.

Wallon, H. (1931). Comment se développe chez l'enfant la notion de corps propre. J. Psychol. Norm. Pathol. 18, 705-748.

Conflict of Interest Statement: The authors declare that the research was conducted in the absence of any commercial or financial relationships that could be construed as a potential conflict of interest.

The reviewer JF and handling Editor declared their shared affiliation.

Copyright $(02018$ Westphal and Lamote. This is an open-access article distributed under the terms of the Creative Commons Attribution License (CC BY). The use, distribution or reproduction in other forums is permitted, provided the original author(s) and the copyright owner(s) are credited and that the original publication in this journal is cited, in accordance with accepted academic practice. No use, distribution or reproduction is permitted which does not comply with these terms. 


\section{OPEN ACCESS}

Edited by:

Fabian Guénolé,

University of Caen Normandy, France

Reviewed by:

Marjorie Roques, Normandie Université, France

François Medjkane,

Centre Hospitalier Regional et Universitaire de Lille, France

Kazushige Shingu,

Nara University, Japan

Pierre-Henri Castel,

Centre National de la Recherche

Scientifique (CNRS), France

*Correspondence:

Olivier Putois

olivier.putois@gmail.com

tThese authors have contributed equally to this work as co-first authors

Specialty section:

This article was submitted to

Psychoanalysis

and Neuropsychoanalysis,

a section of the journal

Frontiers in Psychology

Received: 03 October 2017

Accepted: 01 October 2018

Published: 01 November 2018

Citation:

Potier $R$ and Putois O (2018) A

Lacanian Approach to Medical Demand, With a Focus on Pediatric Genetics: A Plea for Subjectivization.

Front. Psychol. 9:2021.

doi: 10.3389/fpsyg.2018.02021

\section{A Lacanian Approach to Medical Demand, With a Focus on Pediatric Genetics: A Plea for Subjectivization}

\author{
Rémy Potier ${ }^{1+}$ and Olivier Putois ${ }^{2,3 * t}$ \\ ${ }^{1}$ Centre de Recherches Psychanalyse, Médecine et Société CRPMS (EA 3522), Université Paris Diderot, Paris, France, \\ ${ }^{2}$ Université de Strasbourg, SuLiSoM EA 3071, Strasbourg, France, ${ }^{3}$ Department of Psychiatry, Mental Health and \\ Addictology, Strasbourg University Hospital, Strasbourg, France
}

Current psychological research on contemporary medicine, and in particular genetics, often targets the underpinnings of patients' attitudes and behaviors with respect to biomedical knowledge and healthcare practices. But few studies approach these underpinnings as manifestations of the unconscious, while so doing could (in particular) help understand patients' apparent difficulties to understand information, and to subsequently act accordingly (e.g., in making therapeutic decisions, etc.). We hypothesize that Lacan's (1966) remarks ("The place of psychoanalysis in medicine") on the transferential nature of the demand addressed by the patient (or his family) to the doctor can help account for these issues: demand filters medical information received from the practitioner, and thereby motivates subsequent decisions. In this paper, we try and shed light on this thesis, and focus on pediatric genetics. We start by describing the manifest doctor-patient-family relationship in the pediatric genetics consultation, in order to show where unconscious determinants can come to play a role (1). We then explain Lacan's theory of demand: what the patient unknowingly demands is knowledge (savoir), the object of which is the body of jouissance - the libidinal experience of one's body through the first libidinal exchanges with the Other of early infancy, whereby the subject is assigned by the Other (subjectification) a specific fantasmatic status organizing his desire. Patients' understanding and attitudes thus vary so greatly because of this pre-existing filter. Healing and cure are merely apparent objects of the medical demand, which is an invocative drive seeking knowledge on the cause of one's desire: medical demand is an instance of transference. Doctors should thus enable patient subjectivization, i.e., help them realize that their demand's genuine object lies in their preexisting subjective coordinates (2). In pediatric genetics, apparently paradoxical family attitudes heavily draw on what G. Raimbault, drawing on Lacan, called implicit demand, the object of which is knowledge about the family fantasy giving shape to the guilt of possibly transmitting the disease. We give a clinical example, then show how the concept of demand helped us elaborate the core of a research project on the subjective effects of a genetic deafblindness handicap (3).

Keywords: genetics, pediatrics, demand, subjectivization, medical knowledge, transference, desire, doctorpatient relationship 


\section{INTRODUCTION}

One of the main axes of contemporary psychological research on healthcare and biomedicine revolves around the impact of personalized medicine. This is especially true with respect to medical genetics and genomics, which are undergoing an exponential development. This development gives rise to new problems, such as the use of unsolicited or secondary findings, supplemental information unrelated to the patient's initial request, and yet of potentially crucial medical importance (such as BRCA 1 or 2 - see, e.g., Christenhusz et al., 2013).

In the 2000s, psychotherapists and family therapists were already aware of the need to reflect upon the consequences of this emerging state of affairs:

\begin{abstract}
"When we go for a routine physical, rather than making blanket pronouncements about increasing exercise, lowering cholesterol, and other preventive health measures, our physicians and nurse practitioners are likely to draw individualized blueprints of personal risk factors based on our specific personal genotype" (McDaniel, 2005, p. 27).
\end{abstract}

The question raised by this state of affairs is: what are the personal, family and social effects of the possibility to receive individualized medical recommendations based on an unprecedented knowledge of one's genetic and genomic characteristics?

To answer this question, social science research has explored at length the personal and family effects of contemporary medicine (cf. e.g., James et al., 2006; Hens et al., 2016), including the indirect constraints embedded in genetic healthcare pathways (e.g., Vailly, 2013). Within psychology, this question has been scrutinized by cognitive-behavioral psychology (e.g., McDaniel, 2005) or systemic approaches, but few studies have addressed it through the lens of psychoanalysis, with the exception of e.g., Feissel-Lebovici (2001), Aubert-Godard (2005), Driben (2011), Gargiulo et al. (2017). Yet, the originality of psychoanalysis lies in that it can spell out the unconscious determinants at play in the reception of medical information (see e.g. Balint, 1957; Debray, 1996; Gutton and Raimbault, 1975; Raimbault, 1975; Sausse, 1997), of which genetic information is a subset. The specificity of a psychoanalytic approach to this question lies in its grasp of how apparently remote autobiographical elements and repressed childhood situations influence the very thought processes of information understanding, by structuring the individual's personality up to the very way in which she asks for help and assistance - and what she thereby genuinely expects.

Therefore, psychoanalysis can shed an original light on two pressing issues which, albeit encountered daily in clinical practice, are rarely dealt with directly in research papers, especially outside of French-speaking psychoanalytic literature:

(1) the unconscious determinants of patients' difficulties to understand genetic information; and

(2) the unconscious determinants of subsequent attitudes or behavior disregarding (or even contradicting) recommendations based on this information - e.g., in taking therapeutic decisions, from short-term life-or-death transplant to long-term therapeutic compliance.

While biomedical and genetic knowledge have developed exponentially since Lacan's (1966) lecture at the Salpêtrière Hospital (entitled "The Place of Psychoanalysis in Medicine"), we believe that the theory of the demand in the medical field laid out in this lecture can be of help in spelling out the unconscious determinant(s) at play in the reception of genetic information.

Some of the literature partly addresses such unconscious determinants upon the reception of medical information in a Lacanian fashion, e.g., in the French-speaking psychoanalytic tradition (Del Volgo, 1997; Brun, 2005 gathers important collective proceedings on this topic; Lebrun, 2017; Weber, 2017). But we would like to approach them from an angle which, to our knowledge, hasn't been explored as such - especially in genetics - that of the concept of demand ${ }^{1}$ (We leave aside nonLacanian approaches of demand in medicine; integrating them would require a systematic review).

Thus, our goal will be to provide a presentation of the Lacanian approach of demand, and to explore how it can be drawn upon to understand the clinical stakes of pediatric genetics. As we shall see, the interest of this specialty is that the unconscious dynamics (aimed at by the notion of demand) implicitly at work in the background of what is explicitly asked of the medical practitioner, come more readily to the forefront: it is generally parents who come for their child's disease - this leads them to express how they unconsciously represent their child. This family context thus helps shed a strong light on the weight of the unconscious fantasies at work in parental demand, which bear on the psychical appropriation of the information and subsequent decision-making.

In fact, the present paper presents a research trajectory, from the experience of partaking in pediatric genetics consultations within a renowned clinical genetics unit (Imagine Institute, located at Necker Hospital in Paris), to the elaboration of a funded research project on the psychosocial determinants of the impact of genetic deafblindness (DéPsySurdi, see section "Subjectivizing the Demand in Pediatric Genetics: Clinical Practice and Research Perspectives"). The methodological constitution of this project is the result of the present work on demand, which represents its preliminary stage in many respects.

We first provide a description of the manifest doctor-patient relationship in the pediatric genetics consultation, in order to point where unconscious determinants can come to play a role. We then develop Lacan's understanding of the demand in medicine - that is, in the patient-doctor relationship. We then apply this understanding to pediatric genetics, by focusing on what Raimbault, a pupil of Lacan's, called "implicit demand"; and we show how it this concept formed the starting point of the aforementioned research project.

\footnotetext{
${ }^{1}$ While we stuck to the usual English translation, the meaning of the French "demande" differs from that of the English "demand," as will appear below in more detail. While the English "demand" implies a positive requirement, and frequently a dimension of command, the French "demande" (especially in its psychoanalytic understanding) mostly refers to the expression of helplessness - so much so that it often means to beg or to implore.
} 
Our central idea is that Lacan's understanding of the demand, the genuine object of which isn't medical information and/or healing but knowledge of one's fantasies about what takes place in one's body, allows for what we propose to call subjectivization that is, an awareness that the core object of one's demand lies elsewhere than in healing or care. Subjectivization accounts for the apparent discrepancy between the information explicitly received to the patient and his family, and their understanding and subsequent actions.

It is by taking into account this unconscious search for another knowledge at work in the patient's demand that the medical practitioner will be in a position to both enable moments of subjectivization, and deliver an adjusted medical response (both in tone and in content) without being unknowingly caught in the patient's implicit demand.

\section{THE MANIFEST DOCTOR-PATIENT-FAMILY RELATIONSHIP IN THE PEDIATRIC GENETICS CONSULTATION}

This description of the pediatric genetics consultation derives from OP and RP's participation to routine clinical consultations in the pediatric genetics unit of Necker-Enfants Malades Hospital (Paris), and subsequent exchanges with medical practitioners in the context of these consultations. In other words, material in this section is not derived from research projects or investigations, but from routine practice.

In France, Necker Hospital has always been at the forefront of an interdisciplinary dialog between medicine and psychoanalysis - both in medical genetics and in child psychiatry. At the time when Lacan examined "The Place of Psychoanalysis in Medicine" (1966), one of his early followers, Ginette Raimbault (M.D., Ph.D., psychoanalyst, who introduced Balint groups in France along with her husband Emile Raimbault) was head of an INSERM (French National Institute for Mental Health) unit working on hereditary child metabolic diseases. Since then, the interaction between psychoanalysis and pediatric genetics at Necker has been constant: many consultations are carried, on an ordinary basis, by a pediatrician-geneticist and a psychoanalyst, who contributes to the consultation as he sees fit (and can, if needed, meet with patients afterward).

Classical medical genetics is mostly concerned with Mendelian inheritance of pathogenic variants (along with random spontaneous mutations, called de novo); as such, it mostly focuses on monogenic diseases - accounted for by the variation of a single gene - or, at broadest, on a defined set of genes. Pediatric genetics is thus the best setting for psychoanalytic work on the personal impact of genetics: since it revolves around Mendelian transmission, its effects can be best witnessed in clinical contexts where families come to the Medical Genetics Unit to sort out both the name and the cause of their child's disease.
This is typically a three-step process: first a clinical examination (comprising the proposition to undergo genetic sequencing and, in case of acceptance, the signature of an informed consent form), followed by sequencing (genetic analysis, on the basis of questions raised by the clinical examination), and then - a couple weeks later - by the announcement of the diagnosis (or lack thereof), along with therapeutic advice (if possible).

A specific trait of pediatric genetics is that clinical examination involves questions regarding potential antecedents in family history: the geneticist, in addition to undertaking a clinical examination of the child and questioning his parents, searches for signs of the disease in previous generations and relatives while drawing a family tree. This entails that the explicit parental demand to the practitioner directly puts parents themselves in a position to receive confirmation that they have transmitted the disease - if the genetic character of the disease hasn't been established already. This context cannot but trigger family guilt: whatever the results of the analysis, the anxiety to have passed on the disease is in everyone's minds - to the point, not infrequently, of inducing momentary psychical splittings, as when parents, e.g., leave out of the family tree a deceased relative who happened to have signs of the disease.

After sequencing (biological analysis), another consultation is planned for the announcement of the diagnosis. It is often extremely emotional, due to the guilt-laden anticipation conscious or not - of having in fact transmitted the disease: learning that the child indeed has a genetic disease would be synonymous with having passed it on to him, news which can sometimes trigger deferred psychotic or psychotic-like onsets be they momentary or revealing a personality structure if parents are fragile. (In de novo cases, where the child is the first to have the disease because of a spontaneous mutation in the parents' sexual cells, we often witness guilt as well, but in a reversed form, so to speak: parents feel guilty because their child is the only one affected with the disease.)

A striking feature of such consultations is that, after the practitioner has taken the time to announce the diagnosis, and then given information about the transmission of the disease (dominant vs. recessive, etc.) and the therapeutic and lifecourse implications for the child, parents often have great trouble making sense of the medical information they have received - be it immediately or, more frequently, shortly afterward. Often do the geneticists find themselves in a position to have to explain again the mode of transmission and its implications, up to a point where it clearly appears that the real question isn't "what is the disease and how has it been transmitted?" but "Why us ?" - in other terms, an attempt to make sense of blind biological fatality. The geneticist is the bearer of bad news, his speech is very often received as an oracle-like prediction (Feissel-Lebovici, 2001; Munnich, 2014); yet, even when he has successfully isolated the pathogenic variant, parents are often perplexed and cannot make sense of these traumatic news. This is often evidenced in their spontaneous question about what can now be done to cure their 
child - while it has just been made perfectly clear to them that only symptom-oriented care (at best) could hereafter be implemented.

Geneticists experience the same type of perplexity during follow-up consultations about medical decisions and care: often do they see that the previously communicated (and repeated) information concerning the stakes of proper therapeutic decisions doesn't seem to lead the parents to what would, from the outside, appear as the most reasonable decision - such as transplant, choice of medically adequate treatment, etc.

For example, in pediatric immunogenetics, it is not rare to see parents refusing life-saving bone-marrow transplants for their children, because of the residual $10 \%$ risk of lethal outcome while, by refusing, they could be seen as in fact becoming responsible for their children's future death, bound to happen if the immune system keeps deteriorating for genetic reasons.

How can a Lacanian approach to the patient-doctor relationship taking place in pediatric genetics account for this often paradoxical gap between the objective, medical information transmitted to parents and patients, and its subjective reception and elaboration? We first need to lay out Lacan's understanding of the demand in contemporary medical consultations (2). We will then use these elements to explore how they come to play in pediatric genetics (3).

\section{THE MEANING OF THE DEMAND IN THE CONTEMPORARY MEDICAL CONSULTATION}

\section{A Demand for Knowledge About Jouissance of the Body}

In his remarks on "The Place of Psychoanalysis in Medicine" (Lacan, 1966), Lacan writes that psychoanalysis can help medical practice - and is, in this perspective, part of it - since it can spell out what is at stake in the "authentically medical position" (Lacan, 1966, p. 301): namely, the mode of response to what the patient unconsciously expects from the doctor, through what Lacan calls "the demand" (id., p. 302).

Paradoxical as it sounds, the patient's doesn't primarily expect healing, which can be provided by therapeutic devices and agents (surgery, drug, etc.). Aside from healing, "a certain something remains constant, and every doctor knows what it is": demand. And "the significance of the [patient's] demand, wherein the medical function authentically comes to play" (id., p. 302), is that it is a "demand of knowledge." That is, the demand to the medical practitioner is an instance of what psychoanalysis calls transference (Lacan, 1966, p. 308), whereby the subject supposes a knowledge in the addressee of his demand, thereby considered as a "subject supposed to know" (Lacan, 1973, Chap. 18; various texts in Brun, 2005 refer to this point).

The object of this type of knowledge is not the body defined as what can be "photographed, X-rayed, calibrated, diagrammatized" and so on (Lacan, 1966, p. 303), by the medical devices which help establish the diagnosis and heal. In other terms, the body is not to be understood, in the footsteps of the
"Cartesian dichotomy between thought and extension" (id.), as a highly complex machine, in spite of the exponential development of exploration and imaging devices which present a purified version of it (cf. e.g., Potier, 2009). One should be aware that this exponential development fostered an "epistemo-somatic rift" (Lacan, 1966, p. 303) encouraging to (mis) understand the body (soma, in greek) upon which medical knowledge (episteme) should focus - and to miss that it is not to be understood as a complex machine, but as a nexus of "jouissance" (id.). This rift is typical of contemporary medicine: the diversity and complexity of healing devices, machines and substances developed on the basis of biomedical scientific progress tends to overshadow the specific function of the practitioner, whose very authority and personal prestige were deemed throughout the ages to be a central part of his function (Lacan, 1966, p. 297).

What the patient demands from the doctor as subject supposed to know is a knowledge about the jouissance taking place in his body. "The rapport thanks to which the doctor is what he is, is the patient's demand. Inside this strong relationship where so many things take place, this dimension is fully revealed in its original meaning (...): the relation to the body's jouissance" (Lacan, 1966, p. 309).

We thus need to briefly account for the constitution of the subject's relationship to the body's jouissance, in order to shed light on the patient's demand to the doctor.

\section{The Subjectification of Jouissance: Drive, Demand, and Desire}

In this context, jouissance refers to the untamed, not-yetorganized circulation of excitation which takes place in the infant's body during the primordial interactions with his human environment, whereby the infant experiences his body as such (Lacan, 2016, Chap. 13). It is a pure erotic experience of one's organic being, in all its intensity - a jouissance of being (cf. also Dimitriadis, 2017) [It should be noted that while this jouissance involves direct interactions with the Other as real, since it corresponds to a "mythical" (Lacan, 2016, Chap. 13) moment prior to the linguistic constitution of the subject qua separated - more on this just below, the Other is correspondingly not experienced as separated, but as part of a field of jouissance comprising himself and the infant].

At this mythical (i.e., reconstructed) stage of the constitution of the subject, in the infant's state of absolute dependence upon its environment (Freud's Hilfslosigkeit), it is the Other's response to the bodily manifestations of anxiety to which jouissance gives rise which retroactively converts these manifestations into an appeal. This is the first step of the process of subjectification (subjectivation, Lacan, 2016, Chap. 12): the infant's alienation to the Other's response.

The paradigm case is the infant's cry (cf. Lacan, 2016, Chap. 24): it is the "marks of [the Other's] response that had the power to turn his cry into a call" (Lacan, 2006, Remarks on Daniel Lagache's Presentation). While the infant's cry doesn't initially express a specific need (since he wouldn't know what he needs), but instead manifests an unbearable excitation and is thus at the level of jouissance, the Other (typically, the caregiver) interprets 
it as a call for a specific action on his side - which will, in turn, be determined by how He unconsciously represents the infant. This representation is constituted by signifiers, discrete elements of speech considered as distinct sounds, independently of their usual socially determined meaning; the specific signifiers which constitute the Other's representation of the infant will form the latter's ego-ideal, the very core of his subjectivity.

These marks, in which the all-powerfulness of the response are inscribed, are thus circled in reality with the signifier's line. It is not without reason that these realities are called "insignias." The term is nominative here. It is the constellation of these insignias that constitutes the subject's ego-ideal (Lacan, 2006, Remarks on Daniel Lagache's Presentation).

That is to say, the function of the Other's response is to enable a primary identification to bind the infant's jouissance through signifiers which represent him for the Other. Herein lies the "allpowerfulness of the response."

The function of the Other's initial response is thus to turn the bodily jouissance of the cry into what Lacan calls an "invocative drive" addressed to the Other (Lacan, 1973): by understanding the cry as a call, the Other leads the infant to experience what takes place in his body as a drive (with its source in a specific erogenous zone, the mouth), aimed at satisfaction and expressed as a demand. The cry thus becomes "the radical knot where demand and drive come to be bound" (Lacan, 1973, session of May $27^{\text {th }}, 1964-$ modified translation).

At this level of primordial alienation, where the infant qua subject of jouissance is bound to grasp what happens in his body through the response of the Other, he undergoes an identification to what Lacan calls object a (objet petit a) of the Other, wherein he comes to wonder "what the Other wants from him" (Lacan, 2016) in so responding to his cry.

Therefore, he needs the Other to elucidate the signifiers of primary identification (often written $S_{1}$ by Lacan) by drawing on a constellation of complementary signifiers (written $S_{2}$ ) that account for the Other's choice of $S_{1}$. Typically, $S_{2}$ stands for the Oedipal narrative which accounts for the unconscious choice of $\mathrm{S}_{1}$ by the Other - most often the mother. [In most cases, the maternal or mothering Other will be in a position to provide such a constellation by drawing on the Name-of-the-Father, Lacan's formal re-writing of the Oedipal complex (Lacan, 1998); for a more detailed recent presentation, cf. e.g., Razon et al., 2017, see section "The Manifest Doctor-Patient-Family Relationship in the Pediatric Genetics Consultation.”) In such a second step, whereby the primordial Other is divided by the necessity to account for his choice (most often by leaving room in the $S_{2}$ for another figure co-defining the infant's identity through a paternal function, such as the father), the object $a$ to which the infant was identified acquires a new meaning through $S_{2}$ - and the infant can thus know what he is for this Other, i.e., what the Other wants from him (Lacan, 1973, 2016). From the perspective of the Other, the infant becomes an object of desire since he is viewed as a representative of another desired figure; he becomes, as Lacan puts it, "phallicized" (Lacan, 1973). From the perspective of the infant, the maternal Other thus appears as desiring, since she also cathects someone else, who partly accounts for what the infant represents for her. Lacan calls this second step "separation" (Lacan, 1973).

Thus, at the end of this reconstructed two-step process of unconscious subjectification by alienation/separation, the cry has become a demand qua invocative drive. Correspondingly, its object, i.e., what could genuinely satisfy it, isn't merely the oral partial object (breasts, etc.). Since the maternal Other, when giving the breast to a crying infant, draws on the signifier-based framework of Her representation of the infant qua object a of desire, it is Her repressed representation of the infant qua object a, which constitutes him as subject of the unconscious, which is the object of his demand.

Thus, once the subject is constituted, everything that he comes to voice will, from the perspective of the unconscious, have to be understood as a demand, unknowingly articulating the signifiers which constitute the coordinates of the particular object $a$ that he is for the Other.

\section{Consequences on the Patient-Doctor Relationship: Subjectivizing the Demand}

It is for this reason that Lacan starts his conference on "The Place of Psychoanalysis in Medicine" by stressing the "gap between demand and desire" (Lacan, 1966, p. 302): while the manifest demand addressed to the practitioner looks like a demand for healing, the repressed signifiers of the desire of the Other to which the demand can be related show the discrepancy between what he demands and what he genuinely desires.

When he is sent to the doctor, or comes to meet him, the patient does not simply expects to be healed. He puts the doctor to test, to see whether he can bring him out of his condition; this is altogether different from healing the patient, since this demand can imply that the latter very much wants to remain ill. Sometimes the patient wants us to authenticate his status of illness; in many other cases, his obvious wish is that we help him remain ill, treat him in the way he wants, which will help him remain settled within his illness. I just need recall a recent experience: a patient, who recently came in a formidable state of permanent anxious depression having lasted for more than 20 years, was in utter terror at the idea that I could do something for him.

(...) As soon as we've pointed out [the gap between demand and desire], it appears that it isn't necessary to be a psychoanalyst, nor even a doctor, to know that once anyone, be they our best friend, male or female, demands something, it is in no way identical to - and, sometimes, in full opposition with - what they desire (Lacan, 1966, p. 302).

What the patient desires can thus, depending on the structure of the signifiers which constitute him as subject of the unconscious, amount to various types of relationship with the Other - such as, e.g., remain dependent from Him ("help him remain ill") - which are then projected onto the person of the medical practitioner. These types of relationship with the Other refer to the type of object $a$ to which the subject is 
reduced by the desire of the Other - this is the formula of the fundamental fantasy (Lacan, 1973), which formalizes the role and the organ (mouth, etc.) to which the subject identified at the step of separation from the Other. It is this formula, to which the subject identified in separation, which gives its shape to the desire of the Other, and that the subject unknowingly seeks to uncover by voicing his demand, which is at bottom transference, i.e., a "demand of knowledge" (Lacan, 1966, p. 308).

Hence the importance of the medical response: strictly understanding what the patient says as a demand for healing via a cure, and thereby missing that the signifiers used or hinted at by the patient are indirectly referring to something else (the object a) will prevent the doctor from grasping that what he wishes is to know the truth about the structure given to his jouissance by the desire of the Other, i.e., about the fantasy at play.

Correspondingly, it is by taking into account this unconscious search for another knowledge at work in the patient's demand that the medical practitioner will be in a position to deliver an adjusted medical response (both in tone and in content). In the medical consultation, especially in the context of heavy medical examinations, leaving out this dimension will typically lead the patient to persist in fulfilling his unconscious role in the fantasy (e.g., request more and more examinations, or act in opposition with what he is told). Reversely, the medical consultation (as Del Volgo, 1997 has insisted) provides the practitioner with a context propitious to help the patient gain awareness, and question the consistency, of the knowledge of his jouissance that he supposes that the Other holds - in a movement analogous to the end of a psychoanalytic cure, where transference is dissolved, i.e., the consistency of the subject supposed to know collapses (Lacan, 1968(unpublished), Session of January $\left.10^{\text {th }}, 1968\right)$. "On the one hand, [the doctor] deals with an energetic cathexis, the potency of which he cannot suspect if he isn't told about it" - i.e., transference - and "on the other, he needs to put this cathexis between brackets precisely because of the power that he possesses, that he needs to distribute [i.e., medicine, OP], and of the scientific plane within which he is situated" (Lacan, 1966, p. 308). In so doing, he puts his medical knowledge between brackets in order to gain access to the patient's representation of his knowledge about jouissance, in order to be able to provide the right, adjusted medical response.

This analysis of the medical function thus implies that it depends on the doctor to hear the patient's demand as the manifestation of a desire to know something about his jouissance: he can thereby help the patient become aware of his desire, instead of responding to the demand solely by drawing on the position granted to him by his knowledge and position. This is certainly not to say that the medical practitioner has to explicitly interpret the patient's discourse: a medical consultation isn't a preliminary interview prior to the initiation of a psychoanalytic cure. But being aware that the demand's object is knowledge upon the patient's jouissance can help make the latter aware that the truth of his demand (in the psychoanalytic sense of the term: the subjective truth) doesn't primarily lie in medical knowledge once again, a preliminary step to an adjusted medical response in terms of cure and healing.
We propose to call the awareness that the medical practitioner can help the patient experience a subjectivization of the latter's demand. Subjectification, the word aptly chosen by A. Price to translate the French word "subjectivation" (Lacan, 2016, Chap. 12), refers to the constitution of the subject through alienation to, and separation from, the Other; we view subjectivization as referring to something different, namely the process of becoming aware of the essentially subjective nature of the demand to the practitioner concerning what happens in his body. Subjectivizing means understanding, to some extent, that the meaning of this demand derives from elements of one's own subjective coordinates; in Lacanian terms, this amounts to understanding that the signifiers of one's demand have to be referred to the primary signifiers in the Other, which assign the subject to a certain position qua object $a$ of the desire of the Other. A medical consultation carried by a practitioner aware of both medical stakes and the subjective meaning of demand, can help the patient partially grasp this subjective meaning, and question what it is he wants from the practitioner.

Focused on producing in the subject an interrogation on the genuine meaning of his demand (and open up the way for a potential further inquiry on this desire itself), subjectivization in a medical context is a the condition for adjusted medical action, and a potential preliminary step with respect to a potential deeper elucidation - such as the one carried in a psychoanalytic cure, which ultimately aims at helping the subject move beyond his assignation as object $a$ of the Other's desire.

\section{An Instance of a Setting Enabling Subjectivization: The Instant to Say}

We can illustrate this concept by commenting an example through which Del Volgo presents the original clinical setting that she calls the "instant to say" (1997, p. 61), which we view as a typical setting enabling subjectivization. Del Volgo, both a hospital medical practitioner and a Lacanian psychoanalyst, gives examples of how, within the context of a medical consultation, she asks patients about their medical history in such a way as to enable an "instant to say." This refers to a logical moment when patients, by recalling the important events of their life in the course of recounting the history of their illness and its various stages or occurrences, are presented with the opportunity to grasp the signifiers with which they describe the illness in relation to important prior life events. While this opportunity isn't presented explicitly, or as a goal of the consultation, this associative process opens up a space aside the healing-oriented dimension of the medical response, and gives them a chance to grasp and question the meaning of their medical demand - that is, the structure given to their jouissance by prior important life events. In so doing, she doesn't respond do the immediate demand but tries to help the patient gradually become aware of the subjective significance of his symptoms, i.e., of the fantasy which underlies them.

We will comment on a case that she presents in Del Volgo (1997). An elderly asthmatic patient, Ange, experienced a severe asthma crisis upon learning from the specialist that his wife, after 3 weeks of nocturnal hallucinations which made him feel "lost" much like an orphan, was in fact not suffering from 
a brain tumor, as initially suspected. Being asked to recall important elements in his life, he indicates that he has been repeatedly and unexpectedly been put in the position to be the closest to his mother: his father died in the beginning of World War II, when his older brothers had already left the house. He experienced this as becoming the man in the house - an important signifier for his personal history. His first respiratory crisis occurred at age 30, "the age of adulthood" (where he could go see a doctor, unlike childhood where he was once beat up for doing so): he accidentally started spitting blood during physical effort, which (he says) includes physical intimacy. It thus seems that respiratory problems became associated with fantasies of castration as a punishment for Oedipal desire, summoned (in accordance with Freud's bi-phasic trauma theory) in the context of adulthood and conjugal life. It is as if the guilt of desire (being put in the position of a phallicized object $a$ vis-à-vis the Other in the fantasy) could find a somatic expression - castration symbolized as bleeding out during effort; and that, conversely, the presence of the Other was experienced as the approach of a forbidden oral object a, thus causing in his body a symbolic equivalent of castration through hysterical conversion.

This interpretation was confirmed through transference during the next consultation, when he mentioned that a cardiac accident occurred while he was eating sweets on the anniversary day of their first consultation: the reminiscence of the first consultation during the second one, and the structure of the Oedipal fantasy within which he is caught up, accounts for the symbolic equivalence between the forbidden pleasure of eating sweets and becoming intimately close with the mother of childhood. The cardiac accident is thus a transferential replica of his first respiratory problems at age 30, confirming that these series of bodily events can be understood against the background of the way in which his jouissance is structured - namely, through an oral Oedipal fantasy. Those elements constitute the background on which the patient's associations, supported by Del Volgo's psychoanalytic listening, shed a partial light during this sequence; it was then up to the patient to subjectivize the connection between these past events and the actual occurrences of respiratory problems.

We now draw on this conceptualization of the demand as carrying a repressed desire open to subjectivization (and open to further elucidation), and we turn to pediatric genetics.

\section{SUBJECTIVIZING THE DEMAND IN PEDIATRIC GENETICS: CLINICAL PRACTICE AND RESEARCH PERSPECTIVES}

\section{Explicit vs. Implicit Demand in Clinical Practice}

As mentioned above, pediatric genetics is particularly interesting to study the demand at work in contemporary medical practice since the structure of the fantasy which organizes the patient's desire (and thereby filters the reception of information) is often more readily accessible during the consultation. The reason for this is that the demand for diagnosis and cure is voiced for the child by the parents - the unconscious of whom largely contributed to structuring the child's - who feel responsible for his disease since it is viewed as hereditary (at least potentially: the cause is sought for in previous generations).

As we mentioned above, the main proponent of applying Lacan's theory of the medical demand to pediatric genetics was Ginette Raimbault, in charge of research on the unconscious stakes of medical consultation at INSERM (French National Institute for Mental Health), and whose clinical field was a pediatrics unit working on hereditary child metabolic diseases the precise hereditary cause of which was largely unknown at the time, for lack of adequate sequencing apparatus and knowledge. In 1966, right after Lacan gave his lecture on "The place of Psychoanalysis in Medicine," she gave a didactic presentation of her research - which consisted in assisting silently to consultations and elaborating on the unconscious dynamics at stake in the family's demand. This is how she describes these dynamics:

\begin{abstract}
"As early as during the first interview with the medical practitioner, the parents formulate the results of their own research about the etiology of the disease, considered as a trouble. (...) The parents' formulation shifts from 'this makes no sense' to 'this is the sense we give to this disease"' (Raimbault in Lacan, 1966, p. 313).
\end{abstract}

While the subjective sense given by the family to the disease partly depends on the medical antecedents, the lack of information or the powerlessness of medical science (op. cit.), it largely derives from "the elaboration of fantasies concerning the agent of the disease" (Raimbault in Lacan, 1966, p. 313).

\begin{abstract}
"the child's disease thus seems to reveal the family's problem and its singular drama, which is actualized in the disease and feeds off of it, but isn't properly speaking caused by it. The difficulties faced by doctors partly stem from the fact that they only hear the explicit demand ('Cure this crisis!') and not the implicit one ('This is our drama')" (Raimbault in Lacan, 1966, p. 313).
\end{abstract}

Any medical discourse concerning this hereditary agent will thus be filtered by a pre-existing family fantasy organizing what she calls implicit demand to the practitioner.

The specificity of the notion of implicit demand is that it refers to the parents' quest for help with respect to a guilt which, albeit coming to the forefront at the occasion of the child's disease, predates it. Raimbault's main clinical finding is thus that the disease is filtered by the "window of the fantasy": to put it in the Lacanian framework which underlies her work, the disease is experienced by the parents (especially the mother) as a punishment for their normal anticipated fantasmatic elaboration of the status of the child qua object $a$, prior to any medical condition. Since this anticipated elaboration - way before the birth of the child - cannot but include an element of repressed guilt (even in neurotic contexts: a child is always partly viewed by both parents as an Oedipal child), the subsequent disease is experienced, through an unconscious displacement, as punishment for the accomplishment of the Oedipal wish to have a child with one's parent. 
The notion of implicit demand thus directly echoes Lacan's characterization of transference on the doctor as a demand for knowledge upon one's jouissance, and narrows it down to the context of hereditary diseases: what is implicitly demanded is knowledge about the family fantasy giving shape to their guilt. It is in this wake that Raimbault insists that what matters most, on the side of medical practitioners, is to prevent stereotyped attitudes and responses based on unquestioned personal assumptions concerning what stands as appropriate behavior in those medical situations: they are laden with the practitioners' personal subjective organization, and would prevent him from grasping the family's implicit demand (Raimbault in Lacan, 1966, p. 314).

The core of the knowledge that he is unconsciously asked by the family - the object $a$ of the family's demand, so to speak (and it most often is the mother's, in these circumstances) - concerns the particular structure of the desire of having a child, of which they (unavoidably) feel guilty. Responding to their implicit demand would amount to help them subjectivize this family fantasy.

\section{An Example of Implicit Demand: A Consultation in Pediatric Genetics}

The medical context in which hereditary child diseases nowadays take place is pediatric genetics, wherein such implicit demand unfolds. The following example illustrates elements present within a host of consultations, and comes from OP's practice of pediatrician-genetician/psychoanalyst dual consultations in pediatric genetics. Only de-identified data were used; therefore, an ethics approval was not required for the use of this material as per the Institution's guidelines and national regulations. It shows how the explicit demand carries an implicit one, which filters both the reception of information and the subsequent decision-making of patients.

In this context, that of the pediatrician-genetician and psychoanalyst, the difference with both Del Volgo's setting and Raimbault's research is that the psychoanalytic perspective is embodied by a specific person (not the doctor), who also actively partakes in the consultation, sometimes to an important extent when the weight of the implicit demand comes to the forefront. It is not only listening, but also active interventions, which open up a space of subjectivization, i.e., of relating the signifiers of the demand (the explicit demand, in Raimbault's quote) to those of the underlying fantasy of the implicit demand of the family singular drama. This is sometimes needed in order to shed light on the extent to which this demand filters medical information and subsequent behavior.

The following example is reduced to a few elements for anonymity reasons. A young mother of two adolescents was extremely reluctant to try a bone marrow transplant which could save them both of a rapidly developing disease enabled by a hereditary recessive immunodeficiency. Hearing the unmentioned guilt present in her speech, OP told her "in any case Madam, you are not responsible for your sons' disease" - in order to stress that she couldn't know, medically speaking, that mothering them would lead to transmitting them the disease, but that her apparent sorrow might be rooted somewhere else. She replied (thereby illustrating the equivocation enabled by the signifier "guilt"): "what do you mean? I am by no means irresponsible! I'm doing my best here!” Her mastery of French language was more than sufficient to rule out a cognitive explanation for her apparent mistake. In so responding, she showed us how guilty she does feel for their disease, experienced transitively as a punishment for what (in the rest of the consultation, in relation to biographical elements) most likely appeared to be the structurally normal (see section "The Subjectification of Jouissance: Drive, Demand, and Desire"), predating Oedipal fantasy of receiving a child from her father the paradigm forbidden desire of which, at a certain level, she unconsciously expected the consultation to relieve her, by helping her formulate it. The singular drama was thus that she unconsciously experienced this forbidden desire, upon which becoming a mother largely relies, as directly punished by the disease. It is this unconscious connection, qualifying her relation to her children qua phallic objects $a$ (because of the Oedipal structure of the Other organizing her unconscious), that she needed to subjectivize; for ultimately, the way to partly soothe this guilt is to start by acknowledging it, which is the object of her implicit demand to medical knowledge about what takes place within her children's bodies, and therefore filters how she heard OP's intervention.

Unfortunately, this subjectivization (realizing the relation between her experience of the disease and a guilt of a different origin) was made extremely difficult by the pressing therapeutic context, where a decision had to be made in the near future concerning the bone marrow transplant. In other words, aside the response which she unconsciously sought concerning the fantasmatic cause of what was taking place within their children's bodies, a healing-oriented response also had to be given her concerning the stakes and urgency of the transplant. Upon hearing about the necessity to soon make a decision concerning this matter, she said she was extremely reluctant to accept it, because of the residual $10 \%$ chance of lethal outcome (in spite of the certainty of such an outcome in the absence of transplant). One can wonder whether a masochistic need to be punished for the Oedipal character of her fantasy, which enabled her to represent her children as phallicized objects $a$ in the first place, could account for her decision: wouldn't a lethal amount (inexorable in the absence of transplant) symbolically amount to a paradigm punishment for her forbidden fantasy? In this case, what appeared to be the structure of her fantasy could account for her fantasy, with its masochistic components. Her behavior, seemingly paradoxical with respect to the perspective of healing and cure, thus appears in a new light (see section "Consequences on the Patient-Doctor Relationship: Subjectivizing the Demand").

\section{Demand-Based Starting Point of a Qualitative Research: The Subjective Effects of Genetic Deafblindness}

Finally, we would like to give a brief illustration of the demandbased rationale of an ongoing qualitative research based on this conception of the demand in pediatric genetics. This 
multidisciplinary research focuses on the subjective effects of genetic deafblindness on autonomy in child, adolescent and adult patients with Usher, Wolfram and Stickler syndromes (research codename: DéPsySurdi). It is funded by the French Rare Disease Foundation ("Fondation Maladies Rares"); RP is its principal investigator, and it has been made possible by a close partnership with the Reference Center for Genetic Deafness (INSERM U587, dir. Dr. S. Marlin).

What we briefly present here is the nucleus of the psychoanalytic rationale of this research, jointly conceived by RP and OP on the basis of a Lacanian approach to the demand in the context of genetics (and in particular pediatric genetics). This nucleus is both the result of a research on medical demand with a focus on pediatric genetics, and the basis of the specifically psychoanalytical contribution to the DéPsySurdi project; on this basis, collaborators in psychology, medicine and social science joined in order to turn this nucleus into an exploration of the effects of genetic deafblindness at a psychosocial level. (Our methodology, which we cannot fully unfold here, relies on semistructured interviews using sign language or tactile sign language, in order to leave as much room as possible for association, and more generally punctual emergences of formations of the unconscious.)

The gene-based Usher, Wolfram and Stickler syndromes gradually affect both hearing and sight up to partial or total auditory and visual deficits, resulting in deafblindness (a specific handicap, wherein large parts of audio-visual compensation is impossible). The effects of this handicap on one's autonomy appear to vary greatly; it has important psychiatric comorbidities, such as depression due to increased social isolation. We decided to examine the effects of deafblindness on autonomy in child, adolescent and adult subjects because autonomy is centrally impacted by this handicap, and is thus the natural manifest object of family and patient demand: the demand for medical and social help and support greatly focuses on compensating this handicap, especially in parents with children and teens affected with these syndromes. Therefore, various strategies, devices (e.g., technological) and personalized supports (personal or family assistants, etc.) are devoted to this compensation, and thereby help young patients and their parents achieve social participation and self-realization: the explicit objects of the families' demands are means to ease the burden of the handicap and facilitate interaction.

This initial context raises specifically psychoanalytic questions: doesn't the variety of available supports sometimes cloud the subjective significance of the syndromes? In other words, behind the need for help and support, does the current available medico-social leave room for subjectivization in the families' and patients discourse on the handicap? To what extent can they question the signifiers which, at the manifest level, they use to refer to the everyday impact of the handicap, and ways to alleviate its burden? This would mean having the opportunity to relate the gene-based loss of autonomy (along with the parental guilt which accompanies it and is reinforced by genetic sequencing) to what Raimbault called the predating family fantasy which gives its particular sense to their child's handicap. In this respect, a particularly sensitive question is the degree to which the child's participation to the family fantasy - and conversely, his degree of autonomy with respect to it. What room do they leave for the gap between their child's autonomy in the expression of his demand, and their own representation of him (laden with the guilt of his syndrome, which clouds the structural predating guilt)? And in cases where this gap is thin, is his demand devoid of singular desire, i.e., just a reflection of his main caregiver's fantasy, in which he would be caught up? Or does it present aspects of a singular desire of separation qua phallicized object $a$, waiting to be acknowledged as such? This stake is particularly crucial, since the context of deafblindness leaves less room for separation, since communicating often requires to use tactile sign language - and thus to touch. What of the potential equivocity of the signifier in these contexts?

These are the questions which led us to decide to focus on this cluster of syndroms, in order to help doctors position themselves with respect to the unconscious question concerning one's body at play in the demands for support that they receive.

\section{CONCLUSION}

In this paper, we wanted to draw on Lacan's take on the demand to stress that the exponential development of personalized and stratified medicine, which help provide previously unexpected adjusted cure and healing, requires medical practitioners to remain sensitive to the dimension of the demand for knowledge about jouissance, in order to prevent their response (cure, investigations, etc.) from reinforcing the underlying repressed fantasies, with their masochistic basis.

It is even more important when the object of this knowledge is what takes place in someone else's body: these situations are often quite projective, in the sense that it is difficult for caregivers to acknowledge that their understanding of their child's bodily symptoms is heavily influenced by his role in their fantasy. This is particularly true when the child represents the object of the Mother's (and not the couple's) fantasy, as Lacan wrote in the first "Note on the child" in 1969 (Lacan, 1986).

The unconscious guilt of having transmitted the disease, even in cases where transmission cannot be established (which are numerous, even as of today), contributes to these projections. It is for this reason what we chose to focus on pediatric genetics, since this clinical field is both saturated with such projections, but at the same time open to potentially disalienating interventions especially if children themselves, as well as other members of the family, actively partake in the medical exchanges, so as to distinguish their own speech to their parent's implicit demand.

\section{AUTHOR CONTRIBUTIONS}

$\mathrm{RP}$ has contributed to part of the material (including clinical) presented in this paper through an uninterrupted dialog with OP during the latter's post-doctoral research (which he de facto partly supervised); he has co-conceived the 
psychoanalytic basis of the deafblindness research, and is the Principal Investigator of the resulting psychosocial project (DéPsySurdi - http://www.depsysurdi.fr/). He has given useful comments on a previous draft of this paper, and has agreed to the final version. OP has conceived the structure of the paper and its argumentation (topic and organization were based on his post-doctoral research), taken part in most of the consultations mentioned in the paper, has co-conceived the psychoanalytic basis of the deafblindness research, and written the paper.

\section{REFERENCES}

Aubert-Godard, A. (2005). Filiation en question: maladies génétiques, identités incertaines, filiations perturbées. Dialogue 16, 25-44. doi: 10.3917/dia.168.0025

Balint, M. (1957). The Doctor, His Patient and the Illness. London: Churchill Livingstone.

Brun, D. (2005). "Violence de l'annonce, violence du dire," in Proceedings of the 7ème Colloque de l'Association Médecine et Psychanalyse, eds D. Brun (dir.) and É. Freudiennes.

Christenhusz, G. M., Devriendt, K., and Dierickx, K. (2013). Disclosing incidental findings in genetics contexts: a review of the empirical ethical research. Eur. J. Med. Genet. 56, 529-540. doi: 10.1016/j.ejmg.2013.08.006

Debray, R. (1996). Clinique de l'expression somatique : psychanalyse des liens psyché-soma. Lausanne: Delachaux et Niestlé.

Del Volgo, M.-J. (1997). Linstant de dire : le mythe individuel du malade dans la médecine moderne. Erès: Ramonville Saint-Agne.

Dimitriadis, Y. (2017). The psychoanalytic concept of jouissance and the kindling hypothesis. Front. Psychoanal. 8:1593. doi: 10.3389/fpsyg.2017.01593

Driben, A. (2011). Les filles et leur père. Champ Psy. 6, 51-62. doi: 10.3917/cpsy. 060.0051

Feissel-Lebovici, A. (2001). Le gène et son génie. Patient, médecin et psychanalyste face à l'hérédité et au cancer. Erès: Ramonville Saint-Agne.

Gargiulo, M., Tezenas du Montcel, S., Jutras, M. F., Herson, A., Cazeneuve, C., and Durr, A. (2017). A liminal stage after predictive testing for Huntington disease. J. Med. Genet. 54, 511-520. doi: 10.1136/jmedgenet-2016-104199

Gutton, P., and Raimbault, G. (1975). L'enfant devant la maladie somatique: 11 textes. Paris: SPEI.

Hens, K., Peeters, H., and Dierickx, K. (2016). Genetic testing and counseling in the case of an autism diagnosis: a caregivers perspective. Eur. J. Med. Genet. 59, 452-458. doi: 10.1016/j.ejmg.2016.08.007

James, C. A., Hadley, D. W., Holtzman, N. A., and Winkelstein, J. A. (2006). How does the mode of inheritance of a genetic condition influence families? A study of guilt, blame, stigma, and understanding of inheritance and reproductive risks in families with $\mathrm{X}$-linked and autosomal recessive diseases. Genet. Med. 8, 234-242. doi: 10.1097/01.gim.0000215177.28010.6e

Lacan, J. (1966). "La place de la psychanalyse dans la médecine," in Psychanalyse des enfants séparés (2010), ed. J. Aubry (Paris: Flammarion).

Lacan, J. (1973). The Seminar 1964, Book XI, The Four Fundamental Concepts of Psycho-Analysis [1973]. New York, NY: Karnac.

\section{FUNDING}

This research received funding through a grant awarded to the project "DéPsySurdi" (PI: RP) by the Fondation Maladies Rares' Social and Human Sciences program.

OP's post-doctoral fellowship was supported by the "Who Am I?" Laboratory of Excellence \#ANR-11-LABX-0071 funded by the French Government through its "Investments for the Future" program operated by the ANR under grant \#ANR-11-IDEX0005-01.

Lacan, J. (1986). Notes Sur L'enfant (1969). Ornicar 37, 13-14. [English Transl. by R. Grigg, Note on the Child, Analysis, 2, 1990, 7-8].

Lacan, J. (1998). Le séminaire, Livre IV: La relation d'objet (1956-1958). Paris: Le Seuil.

Lacan, J. (2006). Ecrits: The First COMPLETE Edition in English, eds B. H. Fink and R. Grigg (New York, NY: Norton \& Company).

Lacan, J. (2016). The Seminar, book X: Anxiety (1962-1963), tr. A. Price. Cambridge: Polity Press.

Lebrun, J.-P. (2017). De la maladie au malade. Psychanalyse et medicine dans la cité. Erès: Ramonville Saint-Agne. doi: 10.3917/eres.lebru.2 017.02

McDaniel, S. (2005). The Psychotherapy of genetics. Fam. Proc. 44, 25-44. doi: 10.1111/j.1545-5300.2005.00040.x

Munnich, A. (2014). La génétique est-elle inhumaine? Esprit 7, 66-74. doi: 10.3917/ espri.1407.0066

Potier, R. (2009). L'image en médecine, esquisse et précipice. Res. Psychoanalys. Recherches en Psychanalyse 8, 164-169.

Raimbault, G. (1975). L'enfant et la mort: problèmes de la clinique du deuil. Privat: Dunod.

Razon, L., Putois, O., and Vanier, A. (2017). The lacanian concept of cut in light of lacan's interactions with maud mannoni. Front. Psychol. 8:2177. doi: 10.3389/ fpsyg.2017.02177

Sausse, S. (1997). Le miroir brisé. L'enfant handicapé, sa famille et le psychanalyste. Paris: Calmann-Lévy.

Vailly, J. (2013). The birth of a genetics policy. Social issues of newborn screening. New York, NY: Routledge.

Weber, J.-C. (2017). La consultation. Paris: PUF.

Conflict of Interest Statement: The authors declare that the research was conducted in the absence of any commercial or financial relationships that could be construed as a potential conflict of interest.

Copyright (c) 2018 Potier and Putois. This is an open-access article distributed under the terms of the Creative Commons Attribution License (CC BY). The use, distribution or reproduction in other forums is permitted, provided the original author(s) and the copyright owner(s) are credited and that the original publication in this journal is cited, in accordance with accepted academic practice. No use, distribution or reproduction is permitted which does not comply with these terms. 


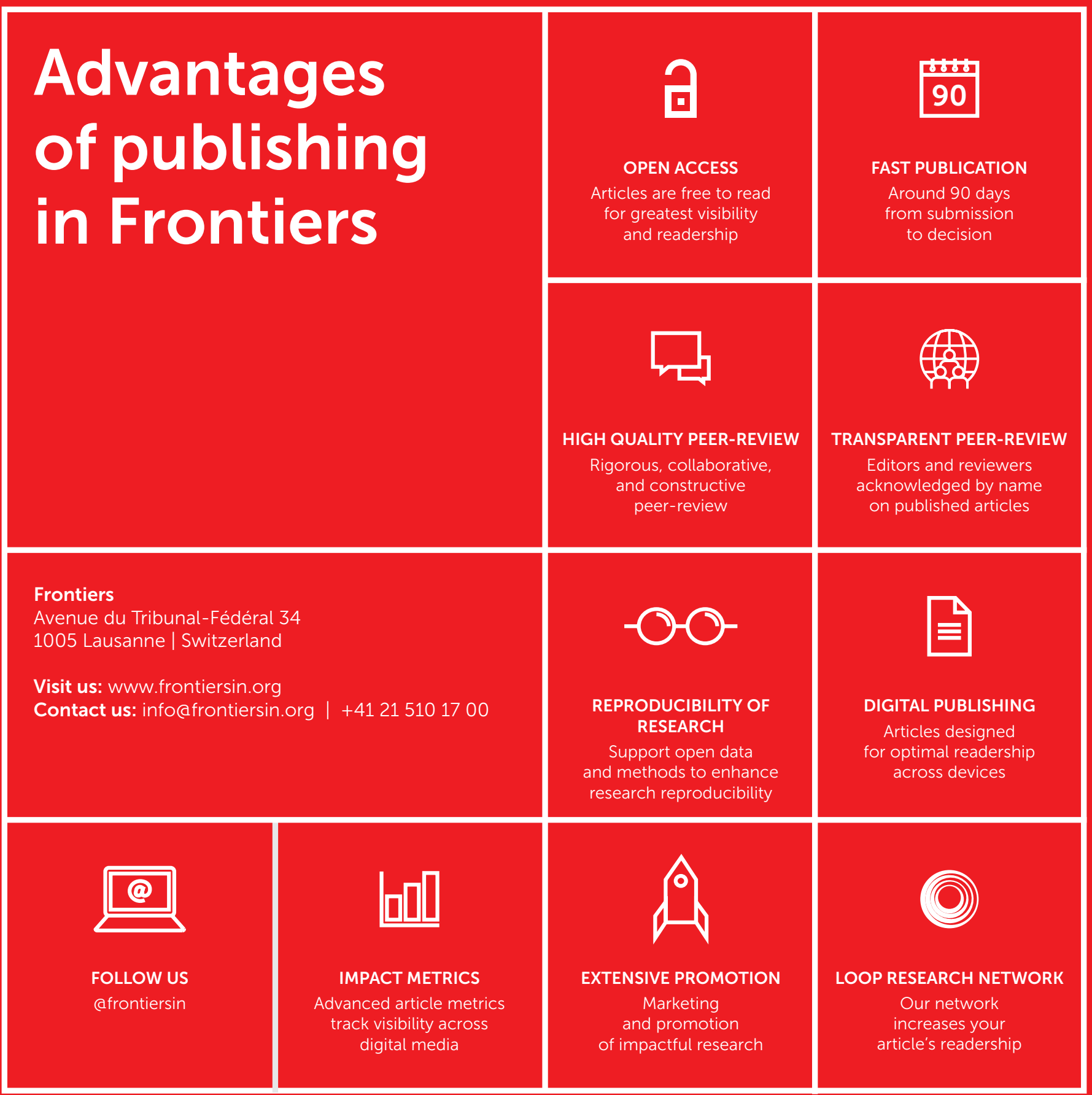

